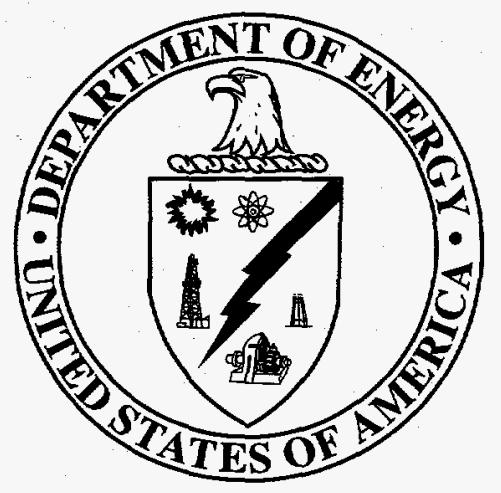

Office of Environmental Management Technology Development

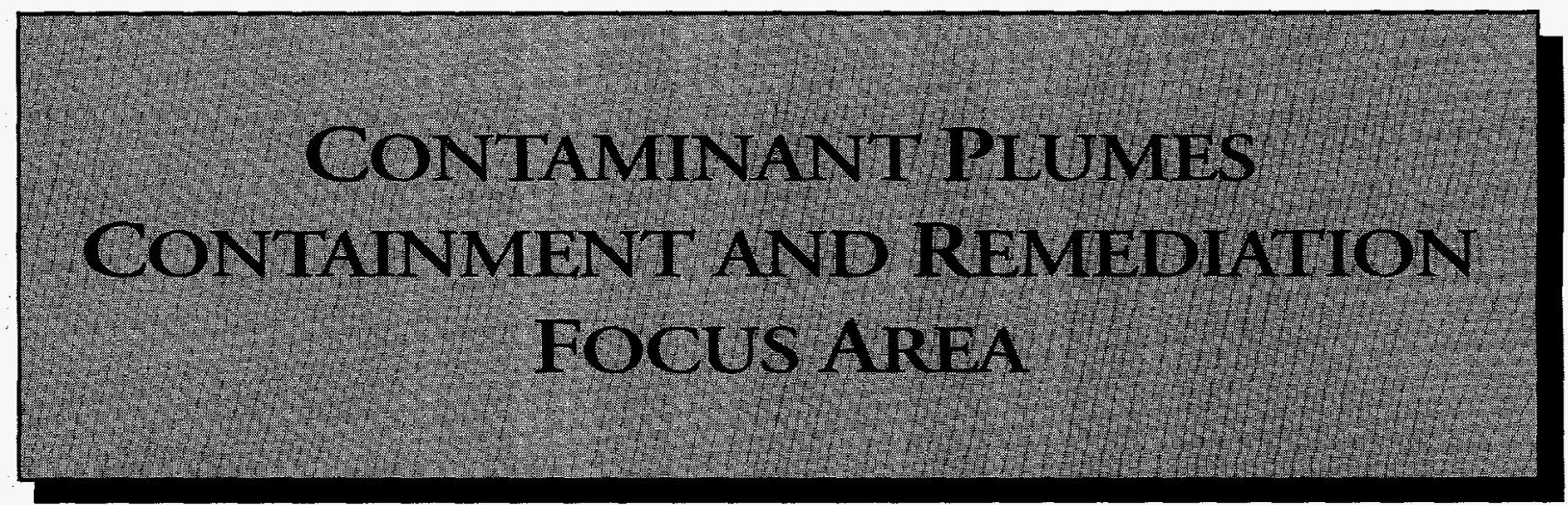

\title{
Technology Summary
}

June 1995 


\section{DISCLAIMER}

This report was prepared as an account of work sponsored by an agency of the United States Government. Neither the United States Government nor any agency thereof, nor any of their employees, makes any warranty, express or implied, or assumes any legal liability or responsibility for the accuracy, completeness, or usefulness of any information, apparatus, product, or process disclosed, or represents that its use would not infringe privately owned rights. Reference herein to any specific commercial product, process, or service by trade name, trademark, manufacturer, or otherwise does not necessarily constitute or imply its endorsement, recommendation, or favoring by the United States Government or any agency thereof. The views and opinions of authors expressed herein do not necessarily state or reflect those of the United States Government or any agency thereof. 


\section{DISCLAIMER}

Portions of this document may be illegible electronic image products. Images are produced from the best available original document. 


\section{CONTAMINANT PLUMES CONTAINMENT AND REMEDIATION}

\section{TABLE OF CONTENTS}

Introduction vii

The Contaminant Plumes Containment and Remediation Focus Area Overview viii

1.0 SITE ASSESSMENT 1

1.1 Integrated Spectroscopic System for Characterizing Contaminant Speciation ...... 3

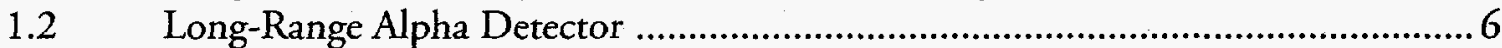

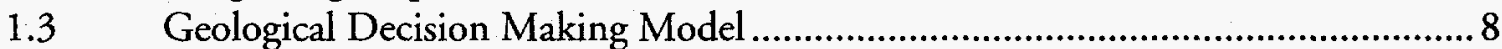

1.4 Characterization of Contaminated Soils and Residues Using Electron and Ion

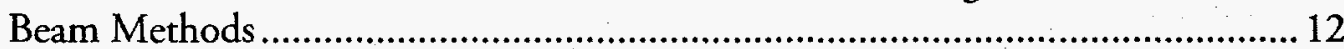

1.5 Multisorbent Arrayed Sampler .................................................................... 14

1.6 Improved In Situ Gamma-Ray Spectrometer ......................................... 17

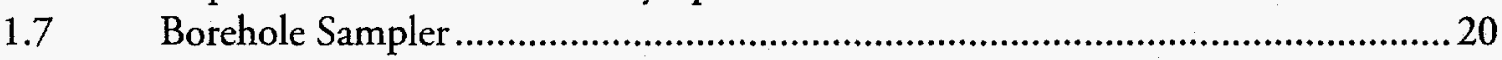

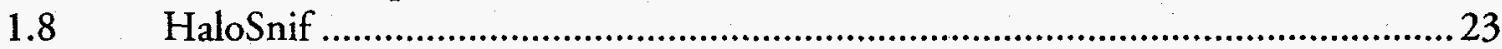

1.9 X-Ray Fluorescence Spectroscopy for Heavy Metals .......................................26

1.10 Crosshole Compressional and Shear Wave Seismic Tomography ....................... 29

1.11 In Situ Permeable Flow Sensor ........................................................................ 31

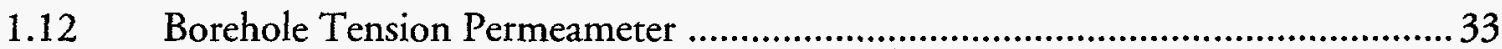

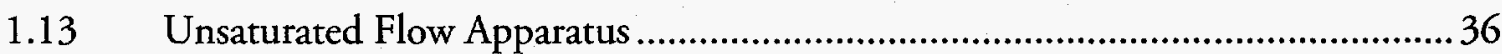

1.14 Measurement-While-Drilling System for Real-Time Screening of Environmental Contaminants .................................................................40 40

1.15 Inverting Membrane Borehole Instrumentation Techniques (SEAMISTTM) ...... 43

1.16 Vadose Zone Monitoring System ..............................................................46

1.17 Hybrid Directional Boring and Horizontal Logging ....................................... 49

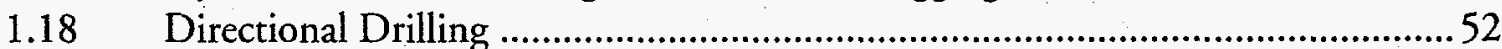

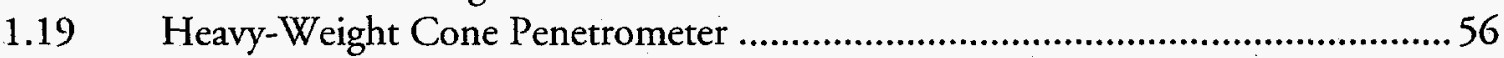

$1.20 \quad$ ResonantSonic ${ }^{\mathrm{SM}}$ Drilling ........................................................................59

1.21 Monitoring of Bioremediation Performance Using Nucleic Acid Probes............63

1.22 TCE Degradation Demonstration - Microbial Monitoring Techniques .............66

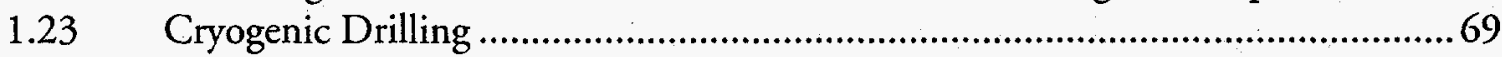

1.24 Electrical Resistance Tomography ............................................................... 72

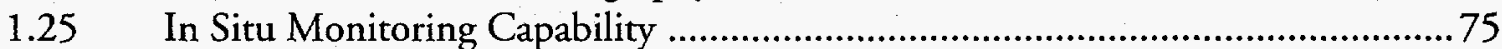

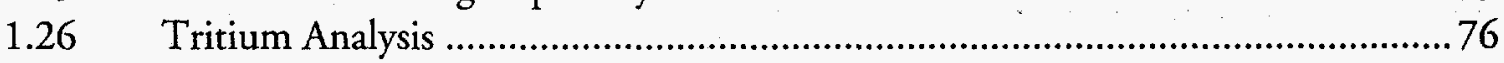

1.27 Rapid Bioassessment Technologies for Cost Effective Risk Assessments

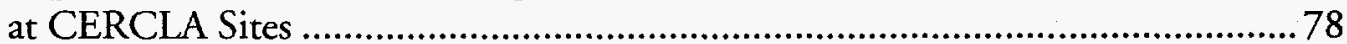

1.28 The Heuristic Optimized Processing System: A Technical Information System for CERCLA Waste Sites 


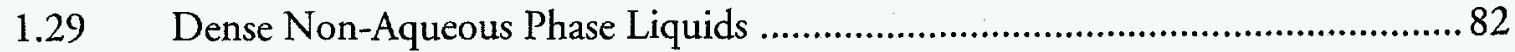

$1.30 \quad$ Monitoring of Microbial Population Changes ............................................ 85

2.0 CONTAINMENT TECHNOLOGY................................................................ 89

2.1 Development and Testing of a Water Permeameter Reactive Barrier................. 91

2.2 Chemical Barriers Feasibility and Field Demonstration ....................................94

2.3 Chemical Enhanced Barriers to Minimize Contaminant Migration ................... 96

2.4 Containment of Contaminants Through Physical Barriers Formed from

Viscous Liquids Emplaced Under Controlled Viscosity Conditions ................... 99

2.5 Development of Frozen Soil Barriers for Arid Sites ....................................... 103

2.6 Cryocell Technology Applications at Non-Arid Sites ...................................... 105

2.7 Subsurface Barrier Emplacement Development............................................. 108

2.8 Verification of Subsurface Barriers Using Time Domain Reflectometry With Waveguides ........................................................................................ 110

2.9 In Situ Groundwater Treatment Using Magnetic Separation ......................... 112

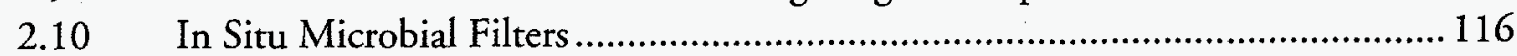

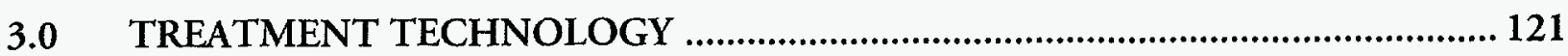

3.1 Thermal Enhanced Vapor Extraction System ........................................... 123

3.2 Remediation of DNAPLs in Low Permeability Soils .................................... 126

3.3 In Situ Treatment of Mixed Contaminants in Groundwater ......................... 130

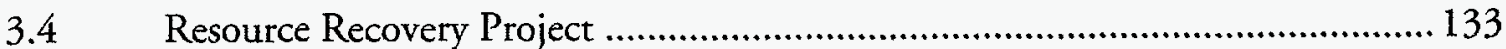

3.5 Passive Soil Vapor Extraction (Barometric Pumping) .................................... 136

3.6 In Situ Corona for In Situ Treatment of Non-Volatile Organic Compounds... 139

3.7 NAPL-Contaminated Soil/Groundwater Remediation Using Foams .............. 141

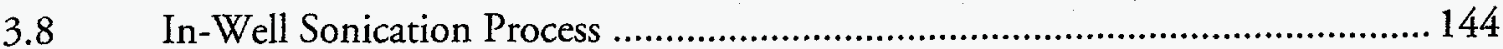

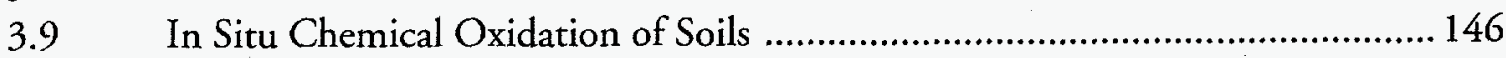

3.10 Heavy Metals-Contaminated Soil Project .................................................... 149

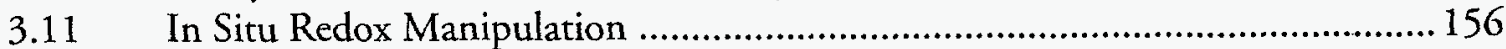

3.12 Tunable Hybrid Plasma ......................................................................... 160

3.13 In Situ Chemical Treatment for Remediation of Soils and Groundwater ......... 162

3.14 Modeling Strategies and Laboratory Experiments for Optimizing In Situ Bioreme-

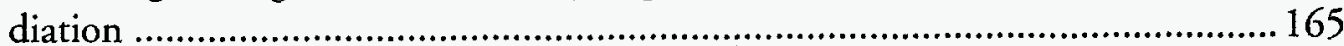

3.15 Bioprocessing Technologies for Uranium-Contaminated Soils ........................ 167

3.16 Demonstration of Co-Metabolic Technology ............................................. 169

3.17 Bioremediation of PCB Contamination ................................................ 172

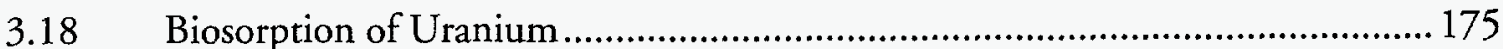

3.19 Adsorption/Desorption Relative to Applying Bioremediation to Organics ....... 178

$3.20 \quad$ Biomass Remediation System ............................................................ 181

3.21 In Situ Bioremediation of Groundwater ............................................... 183

In-Well Vapor Stripping ................................................................... 187

3.23 Mixed Chlorinated Solvent In Situ Bioremediation in the Vadose Zone .......... 190

3.24 Electrokinetic Removal of Heavy Metals from Soils ...................................... 193 
3.25 Electrokinetic Remediation of Heavy-Metal-Contaminated Unsaturated Soil .. 196

3.26 Electrokinetics in Uranium-Contaminated Soils ........................................... 199

3.27 Field Demonstration of Electrokinetics at Old TNX Basin ........................... 201

3.28 Optimal Remediation Design: Methodology and User-Friendly Software for Contaminated Aquifers ...................................................................... 204

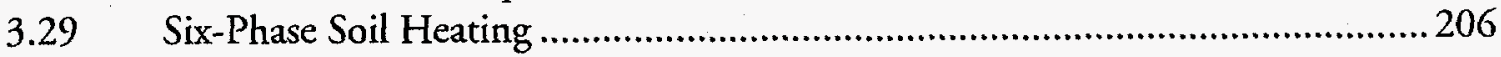

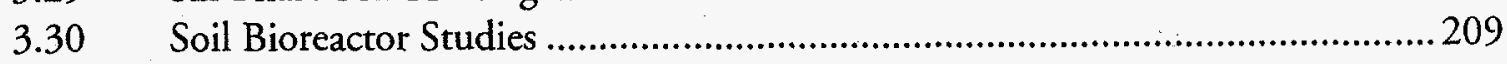

3.31 Cold Plasma Destruction of SRS Off-Gas ................................................. 211

3.32 Integrated Pulsed Ultraviolet Irradiation ................................................... 213

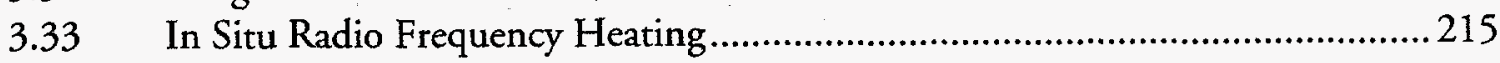

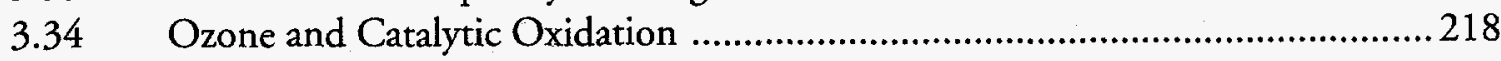

3.35 Off-Gas Treatment Sampling and Analysis ................................................221

3.36 Bioremediation of Toxic Metals ................................................................ 223

3.37 Validation and Publication of Savannah River Bioremediation Field Experiments ..................................................................................... 225

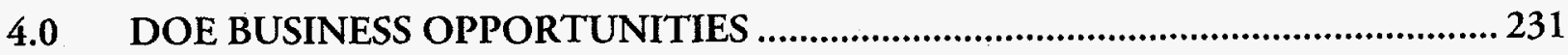

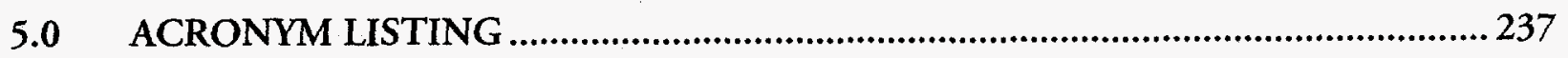

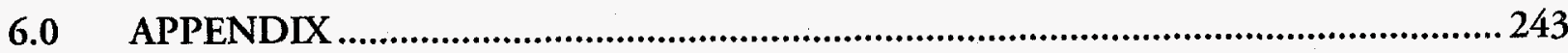

Figures

A. The Office of Environmental Management Organizational Structure as of May 1, 1994 ... xi

B. The Office of Technology Development Organizational Structure as of May 1, 1994 ...... xii

$1.1 \quad$ Integrated Spectroscopic System Process ................................................................... 3

1.2 Schematic of LRAD Soil Surface Monitoring .......................................................... 6

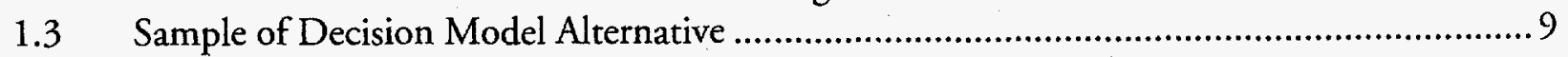

1.5a Multisorbent Arrayed Sampler .................................................................................. 14

1.5b Field Deployment of Prototype Arrayed Sampler at Savannah River Site ........................ 15

1.6 In Situ Gamma-Ray Spectrometer ........................................................................... 17

1.7 Borehole Soil-Gas and Aquifer Sampling and Testing Device (BoreSampler) ..................21

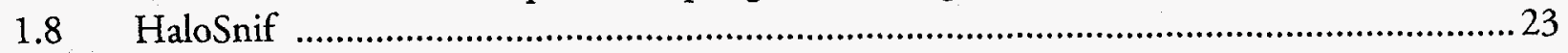

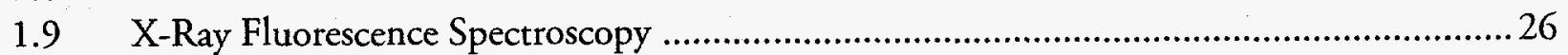

1.10 Fielding of Downhole Receiver Package for Crosswell Tomography ...............................29

1.11 In Situ Permeable Flow Sensor............................................................................ 31

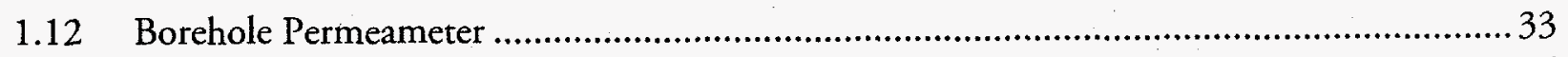

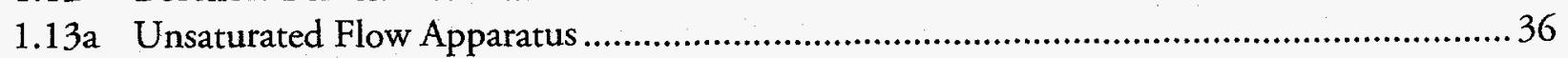

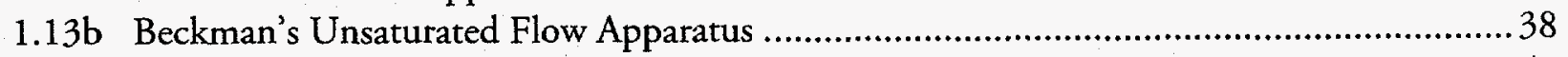

1.14 Environmental Measurement-While-Drilling System ...............................................40

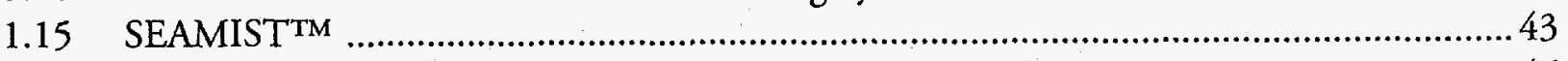

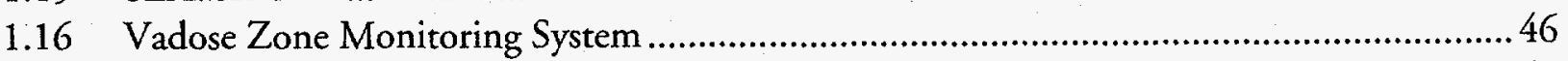

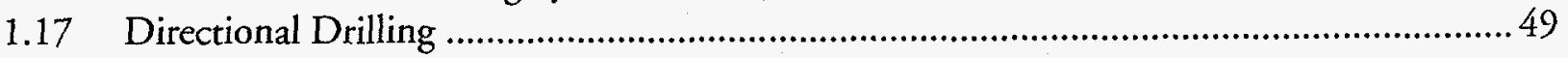

1.18a Horizontal/Directional Drilling Technology Development ..........................................53 
1.18b Downhole Air Motors Lowered into a Natural Gas Well .......................................................54

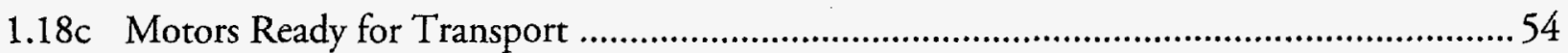

1.19a Source Detection Screening Using Cone Penetrometer Truck .......................................... 56

$1.19 \mathrm{~b}$ Cone Penetrometer Truck …………...........................................................................5

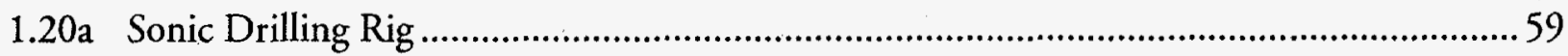

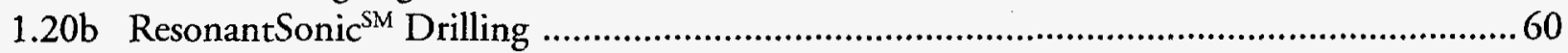

1.21 Nucleic Acid Hybridization Technique .....................................................................63

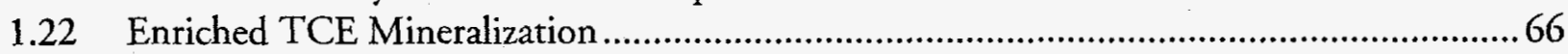

1.23 Frozen Borehole Apparatus for the Cryogenic Drilling Project...........................................69

1.24 Electrical Resistance Tomography …………………....................................................72

1.26 SRS Tritium Analysis System ……………………….................................................76

1.27 The Use of Biotic Indices to Determine the Health of a Stream at Two Points .................. 78

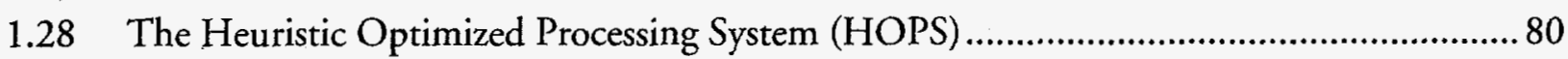

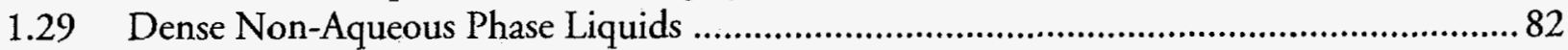

1.30 Monitoring Bioremediation Activities Using Lipid Techniques ........................................8 85

2.1 Demonstration, Testing, and Evaluation of Water-Permeable, Chemically-Reactive

Barrier ……..................................................................................................... 91

2.2 Chemical Barriers Feasibility and Field Demonstration .....................................................99

2.3 Develop and Determine Effectiveness of Permeable Barriers ...............................................96

2.4 Identify and Evaluate the Feasibility of Producing In Situ Barriers....................................99

2.5 Cross-Sectional View of a Cryogenic Barrier at an Arid Site .............................................. 103

2.6 Cross-Sectional View of a Frozen Soil Barrier at a Non-Arid Site ...................................... 105

2.7 Subsurface Barrier Emplacement Development............................................................. 108

2.8 Subsurface Barrier Monitoring System ...................................................................... 110

2.9 Above-Ground Demonstration of In-Situ MAG*SEPSM .............................................112

2.10 TCE Degradation via In Situ Microbial Filter, Huff-and-Puff Adaptation ....................... 116

3.1 Thermal Enhanced Vapor Extraction System ................................................................... 123

3.2 Source Control and Mass Removal of Dense Non-Aqueous Phase Liquid Compounds in Low Permeability Media ..............................................................................................126

3.3 Recirculation Wells for Subsurface Groundwater and Soil Air Remediation ..................... 130

3.4 The Berkeley Pit Test Bed for the Resource Recovery Project .........................................133

3.5 Barometric Pressure Fluctuations …………………..................................................... 136

3.6 Two Potential Mechanisms for Corona Destruction ......................................................139

3.7 Injection/Production Wells Assist in Delivery, Transport, and Monitoring

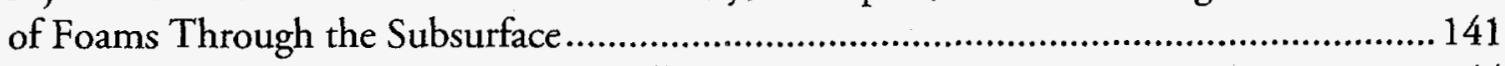

3.8 Schematic Diagram of a Sonication Well .................................................................. 144

3.9 In Situ Chemical Oxidation Process ........................................................................146

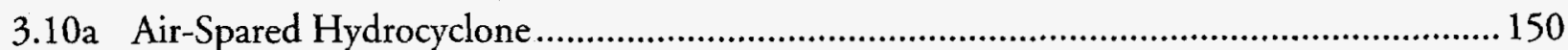

3.10b Schematic of the Campbell Centrifugal Jig .............................................................150

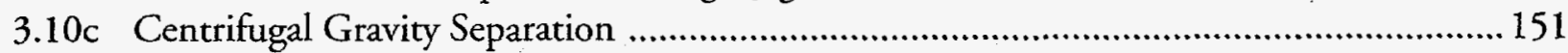

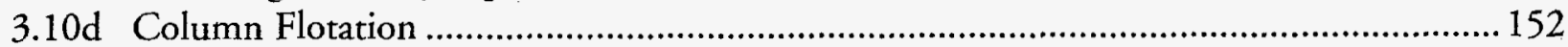

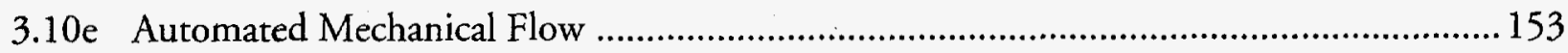

3.10f High Gradient Magnetic Separation ........................................................................ 153 


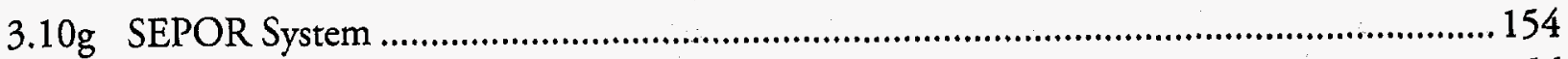

3.11 Permeable Treatment Barrier Concept ……………….................................................156

3.12 Tunable Hybrid Plasma …...................................................................................160

3.13 In Situ Chemical Treatment Conceptual Design .........................................................162

3.14 Mathematical Models to Enhance In Situ Bioremediation .............................................165

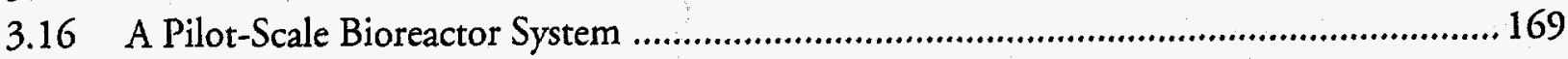

3.17 Laboratory Experiments at Oak Ridge to Identify Favorable Conditions for Anaerobic Dechlorination of PCBs........................................................................... 172

3.18 Biosorption for Treatment of Uranium-Contaminated Surface Water .............................. 175

3.19 Biosurfactants and Bacterial Sensors............................................................................178

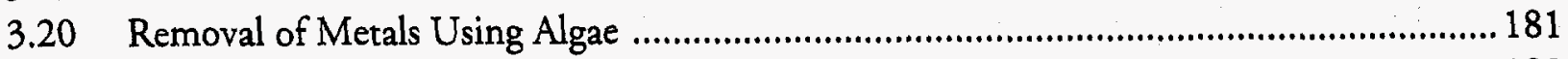

3.21 In Situ Bioremediation ........................................................................................ 183

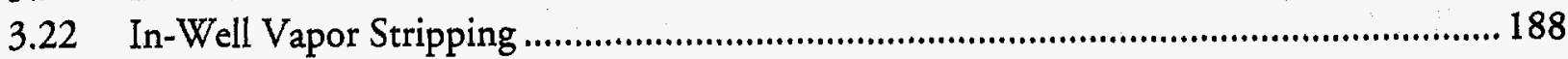

3.23 Treatment Strategy for In Situ Anaerobic and Aerobic Bioremediation of Mixed Chlorinated Solvents....................................................................................... 190

3.24 Comparison of Experiment and Model Results for Zinc Distribution ................................193

3.25 Proposed Electrode Array for Electrokinetic Remediation of the Sandia Unlined Chromic Acid Pit ............................................................................................... 196

3.26 Contaminant Transport Processes Induced by Applying Direct Current Between Buried Electrodes .............................................................................................199

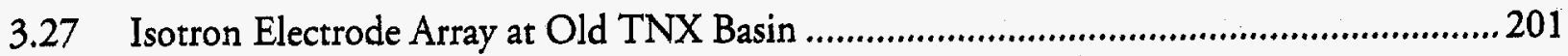

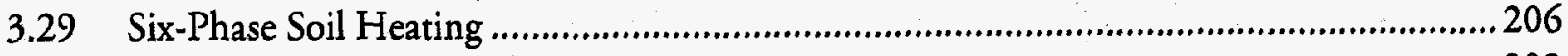

3.30 Conceptualized Full-Scale Bioreactor .......................................................................... 209

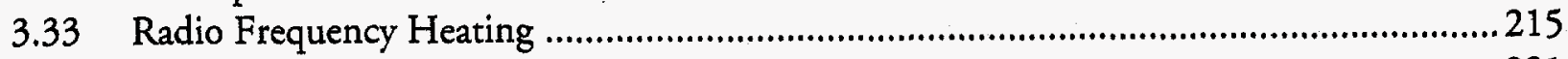

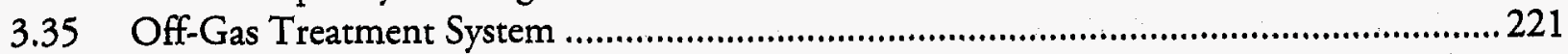

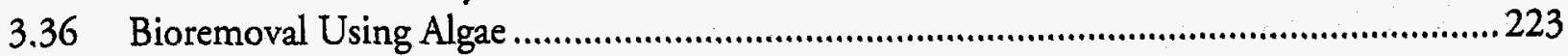

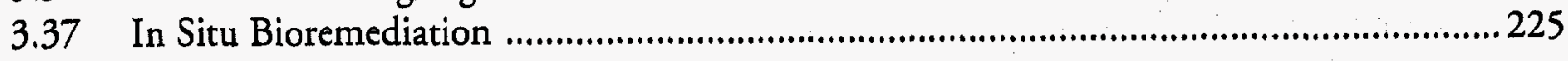




\section{INTRODUCTION}

\section{THE NEW APPROACH}

\section{PURPOSE}

Although positive steps have been taken during the past three decades to remedy the world's environmental problems, the nation's ability to respond to many current and future environmental and economic challenges depends on technological advances produced by a well-organized and productive federal research and development program.

To ensure that such programs focus on the most pressing environmental restoration and waste management problems at the U.S. Department of Energy (DOE), the Assistant Secretary for the Office of Environmental Management (EM) established a Working Group in August 1993 to implement a new approach to environmental research and technology development. The goal of DOE's new approach is to conduct a research and technology development program that will overcome major obstacles in the cleanup of DOE sites. Integral to this new, solutions-oriented approach is an up-front awareness of program needs obtained from customers, users, regulators, and stakeholders. These needs can then be disseminated to the developers of technological solutions.

The key features of the new approach are:

- establishing five focus areas to address DOE's most pressing problems;

- teaming with the customers in EM to identify, develop, and implement needed technology;

- focusing technology development activities on major environmental management problems;

- coordinating management of scientific and development activities in support of EM;

- focusing resources in national laboratories more effectively;

- involving industry in developing and implementing solutions, including technology transfer into DOE and from DOE to the private sector;

- coordinating basic research by involving academia and other research organizations to stimulate technological breakthroughs; and

- enhancing involvement of regulators and stakeholders in implementation of technology development.

DOE has established a framework and strategy for coordinating efforts among DOE organizations, Management and Operations $(\mathrm{M} \& \mathrm{CO})$ contractors, the national laboratories, other government agencies, the scientific community, industry, academia, and the affected public. Full implementation of the new approach is planned for the FY95/96 timeframe. The new strategy will build upon existing programs and will seek continual improvement of all EM operations and processes.

Prior to implementation of the new approach, EM's Office of Technology Development (OTD) carried out an aggressive national program of applied research and development to meet environmental restoration and waste management needs based on the concepts of Integrated Programs (IP) and Integrated Demonstrations 
(ID). These concepts, introduced in 1989, were engineered to manage the research, development, demonstration, testing and evaluation (RDDT\&E) activities within EM.

An IP was the cost-effective mechanism which assembled a group of related and synergistic technologies to evaluate their performance to solve a specific aspect of a waste management or environmental problem. The problem could be unique to a site or common to many sites. An IP supported applied research to develop innovative technologies in key application areas organized around specific activities required in each stage of the remediation process (e.g., characterization, treatment, and disposal).

An ID was a cost-effective mechanism that assembled a group of related and synergistic technologies to evaluate their performance individually or as a complete system to correct waste management and environmental problems from cradle to grave.

\section{BENEFITS}

A keystone for implementation of the new approach is to encourage development of technologies that are better, faster, safer and more cost-effective than those currently available. More importantly, the new approach has been adopted to foster implementation of new and innovative environmental technologies, facilitating the national commitment to long-term environmental, energy, and economic goals.

An important benefit to the new approach is the creation of investment returns for developing new technologies - technology dividends. These technology dividends result from partnerships and leveraging within government and between government and the private sector. The partnerships can consist of technology developers, technology users, problem holders, and problem solvers.

EM technology dividends will include:

- Employment opportunities with new businesses and existing businesses;

- Cleanup of sites posing the greatest threats to human health, safety, and the environment;

- Materials reused and recycled, instead of thrown away or freshly contaminated;

- Pollution prevented;

- More effective and efficient industrial processes, leading to greater U.S. competitiveness globally; and

- Technology transfer to other countries.

By implementing the new approach for the unique environmental problems associated with DOE sites, EM/ OTD, scientists, and engineers at the national laboratories stand at the threshold of opportunity to develop new technologies. This work will enhance quality of life through a cleaner environment, improved global competitiveness, and ensure job opportunities for American workers.

\section{FOCUS AREAS}

Five major remediation and waste management problem areas within the DOE Complex have been targeted for action on the basis of risk, prevalence, or need for technology development to meet environmental requirements and regulations. Other areas may be added or currently identified areas further partitioned to ensure that research and technology development programs remain focused on EM's most pressing remediation and waste management needs. These major problem areas, termed "Focus Areas," are described below. 
Contaminant Plume Containment and Remediation. Uncontained hazardous and radioactive contaminants in soil and ground water exist throughout the DOE Complex. There is insufficient information at most sites on the contaminants' distribution and concentration. The migration of some contaminants threatens water resources and, in some cases, has already had an adverse impact on the off-site environment. Many current characterization, containment, and treatment technologies are ineffective or too costly. Improvements are needed in characterization and data interpretation methods, containment systems, and in situ treatment.

Mixed Waste Characterization, Treatment, and Disposal. DOE faces major technical challenges in the management of low-level radioactive mixed waste. Several conflicting regulations, together with a lack of definitive mixed waste treatment standards hamper mixed waste treatment and disposal. Disposal capacity for mixed waste is also expensive and severely limited. DOE now spends millions of dollars annually to store mixed waste because of the lack of accepted treatment technology and disposal capacity. In addition, currently available waste management practices require extensive, and hence costly waste characterization before disposal. Therefore, DOE must pursue technology that leads to better and less expensive characterization, retrieval, handling, treatment, and disposal of mixed waste.

High-Level Waste Tank Remediation. Across the DOE Complex, hundreds of large storage tanks contain hundreds of thousands of cubic meters of high-level mixed waste. Primary areas of concern are deteriorating tank structures and consequent leakage of their contents. Research and technology development activities must focus on the development of safe, reliable, cost-effective methods for characterization, retrieval, treatment, and final disposal of the wastes.

Landfill Stabilization. Numerous DOE landfills pose significant remediation challenges. Some existing landfills have contaminants that are migrating, thus requiring interim containment prior to final remediation. Materials buried in retrievable storage pose another problem. Retrieval systems must be developed to reduce worker exposure and secondary waste quantities. Another high-priority need is insitu methods for containment and treatment.

Decontamination and Decommissioning. The aging of DOE's weapons facilities, along with the reduction in nuclear weapons production, has resulted in a need to transition, decommission, deactivate, and dispose of numerous facilities contaminated with radionuclides and hazardous materials. While building and scrap materials at the sites are a potential resource, with a significant economic value, current regulations lack clear release standards. This indirectly discourages the recovery, recycling, and/or reuse of these resources. The development of enhanced technologies for the decontamination of these materials, and effective communication of the low relative risks involved, will facilitate the recovery, recycle, and/or reuse of these resources. Improved material removal, handling, and processing technologies will enhance worker safety and reduce cost.

\section{CROSSCUTTING TECHNOLOGIES}

Crosscutting technologies overlap the boundaries of the focus areas while providing simultaneous benefits. These technologies may be used in several or all focus area testing and evaluation programs, and include:

Characterization, Monitoring, and Sensor Technology. DOE is required to characterize more than 3,700 contaminated sites, 1.5 million barrels of stored waste, 385,000 cubic meters $\left(\mathrm{m}^{3}\right)$ of high-level waste in tanks, and from 1,700 to 7,000 facilities before remediation, treatment, and facility transitioning commence. During remediation, treatment, and site closure, monitoring technologies are needed to ensure worker safety and effective cleanup. Cost-effective technologies are needed for all EM characterization requirements. 
Efficient Separations and Processing. Separation and treatment technologies are needed to treat and immobilize a broad range of radioactive wastes. In some cases, separations technologies do not exist. In others, improvements are needed to reduce costs, reduce secondary waste volumes, and improve waste form quality. Separations technologies are also needed for environmental restoration of DOE sites, for groundwater and soils cleanup, and for decontamination and decommissioning of facilities. Many separations agents developed for waste treatment can be adapted for environmental restoration needs.

Robotics. DOE's waste disposal efforts have particular issues-access, safety, final disposal, and cost efficiency. Due to hazardous radiation, massive waste loads, and restricted entry ways, many sites are inaccessible for human labor. It is unsafe to expose humans to radiation, harmful chemicals, and injurious mechanical objects. Human labor requires higher compensation, the need for expensive protective clothing, and stringent decontamination procedures. Robotics systems are safe, efficient, and cost-effective means to automate the handling and processing of mixed waste and characterizing and/or retrieving storage tank waste. Systems can also be designed for surveillance, characterization, cleanup, and decommissioning of retired DOE facilities.

Innovative Investment Area. DOE has set aside funding to foster research and development partnerships within the public and private sector, and to introduce innovative technologies into OTD programs. The Innovative Investment Area supports two types of technologies: (1) technologies that show promise to address specific EM needs, but require proof-of-principle experimentation, and (2) proven technologies in other fields that require critical path experimentation to demonstrate feasibility for adaptation to specific EM needs.

Pollution Prevention. DOE and the Department of Defense (DoD) have similar waste stream pollution problems and common environmental concerns. By combining their resources, these agencies can develop a coordinated interagency environmental research and technology development program that produces cost-effective technological solutions, particularly in the areas of process change or in-process recycling.

\section{TECHNICAL TASK PLANS}

Technical Task Plans (TTPs) are used to identify and to summarize work funded and managed by OTD at headquarters, the field, and the national laboratories. These plans include a project summary, technical task description, budget schedule, and milestone schedule. The EM-50 FY 1994 Program Summary (DOE/ EM-0216) lists TTPs funded between FY92 and FY94.

All tasks require a TTP number. Each TTP number contains information on the fiscal year in which the task is first funded, the DOE Operations Office funding allotment code, and the laboratory/contractor/ university designator. See appendix for further details.

\section{EM ORGANIZATIONAL STRUCTURE}

The Office of Environmental Management (EM) is responsible for managing the cleanup of DOE wastes from past nuclear weapons production and current operations. The EM mission is to bring DOE sites into compliance with all environmental regulations while minimizing risks to the environment, human health and safety posed by the generation, handling, treatment, storage, transportation, and disposal of DOE waste. The EM organization was established to provide focus, accountability, and visibility for DOE's waste management and remediation efforts. See Figure A.

\section{OFFICE OF TECHNOLOGY DEVELOPMENT}

The Office of Technology Development (EM-50) has the overall responsibility to develop technologies to meet DOE's goals for environmental restoration. OTD works closely with EM-30, -40 , and -60 in 


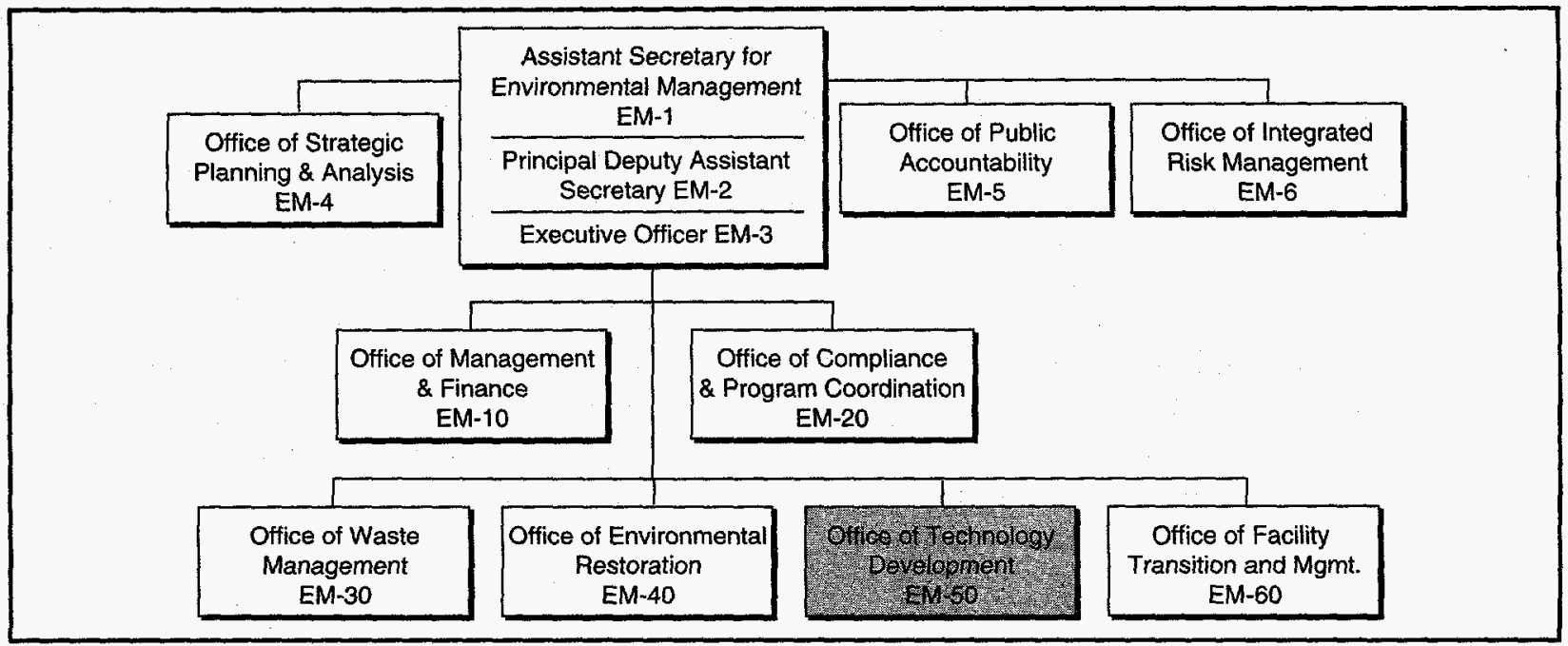

Figure A. The Office of Environmental Management Organizational Structure as of May 1, 1994.

identifying, developing, and implementing innovative and cost-effective technologies. Activities within EM-50 include applied research and development, demonstration, testing, and evaluation (RDDT\&E), technology integration, technology transfer, and program support. See Figure B.

\section{EM-50 ORGANIZATION}

The Office of Technology Transfer and Program Integration (EM-52) provides management, financial, and internal program support to line organizations that comprise EM-50. It also provides efforts to encourage and to facilitate the infusion and diffusion of innovative environmental technologies for internal and domestic application through collaborative partnerships with U.S. and foreign industry or organizations, the national laboratories, other federal agencies, and universities. Technology transfer and technology leveraging are important program components. Enhanced communication to internal and external stakeholders is a goal of this Office.

The Office of Research and Development (EM-53) is responsible for establishing applied research and development (R\&D) program at DOE sites nationwide. Programs are designed to identify operational needs in environmental restoration, waste operations, and corrective activities, and to provide solutions to key technical issues that, if not solved in a timely manner, would adversely affect DOE's ability to meet its cleanup goal.

The Office of Demonstration, Testing, and Evaluation (EM-54) is responsible for identifying environmental management technologies in the research and development stage that are ready for transition to the demonstration arena. Those technologies are complete systems to demonstrate a solution to a specific problem area. Programs are conducted to advance selected technologies so they can be utilized by DOE to meet its cleanup goal in a cost-effective manner.

\section{OTHER EM ORGANIZATIONS}

The Office of Waste Management (EM-30) has program responsibilities for managing waste generated at all DOE sites during weapons processing and manufacturing, research activities, and site cleanup activities. This includes the treatment, storage, transportation, and disposal of several types of waste: transuranic, lowlevel radioactive, mixed, and solid sanitary wastes. EM-30 is also responsible for the storage, treatment, and 


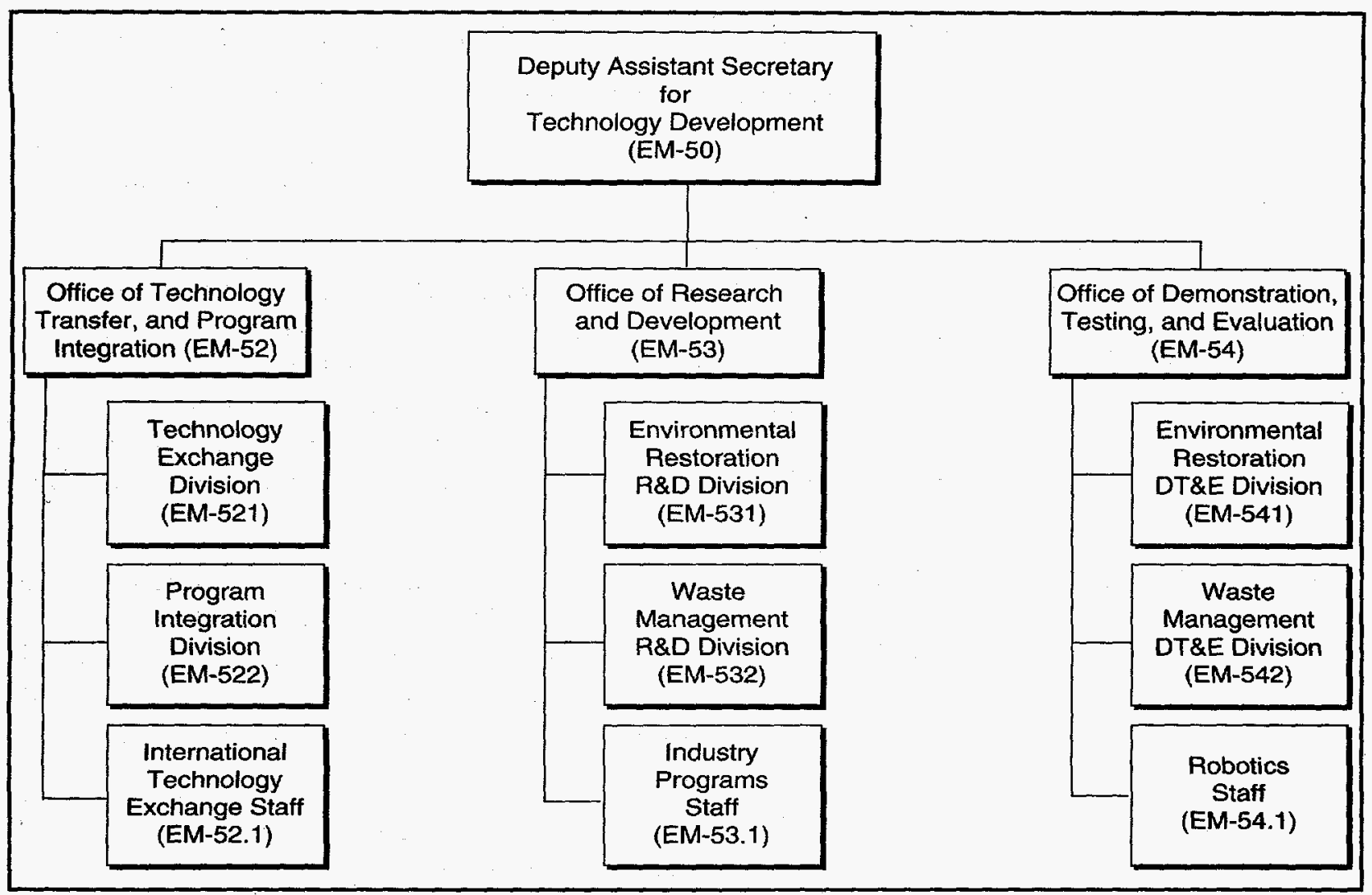

Figure B. The Office of Technology Development Organizational Structure as of May 1, 1994.

processing of defense high-level radioactive waste (HLW), waste minimization efforts, and corrective activities at waste management facilities.

The Office of Environmental Restoration (EM-40) has program responsibilities for assessment and cleanup of inactive hazardous and radioactive facilities and waste sites at all DOE installations and some non-DOE sites. EM- 40 oversees program activities to reduce or eliminate risks to human health and the environment.

The Office of Facility Transition and Management (EM-60) has the responsibility to ensure that shutdown facilities are brought to a deactivated state, are properly maintained, and are eventually decontaminated and/or decommissioned or released for other uses. 


\section{CONTAMINANT PLUMES CONTAINMENT AND REMEDIATION FOCUS AREA OVERVIEW}

EM has established a new approach to managing environmental technology research and development in critical areas of interest to DOE. The Contaminant Plumes Containment and Remediation (Plumes) Focus Area is one of five areas targeted to implement the new approach, actively involving representatives from basic research, technology implementation, and regulatory communities in setting objectives and evaluating results. This document presents an overview of current EM activities within the Plumes Focus Area to describe to the appropriate organizations the current thrust of the program and developing input for its future direction.

The Plumes Focus Area is developing remediation technologies that address environmental problems associated with certain priority contaminants found at DOE sites, including radionuclides, heavy metals, and dense non-aqueous phase liquids (DNAPLs). Technologies for cleaning up contaminants of concern to both DOE and other federal agencies, such as volatile organic compounds (VOCs), polychlorinated biphenyls (PCBs), and other organics and inorganic compounds, will be developed by leveraging resources in cooperation with industry and interagency programs.

The technical objectives of the Plumes Focus Area are to: (1) improve technologies to contain plumes that pose imminent environmental and health risks, (2) demonstrate technologies that will provide significant advances over conventional pump and treat methods of aquifer remediation, and (3) develop technologies to remediate soils overlying aquifers where contaminants threaten ground water supplies.

Near-term technology development goals within the next three years are to expedite the characterization of contaminant plumes, control sources and migration, and facilitate implementation of emerging remediation technologies. Over the next six years, the mid-term goals are to achieve breakthroughs where remediation technologies do not yet exist, especially in the areas of DNAPLs, heavy metals, and radionuclide contaminants in aquifers and overlying soils. Long-term goals are to maintain a coordinated research and development program that provides continuous improvement in plume remediation technologies and promotes the U.S. export of technologies.

The current Plumes Focus Area program is designed to meet the technical and schedule objectives by supporting ongoing site characterization and assessment activities, near-term containment of contaminant plumes, and treatment of contaminants in ground water aquifers and overlying soils. Management and integration functions will ensure that research needs are communicated to investigators performing basic research and that scientific breakthroughs and successes are coordinated appropriately within the focus area.

\section{SITE ASSESSMENT TECHNOLOGY}

Priority technology areas needed for improving site assessment include contaminant characterization techniques, methods of measuring aquifer properties, on-line remediation process controls, and subsurface exploration and access tools.

\section{CONTAMINANT CHARACTERIZATION}

Researchers are developing improved methods to identify contaminant species, their concentrations, masses, or volumes, and their direction and rate of migration. By expediting the assessment phase of plume 
remediation, unnecessary sampling and analysis can be avoided. Non-invasive technologies for determining the presence of mixed radioactive/hazardous contaminants are needed, as well as characterization methods for complex geologic media such as fractured rock or heterogeneous aquifers. High priority technologies include systems for detecting and locating the position of DNAPLs in the subsurface and downhole sensors that continuously monitor contaminant concentrations in groundwater. Specific technologies for contaminant sensing and characterization for plumes are being developed within the framework of the Characterization, Monitoring, and Sensor Technology Crosscutting Program, which also provides technologies for other focus areas.

\section{CHARACTERIZATION OF AQUIFER PROPERTIES}

Improved understanding of aquifer properties that control contaminant flow and transport are important to designing optimum systems for remediating subsurface plumes. Emphasis is placed on technologies to improve the accuracy and reliability of point measurements of ground water velocity (migration rate and direction). Determination of hydrodynamic dispersion and diffusion characteristics for a plume are also of concern. Improved risk assessment requires new methods for estimating the retardation properties for specific contaminants, including reactive parameters and new techniques for estimating natural degradation rates for site-specific aquifer conditions.

\section{ON-LINE PROCESS CONTROLS}

On-line process control sensors are being developed to measure the progress of in situ treatment processes. Methods to monitor biological treatment techniques by sensing microbial population changes are currently in development for arid and non-arid site applications. New capabilities for evaluating the performance of containment systems in conjunction with contaminant characterization technologies are being sought to augment containment technology development efforts.

\section{SUBSURFACE ACCESS}

New technology for gaining access to the subsurface for sampling and characterizing contaminant plumes are needed to reduce the time and cost of site assessments. Researchers are developing and demonstrating techniques which involve drilling, punching, water jetting, and sonic waves. Directional drilling and location control techniques are important for gaining access to contaminant plumes beneath structures. Techniques are sought for use at sites with complex or difficult geologic conditions such as fractured rock or cobble-filled alluvium. The goal of these advanced subsurface access methods is to reduce the cost, time, secondary waste, and subsurface disturbance associated with conventional techniques.

\section{CONTAINMENT TECHNOLOGY}

Containment of contaminant plumes can be accomplished by selectively stopping the migration of target compounds through use of reactive barriers or by preventing the flow of fluids through conventional hydraulic barriers. The Focus Area is seeking major improvements in the implementation of hydraulic barriers, including increased depth, more effective temporary systems, and innovative emplacement techniques.

\section{REACTIVE BARRIERS}

Reactive barriers are being developed to contain plumes, without significant negative influence on the natural flow of groundwater. Unlike conventional hydraulic containment systems, these structures will be water permeable, and they are constructed by injecting a substance over a defined subsurface boundary to react chemically with target contaminants by physically trapping or immobilizing them. The reactive barrier 
avoids or minimizes waste generation; however, methods to simplify monitoring and maintenance of the barriers are required. Funnel and gate systems which channel groundwater flow are well suited for this technology. Reactive processes under examination include: (1) adsorption of chlorinated hydrocarbons with organic substances, (2) precipitation of metals and oxyanions with reagents, (3) sequestration of mobile metal ions and radionuclides (e.g., strontium) with zeolites, and (4) microbial degradation of trichloroethylene (TCE).

\section{DEEP SUBSURFACE BARRIERS}

Improved methods of constructing impermeable barriers at depths greater than fifty feet are being developed. Current construction/emplacement technology is either too costly or ineffective for containing plumes at great depths or in fractured rock. The primary concept being addressed is a barrier formed by injection of viscous liquids which include polybutenes, colloidal silica gel, and polysiloxane. Development of such barriers would facilitate the safe demonstration of in situ treatment technologies and will give a viable alternative for containing plumes beneath underground storage tanks and other structures.

\section{TEMPORARY BARRIERS}

Temporary containment barriers are needed primarily to control source plumes where there is an immediate threat of migration. By limiting the spread of contaminants, potential secondary wastes from future cleanup operations may be reduced. Temporary barriers can also provide safe environments for demonstrating or implementing in situ remediation measures when there is the likelihood of further migration resulting from the treatment process. Frozen soil barriers, circulating air, and biological systems are among the candidate technologies being demonstrated and evaluated. Performance criteria for these candidate technologies include rapid installation in the vadose zone for vertical and horizontal applications in conjunction with in situ treatment technologies.

\section{BARRIER EMPLACEMENT}

New methods of installing containment barriers are necessary to reduce construction costs and increase their depth of application. The ability to install horizontal barriers without disturbing surface conditions or structures, such as tanks, landfills, or other source areas, is a critical need. A prototype system which utilizes a jet grout cutting bar dragged horizontally through the soil has been demonstrated at the Fernald Site. A second demonstration to prove the utility of the technology at other DOE sites will occur in FY95 at a site with more difficult soil conditions. Structural continuity and hydraulic performance of the system are key success indicators.

\section{TREATMENT TECHNOLOGY}

High priority is placed on treating plumes in situ, so that potential worker and public exposure is eliminated. In situ methods minimizes waste materials and reduce costs. Innovative treatment technologies, in conjunction with improved subsurface access techniques such as horizontal wells, are encouraged. The technical areas being pursued by the Focus Area are physical, chemical, and biological treatment methods as well as technologies to manipulate or alter media properties.

\section{PHYSICAL TREATMENT}

Innovative in situ technologies are being developed to improve the destruction or extraction of plume contaminants. The basic concept is to alter the physical state of the contaminants in situ to enhance their mobility, increase their degradation rate, or destroy them directly. For example, in situ heating methods volatilize contaminants, which increases their removal rates by conventional extraction. The MAG*SEP 
technology utilizes engineered particles to magnetically remove heavy metals and radionuclides from groundwater. Barometric pumping technologies remove organics without energy inputs. By eliminating the need for excavation and disposal of geologic media along with contaminants, these technologies reduce secondary waste and life-cycle remediation costs. Wherever practicable, reuse of treatment fluids is also a goal.

\section{CHEMICAL TREATMENT}

New methodologies are being developed for in situ injection of reagents to remediate contaminant plumes. These technologies will provide techniques for the remediation of plumes when bioremediation is not feasible due to toxic or inhospitable environments and low bioavailability. These technologies are directed toward chemical degradation or destruction of VOCs, non-VOC organics (e.g., PCBs and PAHs), and nonmetal inorganics through oxidation processes. Additionally, progress is being made toward increasing the treatability of DNAPLs with surfactant foams.

\section{BIOLOGICAL DEGRADATION}

Biological remediation systems are a priority within the Focus Area. By utilizing the natural abilities of plants or microbes to metabolize, sorb, oxidize, or reduce organic and inorganic compounds, significant cost savings can be achieved. No secondary waste is generated. The public generally considers bioremediation technology to be safe and acceptable, if properly demonstrated. Aims of this technology program are: (1) destruction of chlorinated solvents, DNAPLs, and mixed contaminants, (2) enhancement of microbe nutrient delivery methods, and (3) development of methodology to assess remedial progress. Additionally, progress is being made toward the installation of both permeable and impermeable microbial barriers. Biological methods to separate radionuclides from soil and aqueous phase waste are under demonstration.

\section{SubSURfaCE MANIPUlation OF PROPERTIES}

Technologies are being developed to alter the subsurface environment to increase contaminant removal efficiency, which will expand the use of other treatment technologies at more DOE sites. Manipulation technologies will enhance treatment capabilities and options at sites with difficult geologic media conditions (e.g., low permeability soils). Examples of technologies under development include (1) electrokinetics for concentrating mobile metals in arid and non-arid clays, thus reducing secondary waste volumes, and (2) soil fracturing for increasing soil permeability, thus improving the effectiveness of in situ treatment methods. 

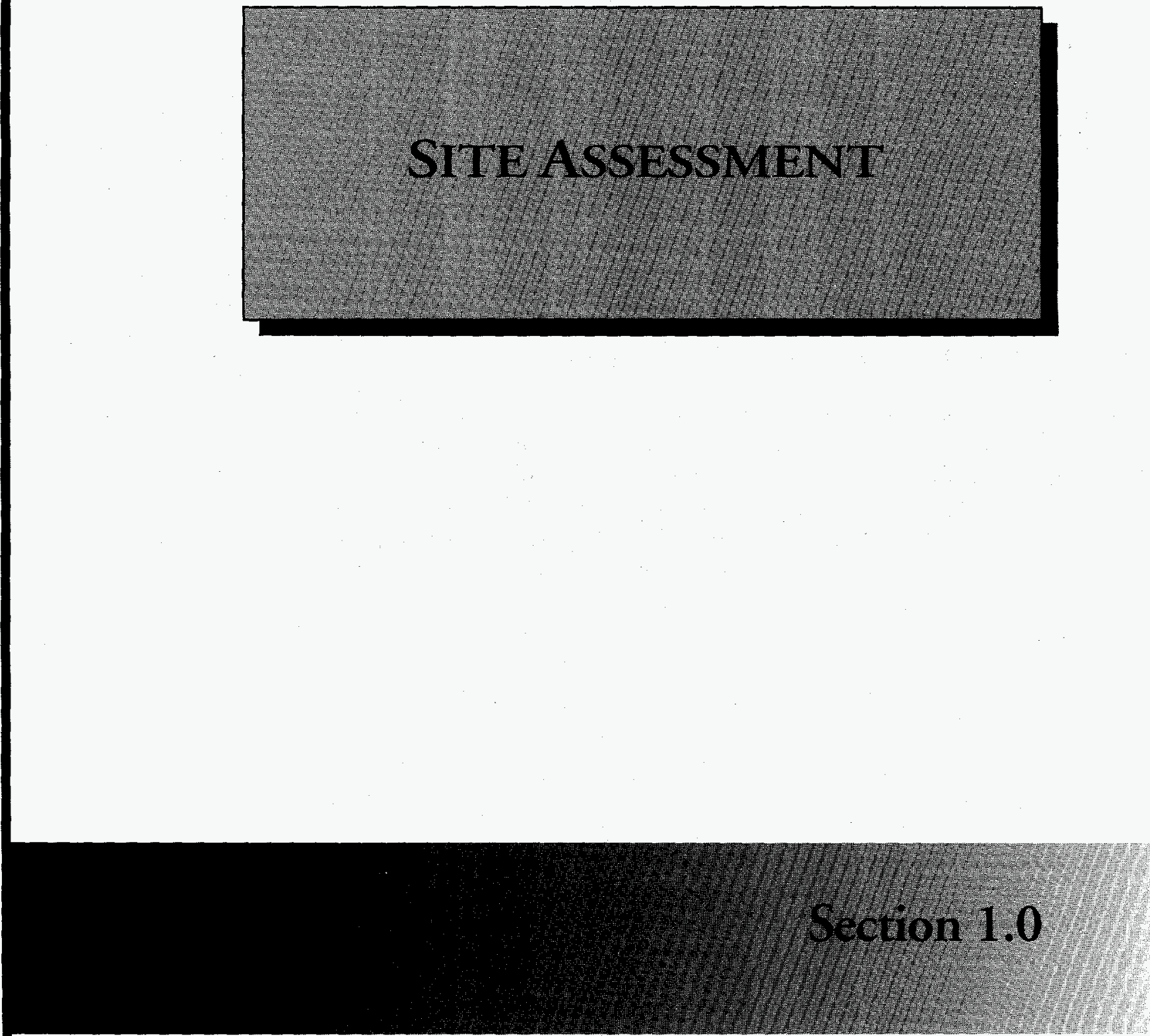
2 


\subsection{INTEGRATED SPECTROSCOPIC SYSTEM FOR CHARACTERIZING CONTAMINANT SPECIATION}

\section{TASK DESCRIPTION}

The focus of this project is to develop a new approach in characterizing contaminant speciation by directly probing molecular structure. The Integrated Spectroscopic System for Environmental Contaminant Speciation (ISSECS) is applied mainly to soils contaminated with radioactive and/or toxic metals such as uranium, plutonium, and chromium. This laboratory-based approach consists of four state-ofthe-science spectroscopic techniques: X-ray absorption spectroscopy, pulsed-laser photoacoustic spectroscopy, pulsed-laser (time-resolved) and continuous-wave luminescence spectroscopy, and laser Raman spectroscopy. See Figure 1.1.

Applying these techniques in combination provides a greater level of information on contaminant spe-

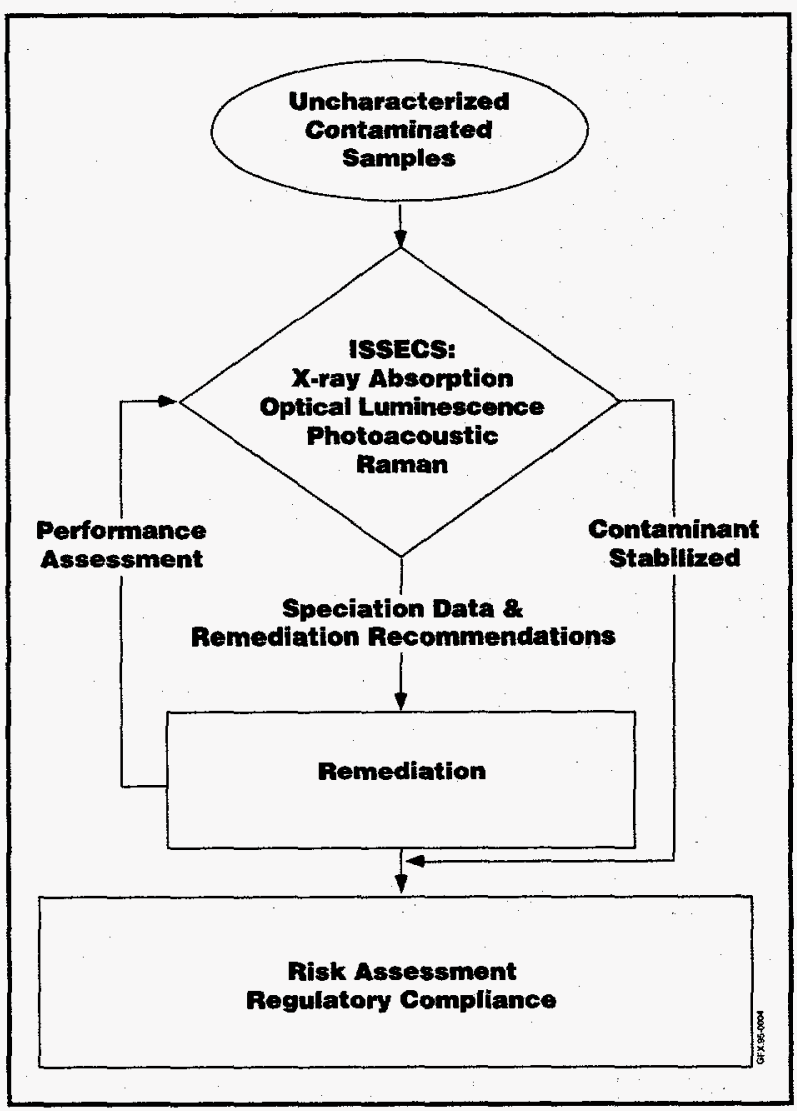

Figure 1.1. Integrated Spectroscopic System Process. ciation than do the techniques separately. The spectroscopies can determine average speciation at the bulk scale ( 1 to $2 \mathrm{~cm}$ ) as well as more precise speciation at the microscopic scale (1 to $10 \mathrm{mi}$ crons). By contrast, conventional approaches rely on microscopic methods only, which can give accurate speciation data for small populations but not for bulk samples.

ISSECS is sensitive, applicable over a broad spatial range, and adaptable to soils, sludges, and groundwater. ISSECS not only addresses all relevant spatial scales for contaminant heterogeneity, but because the characterization tools are all optically based, their application is non-invasive; the contaminated samples can be studied in the exact form as they existed in the environment without having to damage them. Once representative contaminant samples are collected, they are characterized in the laboratory. These data are provided to the site remediation personnel along with recommendations for candidate remediation strategies based on the contaminant speciation. ISSECS also provides feedback on how well the remediation treatment perform as well as post-treatment analyses.

\section{TECHNOLOGY NEEDS}

When new remediation technologies are developed and tested, analytical data are generally available on contaminant concentrations and the spatial extent of the contaminant plumes. However, the contaminants often exist in different chemical species with accessible oxidation states such as toxic and radioactive metals. Unless speciation information is factored into characterization early on, remediation development and testing strategies are conducted strictly by trial and error, which is costly and inefficient.

Several routine analytical approaches are currently used, including electron microscopies, X-ray, and electron diffraction. In principle, these methods can provide contaminant speciation information, 
but in theory are limited because they cannot easily address sample and contaminant heterogeneity over spatial ranges of less than 1 micron to greater than $1 \mathrm{~cm}$.

\section{ACCOMPLISHMENTS}

This technology has been fully demonstrated and evaluated for uranium contaminant speciation in shallow subsurface soils at the Fernald site. These results had a direct impact on the design and evaluation of the cleanup technologies for these soils. More recently, the technology has also been partially demonstrated for uranium-contaminated soils at Los Alamos, Hanford, and Portsmouth, for thorium-contaminated soils at an industrial site in $\mathrm{New}$ Jersey, and for plutonium-contaminated soils at Hanford.

\section{BENEFITS}

Presently, there are no true baseline technologies for characterizing the speciation of environmental contaminants. Most baseline approaches (e.g., X-ray fluorescence, inductively-coupled plasma atomic emission, etc.) give only analytical concentrations and no speciation information. Molecular spectroscopies provide speciation information directly and effectively complements other speciation tools under development, including analytical electron microscopies.

The principal benefit of this characterization technology is that it potentially eliminates trial-anderror in determining the most effective and appropriate remediation technology. An independent cost-effectiveness analysis of ISSECS has shown that implementation of this technology will result in overall cost-savings for all remediation projects for which the optimal remediation technology is not known prior to the start of the cleanup. The extent of cost savings from implementation of ISSECS depends on numerous factors. A management tool has been developed to predict these savings.
The ability for this technology to eliminate trialand-error has the added advantage that secondary waste streams associated with remediation can be reduced. For example, non-applicable remediation technologies do not have to undergo pilot-scale testing, and promising remediation technologies can be fine-tuned based on speciation data to minimize waste. Finally, because this characterization approach yields specific chemical structure information, it can be used to generate important input data into sophisticated risk assessment calculations.

Using ISSECS to do a complete analysis of one environmental sample costs $\$ 5,000$ to $\$ 7,000$. Conducting a representative analysis of an entire plume would typically require 2 to 20 samples, assuming that a fully equipped laser laboratory is already in place. Estimated capital costs to develop the complete laser lab facility are $\$ 650,000$ (not including physical plant). The X-ray absorption spectroscopy technique requires access to a synchrotron radiation facility, such as the Stanford Synchrotron Radiation Laboratory in California. The subcontracting costs for using this facility are factored into the per sample estimate above.

\section{COLLABORATION/TECHNOLOGY TRANSFER}

Federal and state government agencies would be the principal customers for this system, followed by metal manufacturing and processing industries. The entire suite of methods in this technology has been demonstrated only for uranium at this time, but subsets of the methods have also been tested for plutonium, thorium, and chromium. This technology can also be applied to other environmental contaminants that exist in two or more chemically different forms. For example, this technology is applicable for metals such as selenium, mercury, and lead, as well as simple, nonvolatile inorganic ions such as cyanide.

Use of ISSECS should be demonstrated on a caseby-case basis for each contaminant and should require only minimal development work. As ISSECS is shown to be viable for one contaminant, it can be commercialized before the system is tested for other 
contaminants. Market analyses need to be conducted to identify potential customers. Two possibilities for establishing private-sector access to a synchrotron radiation facility are university partnerships and joint-venture agreements with Los Alamos National Laboratory (LANL). A draft commercialization plan and a detailed cost-effectiveness analysis are available for this technology. A patent application has been filed.

\section{For further information, please contact:}

\section{David Morris}

Principal Investigator

University of California

Los Alamos National Laboratory

P.O. Box 1663

Los Alamos, NM 87545

(505) 665-6486

\section{Bruce Erdal}

Technical Program Manager

University of California

Los Alamos National Laboratory

P.O. Box 1663

Los Alamos, NM 87545

(505) 667-8914

\section{Michael Malone}

Program Manager

U.S. Department of Energy

Cloverleaf Building

19901 Germantown Road

Germantown, MD 20874-1290

(301) 903-7996
TTP Numbers: AL121122, AL121121

\section{BIBLIOGRAPHY OF KEY PUBLICATIONS}

Morris, D.E. and S.D. Conradson, "Integrated Spectroscopic System for Environmental Contaminant Speciation (ISSECS)," Technical Information Exchange Meeting with Industry on Environmental Restoration Needs in the Northwest United States: Outreach to Industry - Partnerships for the Future, Vol II., Technology Profiles, DOE-CONF-940145, January 25-27, 1994.

Allen, P.G., J.M. Berg, C.J. Chisholm-Brause, S.D. Conradson, R.J. Donohoe, D.E. Morris, J.A. Musgrave, and C.D. Tait, "Determining Uranium Speciation in Contaminated Soils by Molecular Spectroscopic Methods: Examples from the Uranium in Soils Integrated Demonstration," Proceedings of Waste Management '94, 1994, 3, 2063.

Morris, D.E., D.D. Thornton, and B. Padilla, Integrated Spectroscopic System for Environmental Contaminant Speciation: $A$ New Approach for Determining Contaminant Speciation by Directly Probing Molecular Structures, Los Alamos National Laboratory Report LALP-94-19, April 1994.

Heskett, J.C. and S.R. Booth, Cost-Effectiveness of the Integrated Spectroscopic System for Environmental Contaminant Speciation, Los Alamos National Laboratory Report LA-UR-93-4054, November 1993.

Allen, P.G., J.M. Berg, C.J. Chisholm-Brause, S.D. Conradson, R.J. Donohoe, D.E. Morris, J.A. Musgrave, and C.D. Tait, Speciation of Uranium in Fernald Soils by Molecular Spectroscopic Methods: FY 93 Progress Report, Los Alamos National Laboratory report LA-12799-PR, 1993. 


\section{TASK DESCRIPTION}

The objective of this program is to develop the Long-Range Alpha Detector (LRAD) soil monitor demonstrated at Fernald into a monitoring system for multiple environmental situations. The LRAD soil surface monitor is a large, flat box in which the open end is placed on top of the soil. Radiation from the soil ionizes the air in the box. The amount of ionized air, which is proportional to the amount and type of radiation, is measured. This method is particularly sensitive to alpha radiation, which is emitted by uranium and transuranic elements.

\section{TECHNOLOGY NEEDS}

Detection of alpha contamination on soil surfaces has traditionally been limited by the short range of the alpha particles in soil, air, and alpha detectors. This short range, coupled with the small size and poor sensitivity of traditional detectors, has made surface surveying a difficult and time-consuming process. The LRAD technique relies on detecrion of the air ions created by alpha particles rather than the alpha particles themselves. These ions can be carried over long distances (up to 10 meters) in a moving current of air prior to detection by an ion detector. Alternately, in the LRAD soil surface monitor, the ions can be collected by a directly applied electric field. See Figure 1.2. The ability to monitor entire large and/or rough surfaces also makes LRAD monitors ideal for scanning large areas of soil surface.

\section{ACCOMPLISHMENTS}

- Developed and built two, one-square meter, tractor-mounted LRAD soil surface monitors and a one-quarter square meter, handcart-mounted soil surface monitor.

- Monitored Fernald Soil Treatment Plant and Decontamination \& Decommissioning Areas as part of the Uranium in Soils Integrated Demonstration.

- Monitored three sites at LANL for LANL Health $\&$ Safety personnel.

- Monitored five sites at LANL for LANL Environmental Restoration personnel.

- Monitored the outside of a 40-year-old uranium critical assembly building at LANL for the building supervisory personnel.

- Monitored an inactive firing site at Kirtland Air Force Base (KAFB) for Sandia's Environmental Restoration personnel.

- Monitored calibration pads in both Grand Junction, Colorado, and Grants, New Mexico.

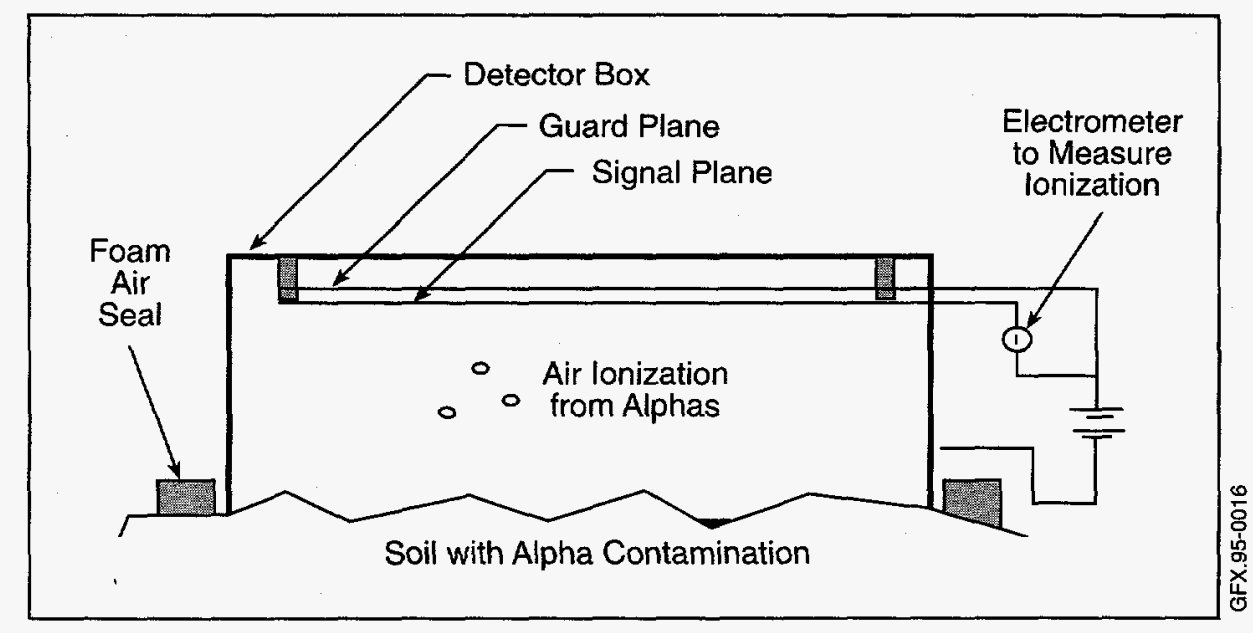

Figure 1.2. Schematic of LRAD Soil Surface Monitoring. 


\section{BENEFITS}

The primary advantage of an LRAD monitor is that it provides a real-time measurement in situ and is much faster (10 - 15 minutes vs. days or weeks), less expensive, and safer than sample analysis. No excavation or transport of contaminated material is required. LRAD monitors are also more advantageous than hand-held alpha monitors because they are 10 to 100 times more sensitive, providing a quicker response to the operator as they move into a contaminated area.

\section{COLLABORATION/TECHNOLOGY TRANSFER}

Eberline Instrument Corporation

Santa Fe, NM

Thermo Analytical

Albuquerque, NM

\section{For further information, please contact:}

John Bounds

Principal Investigator

University of California

Los Alamos National Laboratory

P.O. Box 1663

Los Alamos, NM 87545

(505) 665-0446

\section{Bruce Erdal}

Technical Program Manager

University of California

Los Alamos National Laboratory

P.O. Box 1663

Los Alamos, NM 87545

(505) 667-8914
Michael Malone

Program Manager

U.S. Department of Energy

Cloverleaf Building

19901 Germantown Road

Germantown, MD 20874-1290

(301) 903-7996

TTP Numbers: AL131002, AL121121

\section{BIBLIOGRAPHY OF KEY PUBLICATIONS}

Johnson, J.D., K.S. Allander, J.A. Bounds, S.E. Garner, J.P. Johnson, D.W. MacArthur, LongRange Alpha Detector Sensitivity to Beta Contamination and Soil Moister, IEEE Transactions in Nuclear Science, 41.4, 1994.

MacArthur, D.W., K.S. Allander, J.A. Bounds, R.W. Caress, M.M. Catlett, D.A. Rutherford, LRAD Surface Monitors, Los Alamos National Laboratory Report, LA-12524-MS, 1993.

Garner, S.E., J.A. Bounds, K.S. Allender, R.W. Caress, J.D. Johnson, D.W. MacArthur, $A$ Compendium of Results from Long-Range Alpha Detector Soil Surface Monitoring: June 1992-May 1994, Los Alamos National Laboratory Report, LA-12861MS. 


\section{3 \\ GEOLOGICAL DECISION MAKING \\ MODEL}

\section{TASK DESCRIPTION}

The objective of this task is to develop and demonstrate a geologic decision making model to support environmental restoration and characterization programs by identifying which characterization technology, or combination of technologies, is most likely to optimize DOE's return on investment. Investigations conducted in geologic materials are inherently uncertain. Only a small portion of the material is ever sampled, and the materials are intrinsically heterogeneous and anisotropic. The deposition and fate of contaminants in natural materials are stochastic processes. The uncertainties that accrue often lead to costly site characterization programs that provide ambiguous information to the decision makers responsible for remediation strategy. Given the uncertainties, all alternatives available to the decision maker embody some element of risk, but the development of a decision making model to support characterization should clearly reinforce certain decisions.

This project will adapt and work within a framework of geological decision analysis to quantify the uncertainties inherent when sampling natural materials and to propagate those uncertainties through a decision model. The framework is based on a riskbased philosophy that couples the uncertainty of the geologic information with a decision model seeking to optimize a cost-risk-benefit objective function. In this framework, remediation is defined as a sequence of decisions under uncertainty and risk is defined as the probability of failing to identify the contaminated soil multiplied by the cost of that failure.

The decision model is the link between the data collected during site characterization and the design alternatives available to the decision maker. The objective of the decision model is threefold. First, given a set of data on concentrations of uranium in the soil at Fernald, which design alternative from a suite of possible alternatives is the best? Second, is it worthwhile trying to improve the currently available data by taking additional samples? And third, which of the four demonstration technologies minimizes the objective function of the decision model? A simple model of the design alternatives is illustrated in Figure 1.3.

In the model presented, the decision maker is faced with two alternative decisions - to characterize the site or not to characterize the site. If the decision is made to characterize the site, a number of alternatives based on the results of the characterization activities are available to the decision maker. For each alternative strategy, an objective function can be written. The value of the objective function is calculated for each alternative. The two terms in the objective function that are sensitive to individual characterization technologies are the cost of site characterization and the probability of failure. Additional data is prioritized by its ability to reduce the uncertainty as to which of several alternative strategies is most likely to minimize the cost of the remedial activities while at the same time increase confidence in the ability of the site to comply with the regulatory criteria.

The project also works closely with the developers of alternative characterization technologies to estimate the cost of site-scale characterization activities. Technologies for delineating the distribution of uranium contamination in surface and subsurface soils will be tested and evaluated at the Fernald site in Ohio. The data from these technologies and the control data will first be evaluated using classical geostatistical estimation. The estimation process will generate a map of estimated mean values of concentration and a measure of the error associated with the estimate. This type of analysis has proven beneficial in many situations in identifying locations in space where additional field sampling is likely to provide additional information. 


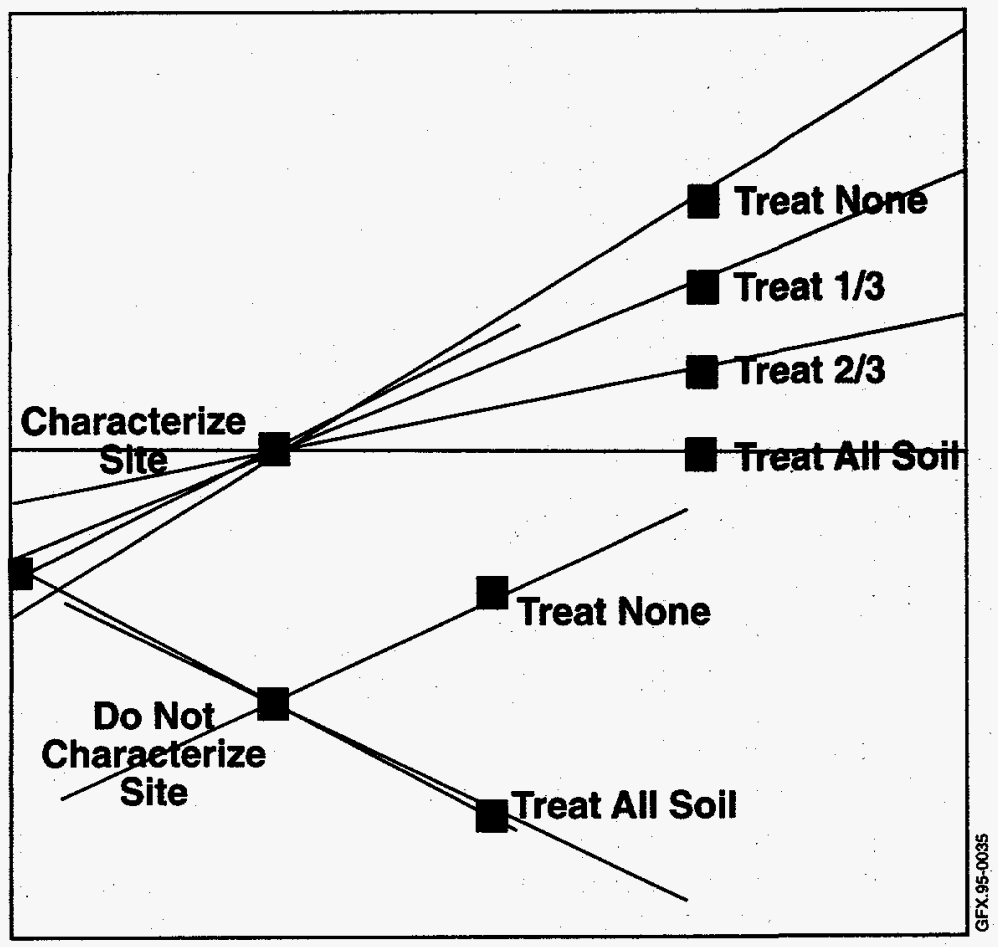

Figure 1.3. Sample of Decision Model Alternative.

\section{TECHNOLOGY NEEDS}

DOE is presently faced with the task of identifying and remediating sites contaminated by radioactive, hazardous, and mixed waste. Uncertainties in characterizing a geologic environment create difficulties in evaluating alternative decision making strategies. In addition, the complexity of resolving a problem that has technical, legal, and political components requires a systematic approach to data collection, evaluation, and the decision making process. Concern over the relationship between site characterization activities and the need to establish the appropriate database for design decisions and evaluation of regulatory compliance have prompted the development of decision analysis techniques. Decision analysis is a promising tool that should expedite the decision making process and help to mitigate the costs of large waste projects.

\section{ACCOMPLISHMENTS}

Major accomplishments for FY94 were the documentation of FY93 analyses and preparation for and execution of the summer field demonstration of technologies at the Fernald Environmental Management Project. Three major shifts were made that dramatically altered the scope and objective of this task. The first was the realization that, with the advent of real-time field analytical sensors, analysis of the data, if conducted in real time, could help optimize sample locations and number of samples while crews were still in the field. The second was the understanding that the purpose of decision tools is to provide information to a broad variety of stakeholders. The third was the need for data management protocols that would satisfy regulatory requirements and data quality objectives.

Currently, data transfer, management, compilation, analysis, and reporting of results have been reduced to a six hour process. Previously, these processes routinely took four to six months. The output is tailored for the decision-maker in the field and is intended to help determine the number and location of additional samples. The economic benefits of near real-time analysis are substantial at sites where characterization is expected to continue over long periods of time.

\section{BENEFITS}

This process evaluates alternative characterization technologies and provides a program manager with the costs, risks, and benefits of alternative strategies. The generic nature of the approach allows it to be applied to any site investigation. The approach will decrease the time required for input and interpretation of technical data in the decision making process. It will also provide a better estimate of the risks and costs involved with alternative decision strategies, and will limit site characterization activities to the collection of site-specific data. Information generated by the analytical process could optimize the design of any additional characterization activities, batch treatment plants, and soil scraping projects to minimize the spread of contamination. This ap- 
proach is is also applicable to many problems facing industry.

\section{COLLABORATION/TECHNOLOGY TRANSFER}

Over the past year, a number of relationships were formed that have contributed to the growth of the task and an aggressive technology transfer program. Internally at Sandia, this task has started the process of integration with the Sandia Environmental Decision Support System (SEDSS). A joint proposal was negotiated with the Uranium Mill Tailings Remedial Action Project (UMTRA). Funding started in April 1994 and the work is expected to continue on through FY95 and FY96. A consortia of industrial, university, and laboratory partners was formed to support the resource requirements of the integrated projects. Current partners in the consortia include Oak Ridge National Laboratory (ORNL), Pacific Northwest Laboratory (PNL), INTERGRAPH, Oregon State University, and others.

Potential Cooperative Research and Development Agreements (CRADAs) are under negotiation with three firms. The U.S. Environmental Protection Agency (EPA) Environmental Monitoring System Laboratory is directly funding this project starting with FY94. Negotiations are underway to support base cleanup for the Air Force. This project has been integrated with the EPA-sponsored SEDSS in support of the UMTRA Project. This project is also supporting the Waste Isolation Pilot Plant (WIPP) Project with applications developed under this task. Chrysler Corporation is also interested in possible application. The project has also been contacted by Fluor Daniels, Jacobs Engineering, M. K. Furgueson, Cornell University, LANL, Weldon Springs, Malinckrodt Chemical, the Nuclear Regulatory Commission, and others regarding possible applications.
For further information, please contact:

\section{Paul Kaplan}

Principal Investigator

Sandia National Laboratories

P.O. Box 5800

Albuquerque, NM 87185-5800

(505) 848-0684

\section{George Allen}

Technical Program Manager

Sandia National Laboratories

P.O. Box 5800

Albuquerque, NM 87185-5800

(505) 844-9769

\section{Mike Malone}

Program Manager

U.S. Department of Energy

Cloverleaf Building

19901 Germantown Road

Germantown, MD 20874-1290

(301) $903-7996$

TTP Number: Al231007

\section{BIBLIOGRAPHY OF KEY PUBLICATIONS}

Clark, I., Practical Geostatistics, Elsevier Applied Science Publishers, New York, 1979.

Freeze, R.A., et al., "Hydrogeological Decision Analysis: Part 1. A Framework," Groundwater, Vol. 28, No. 5., 1990.

Deutsch, C.V., and A.G. Journel, GSLIB, Geostatistical Software Library and User's Guide, Oxford University Press, New York, 1992.

Harr, M.E., Reliability-Based Design in Civil Engineering, McGraw Hill, New York 1987.

Isaaks, E.H., and R.M. Srivastava, Applied Geostatistics, Oxford University Press, New York 1989. 
Jaynes, E.T., (R. D. Rosenkrantz, ed.). Papers On Probability, Statistics and Statistical Physics, D. Reidel Publishing Company, Boston, 1983.

Kaplan, P.G., "A Formalism To Generate Probability Distributions For Performance Assessment Modeling," Proceedings of the Second Annual International Conference, High Level Radioactive Waste Management, American Nuclear Society, La Grange Park, IL, 1991.

Massmann, J., et al, "Hydrogeological Decision Analysis: 2. Applications to Ground-Water Contamination," Groundwater, Vol. 29, No. 4, 1991.

Rautman, C.A., and A.L. Flint, "Deterministic Geologic Processes And Stochastic Modeling," Proceedings of the Third Annual International Conference, High Level Radioactive Waste Management, American Nuclear Society, La Grange Park, IL, 1992. 


\subsection{CHARACTERIZATION OF CONTAMINATED SOILS \\ AND RESIDUES USING ELECTRON \\ AND ION BEAM METHODS}

\section{TASK DESCRIPTION}

Remediation technologies are being developed to clean up U.S. heavy metal and radionuclide contaminated sites. The effectiveness of these technologies is dependent on the form and concentration of contamination. For example, by accurately characterizing the plutonium in incinerator ash, methods can be developed to leach and recover plutonium, a high-value product, from the host material. At Argonne National Laboratory (ANL), Analytical Electron Microscopy (AEM) methods are under development to characterize waste components in contaminated soils.

Following a protocol based on EPA guidelines for determining the nature of radionuclide contamination in soils, characterization information is used to assist remediation technology development and optimization. This characterization method combines electron and ion beam methods. It includes: (1) scanning electron microscopy with backscattered imaging and X-ray energy dispersive spectroscopy (EDS) capabilities, (2) analytical transmission electron microscopy for characterization of sub-micron radionuclide phases with electron diffraction, EDS, and electron energy loss spectroscopy (EELS), and (3) a secondary ion mass spectrometer (SIMS) for trace radionuclide detection. Optical microscopy and X-ray diffraction are also used in characterization studies for representative analysis.

This particular study of radioactive materials includes elemental analysis using inductively coupled plasma mass spectroscopy (ICP-MS) and gamma and alpha spectroscopy for radiochemical characterization of soils. These instrumental techniques are available within the Radioactive Waste Microscopy Group at ANL and for characterizing contaminated soils from various sites.

\section{TECHNOLOGY NEEDS}

Present regulatory, environmental, and social demands require that a large number of sites undergo decontamination of local soils that have been fouled by a wide variety of human activities. Effective remediation of contaminated soil demands that unnatural waste products be removed with minimal processing or alteration of the natural chemistry and morphology of the environment. Such remediation is possible only with detailed knowledge of the chemical and structural composition of both the waste constituent and the native soil.

Soil around the Fernald site in Ohio became contaminated with uranium due to operations that were conducted from the early 1950 s until 1986. The form of the uranium contamination was not known, hindering cleanup efforts. Other DOE sites, including Portsmouth, $\mathrm{OH}$, and Rocky Flats, $\mathrm{CO}$, also have significant volumes of radionuclide contaminated soils. Unless the form of the contaminant is understood, and its chemical and physical characteristics determined, the remediation techniques are determined by trial and error. Developing characterization techniques has helped in the selection of suitable remediation methods.

\section{ACCOMPLISHMENTS}

- Identified the major uranium-bearing phase in Fernald soils as meta-autunite (calcium uranyl phosphate), a U(VI) phase. This determination allows prediction of its fate in the local environment.

- Determined U(IV) phases that have not been removed by soil washing at Fernald as uranium metaphosphate [U(PO3)4] and uraninite. 
- Investigated the form of plutonium and uranium "hot particle" contamination on Johnston Island.

- Determined the form of plutonium in incinerator waste from Rocky Flats and Los Alamos, as a reduced plutonium oxide with some $\mathrm{Pu}$ incorporated into silica glass phases.

- Determined the distribution of thorium oxide particles in contaminated soils for Ecotech, Inc.

\section{BENEFITS}

This methodology is offered as a service to the private sector for characterizing contaminated sites, evaluating remediation approaches, and selecting remediation technologies. Knowledge of the nature of heavy metals in soils and the other phases present will allow the most suitable technologies to be used to cleanup a contaminated site. In the long run, it will reduce remediation costs and the total time required to cleanup the site.

\section{COLLABORATION/TECHNOLOGY TRANSFER}

Ecotech, Inc., Defense Nuclear Agency

For further information, please contact:

Edgar Buck

Principal Investigator

Argonne National Laboratory

9700 S. Cass Avenue

Argonne, IL 60439

(708) $252-5321$

James Helt

Technical Program Manager

Argonne National Laboratory

9700 S. Cass Avenue

Argonne, IL 60439

(708) 252-7335
Michael Malone

Program Manager

U.S. Department of Energy

Cloverleaf Building

19901 Germantown Road

Germantown MD 20874-1290

(301) 9037996

\section{TTP Number: $\mathrm{CH} 231003$}

\section{BIBLIOGRAPHY OF KEY PUBLICATIONS}

Buck, E.C., N.R. Brown, and N.L. Dietz, "The Distribution of Uranium-bearing Phases in Fernald Soils," Materials Resource Society Symposium Proceedings, 333, 437-444, 1994.

Buck, E.C., N.R. Brown, N.L. Dietz, and J.C. Cunnane, "Supporting Soil Remediation by Electron Beam Methods, "Proceedings of the Waste Management '94 Conference, 20th Annual Nuclear Waste Symposium, Tucson, AZ, pp 2131-3135, 1994.

Brown, N.R., B.R. Carlson, E.C. Buck, N.L. Dietz, and J.K. Bates, "AEM Characterization of a Thorium-Contaminated Soil," Proceedings of the Waste Management '94 Conference, 20th Annual Nuclear Waste Symposium, pp 901-904, 1994.

Wolf, S.F., J.K. Bates, N.R. Brown, E.C. Buck, N..L Dietz, J.A. Fortner, and M. Gong, "Characterization Studies of Plutonium-Contaminated Johnston Atoll Coral Soils," Proceedings of the Spectrum '94 Conference, Atlanta, GA, pP 453-458, August 14-18, 1994.

Buck, E.C., J.C. Cunnane, N.L. Dietz, N.R. Brown, and J.K. Bates, Analytical Electron Microscopy Characterization of Uranium-Contaminated Soil from the Fernald Site, Annual Report 1993 ANL-94/34.

Buck, E.C., N.R. Brown, N.L. Dietz, and J.K. Bates, "Uranium-Contaminated Soils: Ultramicrotomy and Electron Beam Analysis," Microscopy Research and Technique, (in press) 1995. 


\section{5 \\ MULTISORBENT ARRAYED \\ SAMPLER}

\section{TASK DESCRIPTION}

The objective of the task is to develop, demonstrate, and deploy a novel sampling system for the multipoint collection of vadose zone soil gas samples. With this unique approach, samples are collected and concentrated at the point at which they emanate from the subsurface strata. Combined with a sufficiently sensitive analytical system, the samples can be collected in small quantities so that the subsurface equilibrium is maintained.

The sampler body consists of a cylindrical stainless steel assembly housing an array of thirteen microminiature solenoid valves in a mounting structure to accept six multisorbent traps. The outlet of each trap is connected to a common sample conduction manifold. A pump at the surface draws an accurately metered sample of air through any selected trap via the manifold. Each end of the sampler body is fitted with an inflatable donut-shaped bladder which acts as a packer to secure the body at any given vertical location in a well. In its current configuration, the sampler body is connected to a control assembly at the surface by 250 feet of a composite cable. This assembly contains all of the necessary electrical and pneumatic circuitry to deploy and activate the sampler body. See Figure 1.5a.

The sampler is loaded with six fresh multisorbent traps, and lowered into a 4 " monitoring well to a predetermined depth. The packers on the sampler are then inflated. Once a decision is made to acquire a sample, the switch controlling the solenoid valves which isolate one of the six traps is thrown, connecting the surface vacuum source to the trap. A sample of soil gas is drawn through the trap, collecting on the sorbent material. $U_{p}$ to six separate samples on separate traps can be taken before the sampler must be returned to the surface, and fresh traps loaded into the system.

\section{TECHNOLOGY NEEDS}

There is a need for subsurface sampling in the vadose zone for a broad range of volatile organic compounds at contaminated sites during site characterization or remediation. Many chemical sensors can monitor target constituents or classes of constituents. However, other species may be present, either as co-contaminants or as by-products of remediation activities. These species may not be amenable to monitoring by specific chemical sensors. Conventional approaches to the acquisition of a soil gas sample at depths of more than a few feet involve the implantation of a tube, and withdrawal of a soil gas sample to the surface. A number of

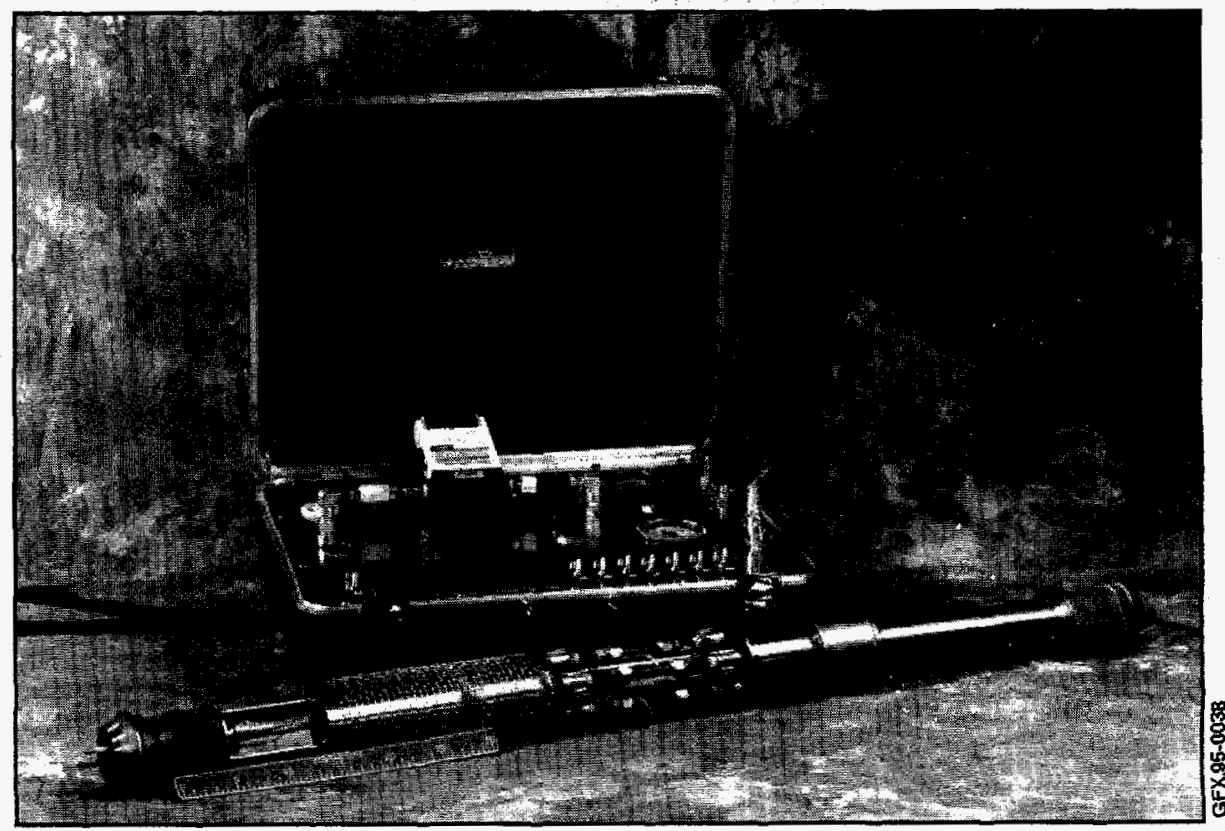

Figure 1.5a. Multisorbent Arrayed Sampler. 
potential problems exist with this approach, including losses of the analytes in long lengths of tubing, and/or disturbance of the subsurface equilibrium during sampling. Therefore, developing a novel sampling system for multi-point collection of vadose zone soil gas samples would eliminate these problems.

\section{ACCOMPLISHMENTS}

- Evaluation of the sorbent traps in the sampler was completed, and standard protocols for their fabrication and analysis were developed.

- Following initial field trials at DOE's Savannah River Site (SRS), modifications were made in the sampler to facilitate its use in the deeper wells at the Hanford 200 West Area and to make the system more rugged. See Figure 1.5b.

- Two field deployments at the VOC-Arid ID site were conducted during FY94, generally in the area of the carbon tetrachloride plume.

- Following the first field deployment, detailed chemical analysis of the samples revealed several semi-volatile organic species which had not been previously reported in the Hanford subsurface.
The variety of carbon tetrachloride concentrations encountered in the samples confirmed the range over which analyte levels in soil gas can vary as a function of air flow into and out of wells resulting from weather changes. During the first field test, the sampler was co-deployed with the Portable Acoustic Wave Sensor (PAWS) in the same wells.

- Data from the second field test of the sampler at the Hanford site was integrated with the ORNL Direct Sampling Ion Trap Mass Spectrometer (DSITMS), so that samples retrieved from the subsurface could be analyzed immediately by thermal desorption DSITMS analysis.

\section{BENEFITS}

Principal cost savings for this technology are associated with the increased confidence in the nature and quantity of subsurface contamination, ultimately reducing the quantity of samples which must be analyzed. Current monitoring technology focuses on a limited number of target species. For characterization studies, there are significant concerns about the integrity of soil gas samples which must be retrieved to the surface through long lengths of tubing.

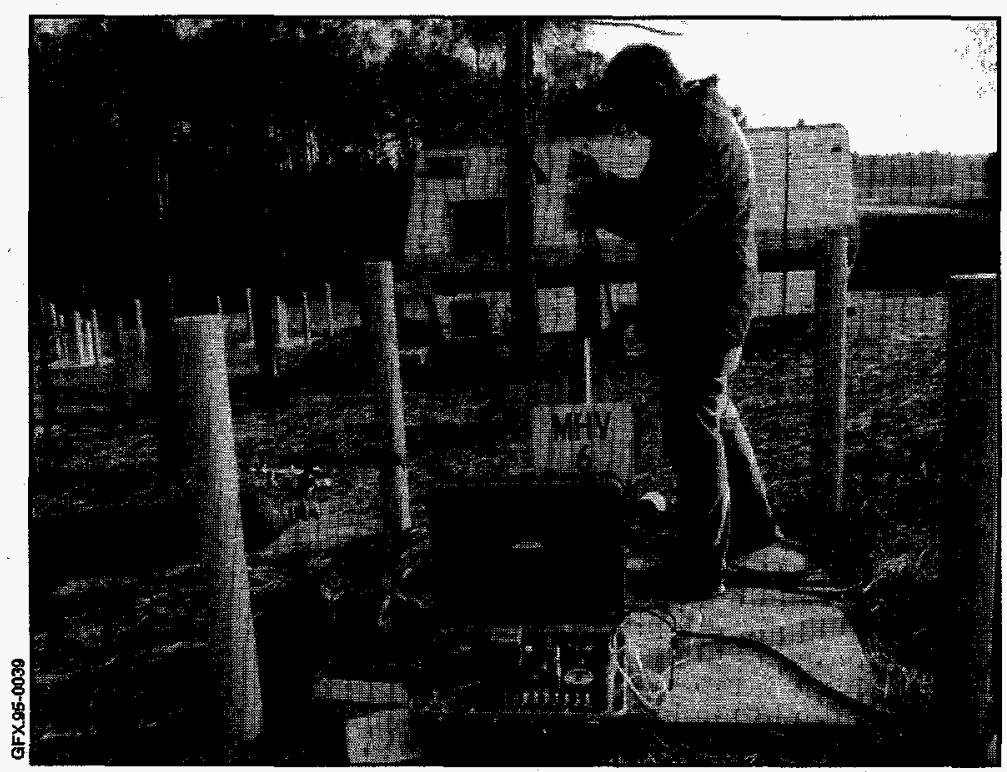

Figure 1.5b. Field Deployment of Prototype Arrayed Sampler at Savannah River Site.
The sampler is intended for use in at least two situations. First, where relatively large concentrations of contaminants exist (ppm levels), the sampler can be employed to collect small samples $(10-20 \mathrm{ml})$ with no disturbance of the subsurface equilibrium. This feature is important in low porosity strata. Second, where porosities are higher, the sampler can concentrate large samples of soil gas. Typically, such a capability would be important when very strict regulatory levels have been imposed. 


\section{COLLABORATION/TECHNOLOGY TRANSFER}

Although several industrial contacts have been made, a commercial partner is still being sought for the sampler. Nevertheless, transfer of the fundamental technology-remote sampling of multiple traps containing sequentially packed sorbents-is occurring. Collaborating with the Army's Waterways Experiment Station, a purely mechanical version of the sampler, employing long $(60 \mathrm{~cm})$ multisorbent traps fitted into a special cone of the Army's Site Characterization and Analysis Penetrometer System (SCAPS), was deployed at the SRS in June 1994. Samples were collected and retrieved to the surface for analysis by thermal desorption DSITMS.

ORNL staff have been working with Westinghouse Hanford Company (WHC) personnel to support the deployment of a simplified version of the sampler. This device remotely collects multiple samples in the headspace of selected underground storage tanks at the Hanford site. Results to date suggest that the in situ sorbent traps may be appropriate for quantitative collection of less volatile vapor species.
For further information, please contact:

Roger A. Jenkins

Principal Investigator

Oak Ridge National Laboratory

P.O. Box 2008

Oak Ridge, TN 37831

(615) 576-8594

\section{Tony Malinauskas}

Technical Program Manager

Oak Ridge National Laboratory

P.O. Box 2008

Oak Ridge, TN 37831

(615) 576-1092

\section{Rashalee Levine}

Program Manager

U.S. Department of Energy

Cloverleaf Building

19901 Germantown Road

Germantown MD 20874-1290

(301) 903-7920

TTP Number: OR141006

BIBLIOGRAPHY OF KEY PUBLICATIONS

None at this time. 


\section{IMPROVED IN SITU \\ GAMMA-RAY SPECTROMETER}

\section{TASK DESCRIPTION}

This task is developing an improved in situ gammaray spectrometer for characterizing radionuclidecontaminated sites. In addition to the demonstrated practical use of the complete system for the rapid and efficient mapping of uranium contamination at various sites, the principal objectives include establishing (1) a compact data-acquisition unit, (2) a software-driven capability for quantifying uranium depth distributions, and (3) a user-friendly, datareduction software package. See Figure 1.6.

The in situ gamma-ray spectrometer includes (1) a large, commercial high-purity germanium detector with a high efficiency for observing low-energy photons, (2) a miniature, modular, programmable data acquisition unit, and (3) a simplified userfriendly data-reduction software package. The custom data acquisition unit is capable of making portable, battery-powered, in situ, high-resolution gamma-ray spectroscopy measurements with 4096channel resolution. This unit contains the hardware and software control necessary for logistical support of the germanium detector, and includes the embedded firmware for controlling all measurementspecific functions. These functions include pulse amplification and shaping, pulse height analysis, region-of-interest and centroid determination, and built-in quality assurance and diagnostic capabilities. The PNL-developed software for the datareduction phase will include a full-screen, windows-type, graphical user-interface for ease of operation, versatility, and visual appeal.

\section{TECHNOLOGY NEEDS}

Before any effective remedial protocols can be established, the three-dimensional distribution of the contaminants must be adequately characterized.

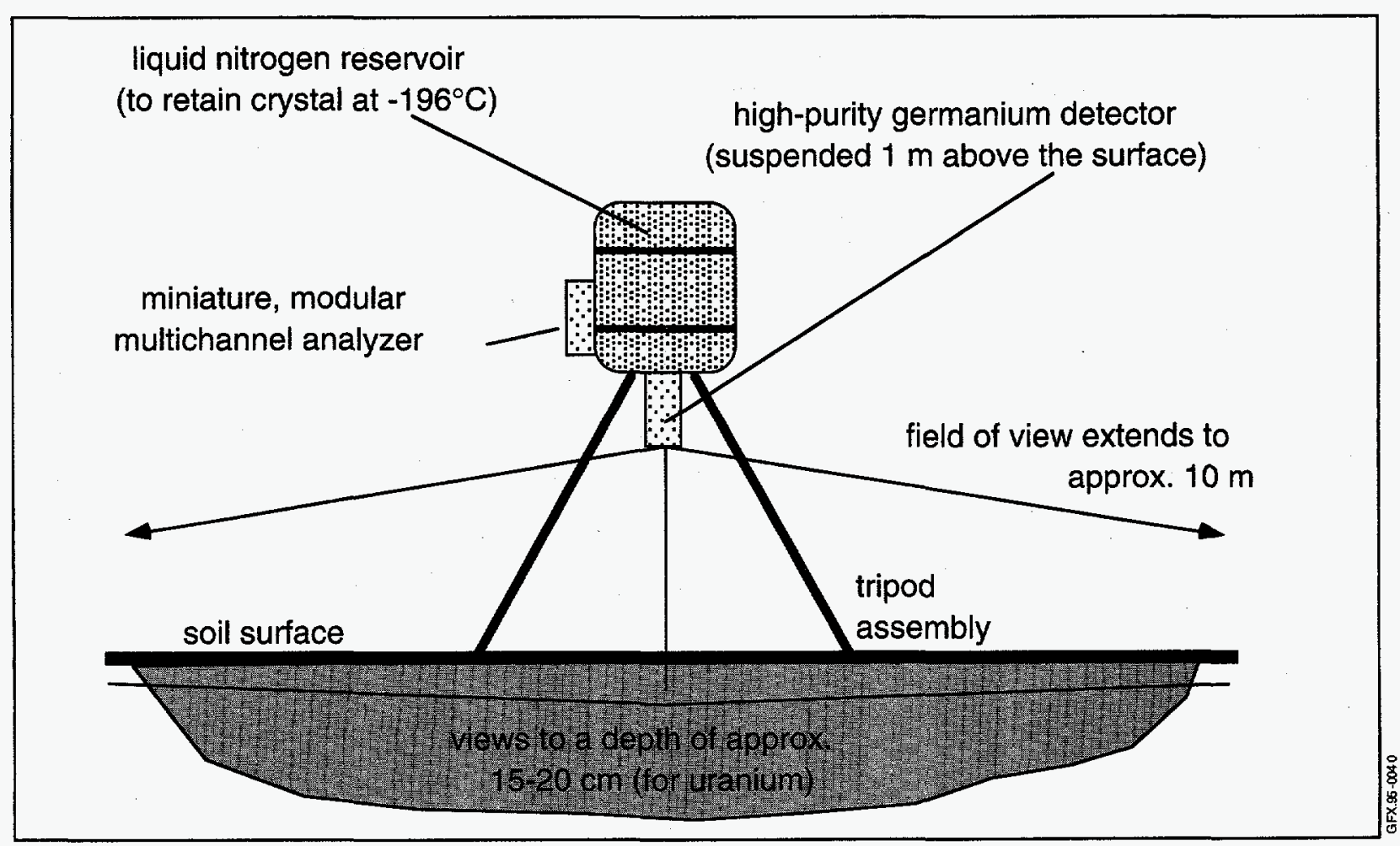

Figure 1.6. In Situ Gamma-Ray Spectrometer. 
Recent field studies at the Fernald Environmental Management Project (FEMP) site have demonstrated that real-time, in situ gamma-ray spectrometry is ideal for the radiological characterization of large areas in a relatively short period of time.

Current technology utilizes bulky power supplies and data acquisition hardware as well as inconvenient and potentially hazardous cable spans. This combination is cumbersome and awkward for a single operator to manipulate quickly in the field. Regardless of the local level of contamination, the individual detection units frequently require nearly constant monitoring and count for a preset length of time at each sampling point by a qualified spectroscopist. Furthermore, a knowledge of the vertical distribution of the contamination at each sampling location is critical to the data-reduction process, thereby necessitating the collection of myriad soil cores and the consequent generation of secondary waste. Developing an improved in situ gamma-ray spectrometer would eliminate these problems.

\section{ACCOMPLISHMENTS}

- Procured a $75 \%$ high-purity germanium detector (n-type) for precise, quantitative, multi-radioisotopic field characterization of photon-emitting contaminants from EG\&G ORTEC (Oak Ridge, TN).

- Established a subcontract with LANL's Nuclear Technology and Engineering Division and obtained a miniature, modular, programmable electronic hardware package for the acquisition and storage of in situ gamma-ray spectra.

- Obtained an experimental data-reduction source code from EG\&G Rocky Flats (Golden, CO). This code was modified and melded with a graphical user interface originally developed at PNL for the generation of synthetic gamma spectra.

- Completed extensive computer simulations (Monte Carlo, etc.) of various vertical radioactivity distributions in support of the depth-profile evaluation phase. These results were incorporated into a master library that may be evaluated by the data-reduction code for identifying subsurface contamination profiles.

\section{BENEFITS}

This technology is an improved in situ gamma-ray spectrometry package that can facilitate rapid and efficient characterization of radionuclide-contaminated soils by making the technology accessible to individual operators with minimal experience or training in gamma-ray spectroscopy. Thus, substantial cost savings can be realized due to reduction of total measurement time, manpower, and overall equipment costs.

\section{COLLABORATION/TECHNOLOGY TRANSFER}

None at this time.

\author{
Alan Schilk \\ Principal Investigator \\ Pacific Northwest Laboratory \\ P.O. Box 999 \\ Richland, WA 99352 \\ (509) 376-9510
}

\section{Steven Slate}

Technical Program Manager

Pacific Northwest Laboratory

P.O. Box 999

Richland, WA 99352

(509) 375-3903

\section{Michael Malone}

Program Manager

U.S. Department of Energy

Cloverleaf Building

19901 Germantown Road

Germantown MD 20874-1290

(301) 903-7996 
TTP Number: RL321103

\section{BIBLIOGRAPHY OF KEY PUBLICATIONS}

Schilk, A.J., R.W. Perkins, R.H. Abel, and R.L. Brodzinski, Characterization of Uranium Contamination in Surface and Subsurface Soils, PNL-SA22752, Pacific Northwest Laboratory, Richland, WA, 1993, Accepted for publication in the Journal of Environmental Radioactivity.

Schilk, A.J., R.W. Perkins, K.H. Able, R.L. Brodzinski, W.P. Brown, R.C. Thompson, and M.A. Knopf, Quantitative In Situ Uranium Contamination Mapping Using High-Resolution GammaRay Spectrometry and Beta Scintillation Counting, PNL-SA-23141, Pacific Northwest Laboratory, Richland, WA, Presented at the ER'93 Environmental Remediation Conference, Augusta, GA, Oct. 24-28, 1993.

Schilk, A.J., R.W. Perkins, K.H. Abel, and R.L. Brodzinski, Surface and Subsurface Characterization of Uranium Contamination at the Fernald Environmental Management Site, PNL-8617. 


\section{TASK DESCRIPTION}

The focus of this task was to design and demonstrate a borehole soil-gas and aquifer sampling and testing device known as the BoreSampler. The BoreSampler has been demonstrated for soil-gas sampling during characterization activities for soil-vapor extraction remediation technologies. Technology transfer to EM-40 was completed in 1994.

The BoreSampler obtains depth-discrete soil-gas and groundwater samples. It samples contaminant concentrations vertically without installing multiple wells. The device accesses the target zone between drilling runs by pounding or pushing a probe below the disturbed zone of drilling in order to collect the desired sample. The probe is removed after the sample has been collected. The BoreSampler is currently designed for use and demonstration with cable-tool drilling. Future improvements of the system may include incorporation with other drilling methods by wire-line and a drive head or driving rods.

The prototype BoreSampler consists of a reinforced probe and intake protruding from the bottom of a larger carrier. The carrier holds a sample container. The carrier provides excess volume retention for groundwater sample purging and valves for excess air discharge. The Boresampler is designed to attach to drilling cable leading to the surface. For water sample collection, the device operates by driving the probe into undisturbed sediments below the bottom of a borehole. A sleeve covering the access holes is opened, allowing water to flow into the probe and through the system until the sample container is full. Before the container fills, excess water passes through the container and fills the carrier, purging the water that first enters the system. Water samples collected in the container and retrieved from the borehole are transferred to sample containers, and sent to a laboratory for analysis.

A reinforced vacuum line leading to the surface is used for soil-gas sampling. A gas-flow orifice is placed in the probe, and the groundwater sample container is removed before deployment. The probe is driven into the sediments below the borehole and the sleeve is opened in the same manner as for water sampling. Gas-sampling apparatus (pump, flow meter, sample containers) are located at the surface to control and collect soil-gas from the unsaturated zone. The soil gas sample is withdrawn through the sample line. Soil gas concentrations are measured on site with field screening instruments. Samples are collected for laboratory analysis. Generated residuals which include soil gas are released to the atmosphere.

\section{TECHNOLOGY NEEDS}

Many DOE sites require vertical profile characterization of contaminants in the vadose zone and saturated zone. Improved capabilities are needed to determine subsurface contaminant concentrations and distributions. The BoreSampler is designed to collect soil-gas and groundwater samples during well drilling. See Figure 1.7. This technology provides an alternative to current methods, such as chemical analysis of retrieved sediment and water samples, or packer systems for soil-gas sampling and bailed groundwater samples.

\section{ACCOMPLISHMENTS}

Field demonstrations of the BoreSampler for soilgas sampling were completed in 1993. A partnership plan was written, but a commercial partner has not yet been identified. The technology was transferred to the Environmental Restoration Program at the Hanford site for their application. Engineering work sheets, including assembly and detail drawings, have been prepared.

\section{BENEFITS}

Current techniques available for obtaining groundwater depth-discrete samples during drilling have limitations. Formation water samples can be col- 


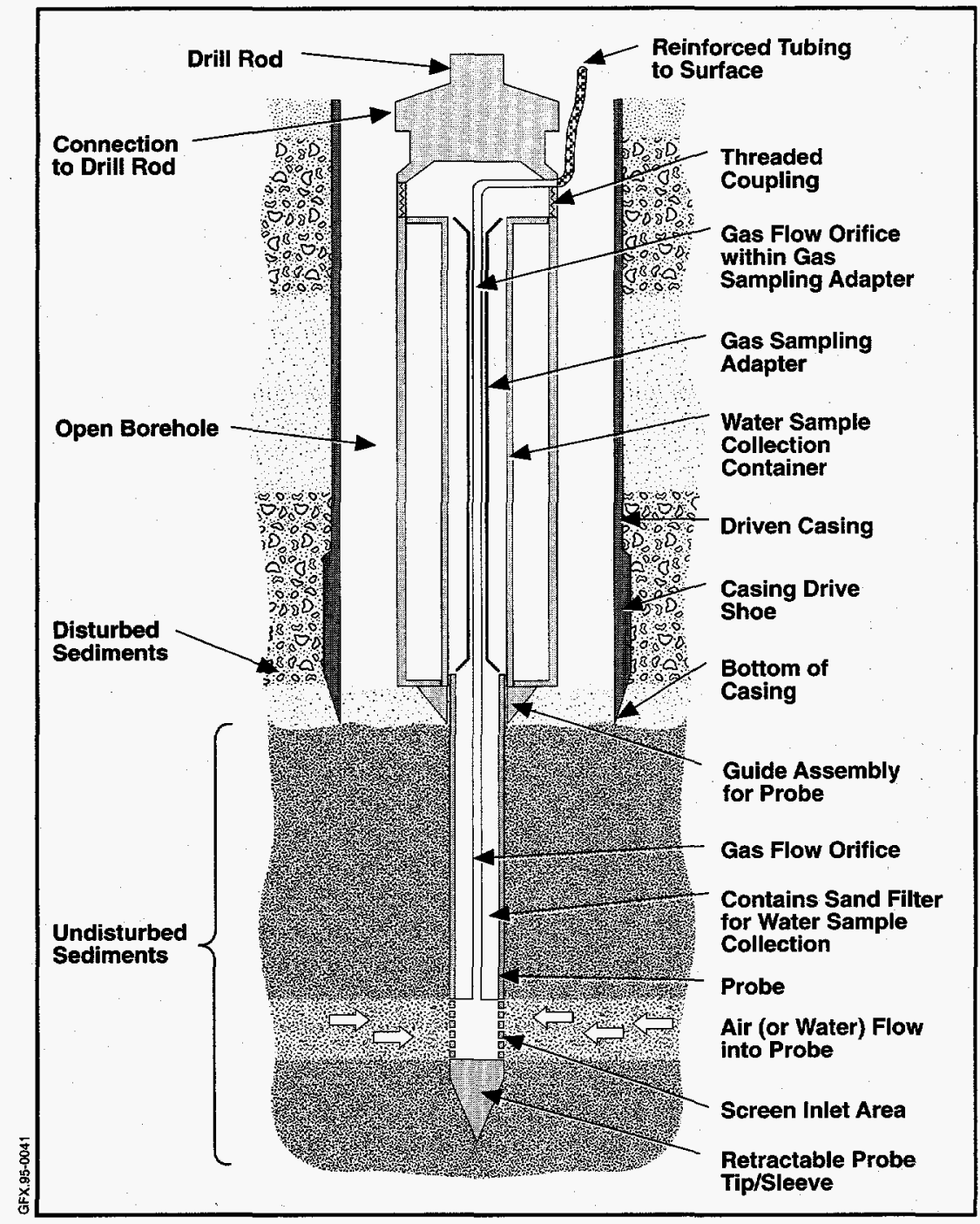

Figure 1.7. Borehole Soil-Gas and Aquifer Sampling and Testing Device (BoreSampler).

lected by bailing or pumping water directly from the borehole, but the collected samples are not representative of a discrete level in the formation. In addition, borehole fluids contain solids which may compromise the representativeness of the water sample.

Screened augers are also used to collect water samples during drilling (Taylor and Serafini 1988); however, this method is applicable only during auger drilling.

Water samples obtained by in situ sediment samplers [e.g. split-spoon or other samplers (Zapico, Vales, and Cherry 1987, Hoffman and Dresen
1990)] also have disadvantages. Using this method, the water has to be extracted from the sediment sample for analysis. Limited volume of water can be obtained by these methods, and the subsampling and/or extraction process may affect the representativeness of the sample for some constituents, especially volatile organics.

A Hydropunch ${ }^{\mathrm{TM}}$ sampler can be used in conjunction with a cone penetrometer or with drill rods (Edge and Cordry 1989). This sample method is limited to water sampling. It is also limited to applications where drive rods can be assembled and driven.

The BAT Enviroprobe can be used to collect soil-gas and water samples; however, a small sample volume is collected $(500 \mathrm{ml}$ maximum). In addition, drive rods need to be assembled to drive and retrieve the sampler.

Shallow-depth soil-gas sampling systems are readily available; however, they are severely limited in depth capability and generally allow only a single measurement for each sample hole.

The BoreSampler is applicable between drilling runs, during the drilling phase of borehole, or well completion to obtain depth-discrete, representative soil-gas or ground-water samples in the undisturbed aquifer materials below the bottom of the borehole. It is a single modular device that can easily be modified to collect soil-gas or groundwater samples. Assembly of drive rods is not necessary. Higher quality groundwater samples can be collected than from other methods. A continuous soil-gas flow is pulled allowing real-time monitoring and unlimited volume. 


\section{COLLABORATION/TECHNOLOGY TRANSFER}

Though the technology has been transferred to the ER program at Hanford for implementation, at the present time the BoreSampler is being developed without the participation of a commercial partner. A partnership plan has been prepared.

For further information, please contact:

\section{Stuart Luttrell}

Principal Investigator

Pacific Northwest Laboratory

P.O. Box 999

Richland, WA 99352

(509) 376-6023

\section{Steven Slate}

Technical Program Manager

Pacific Northwest Laboratory

P.O. Box 999

Richland, WA 99352

(509) 375-3903

\section{Rashalee Levine}

Program Manager

U.S. Department of Energy

Cloverleaf Building

19901 Germantown Road

Germantown, MD 20874-1290

(301) 903-7920
TTP Number: RL321105

\section{BIBLIOGRAPHY OF KEY PUBLICATIONS}

None at this time. 


\section{TASK DESCRIPTION}

HaloSnif was designed to monitor carbon tetrachloride vapor in the vadose zone at the Hanford Site. See Figure 1.8. However, it can measure any volatile chlorinated compound in air, gas, or water. Halosnif was evaluated at Hanford as a real-time monitoring system for measuring carbon tetrachloride concentrations in soil gas extracted at the vapor extraction site.

Targeted toward environmental cleanup, HaloSnif was developed as a monitoring system to provide real-time concentration data for volatile chlorinated hydrocarbons. One specific application demonstrated interfacing HaloSnif to a cone penetrometer rig to give profiles of carbon tetrachloride concentrations as a function of depth. A second application at Hanford included using HaloSnif as a real-time monitor for carbon tetrachloride concentrations in soil gas extracted and subsequently cleaned up. HaloSnif has also been used to monitor real-time concentrations of trichloroethylene, tetrachloroethylene, and carbon tetrachloride in water samples. With this most recent

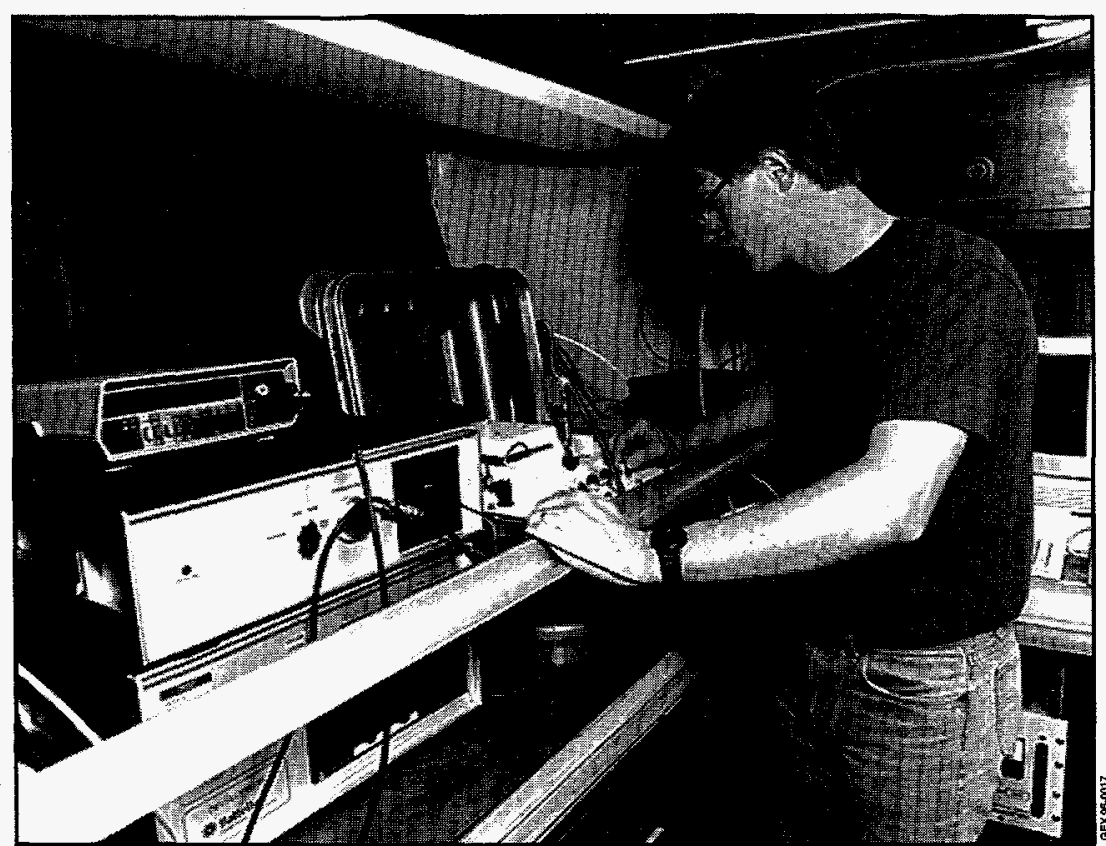

Figure 1.8. HaloSnif. development, HaloSnif may be useful for process or facility monitoring at DOE or industrial sites.

During monitoring operation, HaloSnif operates at sub-ambient pressure (40torr). It continuously draws an air sample through a critical orifice into the plasma excitation chamber where it is mixed with helium and excited with a radio-frequency signal. The plasma chamber is coupled via a fused silica optical fiber to the signal processor unit. The optical emission of the plasma is filtered with a narrow band pass filter designed to monitor the $837.6 \mathrm{~nm}$ emission line from the excited chlorine atom. The intensity of the chlorine emission is directly proportional to the concentration of chlorine containing species in the sample gas. The detection sensitivity for carbon tetrachloride is $5 \mathrm{ppmv}$. The response of the system is linear from the detection limit to 10,000 ppmv. The detection limit for other chlorine containing compounds can be estimated by determining the ratio of chlorine in the compound of interest to that of carbon tetrachloride.

Data acquisition is achieved using the LabView ${ }^{\mathrm{TM}}$ data acquisition software package installed on a Macintosh computer system. The data acquisition system is interfaced to the electrooptical signal processing module via a 1 to 10 volt analog output. Real-time concentrations of total chlorinated compounds are displayed on the monitor for observation by on-site personnel. All data is stored in computer memory for post-run processing and analysis.

\section{TECHNOLOGY NEEDS}

Numerous studies have found chlorinated compounds to be the most prevalent organic contaminants at hazardous waste sites. This fact suggests a need for a detector system which can measure specifi- 
cally for chlorine-containing compounds. The detector system would need to be a real-time detector which is fully reversible when the source of contamination is removed or decreased, and have a wide dynamic range. A compound class specific detector coupled to a cone penetrometer system could be used as a characterization tool to help identify zones of contamination in the subsurface and help understand the mechanisms controlling the dispersion of the volatile contaminants in the subsurface environment. Coupling such a detector system to a remediation action (i.e., soil-gas extraction) can also provide real-time concentration data on the effects of flowrate versus extraction efficiencies for these same volatile compounds. HaloSnif has been developed to fit the needs for monitoring during characterization activities and during a cleanup action at hazardous waste sites.

\section{ACCOMPLISHMENTS}

- Demonstrated HaloSnif technology at the VOCs in Non-arid Soils demonstration site at the SRS.

- Demonstrated HaloSnif technology at the Tinker Air Force Base, Oklahoma City, Oklahoma.

- Monitored carbon tetrachloride concentrations during soil vapor extraction at the Carbon Tetrachloride Expedited Response Action and VOCs in Arid Soils demonstration sites at Hanford.

- Interfaced HaloSnif to a cone penetrometer system to measure carbon tetrachloride concentrations as a function of depth at the VOCs in Arid Soils demonstration site at Hanford.

\section{BENEFITS}

HaloSnif is a chlorinated compound class specific sensor system capable of real-time measurement for numerous environmental and process applications related to air, gas, or water monitoring. HaloSnif's response is insensitive to moisture and other nonchlorinated compounds present in the sample stream. The most important advantages are response, reversibility of response, and range, as explained below.

Instrument Response: HaloSnif is considered a realtime monitor, responding immediately to the presence of chlorine-containing compounds. Equilibration times normally are less than 1 minute to reach $90 \%$ of full scale. Short-term (2-4 hours) baseline drift is approximately \pm 5 ppm.

Reversibility: HaloSnif's response is completely reversible when the source of chlorinated compound(s) is/are removed. Thus, it is immediately ready for reuse.

Range: HaloSnif's response to chlorinated species is linear from its detection limit of the compound (i.e., $4 \mathrm{ppm}$ for carbontetrachloride) to approximately $10,000 \mathrm{ppm}$.

\section{COLLABORATION/TECHNOLOGY TRANSFER}

HaloSnif was developed at PNL and is covered under U.S. patent number 5085499, "Fiber Optics Spectrochemical Emission Sensors" issued in February 1992. Prototype HaloSnif systems have been further refined through a joint partnership between PNL and Quanta Physik. Presently, three units constructed by Quanta Physik have been secured by standard purchase requisitions. The third system is totally integrated to include a power supply, vacuum/ gas handler, and electro-optical processing unit with operation characteristics significantly better than the two previous units.

For further information, please contact:

Khris B. Olsen and Norm Anheier

Principal Investigators

Pacific Northwest Laboratory

P.O. Box 999

Richland, WA 99352

(509) 376-4114 


\section{Steven Slate}

Technical Program Manager

Pacific Northwest Laboratory

P.O. Box 999

Richland, WA 99352

(509) 376-3903

\section{Rashalee Levine}

Program Manager

U.S. Department of Energy.

Cloverleaf Building

19901 Germantown Road

Germantown, MD 20874-1290

(301) 903-7920
TTP Number: RL321105

\section{BIBLIOGRAPHY OF KEY PUBLICATIONS}

Anheier, N.C., K.B. Olsen, and J.W. Griffin, "Fiber-Optic Spectrochemical Emission Sensor: A Detector for Volatile Chlorinated Compounds," Sensors and Actuators, B: 11, p. 447-453, 1993.

Olsen, K.B., J.W. Griffin, T.C. Kiefer, R.S. Matson, and C.J. Flynn, "A Fiber-Optic Spectrochemical Emission Sensor as a Detector for Volatile Chlorinated Compounds," Element Specific Chromatographic Detectors by Atomic Emission Spectroscopy, Ed. Peter C. Uden, ACS Symposium Series 479, 1992. 


\section{TASK DESCRIPTION}

The purpose of this project is to develop a downhole $\mathrm{X}$-ray Fluorescence (XRF) spectrometer for detecting and quantifying inorganic contaminant concentrations in soils above the water table. The XRF instrument consists of an X-ray source and a photon detector. See Figure 1.9.

The instrument probe is placed in a lined borehole created by a cone penetrometer or drilling device. The liner must be very thin, such as a membrane liner, to allow transmission of the relatively lowenergy X-rays. The surrounding soil and the detector are then irradiated with the source $\mathrm{X}$-rays for a specified period of time.

The detector receives a combination of Compton backscatter photons as well as fluorescence photons emitted by certain atoms in the soil. Real-time assays of soil constituents can be performed when the instrument system is properly calibrated. The system also includes an analog-to-digital converter, a multi-channel analyzer, and a computer proces- sor. Calibration of the instrument for a particular element and observation of the number of counts appearing in specific fluorescence range of the energy spectra results in a real-time quantitative determination of the concentration of the element in the soil as a function of depth within the well.

\section{TECHNOLOGY NEEDS}

The development of the downhole XRF probe is driven by the needs across DOE and industry to characterize sites for heavy metal contaminant distribution in a fast, reliable, and economic fashion. Current technology for determination of heavy metals in soils requires sample retrieval, laboratory preparation of the sample, and data evaluation. In situ XRF can provide a quantitative indication of heavy metal content with minimal sample preparation and data evaluation. It can be used for site investigations and post-closure monitoring.

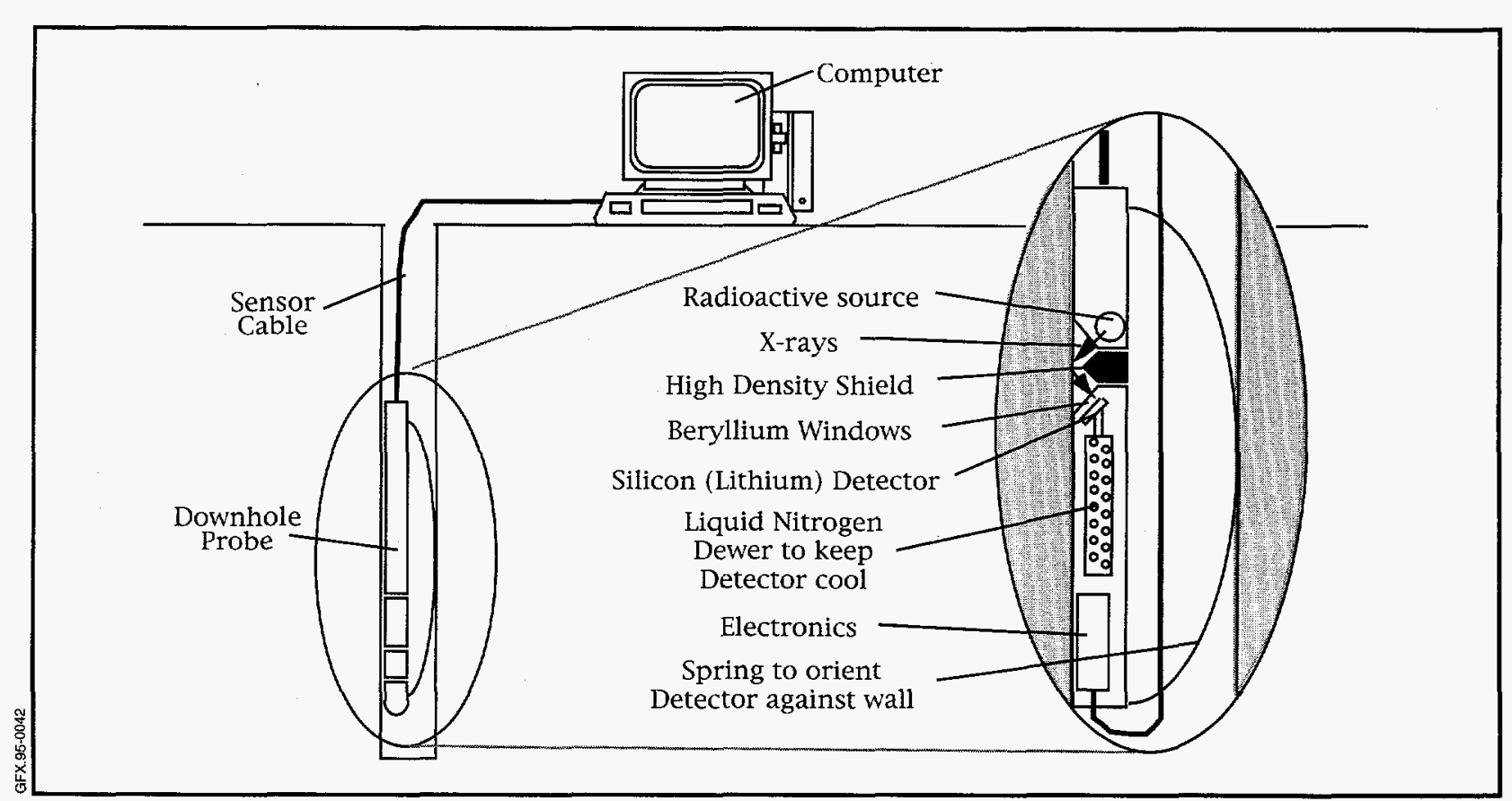

Figure 1.9. X-Ray Fluorescence Spectroscopy. 


\section{ACCOMPLISHMENTS}

- Constructed a downhole cryogenic XRF probe complete with on-board signal processing electronics.

- Designed and procured a new liquid nitrogen cooled detector.

\section{BENEFITS}

The major benefits of this technology are cost savings and rapid information retrieval. Sampling followed by laboratory analysis is an extraordinarily expensive and time consuming process. By making the measurements in situ, costs for each measurement can be reduced by more than a factor of ten. In addition, turnaround time for laboratory analysis is frequently on the order of months; whereas in situ XRF provides results in minutes allowing for engineering decisions to be made on the spot. Since no samples are removed or processed, no secondary wastes are generated. Finally, XRF has the ability to simultaneously determine the concentrations of a broad range of contaminants, which may not be possible with other laboratory based procedures.

\section{COLLABORATION/TECHNOLOGY TRANSFER}

Technology transfer is assured through a CRADA with Scitec Corporation. Scitec will commercially produce the probe once the development phase is completed. A 12-month marketing plan was completed in FY94 and is scheduled for review during FY95.

For further information, please contact:

Bill Boyce

Scitec Corporation

(509) $375-5000$

\section{Ron Brodzinski/Chester Shepard}

Principal Investigator

Pacific Northwest Laboratory

P.O. Box 999

Richland, WA 99352

(509) 376-3529/(509) 373-3675

\section{Steven Slate}

Technical Program Manager

Pacific Northwest Laboratory

P.O. Box 999

Richland, WA 99352

(509) 375-3903

\section{Skip Chamberlain}

Program Manager

U.S. Department of Energy

Cloverleaf Building

19901 Germantown Road

Germantown, MD 20874-1290

(301) $903-7248$

TTP Number: RL321113, RL321114

\section{BIBLIOGRAPHY OF KEY PUBLICATIONS}

Dodd, P.H., R.L. Brodzinski, P.G. Killeen, W.J. Murphy, F.R. Pochet, J.C. Rowntree, J.H. Scott, and P.M. Strydom, "Drilling and Logging in Uranium Exploration," Proceedings of a Symposium on Exploration of Uranium Ore Deposits, International Atomic Energy Agency, Vienna, Austria, March 29April 2, 1976, STI/PUB/434, pg. 781-783.

Nielson, K.K., C.W. Thomas, N.A. Wogman, and R.L. Brodzinski, "Development of a PlutoniumAmericium Monitor for In Situ Soil Surface and Pond Bottom Assay," Nuclear Instruments and Methods $138,227,1976$.

Nielson, K.K., N.A. Wogman, and R.L. Brodzinski, "In Situ Subterranean Gamma-Ray Spectroscopy," Nuclear Instruments and Methods 143, 385 (1977).

Nielson, K.K., N.A. Wogman, and R.L. Brodzinski, "X-Ray Fluorescence Capabilities for Uranium Ore Analysis," Advances in X-Ray Analysis, 21; 51 (1978). 
Nielson, K.K., R.L. Brodzinski, and N.A. Wogman, "In Situ Transuranium Element Measurement Technique for Wastes Associated with Power Reactor Fuels," NBS Special Publication 528, AnalyticalMethods for Safeguards and Accountability Measurements of Special Nuclear Materials, p. 201 (1978).

Brodzinski, R.L., "In Situ Radiation Measurements and Instrumentation for Monitoring Nuclear Waste Storage Facilities," IEEE Transactions in Nuclear Science, NS-27, 1277 (1980).

Reeves, J.H., R.J. Arthur, R.L. Brodzinski, and C.L. Shepard, "A Tube-ExcitedX-Ray Fluorescence Spectrometer for Use in Small-Diameter Boreholes," Proceedings of the 3rd International Conference on Methods and Applications of Radioanalytical Chemistry, Hawaii, April 1994. 


\section{TASK DESCRIPTION}

For the geologic characterization and monitoring of environmental remediation sites, methods are needed for imaging geologic and subsurface properties with minimum intrusion. Crosshole seismic tomography is a semi-intrusive method for these sites. See Figure 1.10 .

The output of this method is an image of the seismic-wave velocity structure between the boreholes obtained by measuring the seismic-wave travel speed between a large number of source and receiver locations at various depths within their respective wells. This velocity structure can be interpreted in

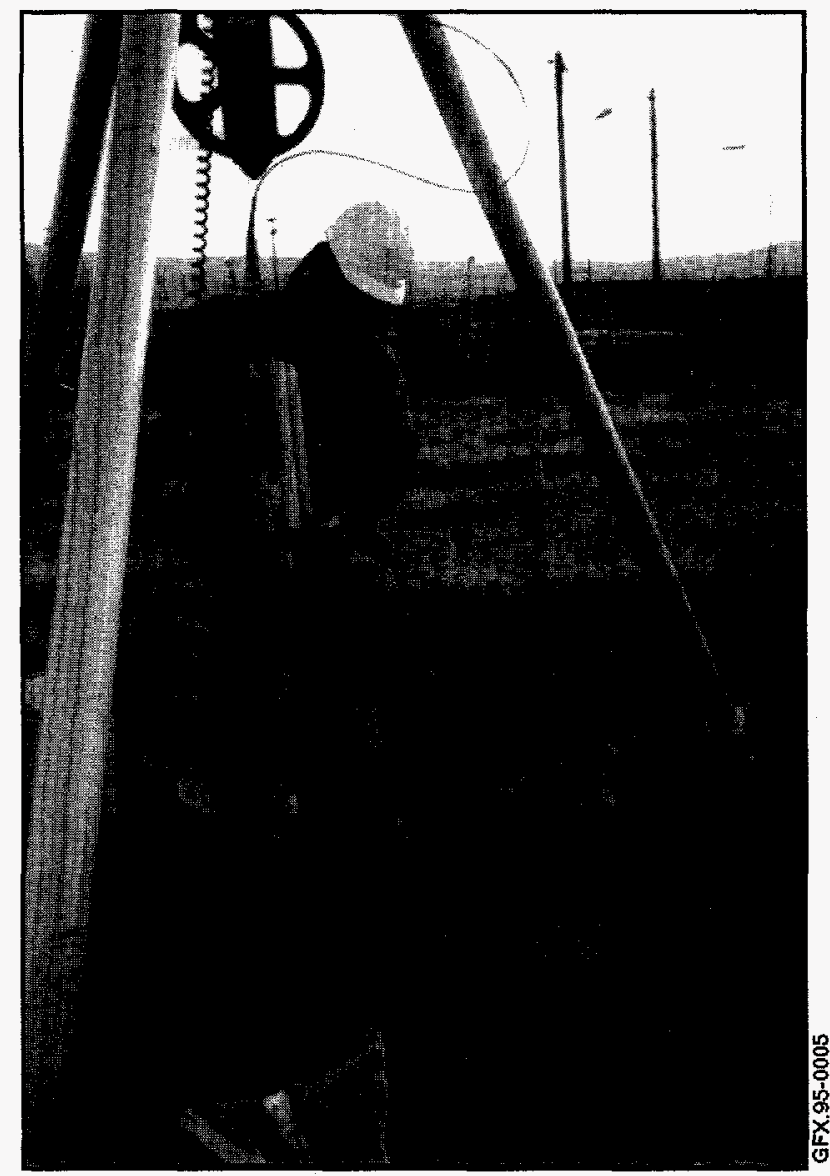

Figure 1.10. Fielding of Downhole Receiver Package for Crosswell Tomography. terms of geology by comparing compressional and shear waves.

Current project objectives are to provide support for EM-30 tasks at the Hanford Site. This will include imaging for monitoring of a simulated tank leak, which will test the capability of the method to detect small changes in saturation in the vadose zone. Other applications under consideration are providing geologic information to aid in hydrologic modeling for tracer tests planned in the 200 West Area at Hanford.

\section{TECHNOLOGY NEEDS}

At the present time, much of DOE's site characterization is done through the measurement of borehole properties and rough extrapolation of this point information to the surrounding media. More reliable information on the geology is needed: (1) to better model the hydrology, (2) to make more informed decisions on the siting of monitoring or remediation wells, and (3) to image temporal changes in the rock properties, especially saturation levels, away from the boreholes.

The measuring of temporal velocity changes is needed for monitoring remediation processes that change the velocity characteristics of the geologic formation, such as vapor stripping, radio frequency heating, and water flooding.

\section{ACCOMPLISHMENTS}

- Performed initial feasibility study using three different downhole sources (airgun, orbital vibrator, and pneumatic vibrator) in existing boreholes at Hanford. Completed preliminary report on results.

- Collected two full tomographic surveys in 200 West Area at Hanford using all three sources. Produced compressional and shear wave tomo- 
graphic images from the first of these survey areas.

- Collected data for direct comparison of four different downhole sources for assessment of their capabilities.

- Extended demonstrated range of the technology by recording data with a hole separation of $400 \mathrm{ft}$ in the sands and gravels at Hanford and collecting full data set with a well separation of $320 \mathrm{ft}$ in both the vadose and saturated zones.

\section{BENEFITS}

The primary benefit of this technology is the ability to map geology between existing boreholes and to extend borehole properties into the surrounding formation more accurately. The existing baseline technology of borehole sampling does not have this capability and carries the risk of hazards encountered due to poor site characterization, such as remobilization of wastes by disturbing impermeable layers and poor remediation process results due to lack of understanding of the geologic structure. Surface seismic techniques can be used for some of this imaging, but will often have less resolution and miss the more subtle features that do not create reflections.

\section{COLLABORATION/TECHNOLOGY TRANSFER}

A non-disclosure agreement has been signed with SIE, Inc.-opening the dialogue on the commercialization of this technology. Analysis codes and data collection procedures have been shown to SIE to enable them to assess the feasibility of marketing crosswell seismic imaging.

Most of the equipment used in the surveys are offthe-shelf technology marketed by Oyo Geospace and Bolt Technology, Inc. These companies have been focusing on the oil and gas industry. The use of these tools in environmental application and the demonstration of this usefulness will open new markets for these already existing technologies.
Patents for the downhole receiver and the pneumatic vibrator source were granted to Sandia and DOE under previous funding. The receiver is presently being marketed by Oyo Geospace.

For further information, please contact:

Greg Elbring

Principal Investigator

Sandia National Laboratories

P.O. Box 5800

Albuquerque, NM 87185-5800

(505) 844-4909

George Allen

Technical Program Manager

Sandia National Laboratories

P.O. Box 5800

Albuquerque, NM 87185-5800

(505) 844-9769

Rashalee Levine

Program Manager

U.S. Department of Energy

Cloverleaf Building

19901 Germantown Road

Germantown, MD 20878-1290

(301) $903-7920$

\section{BIBLIOGRAPHY OF KEY PUBLICATIONS}

Elbring; G.J., H.C. Hardee, and B.N.P. Paulsson, "Results from a Test of a Controlled Downhole Seismic Source," Geophysics, 54, 1193-1198, 1989.

Elbring, G.J., Crosshole Shear-Wave Seismic Monitoring of an In Situ Air Stripping Waste Remediation Process, Sandia Report SAND91-2742, Sandia National Laboratory, Albuquerque, NM, 1992.

Elbring, G.J., "Cross-well Seismic Imaging of an In Situ Air Stripping Environmental Remediation Process," Expanded Abstracts, Society of Exploration Geophysicists 63rd Annual International Meeting, Washington, DC, 476-479, 1993. 


\section{TASK DESCRIPTION}

This technology uses a thin cylinder heater buried vertically in the ground to measure groundwater flow. See Figure 1.11. The temperature distribution over the surface of the cylinder will vary as a function of the magnitude and direction of the groundwater flow past the cylinder. In the absence of any flow past the device, the temperature on the surface of the probe will be independent of azimuth and symmetric about the vertical midpoint of the probe. Groundwater flow past the device perturbs the surface temperature distribution of the sensor. The pattern and magnitude of the temperature variations reflect the direction and magnitude of the groundwater flow velocity. Observations indicate relatively warm temperatures observed on the downstream side and relatively cool temperatures on the upstream side of the probe. If the groundwater flow has a vertical component, then the temperature will no longer be symmetrical about the vertical mid- point. The magnitude and direction of the three dimensional flow velocity vector are determined from the magnitude and the pattern of the temperature variations on the surface of the probe. The sensor should be sensitive to groundwater flow rates as low as a few meters per year.

\section{TECHNOLOGY NEEDS}

Groundwater flow is perhaps the most important mechanism for the dispersal of many types of toxic wastes once they have been released to the subsurface. Therefore, accurate information on groundwater flow is critical to the characterization of waste sites, waste remediation monitoring, and post-closure performance monitoring of remediated waste sites.

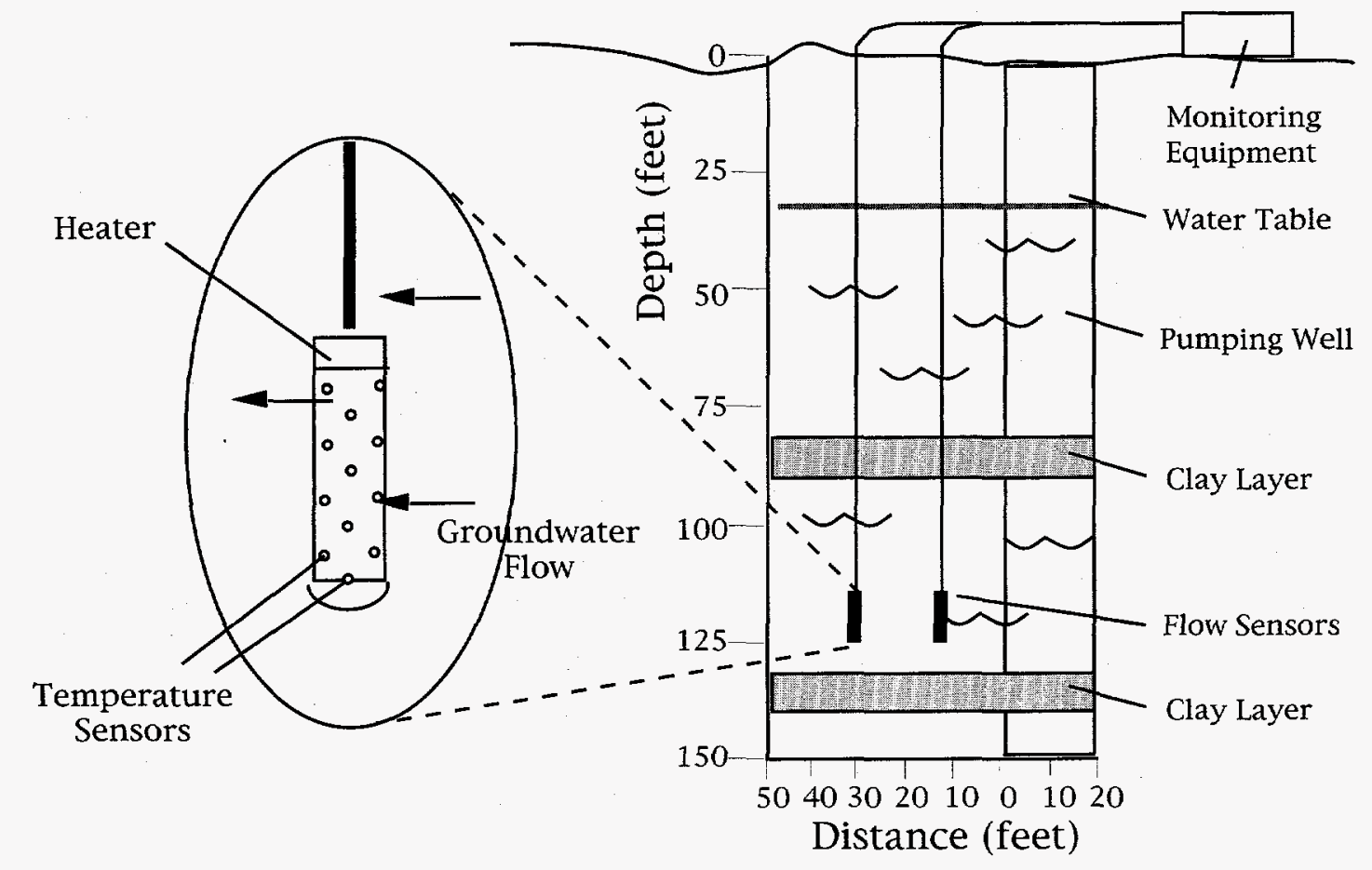

Figure 1.11. In Situ Permeable Flow Sensor. 


\section{ACCOMPLISHMENTS}

This system has been successfully demonstrated at the SRS and the technology has been licensed for use at other sites. Flow velocities as low as a few meters per year can be resolved. Currently, the lifetime of the sensors is about one year.

\section{BENEFITS}

The primary, currently accepted method of obtaining flow velocity information is to make water level measurements in screened boreholes to determine the hydraulic gradients in the subsurface. With hydraulic conductivity data, the velocity field between the boreholes can be modeled. The shortcomings of this technique are:

- To obtain detailed knowledge of the hydraulic conductivity distribution in the subsurface, a pump test must be performed, and the extracted contaminated water must be disposed of as hazardous waste;

- A relatively large number of boreholes (four or more) are required to make one, three-dimensional flow velocity vector measurement, and

- The velocity determination is an average value characteristic of a broad region.

In contrast, in situ permeable flow sensors entail:

(1) crude estimates of the hydraulic conductivity,

(2) drilling a single hole to measure the full three dimensional groundwater flow velocity vector, and

(3) flow velocity that is measured is characteristic of a region with scale lengths on the order of one meter.

\section{COLLABORATION/TECHNOLOGY}

\section{TRANSFER}

This technology was developed by researchers at SNL. While the technology is not patented, Sandia has been granted copyrights for the interpretation software used in the probe. SIE, Inc., of Ft. Worth,
Texas, has been granted a license to commercialize the technology.

For further information, please contact:

Jim Gibson

SIE, Inc.

(817) $249-7200$

Sanford Ballard

Principal Investigator

Sandia National Laboratories

P.O. Box 5800

Albuquerque, NM 87185-5800

(505) 844-6293

George Allen

Technical Program Manager

Sandia National Laboratories

P.O. Box 5800

Albuquerque, NM 87185-5800

(505) 844-9769

Kurt Gerdes

Program Manager

U.S. Department of Energy

(301) 903-7289

TTP Number: AL201101, AL251001

\section{BIBLIOGRAPHY OF KEY PUBLICATIONS}

Ballard, S., In Situ Permeable Flow Sensors at the Savannah River Integrated Demonstration: Phase I Results, SAND92-1952, Sandia National Laboratory, Albuquerque, New Mexico, 1992.

Ballard, S., In Situ Permeable Flow Sensors at the Savannah River Integrated Demonstration: Phase II Results, SAND94-1958, Sandia National Laboratory, Albuquerque, New Mexico, 1994.

Ballard, S., G.T. Barker and R.L. Nichols, The In Situ Permeable Flow Sensor: a Device For Measuring Groundwater Flow Velocity, SAND93-2765, Sandia National Laboratory, Albuquerque, New Mexico, 1994. 


\section{TASK DESCRIPTION}

The borehole permeameter can precisely meter water through a semipermeable membrane in geological formations at depths exceeding 100 feet. The device monitors pressure as well as flow rate, allowing the hydraulic conductivity to be computed as a function of water pressure. See Figure 1.12. Estimates of hydraulic conductivity are needed at sites at which waste is stored or disposed to estimate the rate of contaminant transport from the site to groundwater or to the soil surface. Existing field permeameters operate at near water saturated conditions, conditions far different from ambient field conditions. The borehole tension permeameter was designed to infiltrate water into soil under unsaturated soil conditions to provide data suitable for hydraulic conductivity estimates near ambient soil moisture conditions.
The basic theory underlying the borehole tension permeameter is to meter water into soil surrounding the borehole while monitoring soil water tension (i.e. the energy status of soil water). The permeameter consists of a pair of syringes driven by a single stepper motor under the control of a small computer. The permeameter is lowered to a specific depth. A balloon packer is inflated to force a pliable porous pad into contact with the soil. Water is then metered into the soil at preselected rates, and the soil water tension is obtained with a pressure transducer. Once a steady pressure is obtained the metered rate is increased and a new steady tension is obtained. The permeameter thus obtains data at a range of soil water tensions to determine the hydraulic conductivity at near ambient soil moisture conditions. At many sites, the hydraulic conductivity at ambient water content will be close to the rate water is moving through the soil, a useful estimate for contaminant migration rates.

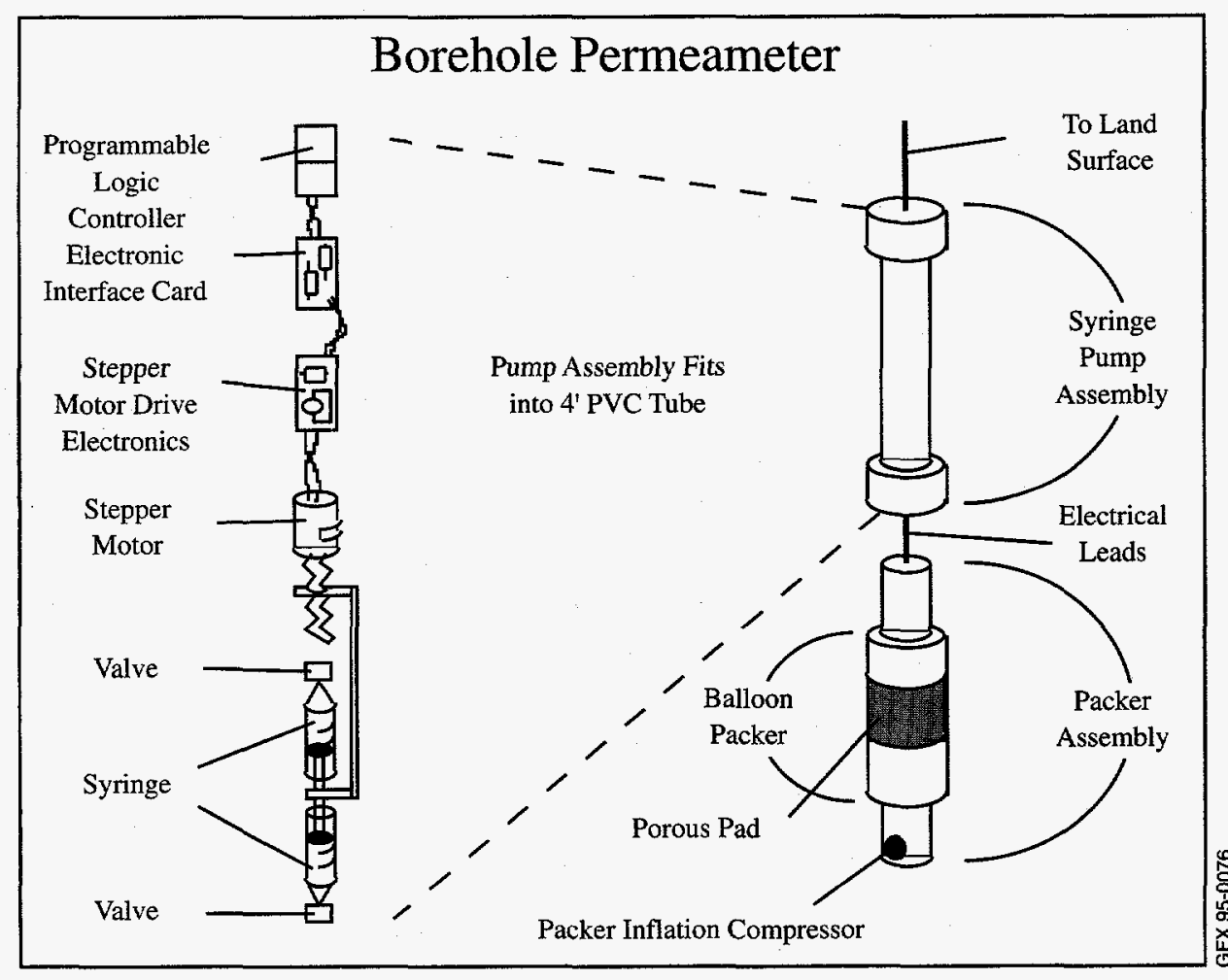

Figure 1.12. Borehole Permeameter.

\section{TECHNOLOGY NEEDS}

Major challenges include miniaturization of hardware to allow operation in a borehole, material selection for porous pad construction, selecting the right syringes, and using the data sets to obtain more accurate values of hydraulic conductivity. These challenges will require modifying numerical solutions.

EPA has no system for certifying borehole permeameters, so this 
is being investigated as part of this task. The goal is for the borehole tension permeameter to become an EPA accepted monitoring technology. EPA has regulations pending for monitoring landfills. This technology could fit this niche.

\section{ACCOMPLISHMENTS}

Laboratory evaluations of the system indicate that the flow rate can be controlled to within one percent of the prescribed flow rate. Precision of pressure measurements appears to be within one millibar. The system operates at a precision unachieved to date for hydraulic conductivity determinations. Other successes include:

- Identifying the system capable of purging atmospheric air from the pump, pressure transducer, and connections.

- Identifying the pump capable of delivering flows over a range of six orders of magnitude.

- Reproducing the pumping rates.

The pump and pressure monitoring components of the system will be available commercially in 1995 . Further development of the packer system and porous pads will evolve around materials selection software. Three years are anticipated for full capabilities including syringe pump system, packer system, below water table capability, and software development.

\section{BENEFITS}

The borehole tension permeameter has several advantages over existing methods and instruments:

- Hydraulic conductivity (and from this, permeability) is estimated for undisturbed soil.

- Measurements are obtained near ambient soil water conditions.

- Existing boreholes can be used to save drilling costs.
- Transporting potentially contaminated samples is not required.

- Measurements can also be taken at higher saturation (extremely "wet") conditions.

- A measurement of hydraulic conductivity "hysteresis" can be taken. Hysteresis is the difference between measurements taken when water is being introduced into the soils (the wetting cycle) and when water is being removed (the drying cycle).

As designed the borehole permeameter costs less then $\$ 5,000$ per unit and can be used in existing boreholes. Placement of the porous pads will require caliper and video logs to locate smooth sections of the borehole. Operation of the borehole permeameter is designed to be a basically stand alone process without operator intervention. Userfriendly software will assist in the stand alone process. Several hours a week will be required to keep track of data and correlate the data to existing soils and geologic information.

\section{COLLABORATION/TECHNOLOGY TRANSFER}

Soil Measurement Systems in Tucson, Arizona, has indicated interest in distributing the borehole tension permeameter. A cost sharing agreement with Soil Measurement Systems is anticipated during FY94. In addition, a CRADA is in development.

Two patent idea forms have been submitted. The patents, if any, will be held by the Idaho National Engineering Laboratory (INEL) or DOE.

\section{For further information, please contact:}

\section{James Sisson}

Principal Investigator

Idaho National Engineering Laboratory

P.O. Box 1625

Idaho Falls, ID 83415

(208) 526-1118 
Ken Merrill

Technical Program Manager LITCO

P.O. Box 1625

Idaho Falls, ID 83415

(208) 526-0797

\section{Skip Chamberlain}

Program Manager

U. S. Department of Energy

Cloverleaf Building 19901 Germantown Road

Germantown, MD 20874-1290

(301) 903-7248
TTP Number: ID141002

\section{BIBLIOGRAPHY OF KEY PUBLICATIONS}

Sisson, J.B., and T.K. Honeycutt, "Tension Permeameter for Deep Borehole Characterization," Proceedings of the 33rd Hanford Symposium on Health and the Environment, Pasco, WA, November 7-11, 1994.

Sisson, J.B., A.L. Ward, T.K. Honeycutt, and D. Betsill, "Automated Determinations of $K$ - $h$-theta Throughout the Main Wetting and Drying Loops," Proceedings of the 1994 Fall-AGU Meeting, San Francisco, CA, December 5-9, 1994. 


\subsection{UNSATURATED FLOW \\ APPARATUS}

\section{TASK DESCRIPTION}

This task is focused on developing the Unsaturated Flow Apparatus (UFA) method and instrument for use as a laboratory technique that simulates the migration of VOCs, microbial nutrients, and water in the subsurface environment of arid sites. See Figure 1.13a. Instead of taking weeks or years to obtain hydraulic transport data on unsaturated environments, the UFA method can generate this information in several hours. The UFA method can address flow transport problems involving fluids in porous media under almost any condition.

Soil samples are often collected from sites using drilling and coring or split-spoon sampling techniques. The soil or bedrock samples are transferred to a specially designed titanium canister and subjected to a gravitational force $(\mathrm{g})$ of as much as $20,000 \mathrm{~g}$ 's in an open-flow centrifugation device. Soils are usually run at less than $1,000 \mathrm{~g}$ 's. A rotating seal assembly fitted to the canister allows an ultralow flow pump to deliver liquid or gas to the sample surface during rotation. When steady state conditions are reached (within a matter of hours), transport parameters can be evaluated, e.g., hydraulic conductivity to measure permeability, diffusion coefficient, and breakthrough retardation. Data specific to remediation site sediments is then compiled.

Contaminants introduced into the UFA samples are collected in the effluent collection chamber. During one year, no more than one liter of contaminants is used in UFA analyses. In addition to the contaminants, any remaining water (e.g., pore water) that exists within the soil is collected in the effluent collection chamber.
The UFA method supports the development of restoration technologies such as vapor extraction (e.g., measures unsaturated vapor migration rates) or bioremediation (e.g., measures nutrient delivery rates) for unsaturated soils. In addition, data obtained using the UFA can be used to validate predictive models of subsurface contaminant migration and to screen the performance of various remediation technologies in the field. Pristine pore waters can also be extracted without altering chemistry, even from highly unsaturated soils. One of the major challenges facing the UFA method is the preparation of the sample, i.e., obtaining undisturbed samples. Special handling may be required for some applications to prevent drying and to maintain original sample structures.

\section{TECHNOLOGY NEEDS}

A method is needed to determine VOC-contaminant distribution and behavior in subsurface envi-

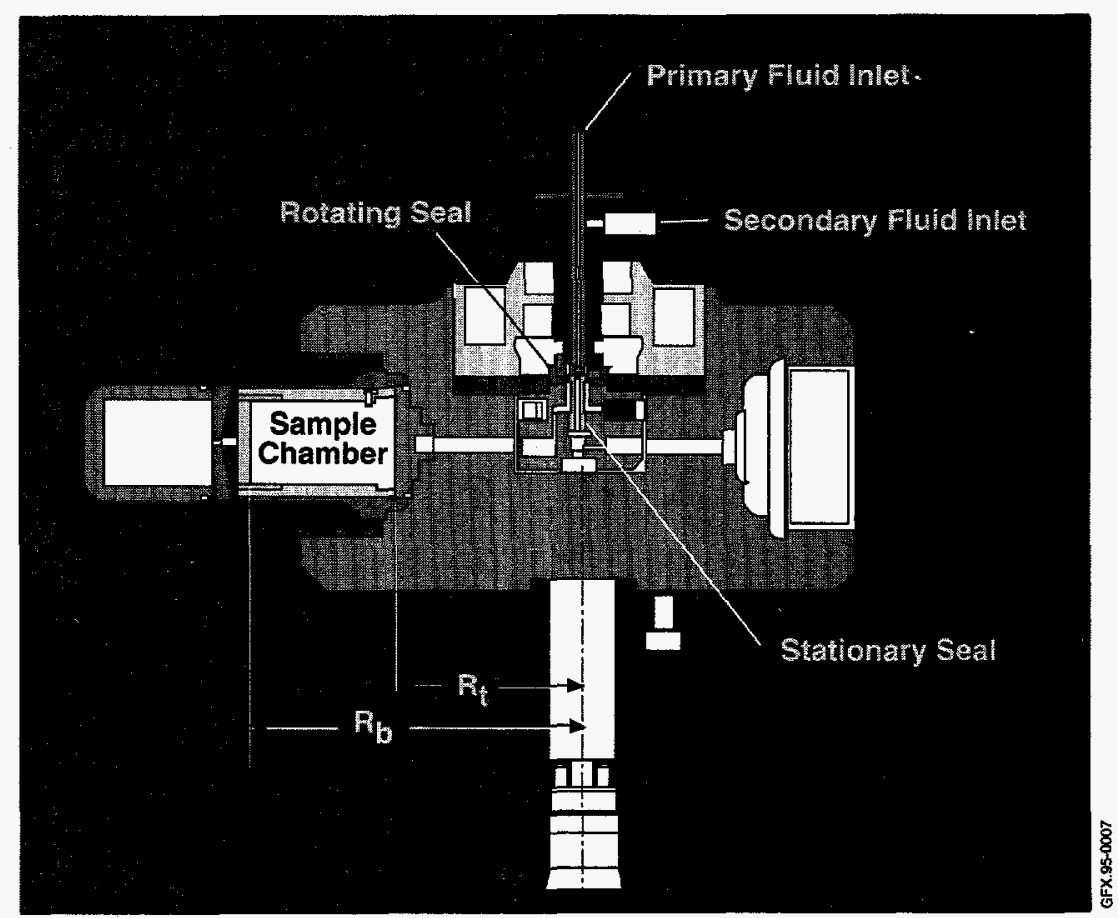

Figure 1.13a. Unsaturated Flow Apparatus. 
ronments. In addition, there is a need for remote, in situ, and other on-site methods that increase the safety and cost effectiveness of local contaminant characterization.

The alternative to the UFA method is dependence on less reliable assumptions (e.g., data bases on wetter vadose zone conditions) to extrapolate contaminant behavior. This could result in choosing a restoration strategy which is less appropriate for this region of the subsurface. Inadequate predictive capability in this area will lead to loss of time, money, and credibility, hindering DOE in meeting its longterm environmental restoration goals.

\section{ACCOMPLISHMENTS}

The major accomplishment of this project was the direct, rapid measurement of the flow behavior of uncontaminated soils and sediments ranging from completely saturated to the highly-unsaturated conditions beneath the Z-plant at Hanford site. Other specific accomplishments:

- Modified the prototype UFA to accommodate VOCs and other non-aqueous phase liquids.

- Completed a new UFA system that is much less expensive and has low-temperature capabilities for frozen soils work.

- Purchased three UFA units outside this project. Several other outside parties have expressed the desire to purchase UFA units over the next year. A brochure was printed for marketing and sales of the UFA.

- Sponsored a symposium at the 1994 annual meeting of the Geological Society of America in Seattle, Washington, entitled "Measurement of Unsaturated Transport in Porous Media."

- Submitted a draft ASTM test method for measuring hydraulic conductivity in the UFA for porous media to ASTM Subcommittee D18.21.

Several new characterization techniques were developed based upon the UFA method that were not anticipated at the outset of this project. These techniques provided significant increases in the fundamental understanding of the subsurface environment at the Hanford site, and are applicable at any site:

- Data gathered using the UFA method was used in combination with data on field moisture contents to map artificial recharge in the subsurface associated with contaminant plumes and surface discharges to disposal cribs and trenches.

- The UFA method, together with borehole samples, was used to construct a hydrostratigraphic map of the subsurface that predicts, in detail, the transport and flow behavior of the soils beneath the Z-plant. This significantly enhanced the conceptual model of the site and the knowledge of contaminant plume migration.

- The UFA instrument was successful in extracting pristine pore water from unsaturated samples, including highly unsaturated soils. This event marked the first time that pristine pore water was obtained in unaltered composition from the vadose zone at any site.

- A UFA gas permeameter was developed that measures the gas permeability of the sample as a function of moisture content which is set using the UFA.

\section{BENEFITS}

The major benefit of this technology is rapid, direct measurement of VOC transport. Improved predictive capabilities of VOC migration, greater probability of choosing successful restoration strategies, improved remediation schedules, and a reduced need in the future for lengthy experimental programs are the secondary benefits from this technology. Cost savings, based on the time and effort spent on experiments alone, is expressed in orders of magnitude, since transport data can be obtained by the UFA in hours as opposed to months or years by more conventional methods.

The UFA method directly measures transport parameters of water contents well below those measured by any existing method. As an example, 
hydraulic conductivities have been measured in soils with water contents ranging from fully- saturated down to highly-unsaturated (water content is only a few percent and hydraulic conductivities are $10^{-10} \mathrm{~cm} / \mathrm{s}$ ) in three days. This technology can also be used to do quick screening. The UFA can provide data to describe field conditions which cannot be obtained under normal conditions.

\section{COLLABORATION/TECHNOLOGY}

\section{TRANSFER}

The UFA instrument is being developed in a joint effort with Beckman Instruments, Inc. See Figure $1.13 \mathrm{~b}$. Beckman developed the rotating seals for the UFA instrument based on existing technology used to spin oil out of whole rock shales. A CRADA has been signed between Beckman and PNL that addresses all intellectual property rights. Beckman is providing prototype instruments for PNL use. PNL will use the instruments to develop and refine the technology and its applications. A spinoff service business has also been started to run samples, train technicians and perform feasibility studies.

Environmental companies may be interested in working with PNL to test the performance of their technologies on arid soils. There may be a need for UFA specialists to work with principal investigators who are assessing the feasibility of laboratory user facilities for site remediation.

For further information, please contact:

\section{Jim Conca}

Washington State University at Tri-Cities

100 Sprout Road

Richland, WA 99352

(509) 375-3268

\section{Judith Wright}

Principal Investigator

Pacific Northwest Laboratory

P.O. Box 999

Richland, WA 99352

(509) 375-3268

\section{Steven Slate}

Technical Program Manager

Pacific Northwest Laboratory

P.O. Box 999

Richland, WA 99352

(509) 375-3903

\section{Rashalee Levine}

Program Manager

U.S. Department of Energy

Cloverleaf Building

19901 Germantown Road

Germantown, MD 20874-1290

(301) 903-7920

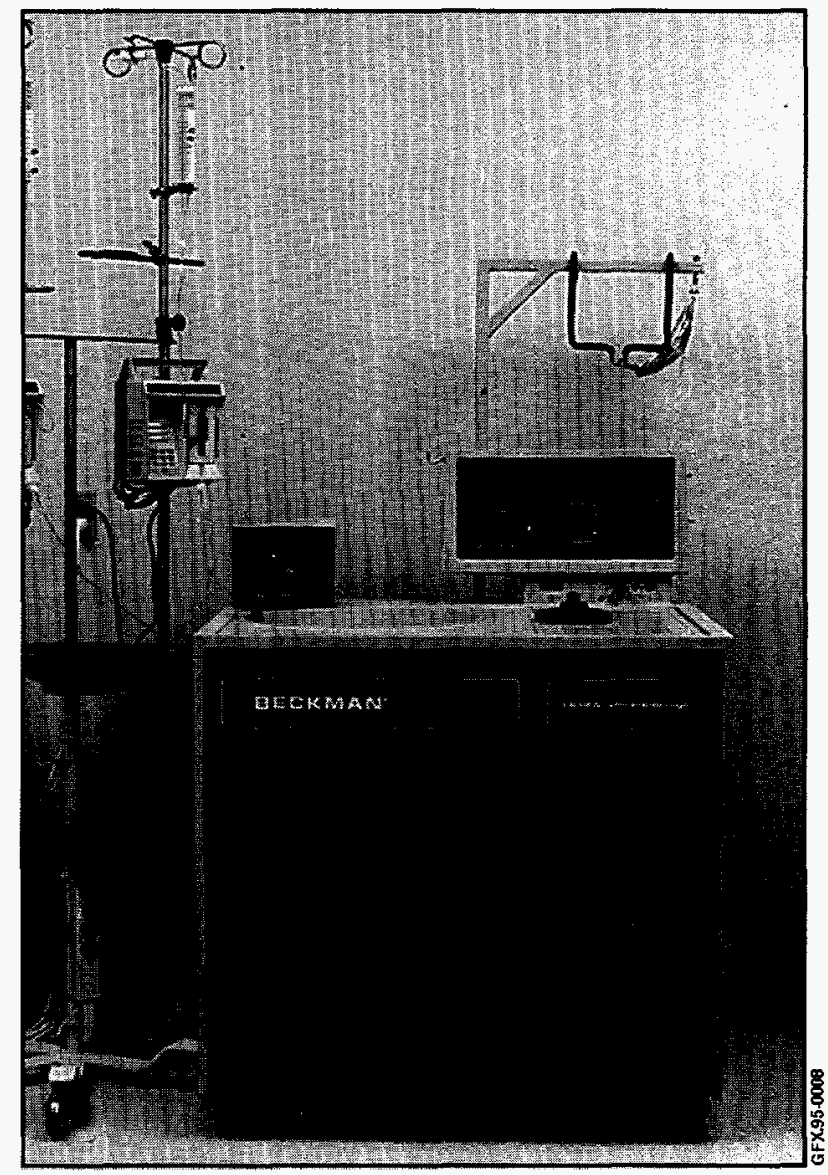

Figure 1.13b. Beckman's Unsaturated Flow Apparatus. 
TTP Number: RL321105

\section{BIBLIOGRAPHY OF KEY PUBLICATIONS}

Conca, J.L., "Diffusion Barrier Transport Properties of Unsaturated Paintbrush Tuff Rubble Backfill," Proceedings of the First International High-Level Radioactive Waste Management Conference, 1:394$401,1990$.

Conca, J.L. and J.V. Wright, "Diffusion Coefficients in Gravel Under Unsaterated Conditions," Water Resources Research, 26:1055-1066, 1990.

Conca, J.L. and J.V. Wright, "Aqueous Diffusion Coefficients in Unsaturated Materials," Scientific Basis for Nuclear Waste Management, XIV 212:879884, 1991.
Conca J.L. and J.V. Wright, "Diffusion and Flow in Gravel, Soil, and Whole Rock, "Applied Hydrogeology, 1:5-24, 1992.

Wright, J.V., "Diffusion Coefficients and Hydraulic Conductivity in Unsaturated Hanford Soils and Sediments," Proceedings of the First International High-Level Radioactive Waste Management Conference, 1:835-842, 1990.

Wright, J.V. and J.L. Conca, Hydrostatigraphy and Recharge Distributions from Direct Measurements of Hydraulic Conductivity Using the UFA ${ }^{T M}$ Method, PNL-9424, March 1994. 


\subsection{ENVIRONMENTAL MEASUREMENT-WHILE- DRILLING SYSTEM FOR REAL-TIME SCREENING OF CONTAMINANTS}

\section{TASK DESCRIPTION}

The long-term objective of this project is to distinguish contaminated areas from non-contaminated areas in real time while drilling beneath a hazardous waste site. In Environmental Measurement-WhileDrilling (EMWD), downhole sensors are located behind the drill bit and linked by a high-speed data transmission system to a computer at the surface. See Figure 1.14. As drilling is conducted, data are collected on the nature and extent of contamination, enabling on-the-spot decisions to be made regarding drilling and sampling strategies. Initially, the downhole sensor will consist of a Geiger-Mueller tube or a simple gamma radiation detector. The design includes data assurance techniques to increase safety by reducing the probability that the system will give a safe indication when an unsafe situation is actually present. These data assurance techniques have been verified in recent field testing.

\section{TECHNOLOGY NEEDS}

The EMWD system is compatible with dry compaction boring, a directional drilling technique that uses minimal drilling fluids and generates little to no secondary waste. Additionally, the system will be adapted to interface with conventional drilling systems, push systems (i.e. cone penetrometer) and sonic drilling. Current technical challenges include development of:

- a data transmission linkage within the borehole that has sufficient bandwidth to transmit data to the surface in real time.

- a downhole gamma-ray spectrometer for identification of specific radionuclides.

- a multiplexing capability that will permit several downhole sensors to function simultaneously.

- identification and integration of other sensors for VOC and heavy metal contaminants.

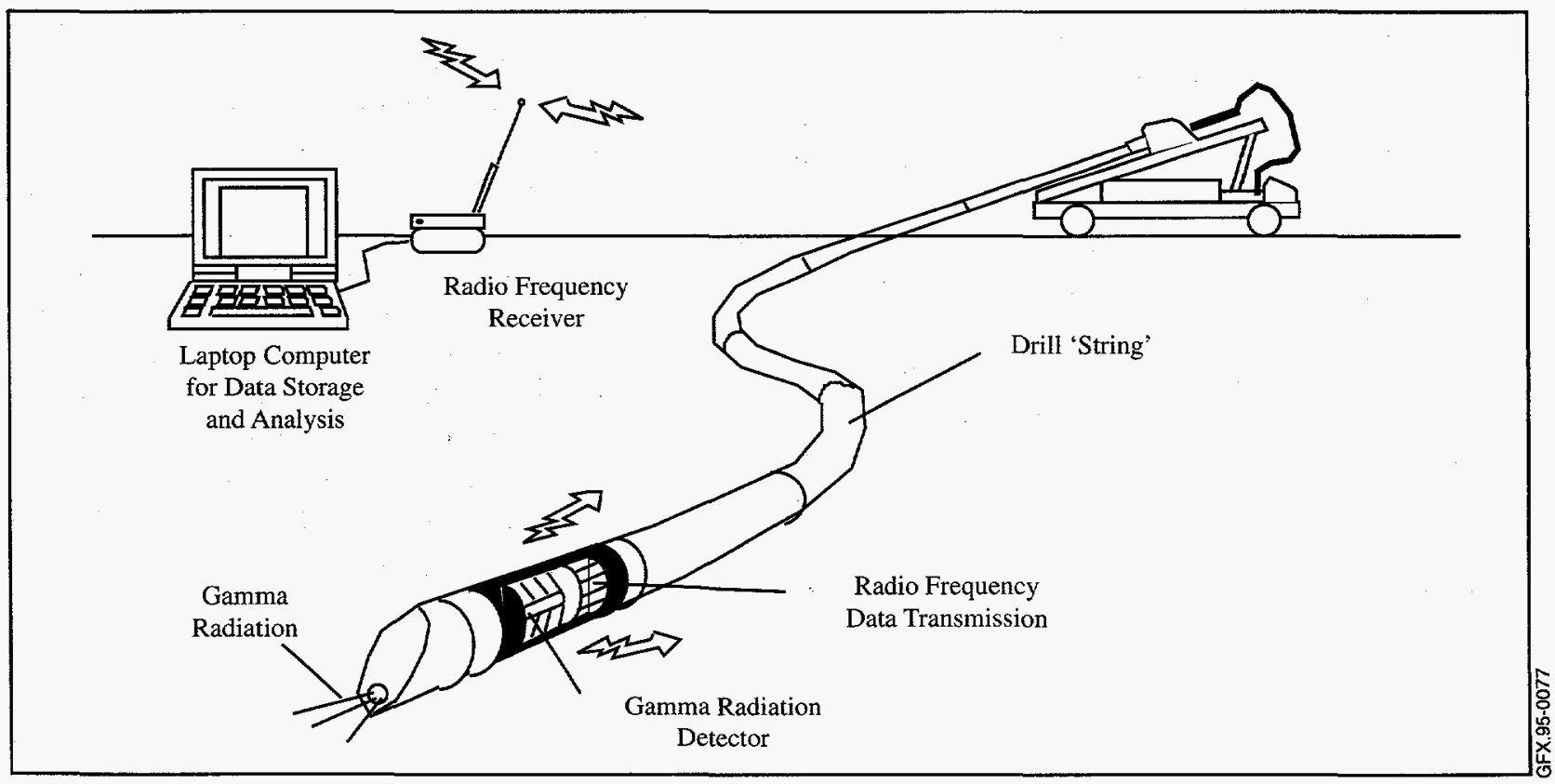

Figure 1.14. Environmental Measurement-While-Drilling System. 
- a total system that is compatible and non-interfering with current drilling practices.

The data transmission linkage is based on proven military technology. Data transmission techniques and data reduction software are similar to instrumentation developed for the Trident II missile and Navy Test Bed universal telemetry system. The first downhole sensor portion of the system is also based on proven technology (Geiger-Mueller tubes have been commercially available for years). Replacing or supplementing the Geiger-Mueller tube with a spectral gamma tool is planned for 1995 to expand the capabilities of the system.

\section{ACCOMPLISHMENTS}

- Preliminary field tests were completed at Grants, New Mexico at the radioactive calibration facility and at SNL. The test at Grants involved a downhole Geiger-Mueller tube and proved successful. The Sandia test included all parts of the measurement system short of a real drilling operation, including a prototype gamma ray counter, FM transmitter, and FM receiver. Results showed that the detector, as designed, will work in the presence of and extended radioactive source.

- The first field demonstration of the complete EMWD system was successfully carried out in August 1994 at the Directional Boring Test Site of Charles Machine Works, Inc., in Perry, OK. The EMWD instrumentation data, consisting of real-time measurements of gamma radiation, were logged onto a computer at the site during the demonstration. Approximately 70 feet of pipe was driven into the ground to drill a shallow angle blind hole. During the drilling, continuous data were generated and transmitted uphole from a Geiger-Mueller tube just behind the drill bit to a nearby computer. All intended objectives of the field demonstration were achieved.

\section{BENEFITS}

There are time, cost, and safety advantages to using the field screening approach of the EMWD system:

- data on the nature of contamination will be available in minutes, as opposed to weeks or months from an off-site laboratory

- substantial cost savings will result by minimizing the number of samples required for off-site confirmatory analyses

- worker safety will be enhanced as a result of minimizing waste generation and by quickly alerting field personnel to potentially hazardous conditions.

A goal of this project is to produce a prototype system that costs less than $\$ 15,000$. Operations and maintenance costs are likely to be low, while reoccurring costs will be limited to a spool of coaxial wire for each drilling operation.

\section{COLLABORATION/TECHNOLOGY TRANSFER}

The unique capability of real-time, high speed data transmission uphole during drilling gives this measurement-while-drilling system a high commercial potential. Its low cost and generic design offering maximum flexibility to integrate additional sensors make it an attractive platform for a variety of downhole sensors. SNL is currently seeking potential partners for adapting the system to accept other sensors types and multiple sensor systems. A market analysis is underway to determine its potential for use in the environmental, oil, and utility industry. A commercially available unit will be marketed in 1996 if the EMWD system is shown to be technically and economically feasible. A field demonstration of the full system at a radioactive/mixed waste site is scheduled for the summer of 1995 . 
This project involves collaboration with Charles Machine Works, Inc., an international leader in the drilling industry.

For further information, please contact:

Charles Machine Works, Inc.

Perry, Oklahoma

(505) 983-6698

\section{Cecelia V. Williams}

Principal Investigator

Sandia National Laboratories

P.O. Box 5800

Albuquerque, NM 87185-5800

(505) $844-5722$

\section{George Allen}

Technical Program Manager

Sandia National Laboratories

P.O. Box 5800

Albuquerque, NM 87185-5800

(505) 844-9769

\section{Skip Chamberlain}

Program Manager

U. S. Department of Energy

Cloverleaf Building

19901 Germantown Road

Germantown, MD 20874-1290

(301) 903-7248
TTP Number: AL241007

\section{BIBLIOGRAPHY OF KEY PUBLICATIONS}

Lockwood, G.L., R.A. Normann, L.B. Bishop, R.J. Floran, and C.V. Williams, "Environmental Measurement-While-Drilling System for Real-time Field Screening of Contaminants," Proceedings of North American No-Dig'95 Conference, Toronto, May 1995. 


\subsection{INVERTING MEMBRANE BOREHOLE INSTRUMENTATION TECHNIQUES (SEAMIST ${ }^{\mathrm{TM}}$ )}

\section{TASK DESCRIPTION}

SEAMIST ${ }^{\mathrm{TM}}$ is an instrumentation and fluid sampler emplacement technique designed for in situ characterization and monitoring. It uses an inverting, pneumatically-deployed tubular membrane made of impermeable material to deploy sensors and/or samplers in boreholes or to tow instruments downhole in a clean, stable borehole environment.

The membrane, made of coated fabric or synthetic film, is forced from a holding canister by air pressure into a drilled or punched well. See Figure 1.15. The membrane descends, averts, and presses against the hole wall, providing wall support and the effect of a continuous packer. After emplacement, the entire hole wall is sealed, thus preventing ventilation of the pore space or circulation of pore water in the well. The membrane is retrievable or, if desired, permanent installation is possible by filling the membrane with grout after emplacement. Semipermanent installation can also be accomplished by filling the membrane with sand after emplacement,

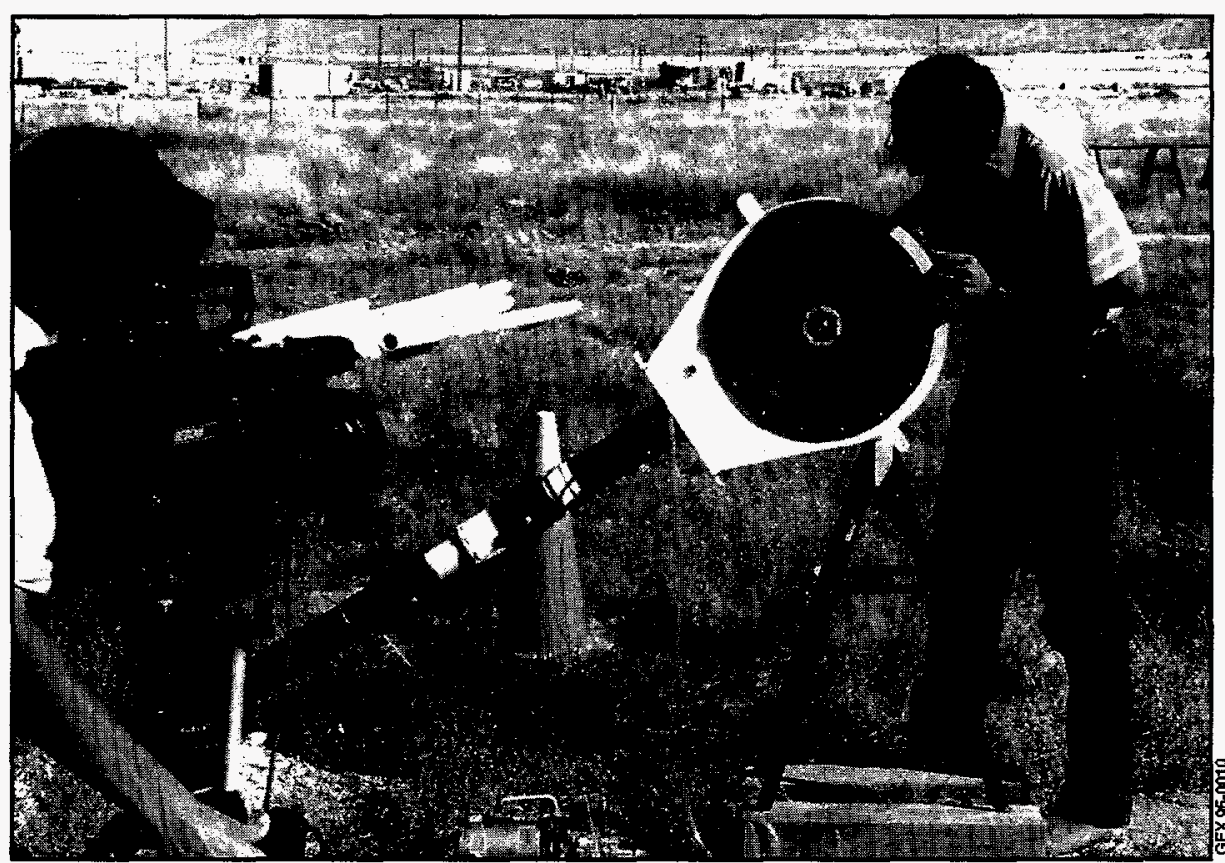

Figure 1.15. SEAMIST ${ }^{\mathrm{TM}}$. which can be removed by vacuuming where membrane retrieval is desired.

Emplacement of monitoring instruments and pore fluid sampling devices using SEAMIST ${ }^{\mathrm{TM}}$ has been demonstrated for vertical, horizontal, and crooked or partially obstructed holes. Instruments or samplers are not dragged along the hole wall at any time. A variety of sensors and/or sampler instruments can be integrated with the SEAMIST ${ }^{\mathrm{TM}}$ deployment system. The membrane can be used to perform vadose zone pore and fracture fluid sampling using absorbent pads. Electrical resistance measurements inside the pads indicate moisture uptake. By attaching an array of absorbent pads to the membrane, high spatial resolution of the contaminant distribution is possible.

Extraction of soil gas samples from a downhole can be accomplished via tubes to surface sample collectors. Getters (such as activated charcoal adsorbers) can also be attached to the membrane surface to adsorb contaminants. Additional classes of sensors and/or samplers that can be deployed using the SEAMIST ${ }^{\mathrm{TM}}$ system include: thermocouple psychrometers, gypsum blocks, pressure transducers, temperature sensors, calorimetric indicators, and hydrocarbon-sensitive adsorbing resistors.

\section{TECHNOLOGY NEEDS}

Many of the problems with conventional vadose zone monitoring techniques are eliminated or minimized by the SEAMIST $^{\mathrm{TM}}$ design. Be- 
cause it is customizable, retrievable, reusable, and leaves the borehole clean, SEAMIST ${ }^{\mathrm{TM}}$ saves time and money in drilling costs, tool rehabilitation (rather than replacement and upgrades), and waste stream disposal. It also minimizes or eliminates problems that conventional systems experience, such as retrieval and repair of buried instrumentation, cross-contamination of samples, single-point sampling with screened wells, and borehole stability. The system is ideal for field work, as the device is easily handled and transported. A small unit can fit into the trunk of a car and installation is fast: emplacement in a 100-foot borehole can take less than five minutes.

The main limitation of the SEAMIST ${ }^{\mathrm{TM}}$ technology is that the borehole must remain open after drilling long enough to allow deployment of the membrane (typically less than 30 minutes). If regions of swelling clays are encountered in the lithology, the membrane pressurized with air may not prevent closure of the borehole. The seal of the interface between the membrane and the borehole wall may not be as absolute as in a grouted hole, but appears to be adequate for most applications.

Some aspects of the system's performance require more time in field tests to evaluate: (1) long-term performance of the membrane and sampling system materials, (2) borehole seal quality, and (3) removability of sand-filled systems.

\section{ACCOMPLISHMENTS}

- Received 1994 R\&D 100 award for technical excellence.

- Two systems installed at Lawrence Livermore $\mathrm{Na}$ tional Laboratory (LLNL) in 1991 are tracking the movement/concentrations of a tritiated water plume (vapor and liquid water sampling) to $40-\mathrm{ft}$ depths.

- Two emplacement systems with disposable membrane liners are in use at Hanford for carbon tetrachloride plume monitoring.

- Membranes coated with liquid-indicating and wicking layers were used to map and measure brine flows underground at the WIPP.
- Transported vapor sampling tubes and adsorbent collectors 230 feet horizontally beneath an old radioactive waste landfill at LANL.

- Transported logging tools and cameras in horizontal boreholes of up to $230-\mathrm{ft}$ length and 1.75 to 4.0 -in diameters. Performed gas sampling and permeability measurements in two vertical boreholes of 11.5-in diameter and 110-ft depth immediately after auguring in Sandia's Chemical Waste Landfill (CWL). Installed three borehole liners of 110-ft length.

- Emplaced, operated and removed a vapor sampling membrane in the CWL 60's pit horizontal borehole that incorporated seven sampling points on 170 ' length, 4" diameter membrane.

- Emplaced, operated ( 2 weeks) and removed SEAMIST ${ }^{\mathrm{TM}}$ membranes incorporating physical process and chemical sensors in 110' deep borehole at the CWL.

- Integrated SEAMIST ${ }^{\mathrm{TM}}$ vapor sampling system with surface-based VOC analysis systems (automated/unattended gas chromatograph and ultraviolet fluorometer).

- Emplaced and currently operating a 400' long 4.5" diameter vapor sampling membrane in the KAFB RB11 landfill horizontal borehole.

- The membrane towed a-lb neutron moisturelogging tool in horizontal boreholes. Typically, four 4.5 -inch diameter holes (200-250 feet) were logged in one day, with data taken every 2 feet.

- SEAMIST ${ }^{\mathrm{TM}}$ linerswere installed to support/seal holes while a long-term monitoring system is designed. Hole diameter was 8.5 inches and depths were 80-100 feet.

- Integrated physical process and chemical sensors with SEAMIST ${ }^{\mathrm{TM}}$ liner.

- SEAMIST ${ }^{\mathrm{TM}}$ systems used as the principal method of injecting and sampling port emplacement in the $\mathrm{Va}$ dose Zone Monitoring System.

- Three membranes were instrumented and installed at theSRS in July 1992 for soil vapor, vapor pressure, and permeability measurements. Maximum depth was $130 \mathrm{ft}$, with 10 sampling elevations per membrane. 
- A vapor sampling system was installed to 90 -foot depths for long-term monitoring for the Tucson International Airport.

- Two Kevlar-reinforced membranes were installed to a depth of 155 feet, then filled with water inside cased walls to prevent collapse of PVC casing during remediation experiments.

\section{BENEFITS}

Costs of a SEAMIST ${ }^{\mathrm{TM}}$ system are based on complexity and length. Simple borehole liners, with no instruments or samplers mounted on the membrane will typically cost $\$ 2000$ for a 100 -foot-deep, 8-inchdiameter hole. Fully-instrumented vapor sampling systems with permeability measurement capability will cost up to $\$ 10,000$ for a 100 -foot borehole. Reusable emplacement canisters can be as low as $\$ 1000$ for a system capable of supporting small diameter blank membrane deployments in less than 100foot boreholes. On the other hand, canisters capable of deploying large diameter vapor sampling system in boreholes over 200 feet cost about $\$ 5000$. Costs of the membrane continue to drop as production is streamlined and production volume increases.

\section{COLLABORATION/TECHNOLOGY TRANSFER}

This project involves collaboration with Science 8 Engineering Associates, Inc. (SEA). SEAMIST ${ }^{\mathrm{TM}}$ was developed by SEA and demonstrated by the Mixed Waste Landfill ID. Eastman Cherrington purchased the patent on the technology in 1993 and is currently commercializing the technology.

\section{For further information, please contact:}

\section{William Lowry}

Science and Engineering Associates, Inc.

1570 Pacheco Street

Suite D1

Santa Fe, NM 87505

(505) 983-6698

\section{Eastman Cherrington Environmental,} Inc.

1640 Old Pecos Trail

Suite $\mathrm{H}$

Santa Fe, NM 87505

(505) 983-3199

\section{Cecelia V. Williams}

Principal Investigator

Sandia National Laboratories

P.O. Box 5800

Albuquerque, NM 87185-5800

(505) 844-5722

\section{George Allen}

Technical Program Manager

Sandia National Laboratories

P.O. Box 5800

Albuquerque, NM 87185-5800

(505) 844-9769

\section{Skip Chamberlain}

Program Manager

U.S. Department of Energy

Cloverleaf Building

19901 Germantown Road

Germantown, MD 20874-1290

(301) $903-7248$

\section{TTP Number: AL221115}

\section{BIBLIOGRAPHY OF KEY PUBLICATIONS}

Dunn, Dalvit S., D. Cremer, W.E. Lowry, C.V. Williams, Final Report SEAMIST ${ }^{\text {TM }} 1993$ Activities, 1994.

Lowry, William E. and S. Dalvit-Dunn, Survey of In-Situ Instruments Suitable for Deployment with the SEAMIST ${ }^{\mathrm{TM}}$ System in the Sandia Mixed Waste Landfill Integrated Demonstration, SEASF-TR-93-023, Contract\#AC-6960. TTP\#AL221115, Santa Fe: Science and Engineering Associates, June 1993.

Lowry, William E. and Carl Keller, Development of the SEAMIST ${ }^{T M}$ Concept for Site Characterization and Monitoring: Final Report, Contract No. 021 12408, Santa Fe: Science and Engineering Associates, 1992. 


\section{TASK DESCRIPTION}

The Vadose Zone Monitoring System provides unattended, automated monitoring of multiple vapor sampling locations for unsaturated zone measurements. The vadose zone is the unsaturated area between the ground surface and the water table. Deep vadose zone refers to sites where the water table is generally deeper than 100 feet. Movement of vapor or volatile contaminants in the vadose zone is by diffusion or advection. Movement by diffusion is a result of a concentration gradient, while advective movement forces vapor or volatile contaminants through the vadose zone by some means, such as changes in barometric pressure with time. By utilizing the Vadose Zone Monitoring System the predominant mechanism of vapor or volatile contaminant movement can be made and, hence, provide more accurate predictions of the rate of movement of the contaminants to the water table.
The Vadose Zone Monitoring System integrates pressure sensors and gas sampling devices in a stand alone field system that performs real time measurement at up to 45 sampling ports in single or multiple wells. See Figure 1.16. The wells can range from test holes of one to two inches in diameter to boreholes eight inches in diameter. SEAMIST ${ }^{\mathrm{TM}}$ membranes are the principal method of injection and sampling port emplacement. The sampling system utilizes a Bruel and Kjaer gas analyzer, a barometric pressure sensor, a differential pressure sensor, and a solenoid valve system to sequentially connect each sampling port to a sensor. Also, temperature sensors and thermocouple psychrometers which measure soil water potential are located in selected wells.

The system being tested at Sandia's Mixed Waste Landfill (MWL) monitors TCE, carbon dioxide $\left(\mathrm{CO}_{2}\right)$, and sulfur hexafluoride $\left(\mathrm{SF}_{6}\right)$. To perform a

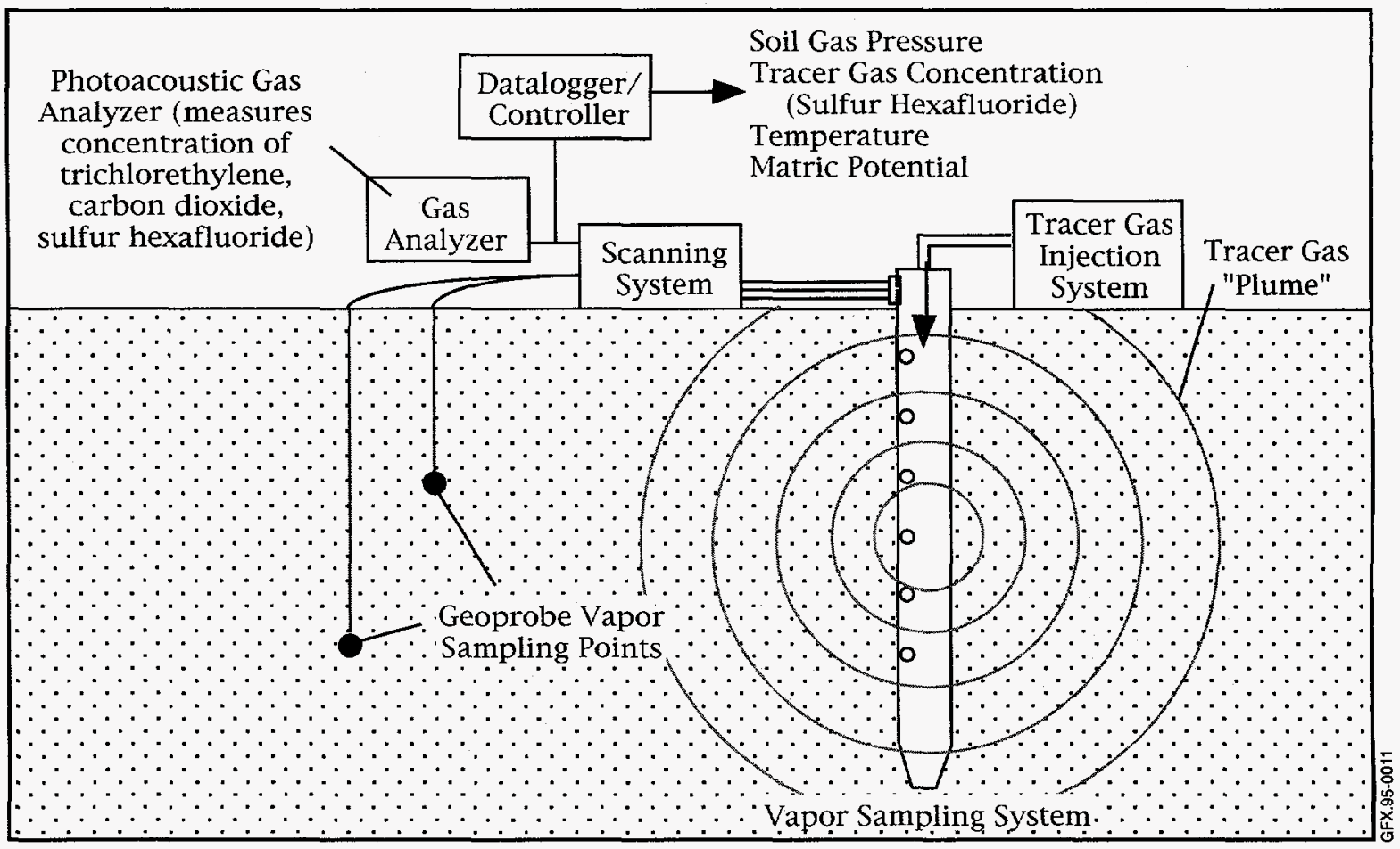

Figure 1.16. Vadose Zone Monitoring System. 
gas movement experiment, 250 parts per million sulfur hexafluoride $(0.025 \%)$ is injected into the ground through a sampling port and the monitoring system is started. Pressure data from 45 ports are collected/stored once every three hours and gas analysis data from 45 ports are collected/stored every six hours. The system runs automatically without supervision. Data are periodically downloaded using a standard portable personal computer and analyzed using standard spreadsheet programs. The pressure data are correlated to gas analysis data from each well to determine the effects of changes in barometric pressure due to a change in weather on the movement of the vapor through the soil. The movement of the vapor is analogous to the movement of TCE, the contaminant of interest, in the soil.

\section{TECHNOLOGY NEEDS}

Post-closure monitoring is required of almost all remediated sites. The standard practice is to monitor groundwater wells for the presence of contaminants. This approach may be problematic at a site with great depth to groundwater. At the MWL sites, the vadose zone extends nearly 500 feet deep. By the time contaminants are detected in the groundwater, significant vadose zone contamination will have occurred. Monitoring the vadose zone beneath the remediated site instead of the groundwater would permit earlier detection of a contaminant release with a smaller contaminated volume, and will result in a less costly additional remediation effort.

\section{ACCOMPLISHMENTS}

- The MWL has demonstrated that the system can fulfill the need to monitor volatile contaminants (e.g., TCE) movement at sites with deep vadose zones.

- Transferred the Vadose Monitoring System technology to LANL's Environmental Restoration group for subsurface assessment and monitoring in August 1994.
- Commercialized a version of the Vadose Zone Monitoring System, MultiScan TM. This commercial system performs real-time sampling and analysis on 16 to 64 sampling ports. Gas sampling and analysis for five samples takes approximately three minutes per port, and pressure sampling takes about five seconds per port.

\section{BENEFITS}

Use of this technology will improve characterization and monitoring efforts. Better data on contaminant distribution and on the effectiveness of remediation efforts will reduce the costs of remediation projects.

The entire system is low maintenance and can run unattended in the field for days. Equipment can operate over a wide range of environmental conditions, therefore only a ventilated rain-proof enclosure is required. Specific costs of the system comprise the purchase of system components (approximately $\$ 40,000)$, as well as operation and maintenance costs.

\section{COLLABORATION/TECHNOLOGY TRANSFER}

An industrial partnership has been established with SEA to provide technical expertise in vapor sampling and analysis systems, particularly in the vadose zone. SEA will market the system when it is made commercially available. A modified version of the Deep Vadose Monitoring System has been transferred for use at the LANL Environmental Restoration site and is being commercialized by SEA as MultiScan ${ }^{\mathrm{TM}}$.

\section{For further information, please contact:}

\section{William Lowry}

Science and Engineering Associates, Inc.

1570 Pacheco Street, Suite D1

Santa Fe, NM 87505

(505) 983-6698 


\section{Cecelia V. Williams}

Principal Investigator

Sandia National Laboratories

P.O. Box 5800

Albuquerque, NM 87185-5800

(505) 844-5722

\section{George Allen}

Technical Program Manager

Sandia National Laboratories

P.O. Box 5800

Albuquerque, NM 87185-5800

(505) 844-9769

\section{Skip Chamberlain}

Program Manager

U.S. Department of Energy

Cloverleaf Building

19901 Germantown Road

Germantown, MD 20874-1290

(301) 903-7248
TTP Number: AL221115

\section{BIBLIOGRAPHY OF KEY PUBLICATIONS}

Dunn, Dalvit S., W.E. Lowry, C.V. Williams, Deep Vadose Zone Monitoring at the Sandia MWLID Program Using the SEAMIST TM In Situ Instrumentation and Vapor Sampling System, Sixth National TIE Workshop, May 1994.

Lowry, William E. and S. Dalvit-Dunn, Survey of In-Situ Instruments Suitable for Deployment with the SEAMIST TM System in the Sandia Mixed Waste Landfill Integrated Demonstration, SEASF-TR-93-023. Contract \#AC-6960, TTP\#AL221115. Santa Fe: Science and Engineering Associates, June 1993.

Lowry, William E. and Carl Keller, Development of the SEAMIST ${ }^{T M}$ Concept for Site Characterization and Monitoring: Final Report, Contract No. 02112408, Santa Fe: Science and Engineering Associates, 1992.

Lowry, William E., P. Zakian, S. Dalvit-Dunn, C.D. Cremer, C.V. Williams, "Deep Vadose Zone Monitoring at the Sandia MWLID Program," Proceedings of the Spectrum '94 Conference, Atlanta, GA, August 14-18, 1994. 


\subsection{HYBRID DIRECTIONAL BORING \\ AND \\ HORIZONTAL LOGGING}

\section{TASK DESCRIPTION}

The primary objective of this project is to develop a cost-effective, minimally intrusive drilling technology which generates minimal secondary waste during emplacement of usable cased/screened directional boreholes. Developing a horizontal capability to depths greater than 20 feet, extension of wellbores to 1000 feet, and incorporating on-board electronic tracking equipment are supporting tasks.

Hybrid directional boring machinery capable of exerting hydraulic thrust forces greater than 80,000 pounds has been adapted from the underground utilities industry and further developed as a prototype for future environmental applications via commercial machinery. See Figure 1.17. Directional control is obtained by proper positioning of the non-symetric face of the boring head. Slow rotation of the boring head cuts and compacts the geologic material. Pushing the non-symetric boring head causes directional change. The machinery can ini- tiate a borehole at ground or shallow pit level, steering down to the desired depth, continuing horizontally at that depth, and then steering back to the surface. If necessary, reaming the borehole to a larger diameter can be accomplished in a similar manner. Casing and/or screen material can be installed in the borehole by attaching it to the drill rod being retrieved from the exit point through the borehole to the launch point.

\section{TECHNOLOGY NEEDS}

This technology is applicable to the characterization, monitoring, and remediation phases of environmental sites. The dominant factor is the local geological material at the boring depth. This technology must be evaluated on a site-by-site basis, using available information from the development project and regional information from industry. Where applicable, this technology will be cost effec-

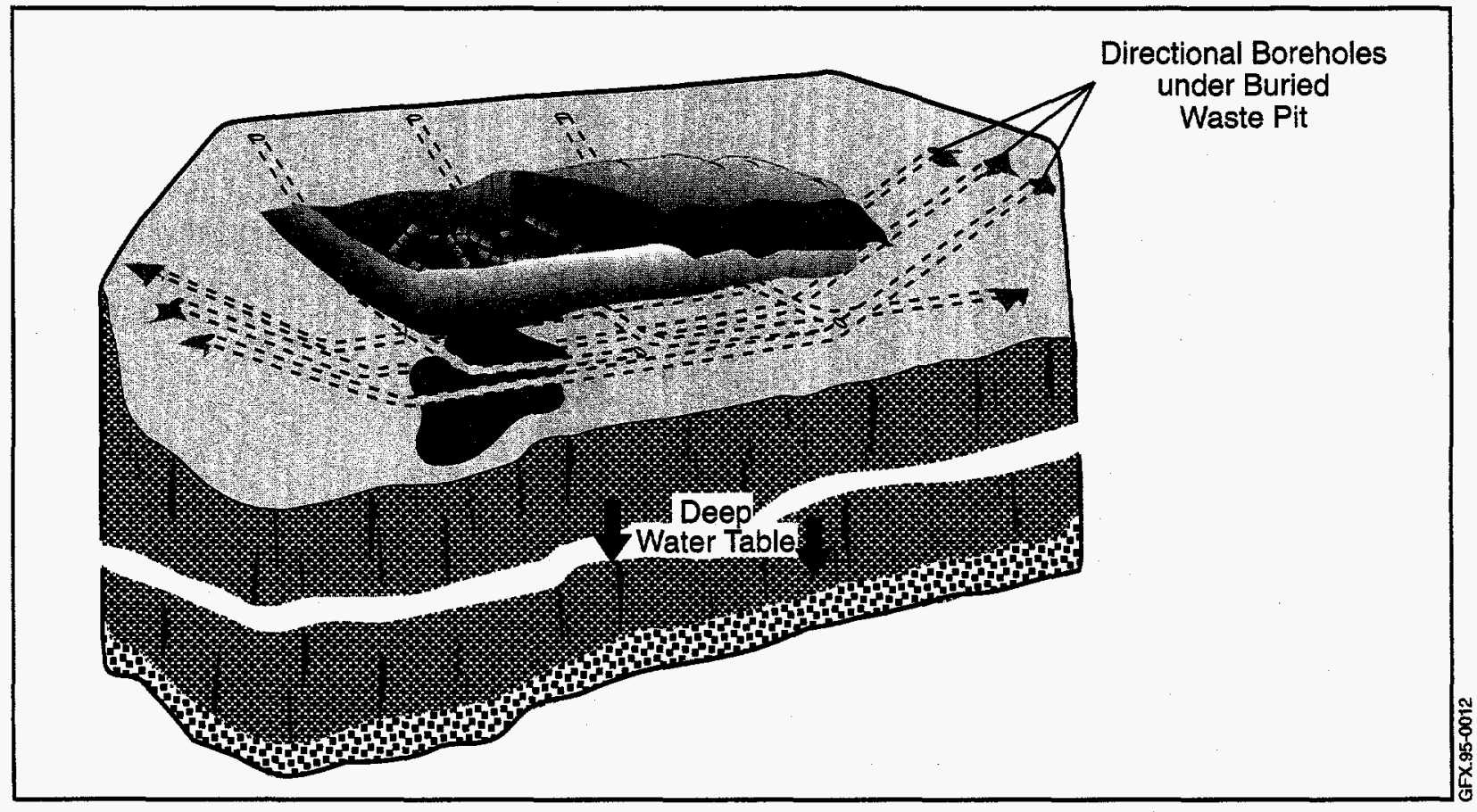

Figure 1.17. Hybrid Directional Boring. 
tive, have minimal site impact, and will generate minimal secondary waste.

\section{ACCOMPLISHMENTS}

- Developed hybrid machinery that can bore deeper with better accuracy, bore further, and provide a sampling capability better than the underground utilities baseline machinery could provide.

- Designed machinery with features that make decontamination easier and more effective.

- Charles Machine Works-Ditch Witch ${ }^{\mathrm{TM}}$ commercialized the machinery and is marketing several types of boring machines to the environmental industry.

- The project team successfully emplaced horizontal wellbores in the coastal plain sediments at the SRS and in alluvial deposits at KAFB. These wellbores had lengths/depths of $570 \mathrm{feet} / 37 \mathrm{feet}$, and 410 feet $/ 29$ feet, respectively.

- In testing, the equipment has been used as deep as 55 feet.

\section{BENEFITS}

A goal of this project is to keep the drilling costs within the range from $\$ 25$ to $\$ 75 /$ foot. This cost compares to $\$ 300$ and $\$ 500 /$ foot for other typically larger directional drilling rigs. Several wellbores have been installed during development testing for approximately $\$ 50 /$ foot. This cost does not include $\mathrm{R} \& \mathrm{D}$ costs associated with the tests or the casing material; however, well planning, labor, materials, and equipment depreciation are included in the cost estimate.

\section{COLLABORATION/TECHNOLOGY TRANSFER}

Charles Machine Works, Inc. has been an industrial partner of SNL since FY91. Demonstrations at the SRS (non-arid) and at the MWL have co-funded this Sandia development project. Charles Machine Works has provided matching private capital. Charles Machine Works entered the environmental machinery market in 1994 with a line of directional boring machinery. Charles Machine Works has received a license to use a sample latch device developed at Sandia. Several patent disclosures have been made individually by Sandia and Charles Machine Works. A partnership has also been established with CERL, Inc., a New Mexico environmental engineering company, to apply the technology to radon remediation of public buildings. This partnership is funded through the Sandia Technology Transfer office.

\section{For further information, please contact:}

Charles Machine Works, Inc.

Perry, OK

(505) 983-6698

Robert Wemple

Principal Investigator

Sandia National Laboratories

P.O. Box 5800

Albuquerque, NM 87185-5800

(505) 844-2230

\section{George Allen}

Technical Program Manager

Sandia National Laboratories

P.O. Box 5800

Albuquerque, NM 87185-5800

(505) 845-7015

\section{Skip Chamberlain}

Program Manager

U.S. Department of Energy

Cloverleaf Building

19901 Germantown Road

Germantown, MD 20874-1290

(301) 903-7248 
TTP Numbers: AL221116, AL221103

\section{BIBLIOGRAPHY OF KEY PUBLICATIONS}

Wemple, R.P., R.D. Meyer, and R.R. Layne, Interim Report - SNL/NM Environmental Drilling Project, SAND93-3884, 1993.

Westmoreland, J., Evaluation of an Air Drilling Cuttings Containment System, SAND94-0214, 1994.

Wemple, R.P., R.D. Meyer, G.E. Staller, and R.R. Layne, Final Report-SNL/NM Environmental Drilling Project, SAND94-2388, 1994.

Staller, G.E. and R.P. Wemple, Casing Pull Tests for Directionally Drilled Environmental Wells, SAND942387, 1994.

Layne, R.R., "Today's Environment," directional drilling segment, produced by Charles Machine Works and The Discovery Channel, September 1994. 


\section{TASK DESCRIPTION}

The abjective of this task is to develop methods to install directional wells that meet data quality objectives, minimize secondary waste generation, and reduce costs for drilling by minimizing operational and contamination exposure hazards to personnel. A secondary objective, during drilling and following the completion of a boring or well, is to support the deployment of instruments, sensors, and other devices to the subsurface for characterization, remediation (including barrier placement), and monitoring purposes. Accurate placement of these boreholes is also an important factor.

Several directional drilling systems have been tested in the past two years at the Savannah River, Sandia, and Hanford sites, including the (1) short radius drilling, (2) mud rotary system (originally developed by New Mexico Institute of Mining and Technology and commercialized by Texas Eastern Developments/Eastman Cherrington Environmental), (3) hybrid system of Eastman Cherrington Environmental, (4) slant compaction rig (Ditchwitch), and (5) river crossing system. Currently, two new methods of directional drilling will be tested at the Hanford site: air rotary and air hammer. Both drilling technologies use air circulation to cool the drill bit and carry the rock cuttings from the hole as the drilling process advances. A vacuum method is being developed to contain the cuttings and filter circulation air to prevent contaminants from spreading.

The most common process of directional drilling can be accomplished using a bent drill pipe section located at the bottom of the drill string just above a downhole motor that is activated by the flow of compressed air or other gas. The directional drilling process currently being investigated would begin with a slant borehole drilled at an angle to horizontal, or a vertical borehole which can be directed to bend in any direction. Steering is accomplished by orienting the drill string of normal drill pipe having a bottomhole assembly, which consists of a bent sub (a slightly bent section of drill pipe), downhole motor, and drill bit. The bent sub is placed directly above the downhole air actuated motor which allows the drill bit, attached to the bottom end of the motor, to be rotated by the flow of the compressed air through the motor. The compressed air flow also carries the rock cuttings to the surface as the drill string is advanced. When the drill string is oriented, the bent sub will cause the hole to veer off as the drill bit is advanced. See Figure 1.18a.

When the desired turn has been made, the drill pipe is rotated slowly as the downhole motor continues to advance the bit. The slow rotation of the drill string cancels all effects of the bent sub and allows the hole to advance in a straight direction from the curved portion of the hole. Figure $1.18 \mathrm{~b}$ shows one of the new 6.5 inch downhole air motors lowered into a natural gas well in a recent directional drilling operation using this new technology. Figure $1.18 \mathrm{c}$ shows two of the 6.5 inch downhole air motors ready for transport to a directional drilling operation at a gas well.

The air hammer can also be used to drill directional holes. By placing it in the drill string below the downhole motor and connecting it to the drill bit, the air hammer can be rotated by the downhole motor and, in this manner, directionally drill rock formations that cannot presently be drilled efficiently by normal air rotary methods. It may be possible to incorporate the air hammer in conjunction with a dual wall drill pipe system. Such a system would allow the inner drill pipe string to be rotated to actuate the air hammer. The outer pipe or casing would have a bent sub section near the bottom and, thus, would allow the entire duel system of pipe to be oriented so that directional drilling could be accomplished.

\section{TECHNOLOGY NEEDS}

In order to characterize the nature and extent of contamination at DOE sites, wells are drilled for sampling and monitoring. The ability to construct horizontal wells or wells that are not vertical in 


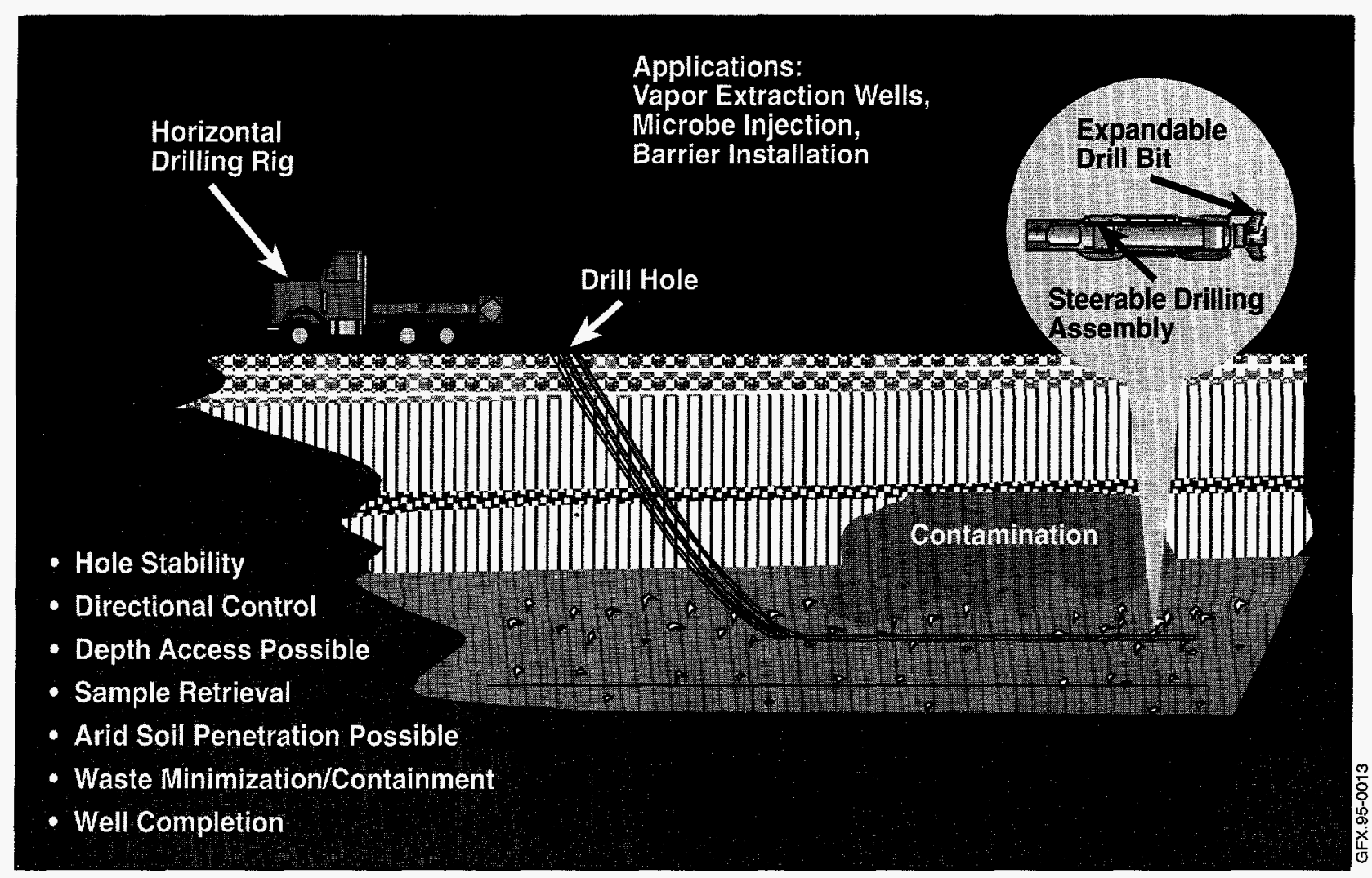

Figure 1.18a. Horizontal/Directional Drilling Technology Development.

contaminated soils or rock will increase the ability to accurately assess the levels of contamination under structures. The directional drilling project will focus on increasing the ability for:

- installation of subsurface treatment systems, such as vapor extraction, leaching, and microbial;

- barrier installations - applications include obtaining access holes beneath cribs, ditches, ponds, trenches, and structures; and

- characterization and/or monitoring, which commonly would involve soil sampling, and the installation of sensors, packers, and instrumentation.

Advanced and improved drilling technologies are needed to:

- reduce costs;

- minimize waste from drilling;
- maintain containment of drill cuttings and effluents while drilling; and

- improve well completion technologies.

\section{ACCOMPLISHMENTS}

Horizontal drilling was initiated in the oil industry during the 1930s to improve production from oil wells. Environmental horizontal drilling was initiated in 1986 to increase volatile extraction capability from a remediation area at the Savannah River Site. To date, five horizontal boreholes (four mud drilled and one shallow hole using no circulation fluid) have been installed at the Savannah River Site. Vapor extraction volume has exceeded that which would be anticipated from several vertical boreholes.

During FY94, design modifications and bench testing of the air turbine motor (ATM) were com- 


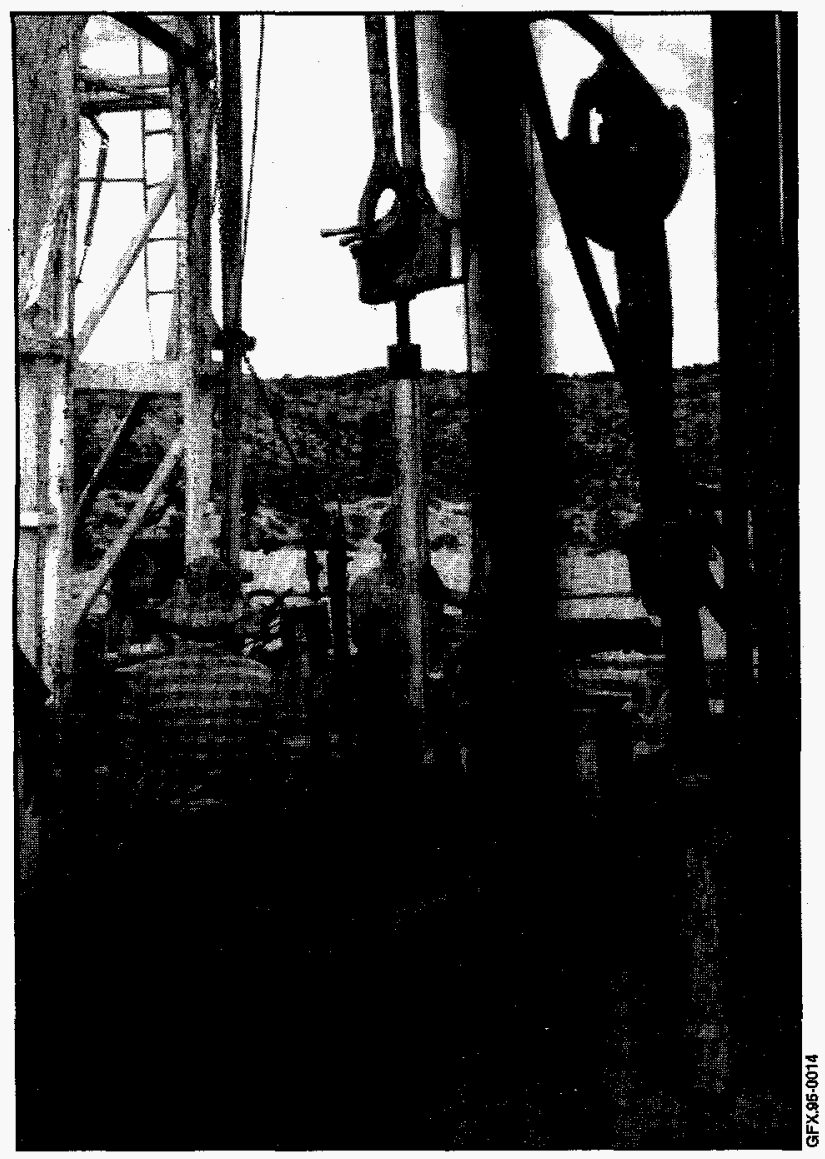

Figure 1.18b. Downhole Air Motors Lowered into a Natural Gas Well.

pleted. A field demonstration of the ATM system was performed in May and July 1994 with positive results. In addition, the Guzzler Cuttings Containment System was also field tested in conjunction with an air rotary rig.

\section{BENEFITS}

A successful horizontal drilling program would offer many benefits:

- Horizontal vapor extraction wells could be drilled in the vadose and groundwater zone of VOC contaminated sites. This would allow more rapid removal of the contaminants from the soil and groundwater and would eliminate the costs of installing multiple vertical boreholes.
- Horizontal boreholes could be used for sampling under suspected leaking underground storage tanks. Currently, only vertical wells along the sides of the tanks are available for monitoring the subsurface sediments below the tanks. However, regulatory agencies are concerned that the vertical wells are not adequately assessing the leaks from the tanks. A steerable, horizontal drilling system would allow exact emplacement of monitoring wells under the tanks. In addition, the horizontal boreholes could be used for pumpand- treat remediation methods for soils surrounding the tanks.

- Horizontal boreholes could be used to emplace containment barriers under tanks, cribs, and contaminant plumes. Current testing at the Fernald Site has shown that grout barriers can be successfully placed using the existing horizontal drilling technology. However, a steerable, horizontal drilling system will be needed to position the barriers under leaking facilities.

- Horizontal drilling methods which use air as the circulating fluid could allow drilling in unsaturated soils and rock. By using air rather than drilling mud, fluid loss to the formation is minimized. Furthermore, air drilling methods will minimize contaminant mobilization problems.

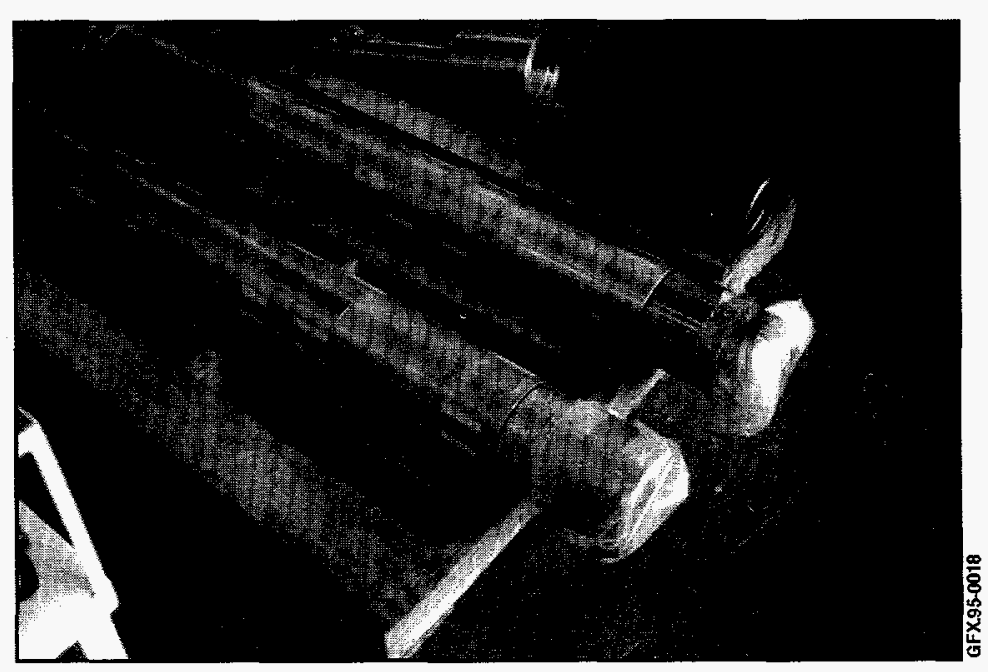

Figure 1.18c. Motors Ready for Transport. 


\section{COLLABORATION/TECHNOLOGY TRANSFER}

Development of the downhole air motor technology is in cooperation with the New Mexico Institute of Mining and Technology. This technology will be commercialized by the Neyrfor-Turbodrilling Company (North America). The technology will be available for environmental drilling operations during the next year. It is expected that the first drilling tests utilizing this new technology will take place at the Hanford site in the late spring or summer of 1995.

Horizontal drilling is applicable to numerous DOE and DoD sites across the United States. Key users were identified and participated in the Horizontal Drilling Workshop held in May 1992. A description of the specific needs at each site is contained in the Horizontal Drilling Workshop Report.

\section{For further information, contact:}

\section{Don Moak}

Principal Investigator

Westinghouse Hanford Company

P.O. Box 1970

Richland, WA 99352

(509) 373-7539

\section{James Berger}

Technical Program Manager

Westinghouse Hanford Company

P.O. Box 1970

Richland, WA 99352

(509) $372-4035$

\section{Rashalee Levine}

Program Manager

U.S. Department of Energy

Cloverleaf Building

19901 Germantown Road

Germantown, MD 20874-1290

(301) 903-7920
TTP Number: RL421103

Other TTPs associated with directional drilling include:

RL411101 (VOC Arid)

AL221103 and SR121101 (VOC Non-Arid)

AL221116 (MWLID)

\section{BIBLIOGRAPHY OF KEY PUBLICATIONS}

BDM International, Evaluation of Alternative Technologies and Subsurface Confinement Barriers for Single Shell Tanks at Hanford, Morgantown, West Virginia, Report prepared for DOE, 226 pp., 1993.

Kaback, D.S., B.B. Looney, J.C. Corey, L.M. Wright, and J.L. Steele, Horizontal Wells for In Situ Remediation of Groundwater and Soils, National Water Well Association Outdoor Action Conference, Orlando, Fla., May 22-25, 1989, 16 pp.

McLellan, G.W., E.J. Jensen, S.P. Airhart, and C.L. Edison, Horizontal Drilling Workshop Summary Report for the Arid Integrated Demonstration Program, WHC-EP-0596, prepared for DOE, Office of Technology by Westinghouse Hanford Company, Richland, Washington, October 1992.

Volk, B.W., Integrated Test Plan for Directional Boring, WHC-SD-EN-TP-020, Rev. 0, Westinghouse Hanford Company, Richland, Washington, February 1993.

Volk, B.W., Letter Report: Results on Feasibility Test of the Ditch Witch At the Hanford Site, Internal memorandum 81730-93-010, Westinghouse Hanford Company, Richland, Washington, April 1993. 


\section{HEAVY-WEIGHT CONE PENETROMETER}

\section{TASK DESCRIPTION}

The objective of this task is to provide a cost effective source detection tool. The heavy-weight cone penetrometer will characterize contamination, install monitoring points, and collect chemical and radiological data. Activities are focused on enhancing the heavy-weight cone penetrometer efficiency in cobbles and gravels. This process includes:

- further upgrading of the thrusting capacity of the truck and reinforcing tools to withstand this force;

- minimizing waste from down hole tool decontamination;

- evaluating the use of mechanical forces to facilitate penetration through gravels; and
- improving sensors such as radiation detection devices.

The cone penetrometer is a truck-mounted device that rapidly penetrates into the ground to collect characterization data. See Figures 1.19a and 1.19b. The device has been geotechnically applied for approximately 50 years, but is relatively new for environmental restoration. The cone penetrometer rod has a conical tip of up to 1.75 inches in diameter. It pushes hydraulically into the ground with pressures up to 70,000 pounds. The hole generated by the cone penetrometer retains the outside diameter of the rod and can be grouted for groundwater protection, preventing the escape of contaminants as the probe is withdrawn. For soil characterization, as the rod progresses into the ground, a computer reads data from sensors located in both the tip and the



Figure 1.19a. Source Detection Screening Using Cone Penetrometer Truck. 


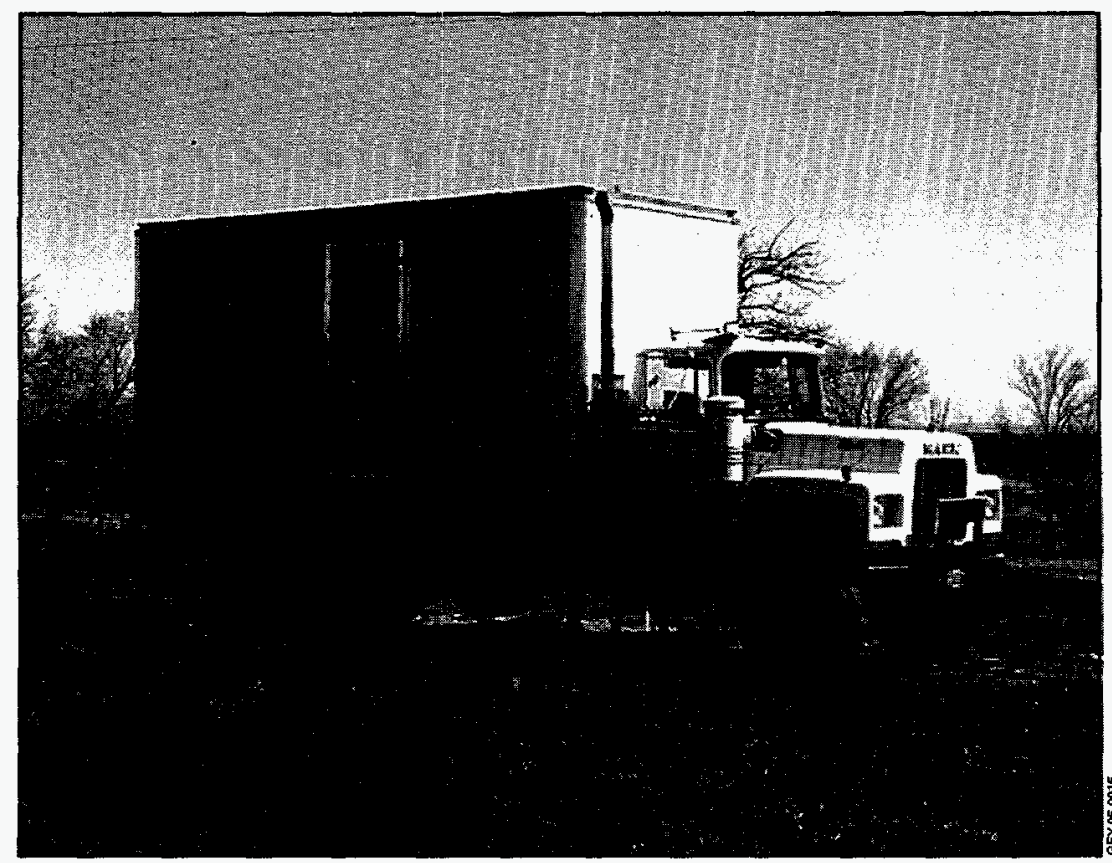

Figure 1.19b. Cone Penetrometer Truck.

side of the probe. The cone penetrometer can monitor for contaminants as the probe is advanced. It can leave screens in place as the rod is withdrawn. The cone penetrometer can advance through fine-grained soil at a rate of 40 to 50 feet an hour. This tool has been adapted for use in the gravel/cobble subsurface common to arid sites.

\section{TECHNOLOGY NEEDS}

At hazardous waste sites, vertical drilling allows access to the subsurface for sampling the soil and groundwater. Information gained from drilling is used to characterize the subsurface environment and to allow measurements of the types and extent of contamination at a site.

\section{ACCOMPLISHMENTS}

At this time the reliability of the cone penetrometer yaries with soil type. When used in gravel, the cone penetrometer remains at approximately $90 \%$ reliability (minimal refusal) with two attempts in gravels to depths of 50 feet. In gravels to $100 \mathrm{feet}$, the percentage drops to approximately $50-75 \%$. In soft soil, the cone penetrometer remains near $100 \%$ reliability. The Heavy-weight cone penetrometer system has been successfully deployed and demonstrated at numerous DOE sites as well as at Fairchild Air Force Base in Spokane, Washington. Cone penetrometers can be designed to collect several types of data in addition to collecting groundwater samples. The cone penetrometer is currently being transferred to the ER program at the Hanford site.

\section{BENEFITS}

The cone penetrometer is a quick tool for initial evaluation of the extent of groundwater and soil contamination present at potential environmental restoration sites. It is less costly than drilling, and does not result in contaminated soils being brought to the surface. Cone penetrometers may be used to deploy many different state-of-the-art line sampling and instrument devices. Additionally, effectiveness of the cone penetrometer is unaffected by weather conditions. Compared to traditional drilling methods, the cone penetrometer minimizes worker exposure to potential industrial and chemical hazards, is very mobile, and consistently achieves required depths.

\section{COLLABORATION/TECHNOLOGY TRANSFER}

This technology is being developed by ANL, PNL and WHC through a contract with Applied Research Associates. Any environmental remediation at sites, where the generation of airborne contaminants or effluents during drilling is not acceptable, will benefit from the cone penetrometer technology. In addition, this technology can be potentially linked with real-time monitoring systems. 
For further information, please contact:

Jimmie L. Bratton

Applied Research Associates, Inc. 4300 San Mateo Boulevard, NE

Suite A220

Albuquerque, NM 87110

(505) 881-8074

Greg McLellan/Bruce Cassem

Principal Investigators

Westinghouse Hanford Company

P.O. Box 1970

Richland, WA 99352

(509) 373-7539/(509) 373-7535

\section{James Berger}

Technical Program Manager

Westinghouse Hanford Company

P.O. Box 1970

Richland, WA 99352

(509) 376-9942

Rashalee Levine

Program Manager

U.S. Department of Energy

Cloverleaf Building

19901 Germantown Road

Germantown, MD 20874-1290

(301) 903-7920

\section{BIBLIOGRAPHY OF KEY PUBLICATIONS}

Cassem, B.R., Test Plan for the Cone Penetrometer on the Hanford Site FY 1992, WHC-SD-EN-TP-011, Rev. 0, Westinghouse Hanford Company, Richland, Washington, 1992.

Cassem, B.R., D.A. Timian, and B.E. Fisk, Demonstration of Heavyweight Penetrometer Technology at the Hanford Site, WHC-SD-EN-TRP-003, Rev. 0, Westinghouse Hanford Company, Richland, Washington, 1992.

Rohay, V.J., Electric Cone Penetrometer Test at the 200 West Area, WHC-SD-EN-TP-004, Rev. 0, Westinghouse Hanford Company, Richland, Washington, 1991.

Cassem, B.R., McGee Ranch Investigation, WHCSD-EN-RPT-005, Rev. 0, Westinghouse Hanford Company, Richland, Washington, 1993.

Richterich, L.R., B.R. Cassem, Fiscal Year 1993 Heavyweight Cone Penetrometer Activities at the Hanford Site, WHC-SD-EN-TRP-006, Rev. 0, Westinghouse Hanford Company, Richland, Washington, 1994.

Richterich, L. R., B.R. Cassem, Cone Penetrometer Testing at the Hanford Site: Final Performance Report, WHC-EP-0797, Rev. 0, Westinghouse Hanford Company, Richland, Washington, 1994. 


\section{TASK DESCRIPTION}

The ResonantSonic ${ }^{\mathrm{SM}}$ drilling system uses a combination of mechanically generated vibrations and rotary power to penetrate the soil. The oscillator or drill head consists of two counter-rotating rollers that generate sinusoidal wave forces and operates at frequencies close to the natural frequency of the steel drill column (up to 150 cycles per second). This frequency causes the column to vibrate elastically along its entire length. See Figures $1.20 \mathrm{a}$ and $1.20 \mathrm{~b}$. In the resonant condition, drill pipe acceleration rates exceed 500 g's. Forces up to 200,000 lbs per cycle are efficiently transmitted to the drill bit face to create an effective cutting action. The vibration of the drill pipe, coupled with the weight of the drill pipe, and downward thrust of the drill head, commonly results in rapid penetration of the formation. In addition, resonant energy emitted along the length of the drill pipe, substantially reduces the amount of friction between the drill pipe and the borehole wall. The ResonantSonic ${ }^{\mathrm{SM}}$ method can provide continuous core samples with- out the use of circulation media and secondary waste generation in this drilling mode is minimal.

The current research program addresses outstanding problems associated with ResonantSonic ${ }^{S M}$ drilling through a DOE CRADA involving PNL, WHC and industry partner Water Development Corporation (WDC). Supporting sonic development activities at SNL are being coordinated with this CRADA. The primary objectives this research effort include: 1) increased reliability of the sonic drill head and drill pipe, 2) improved sampling methods and equipment, 3) reduction of thermal degradation of samples, 4) demonstration of alternative applications for sonic drilling, and 5) development of a resonance monitoring system as an operator aid to minimize downhole pipe failures. Since WDC has provided drilling services at both SNL and Hanford, cooperative efforts are being pursued on the above objectives.

Resonance monitoring systems developed at SNL and PNL/WHC will help to achieve a quantitative understanding of the dynamics of sonic drilling systems. This will allow for

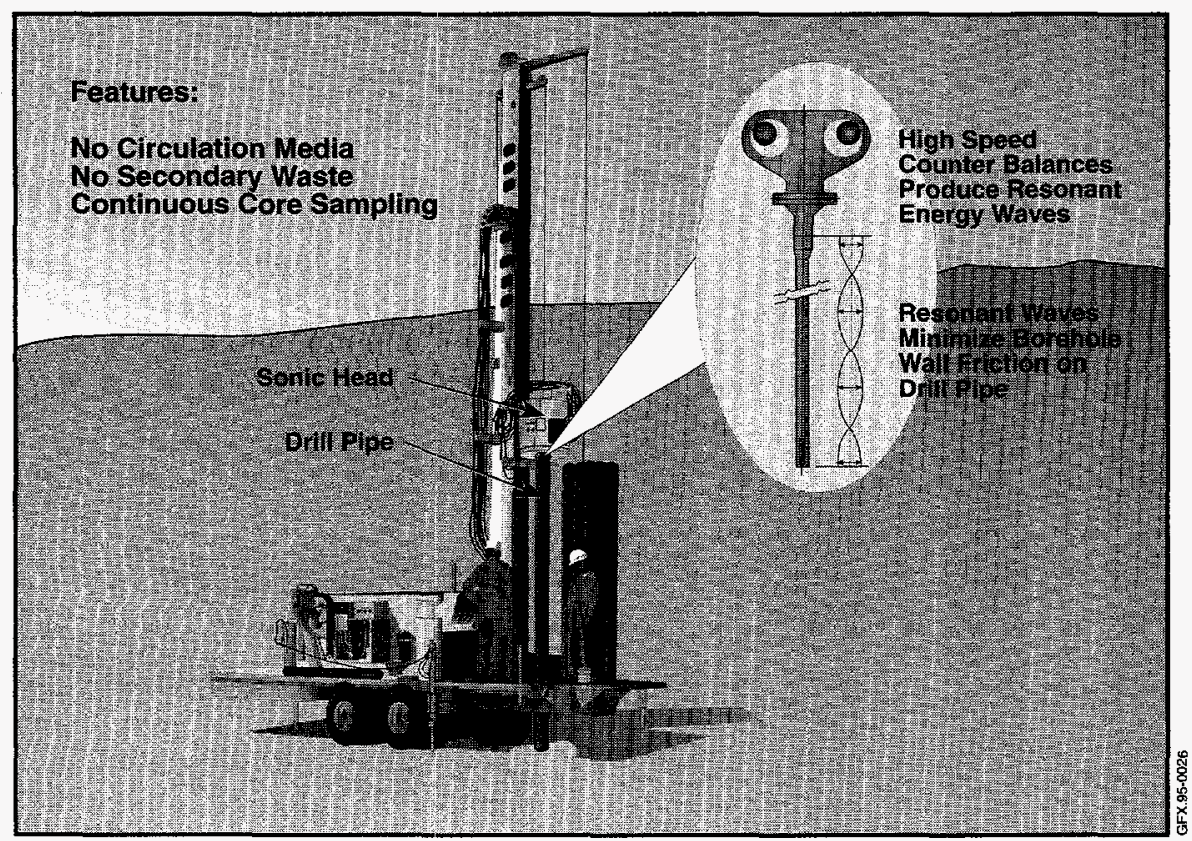

Figure 1.20a. Sonic Drilling Rig. more rational design changes, leading to more robust, capable systems with improved control of operating parameters and higher penetration rates. During the first test sequence, existing sonic hardware and processes are examined to guide the formulation of recommendations for improvements. The improved hardware and processes will be evaluated during the second sequence. This approach is driven by several considerations: (1) field-test observations and follow-up 


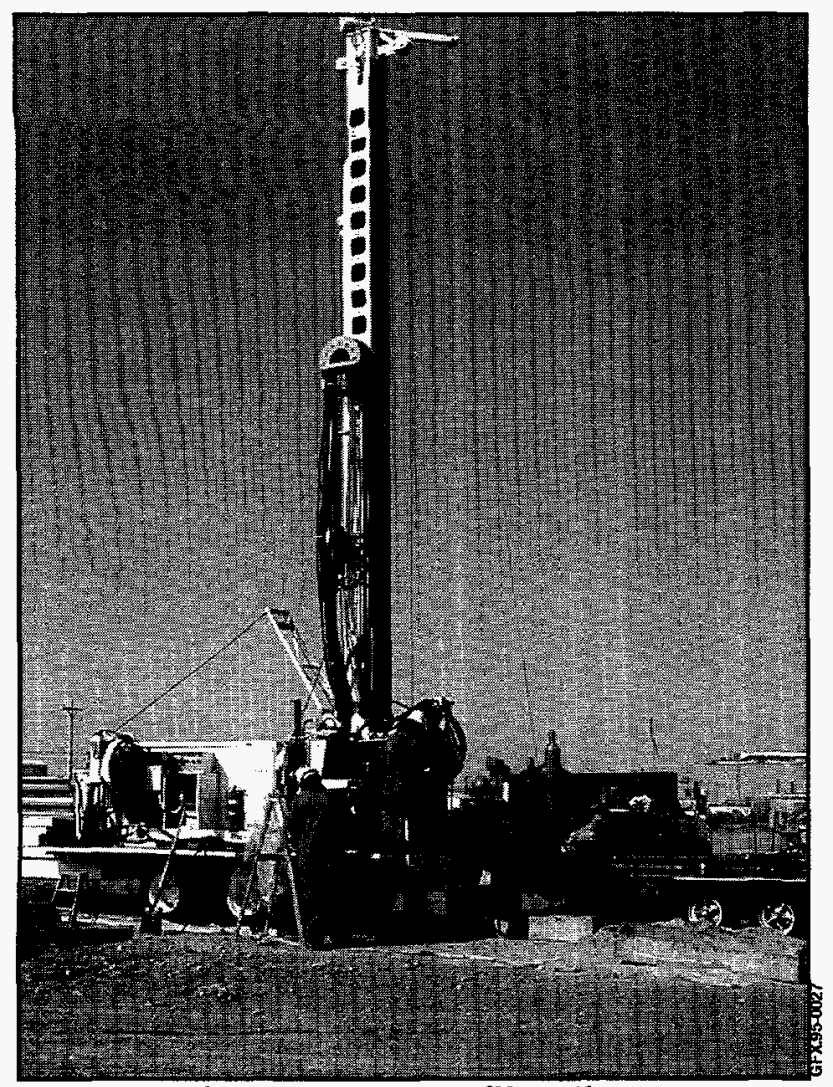

Figure 1.20b. ResonantSonic ${ }^{\text {SM }}$ Drilling.

analyses offer high potential for yielding near-term improvements in sonic hardware; (2) a substantial dynamic database for rig behavior is necessary for overall system and process optimization; (3) fieldtest parameter measurements are required input for dynamic system models which can be applied to optimization studies; and, (4) analyses of dynamic drilling data are essential for identification of the appropriate parameter(s) to be monitored for the eventual application of adaptive (automatic) feedback control.

\section{TECHNOLOGY NEEDS}

Reliable, cost-effective means for accessing underground regions within and adjacent to contaminated sites are required for most environmental characterization, monitoring, and remediation efforts. Such access is crucial for fielding the various technologies to be evaluated during demonstrations. Advanced and improved drilling technologies are needed to:
- reduce costs;

- minimize waste from drilling; and

- maintain containment of drill cuttings and effluents while drilling.

ResonantSonic ${ }^{\mathrm{SM}}$ drilling is a promising method for several drilling applications including: characterization boring, groundwater monitoring wells, vapor and water extraction wells, and barrier installation holes. While the cost per foot of sonic boreholes is already less to that for wells produced by cable-tool drilling, a definite area for improvement is the minimization of downtime. This is directly related to equipment failures both in the drill head and drill pipe due to the intense mechanical loads associated with this drilling method. With improvements in reliability and operational processes achieved via work on the present tasks, sonicrig downtime will be reduced and performance will be optimized. The goal is to reduce overall downtime from equipment failure and drilling related problems to less than $10 \%$. Reduction of downtime rates to levels consistent with other drilling methods will result in significant cost reductions.

\section{ACCOMPLISHMENTS}

- Drilled three 11-inch diameter holes and completed as multiple screened interval wells in excess of 300 feet. Drilling costs compared to the Hanford site baseline were reduced by $42 \%$ and actual drilling and completion time saved 2 weeks per well.

- Tested redesigned sonic drill head which has reduced downtime to less than $10 \%$.

- Developed and demonstrated equipment and techniques to maintain acceptable core sample temperatures during VOC sampling.

- Demonstrated angle drilling capability and efficiency on mixed waste site.

- Designed, manufactured, and demonstrated an instrumented subassembly that provides timeresolved strain and acceleration data for sonic drill strings during production drilling. 
- Measured dynamic strain and acceleration during slant sonic drilling beneath Sandia's CWL in FY93.

- Completed a fully-equipped mobile instrumentation trailer and towing vehicle in FY94 that will be used to provide stand-alone electronic and mechanical support for sonic field tests.

- Procured hardware and developed software in FY94 for handling and processing large (multimegabyte) sonic data files.

- SNL/WHC collaborative field test demonstrating the Guzzler cuttings containment system with the ResonantSonic ${ }^{\mathrm{SM}}$ method.

\section{BENEFITS}

In comparison to the baseline cable-tool drilling, the key advantages of the ResonantSonic ${ }^{S M}$ drilling method are:

- increased rate of drilling;

- containment of drill cuttings;

- minimization of secondary drilling waste;

- sample quality in formations where the baseline method cannot retrieve high quality samples (e.g., caliche, boulders, and cobbles); and

- increased safety due to less hands on exposure to physical hazards and waste contaminants.

Additionally, ResonantSonic ${ }^{S M}$ drilling minimizes contamination of supplemental drilling components and drilling at any angle from horizontal to vertical is also possible.

\section{COLLABORATION/TECHNOLOGY TRANSFER}

The ResonantSonic ${ }^{S M}$ drilling technology is being commercialized by WDC and applied at DOE sites, including SNL and Hanford. A CRADA has been established between WDC and PNL for the purpose of enhancing the sonic drilling technology. Ongo- ing activities at $S N L$ are being coordinated with this CRADA.

For further information, please contact:

Jack Wise and Jerry Mercer

Principal Investigators

Sandia National Laboratories

P.O. Box 5800

Albuquerque, NM 87185-5800

(505) 844-6359

Greg McLellan

Principal Investigator

Westinghouse Hanford Company

P.O. Box 1970

Richland, WA 99352

(509) 373-7219

\section{James Berger}

Technical Program Manager

Westinghouse Hanford Company

P.O. Box 1970

Richland, WA 99352

(509) 376-9942

\section{Rashalee Levine}

Program Manager - VOCs in Arid Soil

U.S. Department of Energy

Cloverleaf Building

19901 Germantown Road

Germantown, MD 20874-1290

(301) $903-7920$

TTP Numbers: AL231005, RL421103

\section{BIBLIOGRAPHY OF KEY PUBLICATIONS}

Cassem, B.R., Integrated Test Plan ResonantSonic ${ }^{S M}$ Drilling System Technology Demonstration-1994, at the Hanford Site, Richland, Washington, WHC-SDEN-TP-047, Rev.O, Westinghouse Hanford Company, Richland, Washington, 1994.

Drumheller, D.S., "Acoustical Properties of Drill Strings," Journal of Acoustical Society of America, Vol. 85, pp. 1048-1064, 1989. 
McLellan, G.W., D.J. Moak, L.R. Richterich, J.F. McCormick, and J.C. Barrow, ResonantSonic ${ }^{S M}$ Drilling: History, Progress and Advances in Environmental Restoration Programs, WHC-SA-1949-FP, Rev. 1, Westinghouse Hanford Company, Richland, Washington, 1994.

McLellan, G.W., B.W. Volk, and V.R. King, Results of Testing the Sonic Drilling System at the Hanford Site, September 1991-May 1992, WHC-SD-ENTRP-002, Rev. 0, prepared for the U.S. Department of Energy, Office of Environmental Restoration and Waste Management, 1992.
McLellan, G.W., and B.W. Volk, ResonantSonic Drilling: History, Progress and Advances in Environmental Restoration Programs, WHC-SA-1949-FP, prepared for the U.S. Department of Energy, Office of Environmental Restoration and Waste Management, 1994.

Richterich, L.R., G.W. McLellan, J.D. Fancher, L.O. Amos, S.W. Setzer, and B.G. Tuttle, Phase I ResonantSonic CRADA Report, WHC-SD-EN-TRP007, Rev. O, Westinghouse Hanford Company, Richland, Washington, 1993.

Westmoreland, J., Evaluation of an Air Drilling Cuttings Containment System, Sandia National Laboratories Report No. SAND94-0214, April 1994. 


\subsection{MONITORING OF BIOREMEDIATION \\ PERFORMANCE USING \\ NUCLEIC ACID PROBES}

\section{TASK DESCRIPTION}

One of the ways to measure bioremediation performance is to show that nutrient addition causes the growth and/or increase in metabolic activity of microorganisms capable of degrading the contaminant of concern. The goal of this project was to demonstrate the use of DNA probes for monitoring the enzyme activity and microbial growth of certain microbial populations as nutrients were added during bioremediation activities. The DNA probe technology was compared to the baseline technology for monitoring population changes (the "most probable number" technique) which involves taking soil samples, culturing the microorganisms in those samples, and counting the microorganisms that have grown in the culture.

Using DNA probes to measure population and activity levels involves utilizing a technique called nucleic acid hybridization. See Figure 1.21. This technique involves three steps. First, nucleic acids (either DNA or RNA) are chemically extracted from the microbial community present in an environmental sample. Second, specific nucleic acid sequences corresponding to a gene of interest (e.g., the ability to degrade trichloroethylene [TCE]) are produced and labeled with a highly sensitive chemical signal. Third, the labeled nucleic acid sequence (i.e., the probe) is applied to the nucleic acids extracted from the environmental sample under conditions that allow the probe to find and bind to identical and highly similar sequences in the environmental sample. After the unbound probe is removed, the resulting signal is measured to identify the presence and relative abundance of microorganisms that are degrading (for RNA) or have the potential to degrade (for DNA) the contaminant of interest. An increase in the intensity of the signal or an increase in the frequency of a positive signal is used to monitor the performance of the bioremediation process.

\section{TECHNOLOGY NEEDS}

Rapid methods are needed to determine the performance of bioremediation processes, including natu$\mathrm{ral} /$ intrinsic attenuation. The baseline technology, the most probable number technique, depends on the ability of subsurface microorganisms to grow in culture. However, this technique can dramatically underestimate the amount of active micro-

Figure 1.21. Nucleic Acid Hybridization Technique. 
organisms at a site. Many microorganisms (oftentimes $90-99 \%$ of the total microorganisms) do not grow under laboratory conditions or are not physiologically active under the laboratory-imposed experimental conditions.

Nucleic acid technology is performed on samples frozen immediately after they are obtained. Thus, the target microorganisms are detected at their environmentally relevant concentrations and physiological conditions, regardless of whether they will or will not grow under laboratory conditions. Nucleic acid technology can be utilized at many sites with contaminants for which the pertinent microbial degradative genes have been identified. More $R \& D$ is needed to extract and quantify RNA from environmental materials to reach the full potential of the technology.

\section{ACCOMPLISHMENTS}

- Extraction and analysis of DNA from Savannah River subsurface sediments demonstrated the ability to detect the microbial genes encoding three different TCE-degrading enzymes.

- The frequency of detection was strongly correlated with the nutrient injection strategy. The highest frequencies detected during the nutrient strategies possessed the best overall bioremediation performance, as determined by contaminant inventories in ground water, sediment, and soil gas samples.

- Extraction and analysis of RNA provided direct evidence that microbial cells were in the process of actively producing two different TCE-degrading enzymes under in situ field conditions.

- Comparison of the DNA- and RNA-based methods with the most probable number (MPN) method showed that the MPN method produced orders-of-magnitude lower estimates of the number of TCE-degrading microorganisms.

\section{BENEFITS}

The baseline technology for assessing microbial biodegradative potential, the MPN method, requires growth and/or activity of the microorganisms under laboratory conditions. Because so few subsurface microorganisms grow and/or thrive in the laboratory, the MPN method does not give an accurate estimate of growth or activity potential at a bioremediation site. Rapid methods of directly analyzing biodegradative potential and biodegradative activity are required. Nucleic acid technology directly extracts nucleic acids from environmental samples frozen immediately after they are removed from the subsurface, allowing analysis of the microbial community under in situ conditions. In addition, results can be generated several times faster using nucleic acid technology than for many of the methods used in the baseline technology. Thus, nucleic acid probes are valuable diagnostic tools for assessing bioremediation performance.

Detection and quantification of RNA corresponding to enzymes that can degrade the contaminant of interest is very strong evidence that microorganisms are degrading the contaminant in situ. Baseline technologies can only infer what is occurring in situ using indirect evidence.

\section{COLLABORATION/TECHNOLOGY TRANSFER}

This technology is widely available and is becoming increasingly accepted as a characterization tool. There are currently no formalized collaborative/ cooperative $\mathrm{R} \& \mathrm{D}$ efforts. The sites and the associated companies using this technology for monitoring bioremediation performance are:

- Hanford Site, WA (DOE); PNL, Richland, WA

- Commercial site, OH; PNL, Richland, WA

- Fallon Air Force Base, NV; PNL, Richland, WA

- Tyndall Air Force Base, MS; University of Tennessee, Knoxville, TN 
- Commercial site, TN; Electric Power Research Institute (EPRI)/University of Tennessee, Knoxville, TN

- Commercial site, proprietary; ECOVA/University of Tennessee, Knoxville, TN

For further information, please contact:

Fred Brockman

Principal Investigator

Pacific Northwest Laboratory

P.O. Box 999

Richland, WA 99352

(509) 375-2831

Steven Slate

Technical Program Manager

Pacific Northwest Laboratory

P.O. Box 999

Richland, WA 99352

(509) 375-3903

\section{Kurt Gerdes}

Program Manager

U.S. Department of Energy

Cloverleaf Building

19901 Germantown Road

Germantown, MD 20878-1290

(301) 903-7289
TTP Numbers: RL321102, OR11101

\section{BIBLIOGRAPHY OF KEY PUBLICATIONS}

Bowman, J.P., L. Jiménez, I. Rosario, T.C. Hazen, and G.S. Sayler, "Characterization of the Methanotrophic Bacterial Community Present in a Trichloroethylene-Contaminated Subsurface Ground Water Site," Applied and Environmental Microbiology, 59:2380-2387, 1993.

Brockman, F.J., W. Sun, A. Ogram, W. Payne, and D. Workman, "Baseline Characterization and Remediation-Induced Changes in TCE Degradative Potential Using Enrichment Techniques and DNA Probe Analysis," Bioremediation of Chlorinated and Polycyclic Aromatic Hydrocarbons (eds. R. E. Hinchee, A. Leeson, L. Semprini, S. K. Ong), pp. 397-403, Lewis Publishers, Boca Raton, Florida, 1994.

Brockman, F.J., W. Payne, D.J. Workman, A. Soong, S. Manley, and T.C. Hazen, "Effect of Gaseous Nitrogen and Phosphorus Injection On In Situ Bioremediation of a Trichloroethylene-Contaminated Site, "in press, Journal of Hazardous Materials, 1995.

Gregory, I., J.P. Bowman, L. Jiminez, D. Zhang, J.M. Fleming, S.M. Pfiffner, and G.S. Sayler, "Cometabolic Gene Distribution and Expression in a Trichloroethylene-Contaminated Site Undergoing In Situ Bioremediation," in review, Applied and Environmental Microbiology, 1995. 


\subsection{TCE DEGRADATION DEMONSTRATION \\ MICROBIAL MONITORING \\ TECHNIQUES}

\section{TASK DESCRIPTION}

This task was an element of the VOCs in non-arid soils demonstration at Savannah River. The task involved the use of analytical, microbial, and molecular techniques to monitor changes in the microbial community structure and the degradative capacities of the subsurface microbial populations during the in situ bioremediation efforts of the demonstration. The in situ bioremediation system is designed to deliver methane and nutrients to the subsurface via horizontal wells to stimulate methanotrophs, a specific indigenous microbial population. Methanotrophs have been shown to degrade trichloroethylene, the major contaminant at this site. Early in the project various reactor designs and operating conditions were investigated to provide insight on factors limiting biodegradation at the site.

\section{TECHNOLOGY NEEDS}

During the demonstration, addition of methane and nutrients to the subsurface was designed to increase populations of degradative bacteria. Thus, monitoring of population changes was an important source of feedback information for controlling the operations to ensure success of the remediation. This work showed that the microbial community structure, physiology, ecology, and degradative capacities of the indigenous subsurface microbial populations can be used as a tool to control bioremediation efforts. The technologies can fol- low the overall microbial community as well as specific microbial populations such as methanotrophs that provide insight for operation of ongoing remediation processes.

\section{ACCOMPLISHMENTS}

Microbial monitoring of groundwater and sediments at Savannah River revealed significant changes in microbial community structure which corresponded to changes in operations of the bioremediation demonstration. The numbers of methanotrophs, which have been shown to degrade TCE, increased four orders of magnitude with the addition of methane to the subsurface. Methanotrophic increases were also demonstrated by signature lipid biomarker technology and by DNA probing. With the addition of nutrients, the degradative capacities found in the groundwater increased dramatically. See Figure 1.22 . The potential to mineralize ${ }^{14} \mathrm{C}-\mathrm{TCE}$ in enrichments also increased significantly as nutrients were added. During treatment with methane alone, less than $50 \%$ of the groundwater samples showed TCE mineralization; however, during treatment with methane in combi-

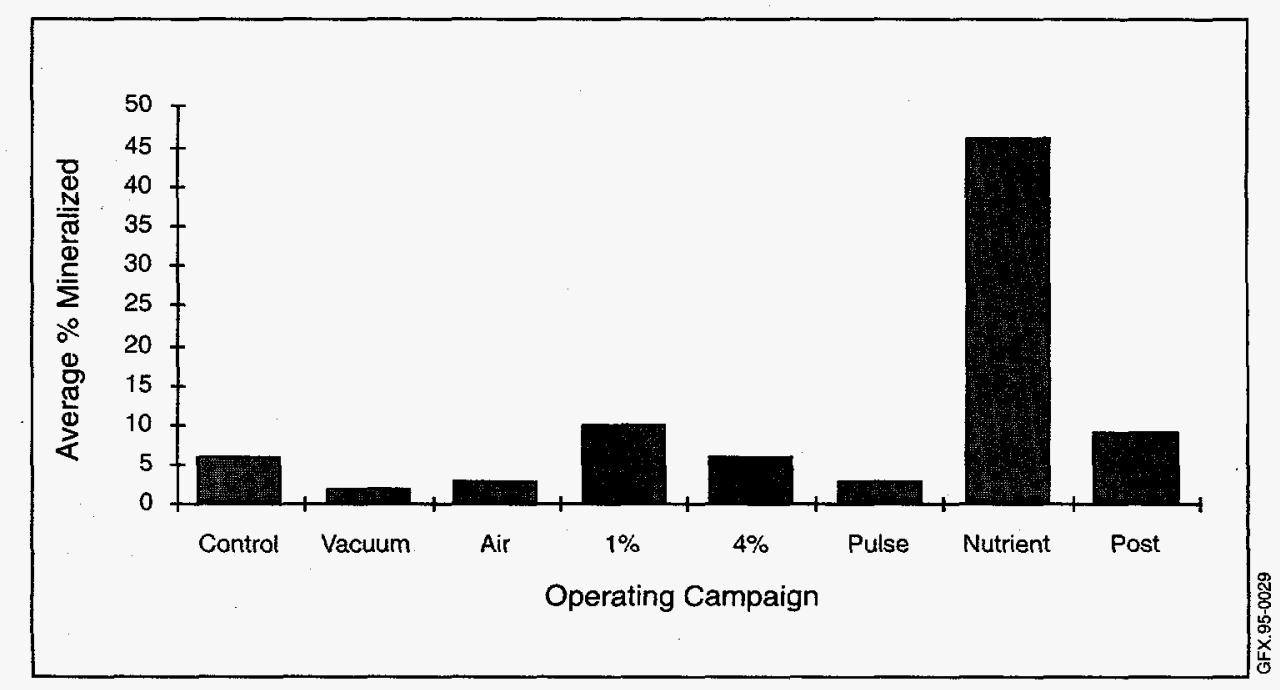

Figure 1.22. Enriched TCE Mineralization 
nation with other nutrients, greater than $90 \%$ of the samples showed TCE mineralization. Nutrient supplementation caused a dramatic and sustained increase in tetrachloroethylene (PCE) degradation as well. Thus, there was a significant increase in the activity of the existing populations in response to the nutrient addition. Bioreactor experiments indicated that in addition to TCE degradation, PCE could be degraded even with bulk phase aerobic conditions.

\section{BENEFITS}

Bioremediation efforts can be designed to stimulate specific microorganisms. The stimulated indigenous microorganisms gain access to vadose zone and aquifer matrices that may be very difficult to treat by air stripping. Specific microbial communities can be monitored efficiently, effectively, and accurately using these analytical, biological, and molecular techniques. Bioremediation is based on biological destruction of the contaminants at the site. Therefore, tisks normally associated with handling, transporting, and treating, or storing contaminated residuals are avoided.

\section{COLLABORATION/TECHNOLOGY}

\section{TRANSFER}

ORNL, the University of Tennessee, the University of Minnesota, and Oak Ridge Institute for Science and Education (ORISE) provided the technologies developed for microbial monitoring during this in situ bioremediation demonstration at the SRS. Technologies involving nutrient supplementation to the subsurface have been transferred to two other cleanup sites. Numerous patents have resulted from the demonstration.

Many undergraduate students, graduate students, technicians, and postdoctoral fellows received some training during the course of this demonstration. Several of these people have moved on to further advanced schooling or positions with national laboratories and national consulting companies. The successful training of these students, technicians, and postdoctoral fellows is a prime example of training the next generation of scientists and technology transfer.

For more information, please contact:
A.V. Palumbo
Principal Investigator
Oak Ridge National Laboratory
P.O. Box 2008
Oak Ridge, TN 37831
(615) 576-8002

\section{John Crockett}

Technical Program Manager

Oak Ridge Institute for Science and Education

P.O. Box 117

Oak Ridge, TN 37831-0117

(615) 576-3253

\section{Kurt Gerdes}

Program Manager

U.S. Department of Energy

Cloverleaf Building

19901 Germantown Road

Germantown, MD 20874-1290

(301) 903-7289

\section{BIBLIOGRAPHY OF KEY PUBLICATIONS}

Bowman, J.P., L. Jiminez, I. Rosario, T.C. Hazen, and G.S. Sayler, "Characterization of the Methanotrophic Bacterial Communities Present in a Trichloroethylene Contaminated Subsurface Groundwater Site," Applied and Environmental Microbiology, 59(8), 1993.

Koh, S., J.P. Bowman, and G.S. Sayler, "Soluble Methane Monooxygenase Production and Trichloroethylene Degradation by a Type I Methanotroph," Methylomonas methanica 68-1, Applied and Environmental Microbiology, 59:960-967, 1993.

Korde, V.M., T.J. Phelps, P.R. Bienkowski, and D.C. White, "Biodegradation of Chlorinated 
Aliphatics and Aromatic Compounds in Total-Recycle Expanded-Bed Reactors," Applied Biochemistry and Bioengineering 39-40:631-641, 1993.

Lackey, L.W., T.J. Phelps, P.R. Bienkowski, and D.C. White, "Biodegradation of Chlorinated Aliphatic Hydrocarbon Mixtures in a Single-Pass Packed-Bed Reactor," Applied Biochemistry and Bioengineering, 39-40:701-713, 1993.

Malachowsky, K.J., T.J. Phelps, A.B. Teboli, D.E. Minnikin, and D.C. White, "Aerobic Mineralization of Trichloroethylene, Vinyl Chloride, and Aromatic Compounds by Rhodococcus Species," Applied and Environmental Microbiology, 60:542-548, 1994.

Niedzielski, J.J., T.J. Phelps, R.M. Schram, S.E. Herbes, and D.C. White, "Biodegradation of Trichloroethylene in Continuous-Recycle Expanded-Bed Bioreactors," Applied and Environmental Microbiology, 56:1702-1709, 1990.

Phelps, T.J., K. Malachowsky, R.M. Schram, and D.C. White, "Aerobic Mineralization of Vinyl Chloride by a Branched-Shaped Gram-Positive Bacterium," Applied and Environmental Microbiology, 57:1252-1254, 1991.
Phelps, T.J., J.J. Niedzielski, K. Malachowsky, R.M. Schram, and D.C. White, "Biodegradation of MixedOrganic Wastes by a Microbial Consortia in Continuous-Recycle Bioreactors," Environmental Science and Technology, 25:1461-1465, 1991.

Phelps, T.J., S.M. Pfiffner, R. Mackowski, D. Ringelberg, D.C. White, S.E. Herbes, and A.V. Palumbo, "Application of Microbial Biomass and Activity Measures to Assess In Situ Bioremediation of Chlorinated Solvents," in R.E. Hinchee et al., (eds.), Bioremediation of Chlorinated and Polycyclic Aromatic Hydrocarbon Compounds, Lewis Publishers, Boca Raton, FL, pp. 404-408, 1994.

Webb, O., T.J. Phelps, P.R. Bienkowski, P.M. DiGrazia, G.D. Reed, D.C. White, and G.S. Sayler, "Development of a Differential Volume Reactor for Measurement of Biodegradation Rates," Applied Biochemistry and Biotechnology. 28:5-19, 1991.

White, D.C., D.B. Ringelberg, J.B. Guckert, and T.J. Phelps, "Biochemical Markers for In Situ Microbial Community Structure," in C.B. Fliermans and T.C. Hazen, (eds.), Proceedings of the First International Symposium on Microbiology of the Deep Subsurface, WSRC Information Services, Aiken, SC, p. 4-45-56, 1991. 


\section{TASK DESCRIPTION}

The objective of this task is to develop a drilling system using liquid nitrogen or liquid nitrogen cooled air as the circulating fluid to overcome the problems of borehole stability while minimizing damage to the environment. See Figure 1.23. The method will modify existing air drilling equipment.

Though commercial cryogenic drilling equipment is not available at this time, ground freezing techniques have been used successfully and economically in other applications such as tunnelling and shaft sinking. The proposed technique will use mainly commercially available drilling equipment. The improvements to the proposed technique are the development of a swivel to introduce the cryogenic fluid and probable modifications to the drill string for low temperature operation.

\section{TECHNOLOGY NEEDS}

Almost all site investigation and remediation projects begin with the drilling of boreholes into the subsoil for sampling and monitoring. Subsequent remediation operations frequently involve the drilling of boreholes for pump-and-treat, vapor extraction, barrier placement and other actions. Major problems currently exist in maintaining borehole stability in loose, sandy soils without introducing additional pollutants and in preventing migration of pollutants along the hole. Since the holes will be used for the monitoring and eventual remediation of polluted regions, any drilling method proposed must not itself alter the terrain penetrated and must be environmentally benign.

Limited success has been obtained at some DOE sites in drilling vertical or directional wells. Particular problems have been encountered at Hanford due

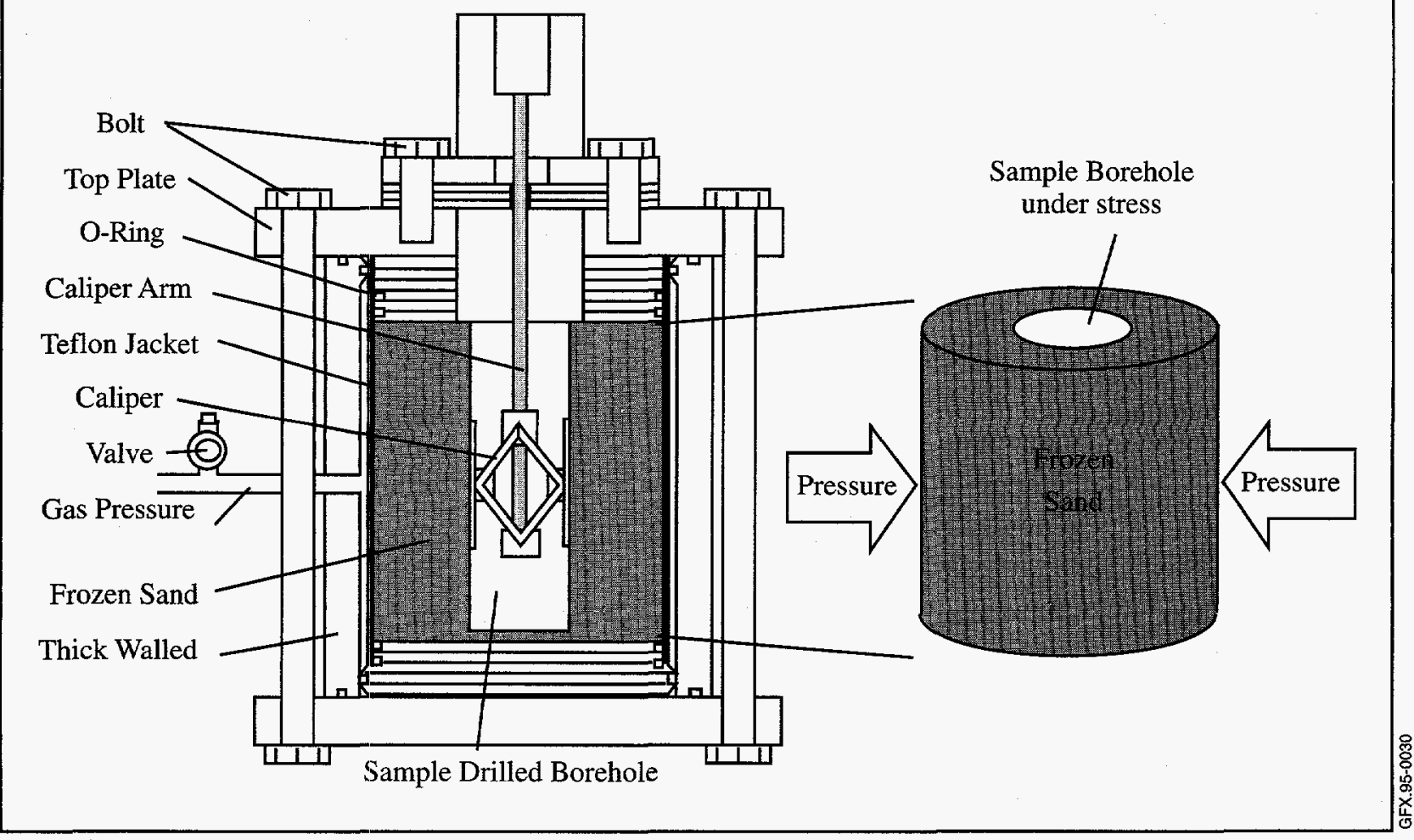

Figure 1.23. Frozen Borehole Test Apparatus for the Cryogenic Drilling Project. 
to the poor degree of subsoil consolidation and the unfortunate combination of sands, gravel and the occasional beds of cobbles or isolated boulders. Another problem occurs in trying to obtain a reasonable "bite" on boulders, which are comparable in size to the borehole. The bit skates or pushes the boulder to the side. As a result, the borehole becomes irregular in size. If the bit does succeed in penetrating the ground, borehole collapse frequently follows as the disturbed ground falls into the hole behind the bit. There is, therefore, a pressing need to develop a means for drilling into loose, sandy or gravelly soils.

Another potential application of the technology is at the INEL site, where problems have been experienced in drilling vertical holes in layers of basalt and unconsolidated sands or volcanic ash. Here the hole traverses the basalt without difficulty. But, as soon as it penetrates an unconsolidated section, the hole collapses causing enlargement of the hole diameter. This results in difficulties in making measurements of the formation properties.

\section{ACCOMPLISHMENTS}

To date, this project has demonstrated in the laboratory that the use of a super-cooled fluid (air or nitrogen) as the flushing medium is capable of freezing the ambient moisture in the ground so as to develop significant strength in the material surrounding the borehole. Drilling with air at ambient temperatures is a mature technology. The air flow rates and pressures to ensure adequate drilling and hole cleaning are well known.

The strength of frozen sand and gravel mixtures has been measured at temperatures as low as $-196^{\circ} \mathrm{C}$. The compressive strength increases with increase in moisture content and with decrease in temperature. Significant strength is developed even for water contents as low as two to three percent. Water levels of $2-3 \%$ are generally surpassed a few feet below the surface even in arid regions such as the DOE Hanford site.
Work in FY93-94 concentrated on preliminary modelling work and the fabrication of prototype field drilling equipment. Model drilling experiments were carried out in a vertical sand or gravelfilled test cell in which the sand may be subjected to radial compression after a hole has been drilled in it using a cryogenic fluid. The test results confirmed a theoretical analysis which links hole failure to the measured unconfined compressive strength of frozen sand. In other experiments, the rates of freezing around the borehole were measured. It was found that the freezing front propagates more rapidly than would be expected from a simple theory based on the conduction of heat through the soil. A substantial cooling effect was obtained from the convection of the chilled flushing fluid through the permeable soil surrounding the borehole.

A side-entry swivel capable of operating at liquid nitrogen temperatures and the swivel support structure to the drilling rig were constructed. Functional tests of this equipment in the laboratory were followed by two field tests at the Lawrence Berkeley Laboratory (LBL), during which the equipment performed well. Some damage to the contractor's drill pipe occurred during the second test, leading to suspension of the test and the decision to obtain a string of drill pipe specifically adapted to lowtemperature drilling.

\section{BENEFITS}

This project will provide a method for drilling and completing horizontal holes in unconsolidated sediments that prevents the movement of pollutants along the borehole and that fixes all formation fluids in place so that they may be sampled more accurately. Further, the method is minimally invasive, introduces no additional pollutants, discourages existing fluids from migrating through the surrounding formations, minimizes surface waste since no drilling fluids are used, and increases worker safety by freezing pollutants in situ. If the hole walls are allowed to warm up, the formation returns to its original condition. 


\section{COLLABORATION/TECHNOLOGY TRANSFER}

Initial field tests were carried out with Westex and UCISCO (Union Carbide). Further tests may include another drilling contractor that has expressed interest in developing cryogenic techniques.

There is substantial interest in the technology at the Savannah River, Los Alamos, Sandia, INEL and Yucca Mountain Repository Sites, all of which have problems in drilling unconsolidated sediments. Discussion with four commercial companies concerning the execution of field tests and eventual commercial exploitation are being conducted. In addition, it has been proposed to carry out demonstrations of the technology at the Alameda Naval Air Station, Alameda, California.

\section{For further information, please contact:}

\section{G.A. Cooper}

Principal Investigator

Lawrence Berkeley Laboratory

1 Cyclotron Road

Berkeley, CA 94720

(510) 642-2996

C.F. Tsang

Technical Program Manager

Lawrence Berkeley Laboratory

1 Cyclotron Road

Berkeley, CA 94720

(510) 486-5782

\section{Kurt Gerdes}

Program Manager

U.S. Department of Energy

Cloverleaf Building

19901 Germantown Road

Germantown, MD 20874-1290

(301) 903-7289
TTP Numbers: SF121105

\section{BIBLIOGRAPHY OF KEY PUBLICATIONS}

Cooper, G.A., "Directional Drilling," Scientific American, May 1994, p. 82-87.

Cooper, G.A. and R. Simon, Field Test of Cryogenic Method for Environmental Well Installation, EnergySources Technology Conference and Exhibition, Houston, TX, 1995.

Simon R. and G.A. Cooper, Use of Cryogenic Fluids for Environmental Drilling in Unconsolidated Formations, ASME Energy-Sources Technology Conference and Exhibition, New Orleans, LA, 1994. 


\section{TASK DESCRIPTION}

Electrical Resistance Tomography (ERT) is used to create a $3-D$ visualization of the subsurface and can be used to monitor processes, such as air stripping, bioremediation, and subsurface heating.

The technology induces an electrical current in the ground and measures the potential distribution that results from the current flowing in the conductive subsurface. Pairs of electrodes are buried with some electrodes acting as current source electrical dipoles and other electrodes acting as potential measuring dipoles. See Figure 1.24.

The resistivity distribution of the area in the vicinity of the borehole is then calculated. The current paths are dependent on the resistivity distribution within the geologic material in the vicinity of the borehole. The ERT inversion process involves solving both the forward and inverse resistivity problems.

The solution to the forward problem uses the finite element method to compute the potential electrical response in the soil due to the current source. The final products of the process are images (tomographs) showing the distribution of resistivity in the plane between the two boreholes used. By interconnecting a network of boreholes, a three dimensional representation of the area being investigated can be developed. By analyzing the resistivity images before, during, and after a remediation process, changes in saturation in the subsurface can be inferred.

\section{TECHNOLOGY NEEDS}

The effects and distribution of many remediation processes are difficult to predict. It is advantageous to be able to monitor this interaction so that the effectiveness of the remediation process can be assessed and process parameters can be modified to improve the effectiveness of the remedial process. There are no alternative methods currently available to image the fluid saturation distributions in two- and three-dimensional cross-sections of the subsurface. Point sampling of fluid saturation can be performed by acquiring core samples. Line measurements of fluid saturation along boreholes can be performed by using well-logging techniques.

ERT is being developed as a tool to allow the 3$D$ visualization of underground remediation processes. This technology, when used either separately or in conjunction with other geophysical, hydrologic, or geochemical methods, is a powerful tool in defining the initial conditions and the interactions between

Figure 1.24. Electrical Resistance Tomography. 
the remedial process and the contaminated environment.

\section{ACCOMPLISHMENTS}

- Successfully monitor the effectiveness of air permeation in the air injection and vacuum extraction tests as well as two in situ demonstrations at the SRS.

- Mapped changes in fluid saturation as the subsurface conditions were modified by the remedial process during air stripping at the SRS. Also used to evaluate the effectiveness of the Radio Frequency Heating and Six-Phase Heating tests.

- Successfully monitored dynamic underground stripping of non-aqueous phase liquids (NAPLs) at LLNL.

- Excellent results from leaking tank simulation tests were also obtained using this technique at Hanford.

\section{BENEFITS}

- Better and more economical than alternative technology of drilling more boreholes to achieve same level of subsurface coverage analysis. It reduces drilling costs by at least $50 \%$, accelerates the drilling phase, and does not require crosshole interpolation of data.

- A cross-cutting technology that can be used in a wide range of applications: tank leak detection, barrier emplacement, barrier monitoring, air sparging, steam injection, and soil heating.

- Can reduce costs of full-scale remedial treatment systems by being employed during pilot tests to determine the spatial extent of treatment processes, supporting decisions of optimal placement of treatment wells.

\section{COLLABORATION/TECHNOLOGY}

\section{TRANSFER}

Several companies are currently negotiating with LLNL to obtain licenses to use the technology and to cooperate in further development. British Petroleum has received a non-exclusive license to use the algorithm for the data inversion process. RIMTech, Inc. has obtained the technology needed to sell service of 2-D crosshole ERT.

For further information, please contact:

\author{
Abelardo L. Ramirez \\ Principal Investigator \\ Lawrence Livermore National Laboratory \\ 7000 East Avenue \\ P.O. Box $808, \mathrm{~L}-1$ \\ Livermore, CA 94550 \\ (510) 422-6909
}

\section{Jesse Yow}

Technical Program Manager

Lawrence Livermore National Laboratory

7000 East Avenue

P.O. Box $808, \mathrm{~L}-1$

Livermore, CA 94550

(510) 422-3521

Kurt Gerdes

Program Manager

U.S. Department of Energy

Cloverleaf Building

19901 Germantown Road

Germantown, MD 20878-1290

(301) 903-7289

TTP Number: SF221102

\section{BIBLIOGRAPHY OF KEY PUBLICATIONS}

Daily, W.D. and A.L. Ramirez, Electrical Resistance Tomography During In Situ TCE Remediation at the Savannah River Site, Lawrence Livermore National Laboratory, UCRL JC-112326, Livermore, CA, 
submitted to the Journal of Applied Geophysics, 1993.

Ramirez, A.L., and W.D. Daily, Heating of Contaminated Soils Using Electrical resistance Tomography, Lawrence Livermore National Laboratory, UCRL JC-115373, Livermore, CA, 1993.

Ramirez, A.L., Daily, W.D., Owen, E., and D. LaBrecque, High Frequency Electromagnetic and Electrical Resistance Tomography of the Savannah River Integrated Demonstration Project, Lawrence Livermore National Laboratory, UCRL JC-107780, Livermore, CA, 1991.

Ramirez, A., W. Daily, D. LaBrecque, E. Owen and D. Chestnut, "Monitoring an Underground Steam Injection Process Using Electrical Resistance Tomography," Water Resources Research, vol. 29, no. 1, pp. 73-88, 1993. 


\section{TASK DESCRIPTION}

The purpose of this task is to provide the SRS Environmental Monitoring Section with a state-ofthe-art, real-time monitoring system and compatible sensors. This system will be the platform on which further sensor development can be based. The system will provide radio telemetry and computer programs to collect, transmit, receive, and store data. This system will also give warnings when monitored parameters exceed pre-established limits.

\section{TECHNOLOGY NEEDS}

With the increase in environmental monitoring tasks in recent years, the need to provide costeffective, accurate, and timely monitoring results has increased proportionately. The ability to provide real-time field environmental measurement will not only provide more timely and more costeffective results, but will also reduce the waste generated in standard laboratory analysis.

\section{ACCOMPLISHMENTS}

Due to project approval delays during FY94, specific accomplishments have yet to be realized.

\section{BENEFITS}

In situ real-time monitoring will result in lower costs as measurements are made in the field. No collection personnel are necessary to collect field samples and transport these samples to a laboratory for analysis. Information is thus obtained faster. The system will also be able to alert operators when monitored parameters exceed set limits, which will permit this equipment to monitor remedial processes.

\section{COLLABORATION/TECHNOLOGY TRANSFER}

This project is being carried out in collaboration with the South Carolina University Research and Education Foundation (SCUREF).

\section{For further information, please contact:}

J. W. Littrell

Principal Investigator

Westinghouse Savannah River Company

P.O. Box 616

Aiken, SC 29802

(803)725-4211

John L. Steele

Technical Program Manager

Westinghouse Savannah River Company

P.O. Box 616

Aiken, SC 29802

(803) $725-1830$

\section{Kurt Gerdes}

Program Manager

U.S. Department of Energy

Cloverleaf Building

19901 Germantown Road

Germantown, MD 20874-1290

(301) 903-7289

TTP Number: SR141021

BIBLIOGRAPHY OF KEY PUBLICATIONS

None at this time. 


\section{TASK DESCRIPTION}

The objective of this task is to develop a remotely operated tritium analysis system which measures field data from a central facility using radio transponders and permanently installed tritium analysis units. See Figure 1.27. The first phase of this project is the development and testing of a prototype analysis system. Upon completion of the analysis equipment, the second phase will be initiated. This phase will include the development of remote operational capability. The remote system will allow a laboratory based operator to poll field units located at distant wells or sample sites. This remotely operated system will be field-tested at SRS. The final objective of the project is to train SRS personnel in the operation and maintenance of the tritium analysis system.

\section{TECHNOLOGY NEEDS}

Tritium in groundwater is one of the most common radiological contaminations at DOE sites across the nation. As part of the effort to remediate these sites, DOE must analyze the groundwater to determine the extent of the contamination. Development of a tritium analysis tool would be beneficial in this analysis not only at the SRS, but at other sites throughout the DOE Complex.

\section{ACCOMPLISHMENTS}

Due to project approval delays during FY94, specific accomplishments have yet to be realized.

\section{BENEFITS}

Development of the tritium analysis system will offer a substantial reduction in the time now required for tritium analysis of field samples and will provide a better means of monitoring known plumes and hot spots.

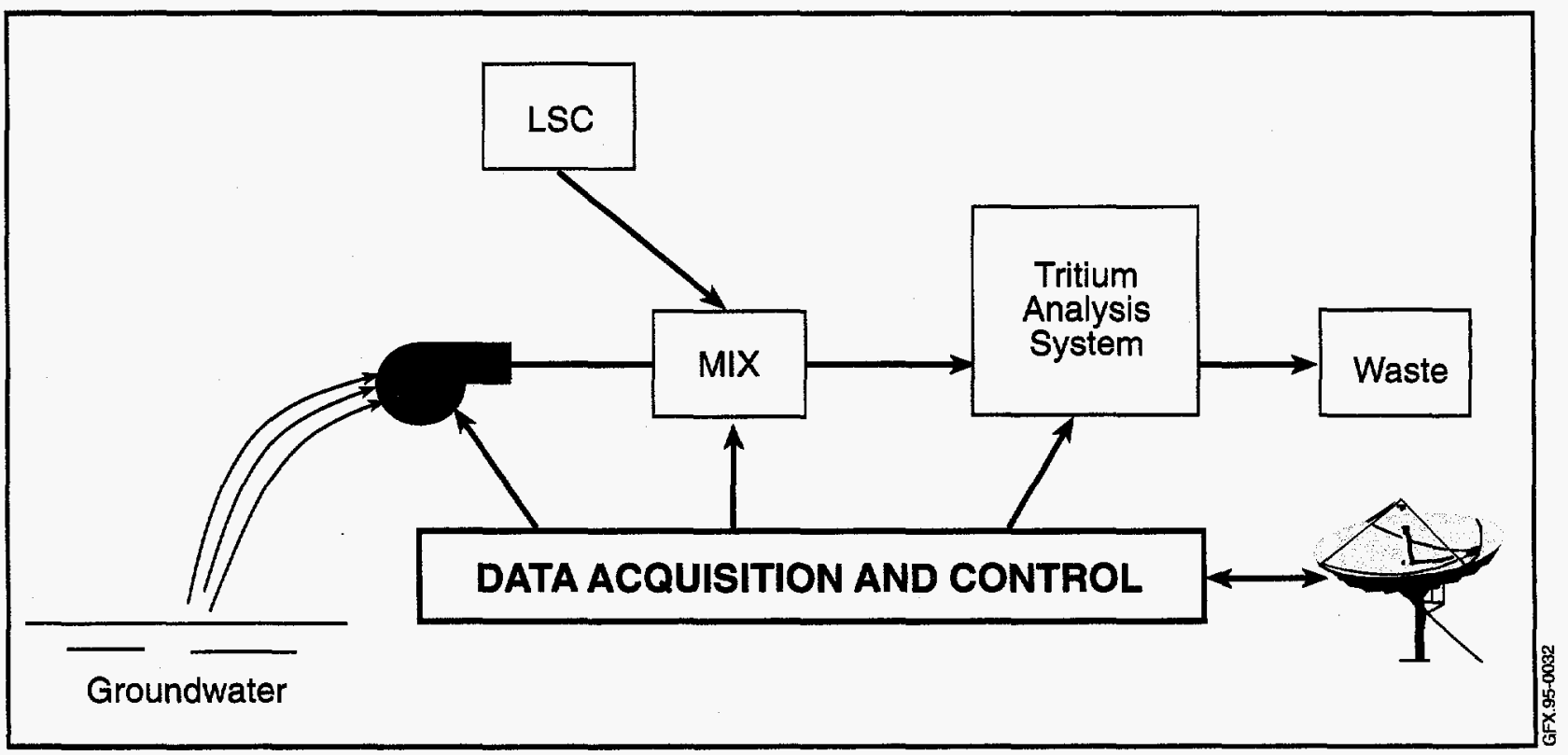

Figure 1.26. SRS Tritium Analysis System. 


\section{COLLABORATION/TECHNOLOGY} TRANSFER

This project is being carried out in collaboration with the University of Georgia-Center for Applied Isotope Studies (Athens, GA).
TTP Number: SR141024

\section{BIBLIOGRAPHY OF KEY PUBLICATIONS}

None at this time.

For further information, please contact:

Ken J. Hofstetter

Principal Investigator

Westinghouse Savannah River Company

P.O. Box 616

Aiken, SC 29802

(803) $725-4135$

John L. Steele

Technical Program Manager

Westinghouse Savannah River Company

P.O. Box 616

Aiken, SC 29802

(803) $725-1830$

Kurt Gerdes

Program Manager

U.S. Department of Energy

Cloverleaf Building

19901 Germantown Road

Germantown, MD 20874-1290

(301) 903-7289 


\section{TASK DESCRIPTION}

The objective of this task is to develop fast, economical methods for using information from aquatic and terrestrial animals and plants to indicate the extent of contamination and environmental risks at Comprehensive Environmental Response, Compensation, and Liability Act (CERCLA) sites. See Figure 1.28 .

There are four subtasks within this task: (1) development of biotic indices based on the attributes of fish and invertebrate communities to measure the degradation of streams near waste sites, (2) development of a bioassay method using tree leaves to map the extent of groundwater tritium contamination near waste sites, (3) development of procedures that use the germination success of native plants to assay mineral and organic toxicants found in wastes sites and, (4) development of assay methods that use changes in the survival, body weight, and behavior of earthworms to assay toxicants in waste sites.

\section{TECHNOLOGY NEEDS}

Environmental regulations require an assessment of the ecological risk associated with CERCLA waste sites. Currently exiting methods often employ modeling techniques that are based on biological surveys with poorly defined objectives and limited ability to

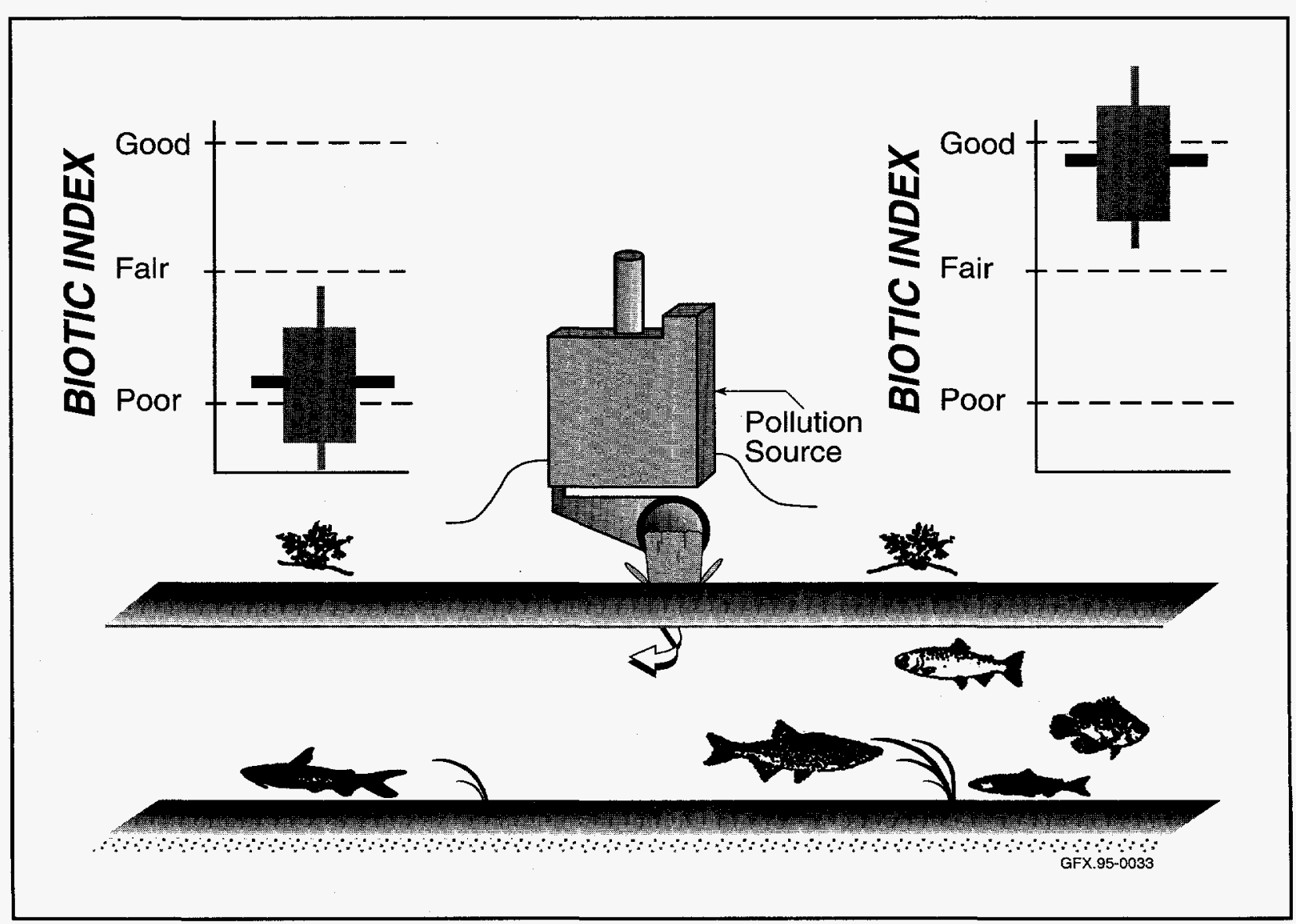

Figure 1.27. The Use of Biotic Indices to Determine the Health of a Stream at Two Points. 
answer basic questions concerning the ecological effects of waste sites. The development of the proposed rapid bioassessment methods could provide easily applied and economical tools useful in identifying, measuring, and determining the extent of waste site impacts. Some of these methods could also be useful for other tasks such as the National Pollutant Discharge Elimination System's outfall monitoring and watershed management.

\section{ACCOMPLISHMENTS}

The bioassay methods using tree leaves have been completed. The other three subtasks are in progress and will be completed by early FY95. These tasks will result in the development and refinement of several techniques that can be used to rapidly and economically assess the ecological impacts of waste sites.

\section{BENEFITS}

The use of indigenous biological population as an indicator of environmental risks will provide a less expensive and more rapid method of assessing the ecological effects of environmental toxicants. This methodology is expected to provide information within days or weeks as opposed to the current toxicological evaluations which can take several months.

\section{COLLABORATION/TECHNOLOGY} TRANSFER

The University of South Carolina

Clemson University

Shealy Environmental Corporation
For further information, please contact:

\section{Michael Paller}

Principal Investigator

Westinghouse Savannah River Company

P.O. Box 616

Aiken, SC 29802

(803) $725-2713$

John L. Steele

Technical Program Manager

Westinghouse Savannah River Company

P.O. Box 616

Aiken, SC 29802

(803) $725-1830$

Kurt Gerdes

Program Manager

U.S. Department of Energy

Cloverleaf Building

19901 Germantown Road

Germantown, MD 20874-1290

(301) 903-7289

TTP Number: SR141018

BIBLIOGRAPHY OF KEY PUBLICATIONS

None at this time. 


\section{THE HEURISTIC OPTIMIZED PROCESSING \\ SYSTEM: A TECHNICAL INFORMATION SYSTEM FOR CERCLA WASTE SITES}

\section{TASK DESCRIPTION}

The Heuristic Optimized Processing System (HOPS) is an information system operating on a desktop-sized computer which can perform on a level that exceeds that of a mainframe computer. See Figure 1.29. This software development effort will offer CERCLA waste site end-users a single application that will:

- rapidly assemble remediation and restoration information from a wide variety of platforms and software,

- access that information without complicated and cryptic menus using a newly designed Spatial Browser Tool,
- offer point, line and polygon tools for spatial analyses; and

- provide a Statistical Toolbox for frequently used routines.

\section{TECHNOLOGY NEEDS}

During the next thirty years the Department of Energy will spend hundreds of millions of dollars complying with CERCLA, the law governing the remediation of hazardous waste sites. A significant portion of these expenditures is the substantial costs of the technical information systems that support remediation efforts and the complete CERCLA process. Characterization, monitoring, and infor-

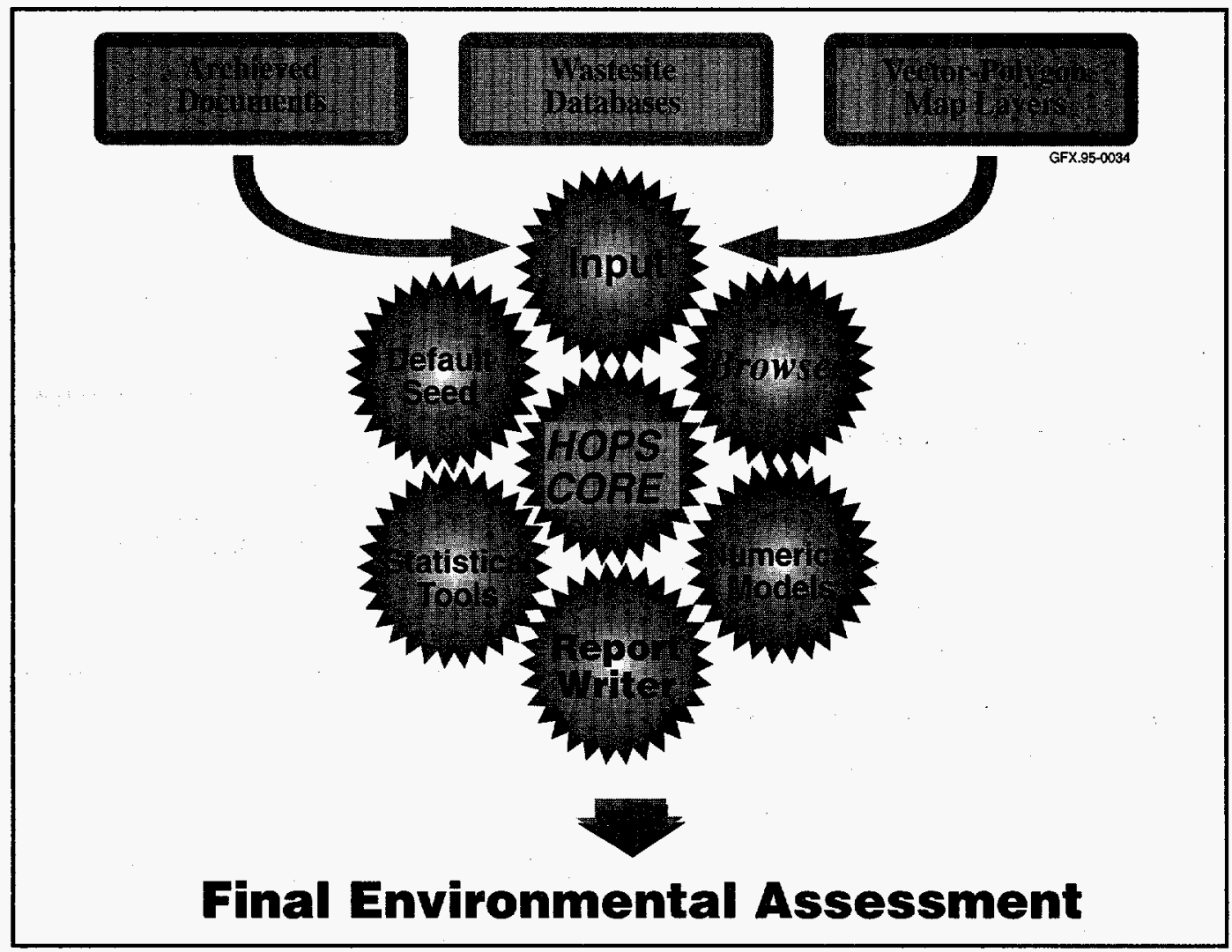

Figure 1.28. The Heuristic Optimized Processing System (HOPS). 
mation integration during the cleanup process require significant real-time interaction among a variety of environmental information originating from an equal variety of software and hardware sources. This interaction typically is expensive and difficult. The objective of this initiative is to reduce those costs.

\section{ACCOMPLISHMENTS}

Completed tasks include: (1) the overall application design for client and server, (2) Sequential Query Language file translators, (3) instant access to a Statistical Toolbox for data analyses, (4) a Spatial Browser Tool for information queries within a geographical information system (GIS) construct, and (5) the direct integration of the HOPS query window (Seed Tool) into the application. End-user interviews are continuing. Text library construction, GIS translators, and glossaries will be completed before full beta version testing.

\section{BENEFITS}

The HOPS information system would represent a unique integration of a variety of data types. This system will allow the rapid integration of spatial and tabular data to provide a more cost-effective and rapid evaluation of waste sites.

\section{COLLABORATION/TECHNOLOGY}

\section{TRANSFER}

- This effort is jointly performed with HOPS International Inc. which has established a new local office in New Ellenton, SC.

- The University of South Carolina-Aiken will assist with data collection.

- C programming language libraries from the Statistical Toolbox have been transferred to the Corning Glass Co. (Fiber Optics Division), a commercial HOPS customer.
- The Spatial Browser Tool will be sent to the ADVO Corporation and Merritz Inc. for GIS applications in marketing analysis.

- All HOPS customers (e.g. Liberty Mutual, Blockbuster Video, Johnson \& Johnson (Lifescan), etc.) will benefit from the Seed Tool modification.

For further information, please contact:

\section{James A. Bowers}

Principal Investigator

Westinghouse Savannah River Company

P.O. Box 616

Aiken, SC 29802

(803)725-5213

John L. Steele

Technical Program Manager

Westinghouse Savannah River Company

P.O. Box 616

Aiken, SC 29802

(803)725-1830

Kurt Gerdes

Program Manager

U.S. Department of Energy

Cloverleaf Building

19901 Germantown Road

Germantown, MD 20874-1290

(301) 903-7289

TTP Number: SR141017

BIBLIOGRAPHY OF KEY PUblications

None at this time. 


\section{TASK DESCRIPTION}

Disposal of chemicals that have low water solubility and a density greater than water results in the formation of distinct areas of pure residual solvent contamination in soil and groundwater. These solvents, known as dense non-aqueous phase liquids (DNAPLs), move downward through the soil into groundwater. As the DNAPLs flow through the soil, a small amount is left in fine pores. DNAPL reaching the water table continues to move downward until it accumulates on an aquitard. The DNAPL then moves and disperses under the influence of gravity and dissolves into the flowing groundwater. See Figure 1.30.

Characterization and remediation of DNAPLs is a common national and international problem. The purposes of this program are: (1) to provide a focus to expedite development and application of technologies for DNAPL characterization and remediation, (2) to provide a well characterized site to perform the work, and (3) to facilitate DNAPL remediation at the Savannah River Site (SRS). Additionally, the program relies on identification and utilization of innovative technologies developed by industry and universities. The solutions provided and data obtained to validate new technologies will directly benefit other DOE sites and industrial sites throughout the country.

The characterization work will emphasize safety by using non-intrusive or minimally intrusive methods. The specific technologies to be tested include: physical and chemical measurements in existing monitoring wells, geophysical logs in existing wells (e.g. caliper $\operatorname{logs}$ ), surface geophysics and cross hole geophysics (computerized tomography), cone penetrometer studies, differential tracer tests, and an injection/extraction test using existing monitoring wells.

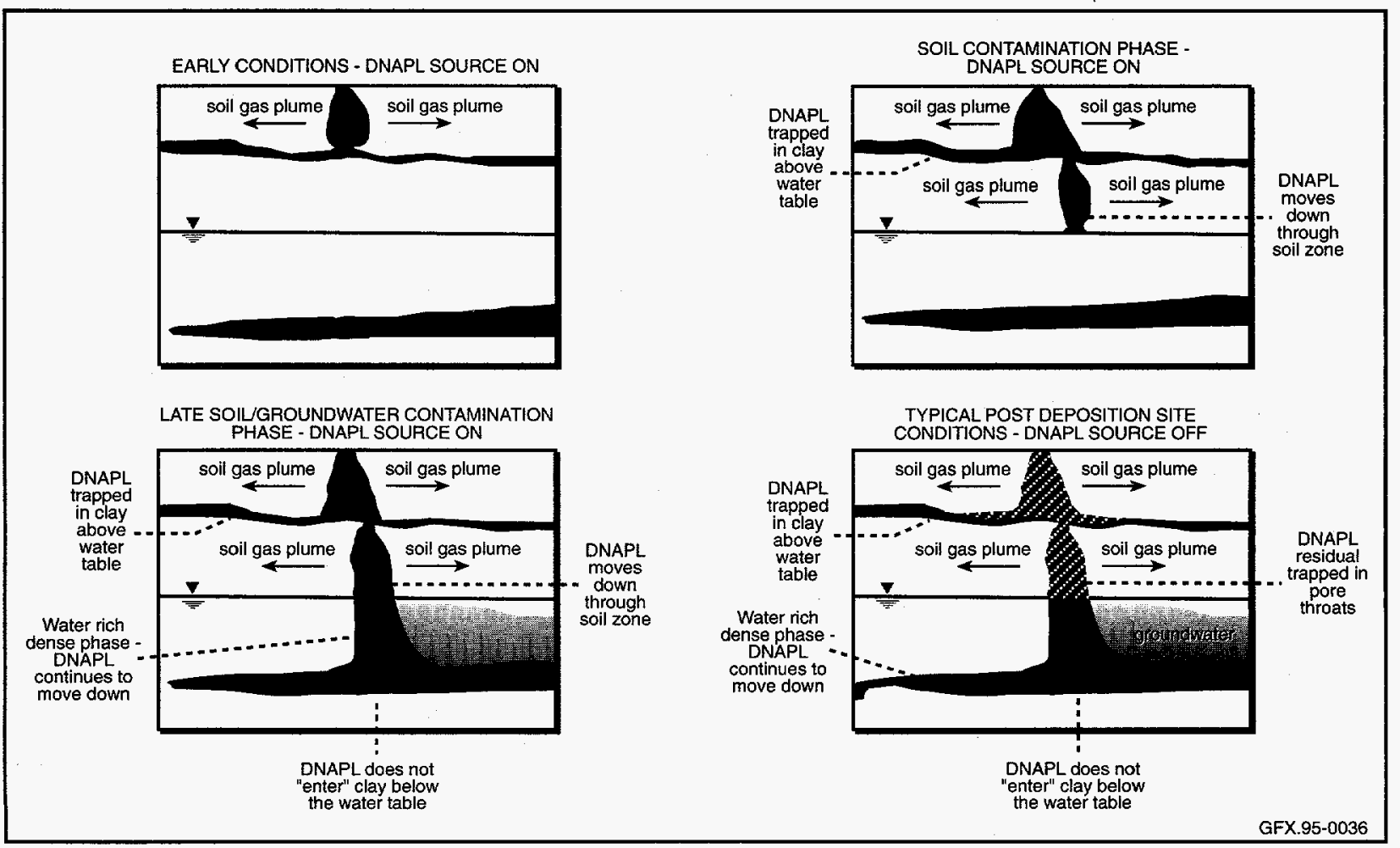

Figure 1.29. Dense Non-Aqueous Phase Liquids. 
The principal objective of the injection-extraction test is to evaluate the presence of DNAPL in the vicinity of existing monitoring wells. The test utilizes alcohol and surfactant solutions to solubilize DNAPL near the well. The solubilized DNAPL is then removed. Differences between the time-concentration response of the well effluent between water injection-extraction and the solution injection-extraction will provide clear confirmation of the presence of DNAPL at the subject location without having to drill additional holes. Additionally, the tests will provide important information to support future alcohol or surfactant remediation.

Innovative remediation methods that target the specific properties of DNAPLs and their discrete underground location enhance recovery of the pure source material - rather than waiting for billions of gallons of water to dissolve the DNAPL to allow collection by conventional pump and treat methods. Above the water table, enhanced DNAPL recovery can be effected by heating or fracturing which are being tested and demonstrated by DOE, $\mathrm{EPA}$, and DoD in other programs. Several alternative remediation techniques are being evaluated for use at SRS. One alternative soil clean up method, proposed by industry, uses sound waves to enhance the removal of DNAPL above the water table. Alcohols or surfactants are being evaluated below the water table to solubilize the DNAPL and expedite collection by recovery wells. Another remediation technique, the hydrophobic lance, is being developed. This device, installed by direct insertion into the ground, use hydrophobic surfaces to physically collect DNAPL without adding solubilizing agents.

\section{TECHNOLOGY NEEDS}

Existing characterization and remediation technologies are inefficient or ineffective in identifying and cleaning up DNAPLs. Technologies that target DNAPLs (i.e., respond to DNAPLs unique properties and spatial distribution) are needed to optimize remediation of DNAPL contaminated sites throughout the country.

\section{ACCOMPLISHMENTS}

The following project milestones have been completed: (1) baseline geophysics in the field; (2) high resolution video survey; (3) test plan for differential tracer test; (4) development of strategies and plans for underground injection control permits, Toxic Substance Control Act permits, Resource Recovery and Conservation Act (RCRA) permits, and other regulatory requirements for the program; (5)cone penetrometer status report and test plan; and (6) the final scope of work.

A request for proposals (RFP) was sent out to seven universities in April 1994. These universities were selected based on pre-screening to determine which universities possessed the requisite capabilities and equipment to perform the research. The sole response to the RFP was received from Princeton University.

\section{BENEFITS}

DNAPLs are difficult to detect in the environment and to remediate. To remediate DNAPL contamination presently requires the pumping and treating of large quantities of DNAPL-contaminated water to remove minute quantities of DNAPL held in aqueous solution. Successful completion of the tasks under this project will make technologies available to detect the presence of DNAPLs and will provide methods of direct remediation of DNAPL contamination.

\section{COLLABORATION/TECHNOLOGY TRANSFER}

This project includes active participation from the following organizations: Clemson University, University of South Carolina, New Pig Corporation, U.S. Geological Survey, U.S. Army Corps of Engineers, RUST Geotech, Virginia Polytechnic University, R. J. Electronics, Brainard Kilman, Westinghouse Savannah River Company, Princeton University, City University of New York, The George Washington University, EPA, and DoD. 
For further information, please contact:

Brian B. Looney

None at this time.

Principal Investigator

Westinghouse Savannah River Company

P.O. Box 616

Aiken, SC 29802

(803) 725-3692

John L. Steele

Technical Program Manager

Westinghouse Savannah River Company

P.O. Box 616

Aiken, SC 29802

(803) $725-1830$

\section{Kurt Gerdes}

Program Manager

U.S. Department of Energy

Cloverleaf Building

19901 Germantown Road

Germantown, MD 20874-1290

(301) 903-7289 


\subsection{0 \\ MONITORING OF MICROBIAL \\ POPULATION CHANGES}

\section{TASK DESCRIPTION}

This task involves the use of analytical lipid techniques, and microbial and molecular techniques (e.g., DNA probes) to monitor changes in the microbial community structure and the degradative capacities of subsurface microbial populations during in situ bioremediation efforts. The in situ bioremediation involves the recirculation of groundwater and the addition of nutrients to stimulate specific indigenous microbial populations that have been shown to degrade carbon tetrachloride, the major contaminant at this site. The task will explore a common extraction procedure for the molecular and lipid techniques. See Figure 1.31.

\section{TECHNOLOGY NEEDS}

Modification of subsurface environments for bioremediation is designed to increase populations of degradative bacteria. Thus, monitoring these changes gives important feedback for controlling the modifications to ensure remediation success. This work will relate the microbial community structure, physiology, ecology and degradative capacities of the indigenous subsurface microbial populations to the bioremediation efforts. The lipid and DNA technologies used will be able to follow the overall microbial community as well as specific microbial populations such as methanogens, denitrifiers, and sulfate reducers that may provide insight for operation of ongoing remediation processes.

\section{ACCOMPLISHMENTS}

Scoping samples were collected and degradative microorganisms from the site were isolated. In past efforts, microbial monitoring of groundwater and sediments at Savannah River revealed significant changes in microbial community structure which corresponded to changes in operations of the bioremediation demonstration.

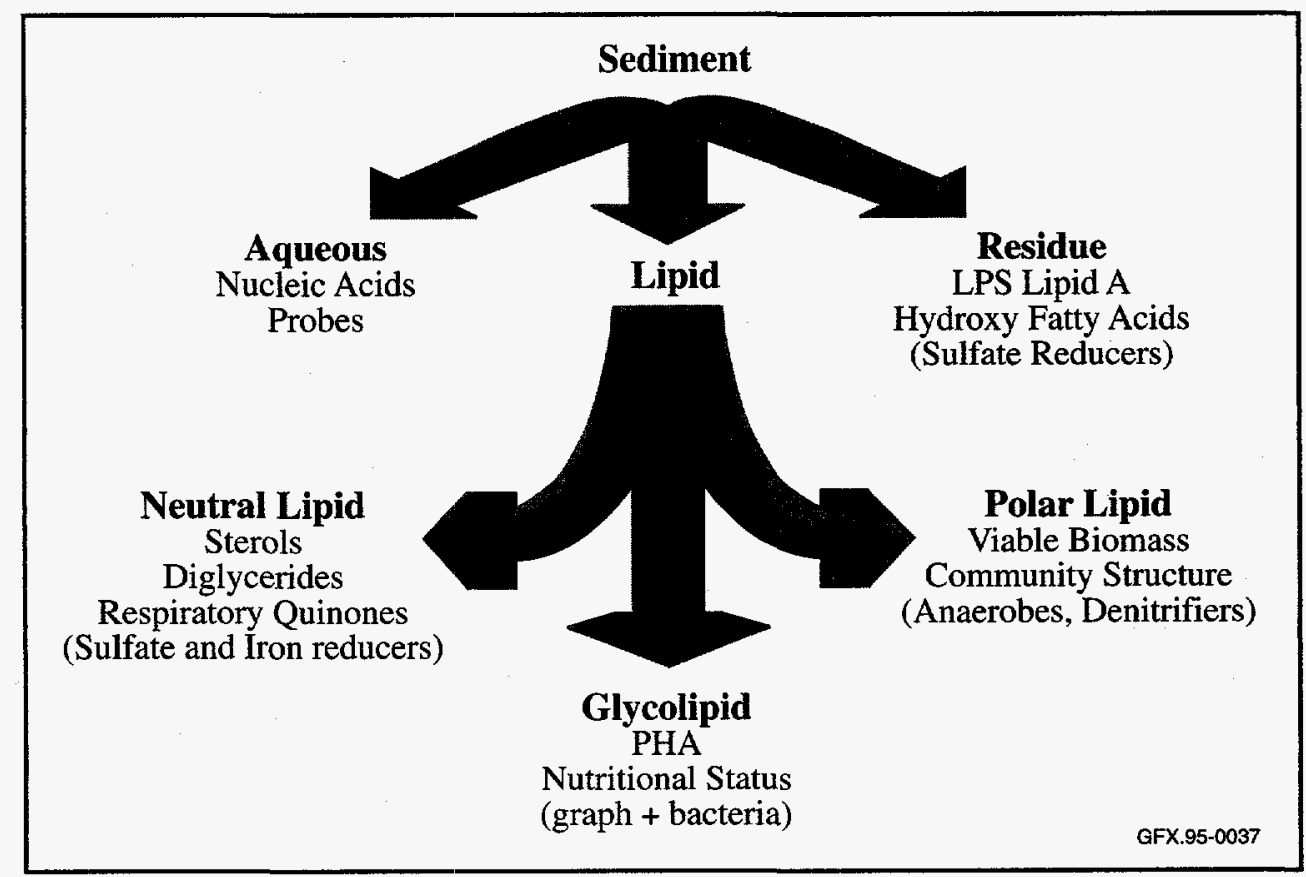

Figure 1.30. Monitoring Bioremediation Activities Using Lipid Techniques.
The numbers of methanotrophs, which have been shown to degrade TCE, increased 10,000 -fold with the addition of methane to the subsurface. Methanotrophic increases were also demonstrated by signature lipid biomarker technology and by DNA probing. With the addition of nutrients, the population responses were less dramatic; however, 
the degradative capacities found in the groundwater increased dramatically.

The porential to mineralize ${ }^{14} \mathrm{C}$-TCE in enrichments increased from less than fifty percent of the groundwater samples during methane treatments to greater than ninety percent during methane with nutrients treatment. Nutrient supplement also caused a dramatic and sustained increase in PCE degradation.

\section{BENEFITS}

Specific microbial communities can be monitored efficiently, effectively, and accurately using these analytical, biological, and molecular techniques. The monitoring technologies evaluate the progress of the bioremediation so that modifications can be made to increase the effectiveness of the activities.

\section{COLLABORATION/TECHNOLOGY TRANSFER}

In previous efforts on microbial monitoring, ORNL, ORISE (Dr. S. Pfiffner) and the University of Tennessee (Dr. D.C. White and Dr. G. Sayler) have provided technologies developed during the In Situ Bioremediation of Trichloroethylene Demonstration at the SRS for use in microbial characterization in the DOE Subsurface Science Program, this demonstration, Remediation Technologies Development Forum Chlorinated Solvents working group activities, and joint activities with the National Center for Manufacturing Sciences. Additional probes developed as part of the activities in this demonstration will be transferred to other DOE and industrial activities as appropriate. Additional indicators of microbial community structure and specific groups will be identified as part of this work and will also be transferred to other DOE monitoring efforts.

By participating in this program, undergraduate, graduate, and postdoctorate students as well as technicians have been trained and have advanced in their scientific careers. This training is a prime example of the commitment of the program to enhance technology transfer.
For further information, please contact:

\author{
Anthony Palumbo \\ Principal Investigator \\ Oak Ridge National Laboratory \\ P.O. Box 2008 \\ Oak Ridge, TN 37831 \\ (615) 576-8002
}

\author{
Anthony Malinauskas \\ Technical Program Manager \\ Oak Ridge National Laboratory \\ P.O. Box 2008 \\ Oak Ridge, TN 37831 \\ (615) 576-1092
}

\section{Rashalee Levine}

Program Manager

U.S. Department of Energy

Cloverleaf Building

19901 Germantown Road

Germantown, MD 20874-1290

(301) 903-7920

\section{TTP Number: OR141006}

\section{BIBLIOGRAPHY OF KEY PUBLICATIONS}

Bowman, J.P., L. Jiminez, I. Rosario, T.C. Hazen, and G.S. Sayler, "Characterization of the Methanotrophic Bacterial Communities Present in a Trichloroethylene Contaminated Subsurface Groundwater Site," Applied and Environmental Microbiology, 59(8), 1993.

Phelps, T.J., S.M. Pfiffner, R. Mackowski, D. Ringleberg, D.C. White, S.E. Herbes, and A.V. Palumbo, "Application of Microbial Biomass and Activity Measures to Assess In Situ Bioremediation of Chlorinated Solvents," In R.E. Hinchee, A. Lesson, L. Semprini, and S.K. Ong. [eds.] Bioremediation of Chlorinated and Polycyclic Aromatic Hydrocarbon Compounds, Lewis Publishers, Boca Raton, FL , pp.404-408, 1994. 
Phelps, T.J., J. Niedzielski, and D.C. White, "Biodegradation of Mixed Organic Wastes by Microbial Consortia Enriched From Subsurface Sediments." In: C.B. Fliermans and T.C. Hazen (eds.), Proceedings of the First International Symposium on Microbiology of the Deep Subsurface, WSRC Information Services, Aiken, SC, p. 7-71-80, 1991.

White, D.C., D.B. Ringelberg, J.B. Guckert, and T.J. Phelps, "Biochemical Markers for In Situ Microbial Community Structure," In: C.B. Fliermans and T.C. Hazen, (eds.), Proceedings of the First International Symposium on Microbiology of the Deep Subsurface, WSRC Information Services, Aiken, SC, p. 4-45-56, 1991. 

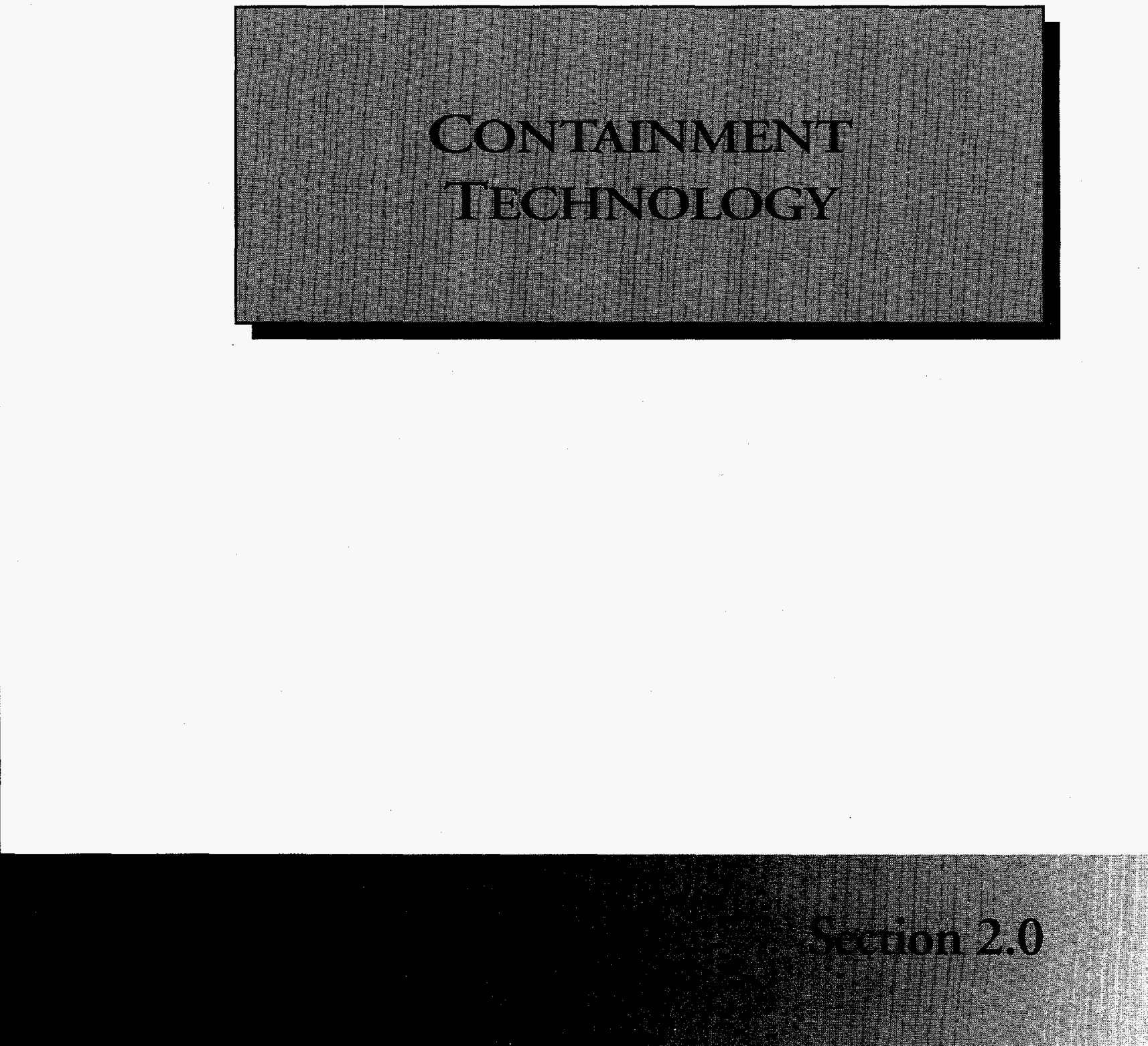


\section{1 \\ DEVELOPMENT AND TESTING OF A WATER-PERMEABLE REACTIVE BARRIER}

\section{TASK DESCRIPTION}

This task continues to demonstrate, test, and evaluate water-permeable chemically-reactive barriers in integrated environmental containment systems which was started in mid-FY92. See Figure 2.1. Potential applications of permeable-reactive barrier technology, emplacement techniques, and regulatory acceptance have been updated and compiled. Field and laboratory test plans, which focus on chemical interaction characterization, are being completed.

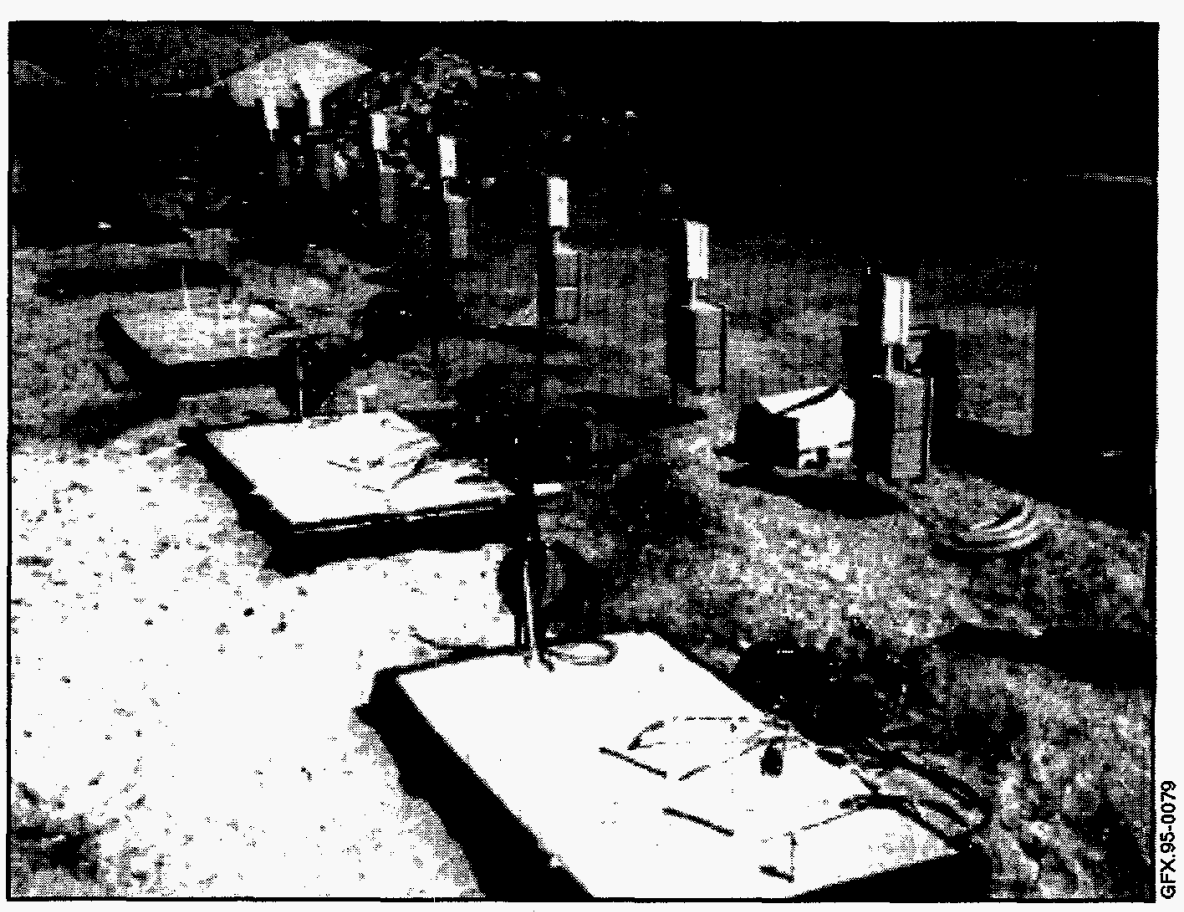

Figure 2.1. Demonstration, Testing, and Evaluation of WaterPermeable, Chemically-Reactive Barrier.

The basis for selection/elimination of reactive barrier approaches to develop pilot-scale permits at selected Los Alamos sites depends on the field-scale system test results and laboratory comparative survey results. Combination strategies will also be evaluated to define the pilot-scale tests for permitting. The range of potential barrier applications and the viability of low gel loading for barrier stability will limit the evaluation of the physical condition. The stability of gel materials is subjected to saturated, variably saturated/unsaturated and surface conditions over a two year period.

This task will evaluate several components in an integrated field-scale system. These components include: (1) multi-component, gel-enhanced barrier materials, (2) chemical tracer characterization approaches, (3) reservoir management technology, and (4) remote monitoring of the hydrologic systems. The evaluation consists of technical performance, chemical/process engineering, cost-effectiveness, regulatory action, compliance, and acceptance. Operational safety/risk, quality assurance, and technology transfer are also incorporated.

\section{TECHNOLOGY NEEDS}

Numerous materials have been proposed as subsurface chemically reactive barriers for contaminant transport, ranging from peat moss to synthetic silica titanates. While many of these proposals appear promising in laboratory studies, real world conditions pose many complications that may decrease a barrier's effectiveness. In a field application, the barrier will be subjected to meteorological cycles, water and soil chemical incompatibilities, biological disturbances, and imperfections in emplacement. 


\section{ACCOMPLISHMENTS}

- Three permeable-reactive barrier test cells were constructed for baseline testing of zeolite, peat, and clay sorbents.

- Two oil industry materials (colloidal silica gel and a polyacrylamide) are being evaluated for long-term stability in a field test cell.

\section{BENEFITS}

Semi-permeable barriers that sorb or detoxify mobile hazardous substances have advantages over conventional barrier techniques. Conventional techniques use impermeable substances to block the pores of a water-bearing zone to prevent movement of contaminants. Although contaminant movement away from the site may be prevented, conventional techniques require extensive groundwater management. Unless the accumulated water is removed via pumping, it builds up against the barrier. Eventually, the water overtops or moves around the barrier laterally. Permeable barriers avoid the water management and groundwater flow interruption problems because they are designed to destroy contaminants rather than absorb them. Thus, further management or removal of the hazardous substances becomes unnecessary.

\section{COLLABORATION/TECHNOLOGY TRANSFER}

This effort has relied on close linkages to industry and university collaborators. Dupont researchers provided the colloidal silica gel material and expertise in gel production. Pfizer Oil Field Chemicals provided information from previous development efforts on polymers and cross-linkers for petroleum applications.

Los Alamos researchers have participated in compilating potential barrier approaches as part of a report for the Rocky Flats Technology Office. A series of additional information exchanges are ongoing. Discussions and exchange visits with Scientific Ecology Group personnel led to the definition of potential linkages with soil washing systems or barrier material recycling as paral- lel approaches. Significant overlaps in process characterization needs were identified.

Discussions and exchanges of information with Rocky Mountain consultants regarding previous experiences and lessons from slurry wall environmental applications have continued to enhance the understanding of current and past industry practice. Similarly, discussions with personnel from Law Environmental, Mission Research, Inc., and Harding Lawson Associates gave valuable information and identification of options for conventional trench emplacement. Cassette systems for trench emplacements and enhancement of jet grouting, and directed hydrofracture are potential specialized emplacement approaches.

For further information, please contact:

David Janecky

Principal Investigator

Los Alamos National Laboratory

P.O. Box 1663

Los Alamos, NM 87545

(505) 665-0253

Jake Turin

Principal Investigator

Los Alamos National Laboratory

P.O. Box 1663

Los Alamos, NM 87545

(505) 665-6339

\section{Bruce Erdal}

Technical Program Manager

Los Alamos National Laboratory

P.O. Box 1663

Los Alamos, NM 87545

(505) 667-8914

Jeffrey $S$. Walker

Program Manager

U.S. Department of Energy

Cloverleaf Building

19901 Germantown Road

Germantown, MD 20874-1290

(301) 903-7966 
TTP Number: AL141003

\section{BIBLIOGRAPHY OF KEY PUBLICATIONS}

Kovarik, F.S., J. Killough, K. Mohanty, and R. Rajagopolan, Barriers and Post Closure Monitoring, Los Alamos National Laboratory Sub-Contract to Institute for Improved Oil Recover (IIOR), University of Houston, Houston, 'Texas, 1993. 


\section{TASK DESCRIPTION}

This task examines the sorption and immobilization capacity of a natural iron mineral for removing a number of target contaminants without impeding groundwater flow. Ferric oxyhydroxide or hydrated iron oxide is a naturally occurring non-hazardous substance that has sorption affinities for a number of contaminants found at DOE sites. Contaminants such as uranium, molybdenum, chromium, arsenic, copper, lead, zinc, and radium can potentially be removed from groundwater.

The iron is injected as a solution in water. Reaction with natural aquifer mineral alkalinity converts the iron to the sorbing phase. Precipitation of the iron mineral within the aquifer pores coats the rock particles, which forms a barrier zone around the contaminated area. This coating extracts the contaminants from the groundwater and confines them in the barrier zone. See Figure 2.2.

The objectives of this investigation are: (1) to determine the sorptive capacity of the iron mineral for target contaminants, the mobility of the iron mineral, and the formation permeability changes that occur when it is introduced into the subsurface, and (2) to design and field test a low-cost, water-permeable barrier system formed in situ.

\section{TECHNOLOGY NEEDS}

This effort is directly applicable to remediation of uranium contamination at the Monticello (UT) Mill Site. Because uranium and other metal contamination of groundwater occurs at a number of DOE, DoD, EPA, and industrial waste sites, this technology has widespread application. DOE sites with uranium or metal contamination include UMTRA facilities, Pantex, Fernald, Nevada Test Site (NTS), Y-12, and the Gaseous Diffusion Plant at Oak Ridge.

The positive results of the laboratory testing phase called for a field demonstration. The construction phase for a field demonstration at Monticello was completed, but the project has been suspended due to Monticello site remediation scheduling issues. Alternate sites have been investigated. However, it is unlikely that a field demonstration will be implemented until FY96.

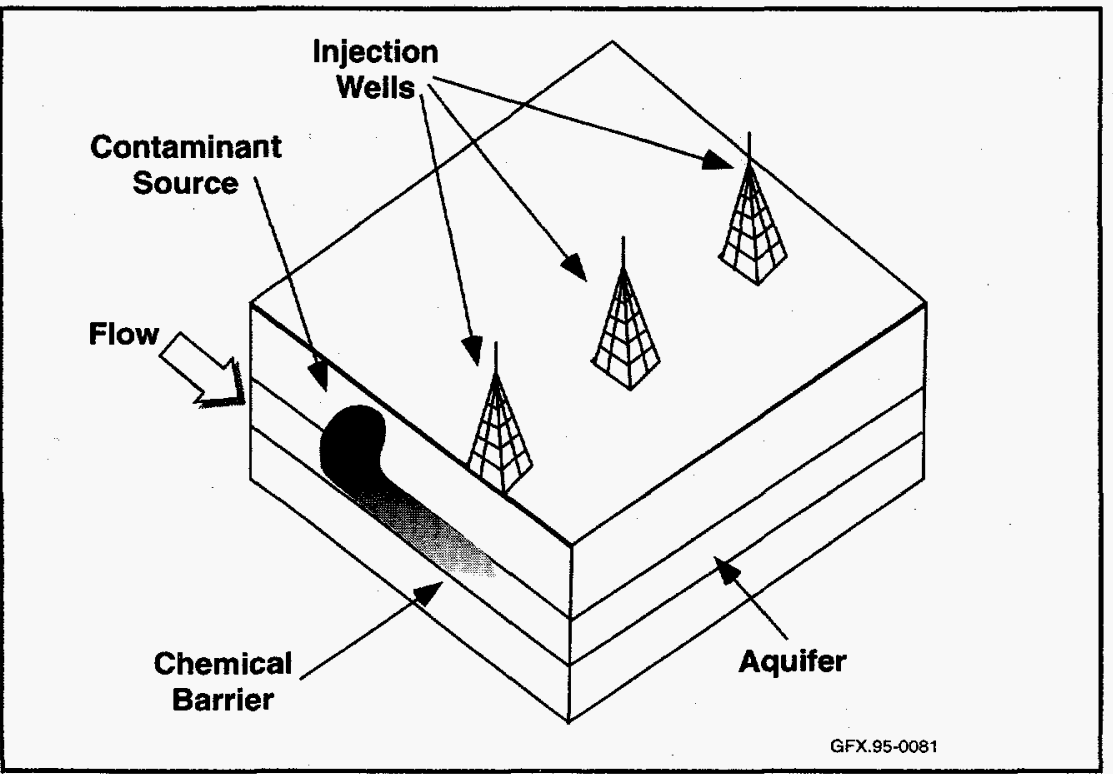

Figure 2.2. Chemical Barriers Feasibility and Field Demonstration.

\section{ACCOMPLISHMENTS}

- Identified ferric oxyhydroxide as an effective sorbent for uranium, molybdenum, chromium, arsenic, lead, copper, zinc and radium.

- Completed the studies of the sorption characteristics of ferric oxyhydroxide for uranium and molybdenum contaminated groundwater at Monticello. 
- Completed laboratory studies that suggested emplacement of ferric oxyhydroxide caused minimal decrease in permeability and that the material was very immobile.

- Completed field construction for a demonstration project, but the demonstration was suspended due to Monticello site remediation scheduling issues.

\section{BENEFITS}

The currently available technologies for installation of subsurface barriers to groundwater movement involve direct mixing of clay-based grouts or cements with aquifer material to plug the permeability. In addition to the expensive effort to deep-soil mix or excavate, surface mix, and re-fill, these approaches often yield additional waste management requirementsand producesignificantsurface disruption. This project will inject a natural mineral material, dissolved in water to form an insoluble precipitate in the pores of the water-bearing zone. This mineral phase will coat the walls of the pores and extract contaminants from the moving water. Because emplacement is done from surface wells, little waste or surface disturbance occurs.

\section{COLLABORATION/TECHNOLOGY TRANSFER}

Laboratory studies on the use of this sorbent for uranium mill tailings remediation have been carried out under the Surplus Facilities Management Program and the Grand Junction Projects Program Support Research and Development Program. Published papers and participation in technical conferences have led to inquiries from DOE and private industry interested in testing this technology.

\section{For further information, please contact:}

\author{
Stanley J. Morrison \\ Principal Investigator \\ RUST Geotech, Inc. \\ P.O. Box 14000 \\ Grand Junction, CO 81502 \\ (303) 248-6373
}

David A. Emilia

Technical Program Manager

RUST Geotech, Inc.

P.O. Box 14000

Grand Junction, CO 81502

(303) 248-6417

Jeffrey S. Walker

Program Manager

U.S. Department of Energy

Cloverleaf Building

19901 Germantown Road

Germantown, MD 20874-1290

(301) 903-7966

TTP Number: AL931002

\section{BIBLIOGRAPHY OF KEY PUBLICATIONS}

Morrison, S.J., R.R. Spangler, and V.S. Tripathi, (in press), "Adsorption of Uranium(VI) on Amorphous Ferric Oxyhydroxide at High Concentrations of Carbon(IV) and Sulfur(VI) Concentrations," Journal of Contaminant Hydrology.

Morrison, S.J., V.S. Tripathi, and R.R. Spangler, (in press), "Coupled Reaction/Transport Modeling of a Chemical Barrier for Controlling Uranium(VI) Contamination in Groundwater," Journal of Contaminant Hydrology.

Morrison, S.J. and R.R. Spangler, "Chemical Barriers for Controlling Groundwater Contamination," Environmental Progress, v. 12, pp. 175-181, 1993.

Morrison, S.J. and R.R. Spangler, "Extraction of Uranium and Molybdenum from Aqueous Solutions: A Survey of Industrial Materials for Use in Chemical Barriers for Uranium Mill Tailings Remediation," Environmental Science and Technology, vol. 26, pp. 1922-1931, 1992. 


\section{TASK DESCRIPTION}

The goal of this task is to develop permeable, reactive barriers as a cost-effective approach to in situ groundwater remediation. See Figure 2.3. Five major task areas are required to develop a useful barrier: 1) identify contaminants of concern; 2) perform literature reviews and conduct scoping experiments to identify suitable sequestering agents; 3 ) develop adsorption isotherms, adsorption kinetics data, hydraulic conductivity, and other necessary chemical, physical, and long-term stability data required to design a barrier; 4) design barriers and model performance; and 5) conduct a field demonstration to evaluate performance of the barrier under field conditions.

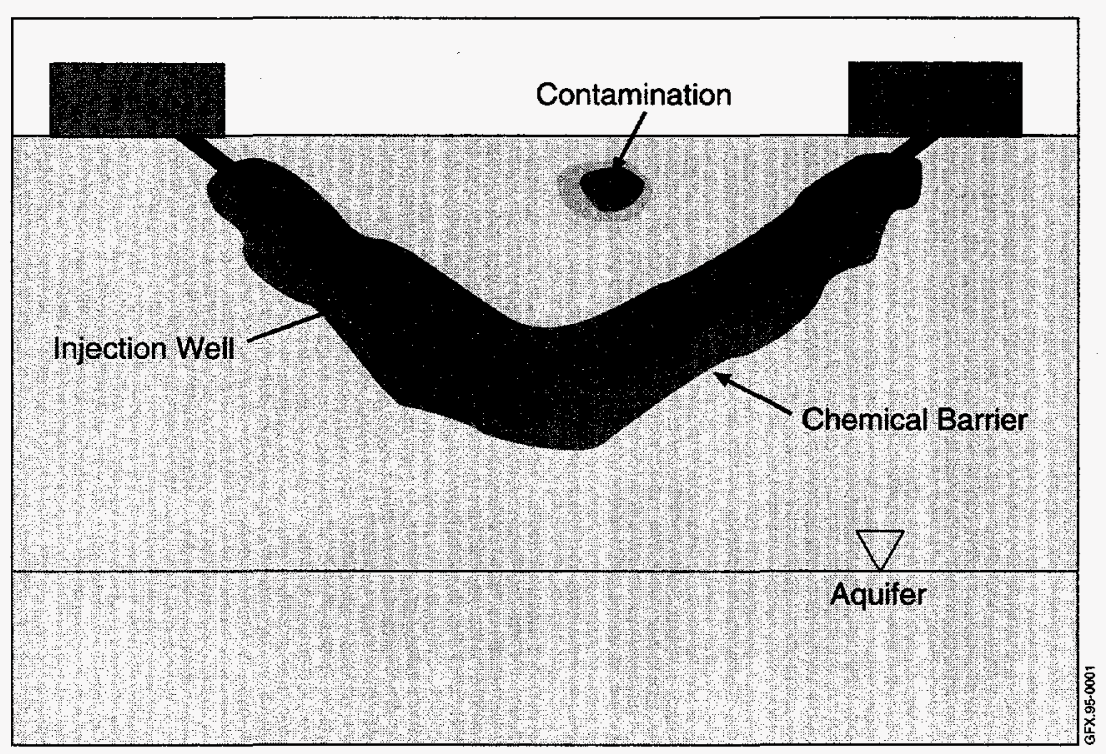

Figure 2.3. Develop and Determine Effectiveness of Permeable Barriers.

In Task 1, the most problematic contaminants of concern with respect to groundwater contamination at DOE sites were found to include $\mathrm{Sr}-90, \mathrm{Cr}$, chelated Co-60, U, Tc-99, and chlorinated hydrocarbons. A number of DOE sites were identified as suitable for field demonstrations.

In Task 2, a number of sequestering agents were identified that have good potential as effective sor- bents for a number of the contaminants of concern. Currently, the focus is on Tasks 3 and 4 which will develop the sequestering agents and complete the engineering calculations for the barrier.

Effort has been applied toward Task 5, which includes a literature review of emplacement technologies, a preliminary field demonstration plan, and meetings with regulators to discuss the acceptability of this technology from a regulatory standpoint. A field demonstration is expected by the end of FY95.

\section{TECHNOLOGY NEEDS}

Low cost and effective technologies are needed as alternatives to conventional pump-and-treat, dig-and-treat, and complete containment methods. Pump-and-treat and digand-treat technologies are expensive. Containment methods that attempt to isolate the waste site from infiltration or groundwater typically fail because total control of groundwater flow is usually impossible.

Technically feasible and cost-effective permeable, reactive barriers are needed that do not significantly restrict the flow of groundwater and will selectively remove hazardous components. Selective barriers are needed for a range of contaminants, including organic solvents, radionuclides, and toxic metals. For contaminant mixtures, a combination of different barrier materials could be used. This investigation will provide data on a variety of selective sequestering agents and will examine emplacement methods that do not require excavation. 


\section{ACCOMPLISHMENTS}

- Determine the equilibriurn isotherm data on the sorbent capacity of three zeolites and found that clinoptilolite is the most cost effective.

- Completed four of the six synthesis steps for an organic complexing agent for strontium.

- Demonstrated phosphate co-precipitation for chromate in batch studies under diffusion-controlled conditions.

- Laboratory testing of $\mathrm{Mg}$-Al hydrotalcite absorbance of chromate showed good removal capacity.

- Activated carbon derived from waste tires showed promise as a carbon tetrachloride sorbent from ground water.

\section{BENEFITS}

Semi-permeable barriers that absorb or detoxify mobile hazardous substances have advantages over conventional barrier techniques. Conventional techniques use impermeable substances to block the pores of a water-bearing zone to prevent movement of contaminants. Although movement away from the site may be prevented, conventional techniques require extensive groundwater management. Unless the accumulated water is removed via pumping, it builds up against the barrier and eventually overtops or moves around the barrier laterally. Permeable barriers avoid the water management and groundwater flow interruption problems. If the permeable barriers are designed to destroy the contaminants rather than absorb them, further management or removal of the hazardous substances becomes unnecessary.

\section{COLLABORATION/TECHNOLOGY TRANSFER}

This investigation will be carried out in collaboration with EBASCO Services, Inc., and WHC, Richland, Washington. In addition, work is ongoing in collaboration from various institutions that will synthesize some test compounds. These include Pennsylvania State University, Eastern Montana College, UOP Company, Allied Signal, and SNL.

Details of the efficacy of various chemical reagents in sequestering contaminants will be published in DOE technical reports and journal articles. Details of barrier emplacement and non-destructive monitoring will be shared in appropriate engineering literature. Because chemical barrier reagents have applications in other containment activities, such as liners and caps, sequestering agent data and results will be available to designers and engineers of the waste management systems.

For further information, please contact:

\section{Kirk Cantrell}

Principal Investigator

Pacific Northwest Laboratory

P.O. Box 999

Richland, WA 99352

(509) 376-8647

\section{Steven Slate}

Technical Program Manager

Pacific Northwest Laboratory

P.O. Box 999

Richland, WA 99352

(509) 375-3903

Jeffrey $S$. Walker

Program Manager

U.S. Department of Energy

Cloverleaf Building

19901 Germantown Road

Germantown, MD 20874-1290

(301) 903-7966

\section{BIBLIOGRAPHY OF KEY PUBLICATIONS}

Cantrell, K.J., J.E. Amonette, H.T. Schaef, B.P. Hay, R.J. Serne, and E.A. Jenne, Preliminary Field Site Selection and Experimental Plan for the Chemically Enhanced Barriers Project, Draft, Pacific Northwest Laboratory, Richland, Washington, 1993. 
Cantrell, K.J., J.E. Amonette, B.P. Hay, M.D. Waddington, H.T. Schaef, T.W. Wietsma, P.F. Martin, D.S. Burke, V.L. LeGore, and D.I. Kaplan, FY93 Laboratory Results for the Chemically Enhanced Barriers Project, Draft, Pacific Northwest Laboratory, Richland, Washington, 1993.

EBASCO Environmental, Selection of Subsurface Permeable Barrier Test Facility for Implementation at $100 \mathrm{~N}$ Area, EBASCO Environmental, Richland, Washington, 1993.

Riggsbee, W.H., R.L. Treat, H.J. Stansfield, R.M. Schwarz, K.J. Cantrell, and S.J. Phillips, Review of Potential Subsurface Permeable Barrier Emplacement and Monitoring Technologies, PNL-9335, Pacific Northwest Laboratory, Richland, Washington, 1993.

Amonette, J.E., T.D. Brewer, and H.T. Schaef, Retention of Chromate by Synthetic Hydrotalcites, 30th Annual Meeting, Clay Minerals Society, San Diego, California, 1993. 


\subsection{CONTAINMENT OF CONTAMINANTS THROUGH PHYSICAL BARRIERS FORMED FROM VISCOUS LIQUIDS EMPLACED UNDER CONTROLLED VISCOSITY CONDITIONS}

\section{TASK DESCRIPTION}

This task examines liquids which, when injected into the subsurface, greatly increase their viscosity to produce nearly-inert impermeable barriers. Appropriate emplacement of these substances provides an effective containment of the contaminated zone by entrapping and immobilizing both the contaminant and the plume. See Figure 2.4 . solidifies at ambient aquifer temperatures. The barrier fluid under investigation belongs to the polybutene (PB) family. Approved by the Food and Drug Administration for food contact, polybutenes are chemically and biologically inert. They are hydrophobic and impermeable to water and gases.

To emplace this fluid, the subsurface vadose zone must be heated. Then, at the same temperature, the barrier fluid is injected into this zone. After the injection of the barrier fluid, the vadose zone is cooled, which creates a chemically inert monolith or cage. The cage entraps and isolates the contaminated region.

The second type of barrier fluid requires an increase in viscosity through a gelation process. This type of fluid under investigation is a silicon-based chemical grout, colloidal silica (CS). Chemically and biologically inert, CS poses no health hazard. It is unaffected by filtration. Its containment performance is controlled by the gelation time, which depends on the $\mathrm{pH}$, temperature, chemistry of the injected suspension, and chemistry of the aquifer porous medium.

In the third type of barrier fluids, the increase in viscosity results from crosslinkage of the injected substances. The cross-linking process is achieved by temperature control of the injected substance. The barrier fluid under investigation is polysiloxane (PSX). Chemically and biologically inert, PSX is a silicon-based polymer. Used primarily for medical implants, PSX is being applied on hazardous waste remediation. It is unaffected by the aquifer or waste chemistry.

The first type of fluid is characterized by a viscosity strongly dependent on temperature. It virtually 


\section{TECHNOLOGY NEEDS}

Conventional containment technologies have been restricted to physical collection in trenches, subsurface cementation walls, and clay-slurry walls. These methods are applicable to certain contaminant problems, which include immiscible organic contaminants, solutes, heavy metals, and mixed wastes.

Contaminants from buried wastes or from contaminated soils in the vadose zone can migrate toward previously uncontaminated regions of the aquifer. Excavation of contaminated soils and disposal in protected facilities are expensive as well as hazardous.

Containment on-site which controls groundwater flow can limit off-site contamination. Thus, the development of effective in situ containment technologies is necessary to control the release of contaminants from buried sources. A variety of barrier fluid technologies must also be developed for different soil and waste conditions to improve the in situ containment technologies.

\section{ACCOMPLISHMENTS}

- Identified three promising substances for evaluation as barrier fluids-polybutene (PB), colloidal silica (CS), and polysiloxanes (PSX).

- Identified the Hanford site as the first application of this barrier technology. A meeting was held with officials from the PNL, WHC, and DOE to discuss the field application of the technology.

- Investigated and selected the five most promising combinations of these fluids: pure $\mathrm{PBs}$, conjunctive use of $\mathrm{PBs}$ and $\mathrm{CS}, \mathrm{CS}$ suspensions (with and without microfine cements), and pure PSXs.

- Completed analysis of the rheological properties of the barrier fluids.

- Conducted laboratory studies of barrier fluid flow and emplacement in porous media in columns and three-dimensional flow chambers. Determined that all three types of liquids are effective in sealing porous media.
- Identified the dominant mechanisms in CS gelation in porous media and developed processes to control the gel time and the texture of the gels.

- Determined the need and designed protocol for the sequential injection of CS.

- Developed processes to control the initial viscosity and gel time of PSXs.

- Expanded and modified TOUGH2 $2^{\mathrm{TM}}$ (the general computer model for the simulation of mass and heat flow and transport in the subsurface) to predict the flow of gelling fluids and evaluate the performance of barrier liquids.

- Used the modified TOUGH2 $2^{\mathrm{TM}}$ to design largescale two-dimensional experiments of barrier fluid injection. Conducted a sensitivity analysis of the relevant parameters.

- Using TOUGH2 $2^{\mathrm{TM}}$, designed a first-level injection test to be conducted at the Hanford site.

- Working with Bechtel, finalized a work plan for the first-level injection test and forwarded it to the Office of Regulatory Analysis of the WHC for the handling of the regulatory approval process.

\section{BENEFITS}

These investigated materials will form inert grouts that can easily be injected from the ground surface to develop in situ hydraulic barriers for prevention of off-site contaminant movement. Injection from the surface avoids excavation of waste. The grouts are initially liquid and readily permeate the subsurface porosity. By controlling the temperature or compositional adjustment, the liquids gel and seal the pores of the permeable zone.

\section{COLLABORATION/TECHNOLOGY}

\section{TRANSFER}

The general purpose TOUGH2 $2^{\mathrm{TM}}$ model, developed at LBL is being appropriately modified and used for the simulation of the processes involved 
in barrier fluid behavior and the design of experiments. Most of the numerical and experimental work is carried out at LBL. Large-scale two-dimensional laboratory work will be conducted at Texas A\&M University. Laboratory work on the rheological properties of the barrier fluids is conducted at the University of California, Berkeley.

While the bulk of the work is conducted at LBL, there is significant collaboration with other organizations. Texas A\&M University in College Station is a participant in this study. Their principal responsibility is the evaluation of the performance of barrier fluids in large two-dimensional laboratory experiments using their specialized facilities. The University of California, Berkeley, is involved in the selection and rheological study of polymer-type barrier fluids.

LBL is actively exchanging information and exploring possible collaborations with a number of private firms, i.e., Bechtel, DuPont Chemicals, Dow-Corning, and Martin Marietta. There is a collaborative agreement between Bechtel to work on the issue of barrier fluid emplacement. 'There is a preliminary agreement with DuPont Chemicals to collaborate both within the scope of this project and in a longterm project. Discussions of a Memorandum of Understanding (MOU) or a CRADA are continuing. Dow-Corning is involved in the development of PSXs with specific initial viscosities and finalproduct properties. Martin Marietta is interested in applying this technology to Oak Ridge sites. Moreover, the investigators have seen significant interest and received invitations for presentations and discussions from the EPA, the Department of the Navy (Naval Air Weapons Station, Hunters Point Shipyard), the Department of the Army, the McClellan Air Force Base, LLNL as well as the State of California (Regional Water Quality Control Board).

The new technologies and the corresponding design package will be made available for use throughout the DOE Environmental Restoration program as well as other U.S. agencies (EPA and DoD). Localized contamination problenns are expected to be especially amenable to barrier containment. Many DOE sites would be candidates for the pilot- and field-scale application of the technologies. These include Hanford's Underground Storage Tank sites, the buried waste sites at INEL, Rocky Flats, NTS, SRS, and LLNL. Many industrial sites with localized contamination problems are also candidates for the application of these technologies.

For more information, please contact:

Karsten Pruess or George Moridis

Principal Investigators

Lawrence Berkeley Laboratory

1 Cyclotron Road

Berkeley, CA 94720

(510) 486-6732

\section{Chin-Fu Tsang}

Technical Program Manager

Lawrence Berkeley Laboratory

1 Cyclotron Road

Berkeley, CA 94720

(510) 486-5782

Jeffrey S. Walker

Program Manager

U.S. Department of Energy

Cloverleaf Building

19901 Germantown Road

Germantown, MD 20874-1290

(301) 903-7966

TTP Number: SF131001

\section{BIBLIOGRAPHY OF KEY PUBLICATIONS}

Moridis, G.J., P. Persoff, H.Y. Holman, S.J. Muller, K. Pruess, and C.J. Radke, "New Barrier Fluids for Subsurface Containment of Contaminants," Proceedings of the ER '93 Environmental Remediation Conference, Augusta, Georgia, October 24-28, 1993 , and LBL Report No. LBL-34673, Lawrence Berkeley Laboratory, Berkeley, California. Submitted for publication in the Journal of Geotechnical Engineering of the American Society of Civil Engineers.

Persoff, P, G.J. Moridis, and K. Pruess, "Containment of Contaminants in the Subsurface Using Barrier Fluids," EOS, Transactions of the American 
Geophysical Union, 1993 Fall Meeting Supplement, 74(3): 288-289. San Francisco, California, December 6-11, 1993 .

Moridis, G.J., P. Persoff, H.Y. Holman, S.J. Muller, K. Pruess, P. Witherspoon, and C.J. Radke, Containment of Contaminants Through Physical Barriers From Viscous Liquids Emplaced Under Controlled Viscosity Conditions, FY93 Annual Report, LBL Report No. LBL-35114, Lawrence Berkeley Laboratory, Berkeley, California.

Finsterle, S., G.J. Moridis, K. Pruess, and P. Persoff, Physical Barriers Formed From Gelling Liquids: 1. Numerical Design of Laboratory and Field Experiments, LBL Report No. LBL-35113, Lawrence Berkeley Laboratory, Berkeley, California, 1994. Submitted for publication in Water Resources Research of the American Geophysical Union.

Finsterle, S., G.J. Moridis, K. Pruess, and P. Persoff, Physical Barriers Formed From Gelling Liquids: Numerical Design of Laboratory and Field Experiments,
(LBL report number pending), 1994 AGU Spring Meeting, Baltimore, MD, May 23-27, 1994.

Persoff, P., S. Finsterle, G.J. Moridis, and K. Pruess, Physical Barriers Formed From Gelling Liquids: Laboratory Grout Emplacements in Unsaturated Sands, (LBL report number pending), 1994 AGU Spring Meeting, Baltimore, MD, May 23-27, 1994.

Moridis, G.J., and K. Pruess, Air Barriers for Waste Containment in the Vadose Zone, (LBL report number pending), to be presented at the 1994 AGU Spring Meeting, Baltimore, May 23-27, 1994.

Persoff, P., G.J. Moridis, J. Apps, K. Pruess, and S. Muller, "Designing Injectable Colloidal Silica Barriers for Waste Isolation at the Hanford Site," (LBL35447) Proceedings of the 33rd Hanford Symposium on Health and Environment, In-Situ Remediation: Scientific Basis for Current and Future Technologies, Pasco, Washington, November 7-11, 1994. 


\subsection{DEVELOPMENT OF FROZEN SOIL BARRIERS FOR ARID SITES}

\section{TASK DESCRIPTION}

This task addresses the feasibility of using frozen soil barriers (ground freezing technology) to contain hazardous and radionuclide-contaminated soil in an arid setting. See Figure 2.5. The project is a lab-based investigation of containment characteristics of frozen water in soil, including the behavior of associated solutes, transport mechanisms through unfrozen water films or pockets, mechanical effects such as heave, and other freezing-related processes.

Assuming favorable results from the lab-scale investigation, a frozen soil barrier will be installed and tested at an uncontaminated site as part of a new project in FY95. Installation involves drilling to install pipes through which refrigerant is circulated. The holes are positioned to create a confined subsurface volume as the soil around the boreholes freezes. A critical aspect of this project is the successful, controlled addition and removal of water from the unsaturated subsurface to create the barrier.
Upon completion, the project must establish the capability for removing water to prevent contaminant migration, which is a possible requirement in the technology's future use at unsaturated contaminated sites. Assuming the successful addition of water, barrier integrity/performance would then be evaluated by means of tracer tests, monitoring of thermal conditions, and other appropriate methods. Furthermore, the barrier would then be available as a test bed within which other investigators could conduct studies of hazardous waste treatment technologies.

\section{TECHNOLOGY NEEDS}

Many of DOE's contaminant sources (e.g., landfills, dry wells, evaporation ponds, etc.) are located in arid climates and are typically far above the natural groundwater level. Frozen soil barriers may be useful in providing containment at these sites. However, most experience with their hydraulic per-

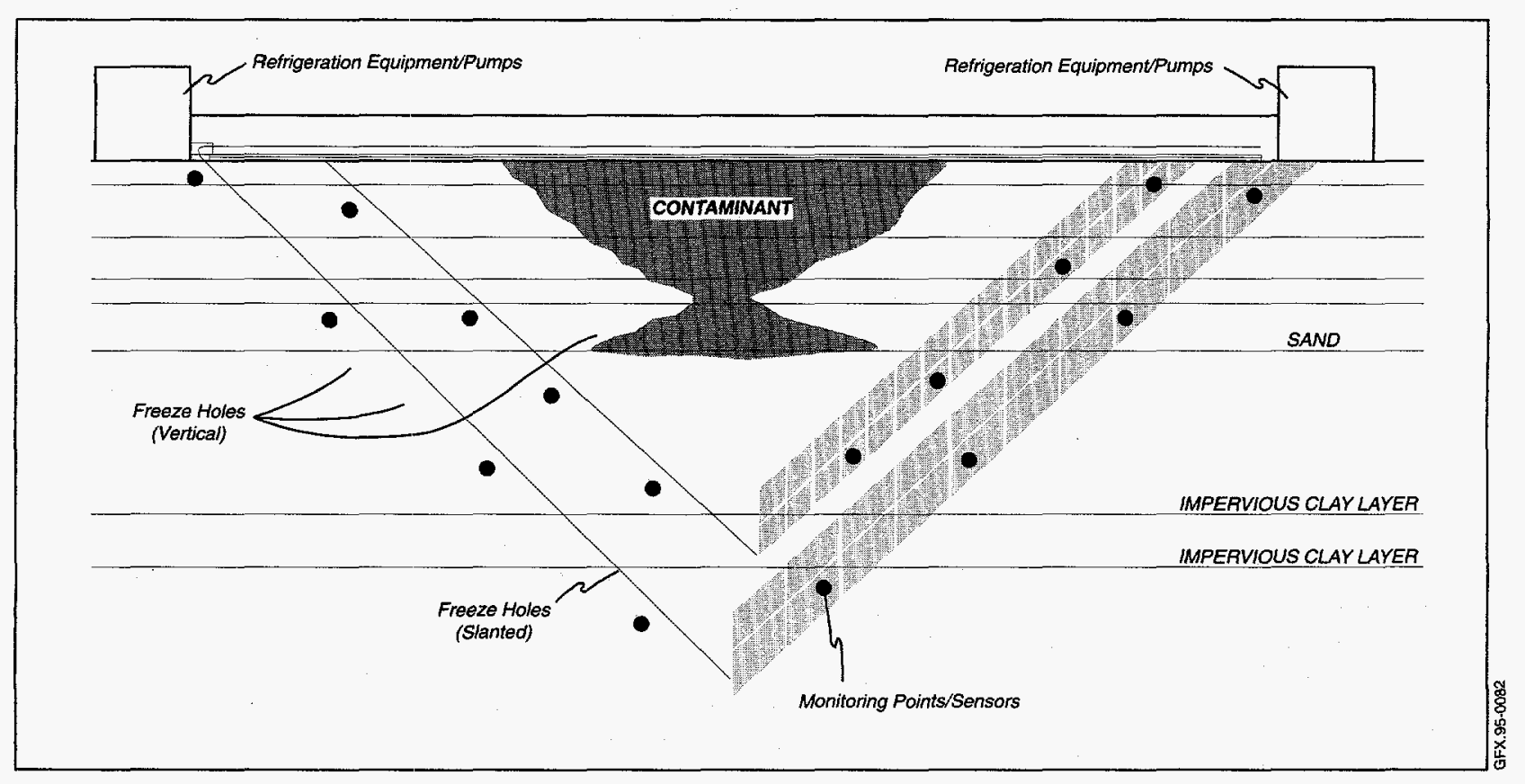

Figure 2.5. Cross-Sectional View of a Cryogenic Barrier at an Arid Site. 
formance is usually associated with natural, fully saturated environments. Under arid conditions, performance may be affected by the ability to first create full saturation, (i.e., achieve near-zero air porosity), then maintain saturation until a frozen state is achieved. This project will examine potential performance factors arising from arid site conditions and evaluate specific measures to mitigate or minimize adverse effects.

\section{ACCOMPLISHMENTS}

- Held a series of technical workshops and planning sessions on frozen soil barrier formation and performance.

- Laboratory-scale studies by Michigan State University tested the permeability of frozen soil from DOE sites at various saturation levels, with and without the presence of organic and metal contaminants.

\section{BENEFITS}

Frozen soil barriers offer distinct advantages over other barrier technologies. With slant, horizontal or directional drilling, they can provide complete side and floor containment around a contaminated zone. The technology uses off-the-shelf conventional equipment. These barriers can be installed to deeper depths than conventional technologies. Breaches in the barrier can be sealed by adding moisture. The barrier uses benign materials and can be removed by thawing.

\section{COLLABORATION/TECHNOLOGY TRANSFER}

Project scientists are working with Hanford personnel so that laboratory-scale results will meet the needs of EM-30 for containing waste from underground storage tanks. A related task, newly funded in FY95, will install a one-third scale barrier around a simulated underground storage tank at Hanford. This project will use leverage funds from a private firm and EM-30. The technology is directly relevant to tank containment at Hanford. Its demonstration will meet a Tri-Party Agreement milestone on the testing of subsurface barriers for tanks.

\section{For more information, please contact:}

\author{
Stanley J. Morrison \\ Principal Investigator \\ RUST Geotech, Inc. \\ P.O. Box 14000 \\ Grand Junction, CO 81502 \\ (303) 248-6373
}

David A. Emilia

Technical Program Manager

RUST Geotech, Inc.

P.O. Box 14000

Grand Junction, CO 81502

(303) 248-6417

\section{Jeffrey S. Walker \\ Program Manager \\ U.S. Department of Energy \\ Cloverleaf Building \\ 19901 Germantown Road}

Germantown, MD 20874-1290

(301) 903-7966

TTP Number: AL921201

BIBLIOGRAPHY OF KEY PUBLICATIONS

Andersland, O.B., S.H. Davies, and D.C. Wiggert, Performance and Confirmation of Cryogenic Containment Barriers in Dry Soils, Task 1: Barrier Performance, 1994, (draft report submitted to RUST Geotech, Inc.) 


\subsection{CRYOCELL TECHNOLOGY APPLICATIONS AT NON-ARID SITES}

\section{TASK DESCRIPTION}

This task addresses the feasibility of frozen soil barriers as ground freezing technology to contain hazardous and radionuclide-contaminated soil in a non-arid environment. Because ground freezing has long been a civil engineering technique for ground control and water entry control, this project is essentially a new application of an established technology. A series of holes are drilled and refrigerant is circulated, freezing the soil around the holes such that a confined volume is created, thereby preventing contaminant migration. See Figure 2.6.

The objective of this task is to design, install, and pre-test a soil freezing facility at an uncontaminated site. After successful completion of these objectives, a soil freezing technology demonstration would be performed to show construction of a containment system around an instrumented underground tank and associated piping. Data from this demonstration will be provided for the analysis of other possible field applications within the DOE complex.
An additional task was added during FY94, which consisted of lab-scale tests on the ability of arid soils from DOE sites to act as impermeable barriers when frozen. Permeability measurements were made and the ability to retard contaminant flow was evaluated.

\section{TECHNOLOGY NEEDS}

DOE has hundreds of contaminated sites such as trenches, pits, landfills, tanks, and contaminated soil areas, which may require a rapidly-installed, temporary barrier to contain lateral and vertical movement of contamination until further treatment is performed. Barrier technologies are needed which avoid excavation of large amounts of material, such as baseline slurry wall trenching, and which can form barriers at relatively great depths.

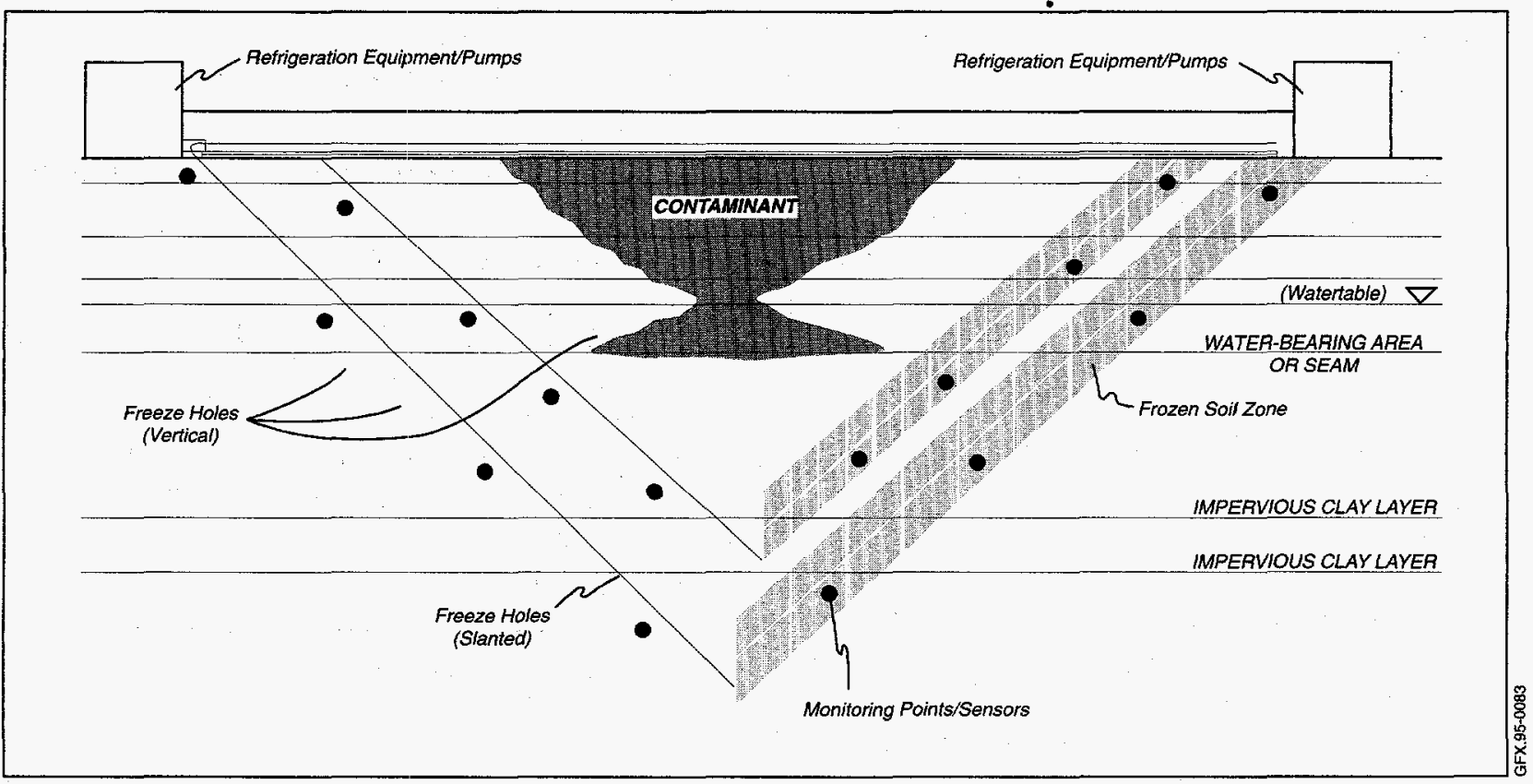

Figure 2.6. Cross-Sectional View of a Frozen Soil Barrier at a Non-Arid Site. 


\section{ACCOMPLISHMENTS}

Drilling and analysis of site characterization boreholes was completed in October 1993. Site soil permeability problems affecting surrogate (fluorescein and rhodamine) migration rates to the barrier during the diffusion tests were identified in the Phase I report. A sand backfill was used to alleviate this problem. Barrier installation (freezing) was completed in July 1994. Testing was completed in October 1994. The barrier has been excavated (trenched) for final inspection.

A series of tests were performed, including:

- a well casing installation test to maximize the accuracy of freeze pipe placement;

- a barrier diffusion test to demonstrate barrier integrity;

- a moisture addition test to verify the ability to adjust moisture content throughout the barrier;

- a leaking underground tank containment test;

- a soil movement (e.g., heave) analysis both inside and outside the barrier;

- a heat grid test to verify the ability of heat pipes to control barrier size;

- a freeze pipe heat transfer test to verify the ability of freeze pipes to remove heat from the soil zone and form overlapping ice columns; and

- a test to determine computer modeling as a predictive tool.

\section{BENEFITS}

The benefits of the cryocell technology are:

- Use of environmentally benign materials (refrigerants are circulated within a dual tube borehole);

- No creation of unwanted reactions and by-products in the subsurface;

- A means to fully contain waste, including a bottom, without excavation (soil disturbance);
- Ease of removal, if necessary (by barrier thaw); and

- Significant advantages over current containment technologies because it can be repaired in place by adding water, should a breach occur.

Other advantages of this type of containment technology are its minimal operation and maintenance requirements, and its applicability to a wide range of contaminants.

\section{COLLABORATION/TECHNOLOGY TRANSFER}

Martin Marietta Energy Systems, Inc. provided project management, and SEG, Inc., performed the design, construction, and testing. SEG, and its teaming partner, RKK Ltd., have significant experience in frozen soil applications from the civil engineering industry. In radioactive and hazardous waste applications, their design and supporting software have received substantial peer review by technical experts.

Assuming a frozen soil barrier can be successfully installed and tested, the technology could then be deployed at contaminated sites across the DOE complex. In FY95, SEG, RKK, Ltd., PNL and DOE will cooperate on installing and testing a frozen soil barrier in the arid soils at Hanford. The demonstration will address the viability of this technology as a barrier for underground storage tank remediation. The initial barrier would also be available as a test bed/barrier, within which other researchers could test, develop, and refine new treatment methods, perhaps even using actual hazardous materials.

\section{For more information, please contact:}

\author{
Rick Swatzell \\ Principal Investigator \\ Martin Marietta Energy Systems, Inc. \\ HAZWRAP \\ P.O. Box 2003 \\ Oak Ridge, TN 37831 \\ (615) 435-3126
}


Randy Snipes

Technology Program Manager

Martin Marietta Energy Systems, Inc.

HAZWRAP

P.O. Box 2003

Oak Ridge, TN 37831

(615) 435-3128

Jeffrey S. Walker

Program Manager

U.S. Department of Energy

Cloverleaf Building

19901 Germantown Road

Germantown, MD 20874-1290

(301) 903-7966
TTP Number: OR121119

\section{BIBLIOGRAPHY OF KEY PUBLICATIONS}

SEG, Inc., Phase I - Site Selection and Development Plan Report, 1993.

SEG, Inc., Draft Report: Task 1 - Formation of a Cryogenic Barrier, 1994. 


\section{7

\section{TASK DESCRIPTION}

The Subsurface Barrier Emplacement Program consists of placing an impermeable barrier beneath an existing waste site. The barrier, which is composed of a grouting material, has to be emplaced without disturbing the waste site.

Two emplacement technologies are being tested: permeation and jet grouting. Permeation grouting injects a low viscosity grout into the soil at low pressure filling the voids without significantly changing the soil's structure or volume. Jet grouting, on the contrary, injects grout at high pressure and velocity, thereby completely destroying the soil's structure. The grout and the soil are intimately mixed, forming a homogeneous mass. See Figure 2.7. Initially, feasibility of each technique will be evaluated, followed by evaluation of design parameters such as borehole separation, depth and limitations.

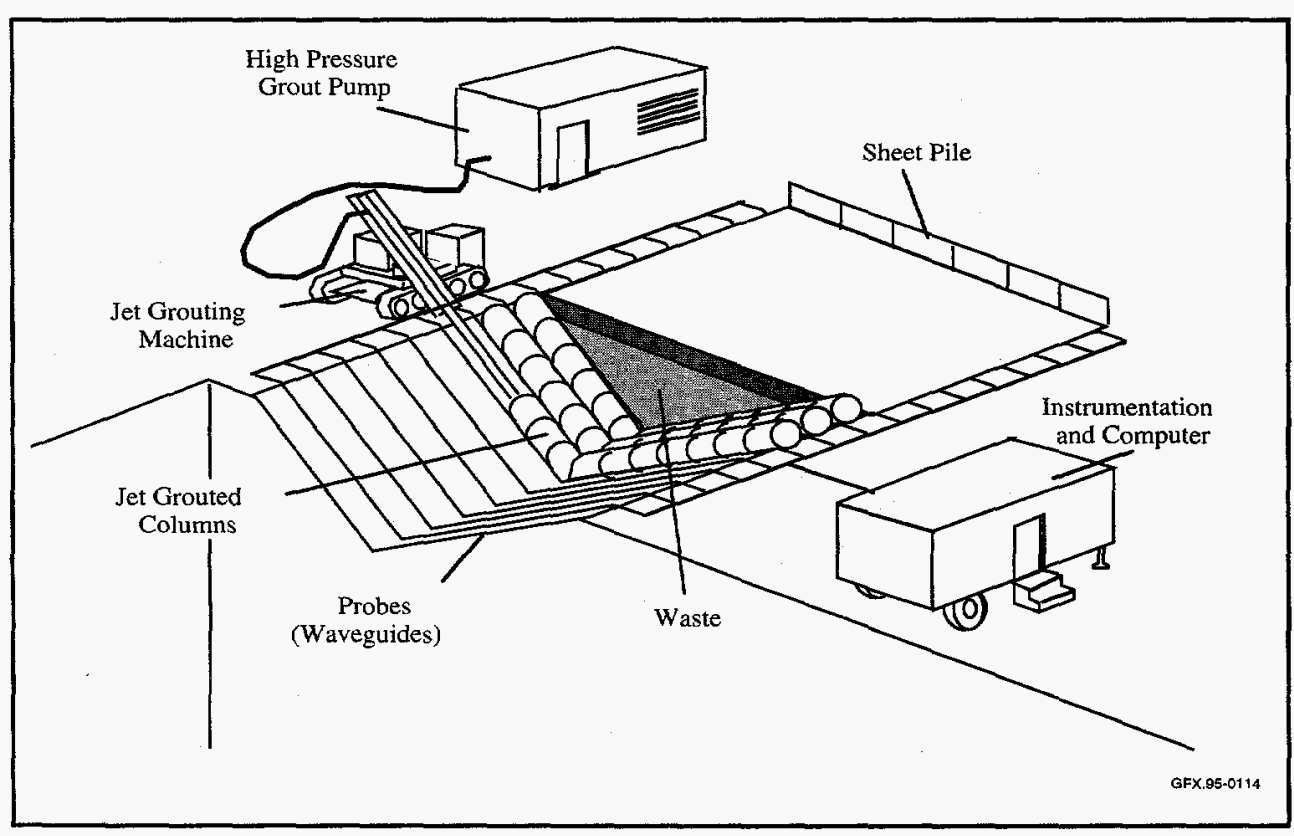

Figure 2.7. Subsurface Barrier Emplacement Development.

\section{TECHNOLOGY NEEDS}

The current state-of-the-art for subsurface barrier emplacement in near surface soils are primarily vertically emplaced barriers. Subsurface horizontal to sub-horizontal barriers that retard vertical mass movement are not currently employed in the civil engineering applications. Adequate subsurface barrier emplacement techniques must be developed, regardless of whether the barrier is horizontal or vertical.

\section{ACCOMPLISHMENTS}

- Completed report/literature review summarizing the technological aspects of all system components required for demonstrating a subsurface barrier emplacement.

- Completed field-scale permeation grouting experiment. Field testing consisted of grouting in vertical and horizontal boreholes using four different barrier materials. The barrier materials used were two ultrafine cements, a mineral wax/bentonite mixture, and a sodium silicate grout. $\mathrm{Nu}$ merous non-intrusive geophysical techniques were used to identify where the grout flowed. Geophysical techniques included: cross hole seismic tomography, grout penetrating radar, electromagnetic induction, neutron probe and downhole temperature logs. Fi- 
nally, the cementitious grout site was excavated exposing the grout. Observations were compared with the crosshole tomography results. Comparisons were quite favorable, but the geophysical techniques were still limited in that they could identify grout masses and not flaws in the continuity of the grouted soil.

- Completed field-scale jet grout demonstration employing a variety of shapes using multiple materials. Installed configurations included ytrough, cone, and rectangular monolith. Geophysical techniques were employed to image subsurface grout bodies. The preliminary results again indicated that current geophysical techniques were inadequate in verifying the continuity of a grout barrier.

\section{BENEFITS}

The anticipated benefits of installed barriers are that the waste volume will remain fixed allowing additional time to develop remedial treatments. In some instances, the remediation alternative may be enhanced by the installed barrier. In addition, the timing of cleanup becomes less critical.

\section{COLLABORATION/TECHNOLOGY TRANSFER}

The industrial partner is Applied Geotechnical Engineering and Construction, Inc. The partner has strong interest in the success of subsurface barriers.
For further information, please contact:

\section{Brian Dwyer}

Principal Investigator

Sandia National Laboratories

P.O. Box 5800

Albuquerque, NM 87185-5800

(505) 845-9894

\section{George Allen}

Technical Program Manager

Sandia National Laboratories

P.O. Box 5800

Albuquerque, NM 87185-5800

(505) 845-7015

\section{Skip Chamberlain}

Program Manager

U.S. Department of Energy

Cloverleaf Building

19901 Germantown Road

Germantown, MD 20874-1290

301-903-7248

TTP Number: AL231004

\section{BIBLIOGRAPHY OF KEY PUBLICATION}

Dwyer, B.P., "Feasibility of Permeation Grouting for Constructing Subsurface Barriers," Proceedings of the 33rd Hanford Symposium on Health and the Environment on In Situ Remediation: Scientific Basis for Current and Future Technologies, Pasco, Washington, November 7-11, 1994. 


\subsection{VERIFICATION OF SUBSURFACE BARRIERS USING TIME DOMAIN REFLECTOMETRY WITH WAVEGUIDES}

\section{TASK DESCRIPTION}

The objective of this task is to design a sub-surface barrier performance monitoring system which will indicate liquid contaminants are migrating past the barrier system so that corrective actions can be taken.

Sub-surface barrier systems will operate below underground waste disposal structures at various DOE sites to prevent the transport of chemical and radioactive contaminants into soil and water table. See Figure 2.8. State and federal regulators are requiring that the sub-surface barrier system have a detection or performance monitoring verification system in place. The sub-surface barrier performance monitoring system will detect moisture increases above baseline after the barrier system has been installed.

The system consists of: 1) sensors or waveguides constructed of stainless steel emplaced adjacent to or within the barrier material spaced a few feet apart, and 2) electronics devices which are connected to the sensors.

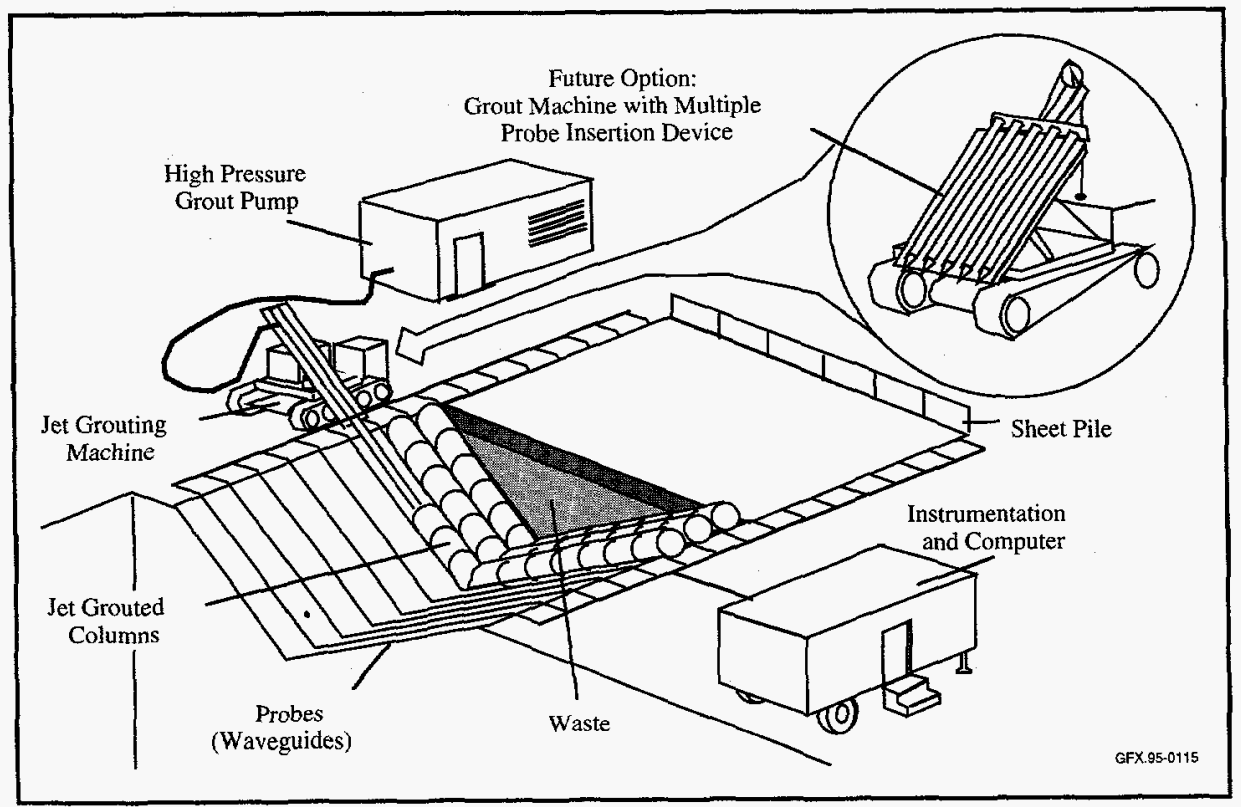

Figure 2.8. Subsurface Barrier Monitoring System.
The electronics package sends a pulse into the sensor and measures the difference between the input pulse and reflected pulse. This difference translates into changes in moisture near the sensor. The correlation to moisture content in soil was shown to be accurate by experimentation/comparison to other reliable moisture detection systems. If the sensors detect moisture content above that of background via the electronics package, the computer software can then alert operators that corrective actions are necessary. The system inherently allows a diagnostic assessment method to be performed because adjacent sensors can be individually analyzed to determine operability.

\section{TECHNOLOGY NEEDS}

Major technical challenges include design and construction of a sensor insertion mechanism. The actual emplacement of sensor array into a barrier system with subsequent performance of an electronics package monitoring test is another major challenge. The required infrastructure is extensive.

Time domain reflectometry is used in industry to detect faulty wiring, so commercial units are available. The probes, however, are currently custom-made by a machine shop to allow the use of special, corrosionresistant materials. Future collaboration with a vendor may result in commercial production of these special probes. 


\section{ACCOMPLISHMENTS}

Experimentation and testing are in progress as part of design and validation of this task. However, generalized moisture detection has been completed with commercial time domain reflectometry (TDR) systems, which performed well.

\section{BENEFITS}

This technology provides real time monitoring of barriers on surface and subsurface. This monitoring system will give the regulators, waste disposal structure operators/owners, and the public assurance that the barrier system is performing as designed.

In a cement based sub-surface barrier system, the sensor system satisfies multiple objectives. Sensors embedded in to the cement-like barrier provide: 1) a "yes/no" moisture detection capability which will alert operators to moisture conditions prior to any moisture penetrating past the barrier, 2) barrier emplacement quality control so that any discontinuities, windows, or pockets in the barrier can be detected and located, 3) a method to determine where and if discontinuities occurred after a seismic event, and 4) a method to allow a more detailed determination of the amounts of moisture (if any) passing through the barrier in the vicinity of the sensors using the same electronic package.

Approximate start-up costs range from $\$ 35,000$ to $\$ 45,000$ and include: 1) One 25 meter long sensor array; 2) electronics package, not including batteries and solar cells; 3) insertion device; 4) software development; and , 5) setup/startup costs. The track drill (where the probe insertion device will be attached) is already purchased and available. This technology will utilize this existing piece of equipment to reduce costs. The life-cycle cost will depend upon the replacement of the electronics package for upgrading. The estimated cost is $\$ 4,000$ to $\$ 15,000$ every five years.

\section{COLLABORATION/TECHNOLOGY TRANSFER}

This project will involve collaboration with a geotechnical instrumentation and monitoring instrument specialty company, which will be selected in the future.

For further information, please contact:

Willis Stewart

Principal Investigator

Westinghouse Hanford Company

P.O. Box 1970

Richland, WA 99352

(509) 372-0459

James Berger

Technical Program Manager

Westinghouse Hanford Company

P.O. Box 1970

Richland, WA 99352

(509) 376-9942

\section{Skip Chamberlain}

Program Manager

U.S. Department of Energy

Cloverleaf Building

19901 Germantown Road

Germantown, MD 20874-1290

(301) 903-7248

TTP Number: RL441002

BIBLIOGRAPHY OF KEY PUBLICATIONS

None at this time. 


\section{TASK DESCRIPTION}

The goal of this project is to demonstrate the technical and economic feasibility of the MAG*SEP groundwater remediation process developed by Bradtec U.S., Inc. (Bradtec) in conjunction with the Barrier Member Containment (BMC) Corporation's barrier/interceptor-well. This process is designed to remove inorganic contaminants from groundwater by using ion-exchange principles to adsorb targeted contaminants onto resin coated magnetic particles, capture the particles magnetically, chemically remove the contaminants, and recycle the particles. Non-targeted ions are not adsorbed by the particles.

The system to be demonstrated at the SRS include the magnetic particle injection system, a magnetic separator, and the regeneration/recycle system. See Figure 2.9. The technology has application for the removal of heavy metals in either groundwater or an effluent stream. The SRS demonstration is targeting cadmium, chromium, nickel, and lead contaminants in groundwater.

The technology can be applied in situ for the recovery of radionuclides, heavy metals, and nitrates from groundwater. For in situ treatment, a high-density polyethylene barrier/interceptor-well is installed in the subsurface to contain and isolate contaminated groundwater. The contaminated groundwater is channeled through a pass-through pipe to a treatment cell installed immediately down gradient of the barrier. Within the treatment cell is the MAG*SEP ${ }^{S M}$ mixing zone (where $M A G^{*} S E P^{S M}$ particles are injected and mixed with the water) and the magnetic filter for collection of the $M \mathrm{GG}^{*} S E P^{\mathrm{SM}}$ particles. The collected particles are then pumped to the surface for regeneration and reuse.

The selective adsorption $M A^{*}{ }^{*} E^{S M}$ particles are composites manufactured in one of two forms. They can range in size from 1 to 15 microns and have a magnetic core, a polymer coating for durability, and a functionalized resin coating or selective seed materials embedded in the polymer coating.

In treating contaminated water, these particles are injected into the water where they adsorb the targeted contaminants. Because the particles are small, and adsorption is a surface phenomenon only, the adsorption kinetics are rapid, typically less than five minutes. The particles are then recovered from the water using a magnetic filter. The magnetic core gives the particle a very high magnetic susceptibility. Once the particles

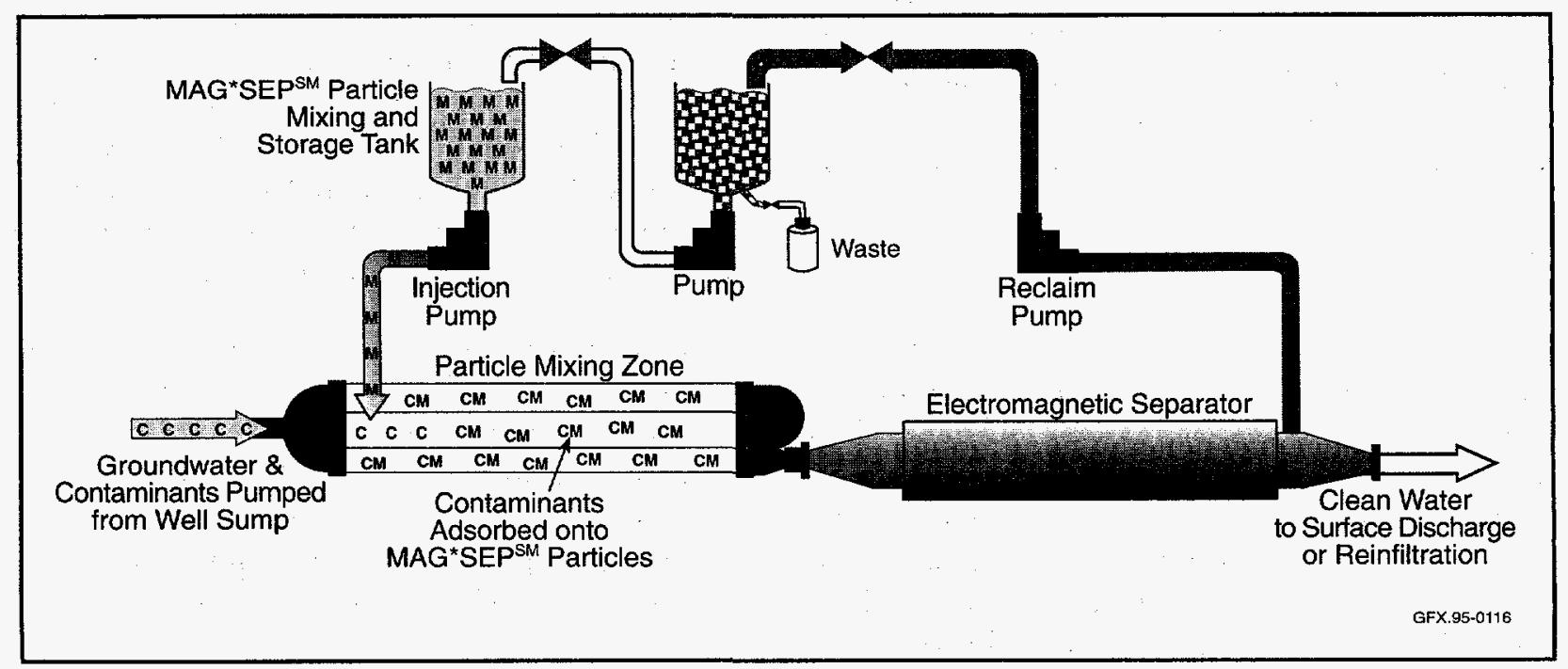

Figure 2.9: Above-Ground Demonstration of In-Situ MAG*SEP ${ }^{S M}$. 
have been recovered on the magnetic filter, the filter is backwashed, the particles regenerated (much in the same manner as ion exchange resin is regenerated), the contaminants recovered for recycle or treatment, and the particles reused.

The specific tasks within this project include optimizing the adsorbent particles for remediating the contaminated waters from the SRS D Area coal pile groundwater. Researchers are developing and testing the particle injection and mixing apparatus, the Babcock and Wilcox Nuclear Technologies (BWNT) open gradient magnetic separator (OGMS), and the particle regeneration system. The demonstration of these technologies will be integrated with an innovative barrier containment system.

Additional activities in support of the MAG*SEPSM demonstration are being conducted under related TTPs. These tasks include providing initial information used in selecting the demonstration site, providing analytical data both pre-and post-test on the operation of the EnviroWall barrier, and providing necessary regulatory permitting for the demonstration and testing of the MAG*SEPSM process at the SRS.

An integral activity required for the successful demonstration of the MAG*SEPSM technology is to identify or, if necessary, develop characterization tools that will provide real time, quantitative data in a non-intrusive manner. Such tools will enable workers to minimize their exposure to contaminants. At the same time, data will be provided instantly. This feature will shorten characterization time and minimize intrusive sampling locations, allowing sampling locations to be selected based on sound information.

\section{TECHNOLOGY NEEDS}

Groundwater contamination consisting of heavy metals, radionuclides, nitrates, and organics is a major problem across the DOE Complex as well as within private industry. Technologies capable of removing these contaminants, which typically appear in very low concentrations over large areas, are needed to meet drinking water standards. These technologies must be capable of removing contaminants while minimizing secondary wastes. A process that would remove contaminants in situ is also needed.

SRS D Area coal pile runoff basin has a contaminated groundwater plume that has been identified for treatment utilizing the $M^{\prime} G^{*} S E P^{S M}$ process. A three-month field demonstration of the process will illustrate how the components of the system work in the field and determine whether the system is capable of remediating the targeted contaminants to drinking water standards.

Groundwater plumes throughout the DOE Complex contain some or all of the contaminants targeted in the most current Mag*Sep demonstration. The Mag*Sep system, with the resin being used in this demonstration, could be applied to plumes containing cadmium, chromium, lead, or nickel at the following DOE locations: Pantex, SWMU\#133; Pinellas shallow water aquifer; INEL TRA 05 injection well; Richland 1100 Area isolated Units \#1. With an adaptation of the resin, other contaminants or combinations of contaminants could be targeted.

\section{ACCOMPLISHMENTS}

Argonne National Laboratory is providing technical oversight on the project, assisting with evaluation of several components of the system, including the groundwater injection and particle mixing apparatus, and the magnetic separator. ANL has assisted with optimization of these components to improve system performance. ANL will also participate in evaluation of the entire $M A G^{*} S E P$ system to determine if the system should be operated for a three month field demonstration of the technology on SRS D Area coal pile groundwater.

ANL has begun an economic evaluation of the technology to identify how the operating cost is affected by various system parameters. Ultimately, the cost of utilizing MAG*SEPSM technology for groundwater remediation will be compared to that of other commercially available pump-and-treat technologies. Specific accomplishments include:

- Completed chemical analyses for potential application of using the MAG*SEPSM particles in a 
groundwater remediation system for the contaminated waters from SRS D Area, $F$ and $H$ Area, and Berkeley Pit has been completed.

- Completed a review of existing monitoring data and the SRS D Area site was selected for the technology demonstration.

- Identified a candidate adsorber material (the amino form of iminodicarboxylic acid) for selective removal of contaminants. Optimization efforts are underway to combine the magnetic particle and the functionalized resin that provides the best system performance.

- Approved the characterization plan for the demonstration on September 9, 1994.

- Approved the permitting for the EnviroWall Barrier on September 16, 1994.

- Approved the location for all the monitoring wells on October 5, 1994.

- The Treatability Study Workplan and the Waste Treatment Plan was submitted to EPA, Region IV and the South Carolina Department of Health and Environmental Control on January 20, 1995.

- SRS was scheduled to complete installation of the monitoring wells on March 10, 1995.

- The construction, installation, and integration of EnviroWall's barrier containment system with BRADTEC's MAG*SEP ${ }^{\text {SM }}$ technology and BWNT's OGMS is scheduled to be completed in early FY95. The field demonstration of these integrated systems is scheduled for summer 1995.

\section{BENEFITS}

The benefits of the MAG*SEPSM technology include:

- applications for the removal of heavy metals in groundwater or an effluent stream;

- applications in situ and ex-situ; and

- minimal generation of secondary waste.
The use of a barrier to contain contamination in conjunction with subsequent treatment of the groundwater collected behind the barrier using $M A^{*} S E P^{S M}$ will serve to prevent the spread of contamination as well as to more effectively remediate sites. This methodology is expected to result in lower remedial costs and improved remedial efficiency.

\section{COLLABORATION/TECHNOLOGY}

\section{TRANSFER}

The project team for this effort includes ANL, Bradtec U.S., Inc., Westinghouse Savannah River Company, Barrier Member Containment Corporation, BWNT, E.I. du Pont, and RUST Environmental and Infrastructure. Bradtec has exclusively licensed the MAG*SEP ${ }^{*}$ concept for application in North America.

\section{For further information, please contact:}

\author{
Michael Dunn \\ Principal Investigator \\ Bradtec U.S., Inc. \\ (404) 640-7059
}

\section{Donald O. Johnson}

Principal Investigator

Argonne National Laboratory

(708) 252-3392

\section{Karen Jerome}

Principal Investigator

Westinghouse Savannah River Company

P.O. Box 616

Aiken, SC 29802

(803) 644-6786

\section{James E. Helt}

Technical Program Manager

Argonne National Laboratory

Idaho Site

P.O. Box 2528

Idaho Falls, ID 83403-2528

(708) 252-7335 
John L. Steele

Technical Program Manager

Westinghouse Savannah River Company

P.O. Box 616

Aiken, SC 29802

(803) $725-1830$

\section{Jeffrey $S$. Walker}

Program Manager

U.S. Department of Energy

Cloverleaf Building

19901 Germantown Road

Germantown, MD 20874-1290

(301) 903-7966
TTP Number: $\mathrm{CH} 231005$

The following TTPs support the demonstration of MAG*SEP ${ }^{* M}$ at the Savannah River Site: SR131005, SR141012,SR141013, SR141014, SR141015, and SR141016.

\section{BIBLIOGRAPHY OF KEY PUBLICATIONS}

Sliger, E., "In Situ Groundwater Treatment: Using MAG*SEPSM," Proceedings of the Spectrum '94 Conference, Atlanta, Georgia, pp. 225-230, August 14$18,1994$.

Bradtec, Groundwater Treatment Using $M A G^{*} S E P^{S M}$ Technology: Initial Development and Assessment of Process Chemistry for Selected Heavy/Transition Metal Removal from Savannah River Site and Berkeley Pit Groundwater, 1993, Draft.

Bradtec, Magnetic Separation (MAG* $S E P^{S M}$ ) Evaluation: Savannah River Site (SRS) D Area Coal Pile Runoff Site - Conceptual Design Report, 1993, Draft.

Bradtec, Particle Injection/Mixing Zone Test Report, 1994. 


\section{TASK DESCRIPTION}

The in situ microbial filter consists of a permeable wall of TCE-degrading microorganisms which is emplaced in the subsurface so that it will intercept a contaminant plume. As the plume passively flows through the biofilter with the natural hydraulic gradient, contaminants are degraded by microorganisms in the filter. The filter can be formed by direct injection of microorganisms into the subsurface to form a wall or by injecting the microorganisms into an emplaced sand trench.

Success of the in situ microbial filter for TCE degradadtion is predicated upon the development of a methanotrophic microorganism that can attach to the subsurface and degrade contaminants for an extended period of time in the absence of added nutrients. The microorganism of choice is Methylosinus trichosporium OB3b. Studies on its growth requirements revealed conditions that would enhance the expression and activity of the enzyme responsible for TCE degradation--soluble methane monooxygenase. In laboratory experiments $\mathrm{OB} 3 \mathrm{~b}$ maintained TCE degradation activity in the absence of added nutrients for up to one month.
Due to the ability of the in situ microbial filter to degrade contaminants for extended periods of time in the absence of added nutrients, this bioremediation technology avoids the problems often associated with nutrient injection, such as displacement of contaminants. Once the filter's degradation capacity becomes exhausted, the filter is replenished by adding more bacteria.

Although originally designed to treat relatively fastmoving plumes that could passively flow through the filter, the in situ microbial filter concept can also be modified to use at sites where the water is slowmoving. At these sites an adaptation of an oil field production technique called huff-and-puff is used, whereby an annular filter is set up by injecting microbes into a well. Once the filter is established, groundwater is withdrawn up through the filter to allow the microorganisms to degrade the contaminants. See Figure 2.10.

Besides groundwater flow velocity, other parameters which affect the design and effectiveness of the in situ microbial filter are groundwater $\mathrm{pH}$ and dissolved oxygen content. Groundwater $\mathrm{pH}$ needs to be in the $7.0+0.5$ range for the microbes to stay metabolically active. Dissolved oxygen content is also critical since the degradation of TCE requires oxygen. It appears that a dissolved oxygen content less than about $0.5 \mathrm{ppm}$ is inadequate.

\section{TECHNOLOGY NEEDS}

Reliable and cost-effective field technologies are needed to clean up the many sites containing groundwater that is contaminated with chlorinated

Figure 2.10. TCE Degradation Via the In Situ Microbial Filter, Huff-andPuff Adaptation 
solvents. In situ technologies, especially in situ bioremediation, provide the most economical approach.

However, bioremediation using nutrient injection techniques poses unique challenges in terms of how to deliver the nutrients to the subsurface and how to ensure that the degradative microorganisms will come in contact with the contaminants. The in situ microbial filter process is an adaptation of a bioaugmentation strategy that offers an alternative approach to solving these problems.

\section{ACCOMPLISHMENTS}

A laboratory model consisting of a 1-meter box containing a sand filter was developed. Bacteria were injected onto the sand filter and water contaminated with about $100 \mathrm{ppb}$ TCE was allowed to flow through the filter. Effluent samples were clean, indicating TCE degradation activity. The filter maintained degradation activity for up to four weeks.

\section{The Wilson Corners Site}

The first field treatability test of the in situ microbial filter concept was conducted in 1994 at the Wilson Corners site, Kennedy Space Center, National Aeronautics and Space Administration (NASA) and was jointly funded by NASA and DOE. Groundwater contamination beneath Wilson Corners originated from degreasing operations using TCE. Currently, the groundwater contains vinyl chloride (VC) and cis-1,2dichloroethylene (c-DCE) in addition to TCE, suggesting in situ anaerobic degradation of TCE by indigenous microorganisms. A downhole column device (the "treatability tool") was designed for use at the Wilson Corners site to evaluate the treatability of the water at the site using the in situ microbial filter approach.

Treatability testing at two of the most promising wells at the Wilson Corners site indicated that the site contained too much contamination and too little oxygen to support aerobic degradation of contaminants by the $\mathrm{OB} 3 \mathrm{~b}$ microbes. Although degradation occurred, contaminant could not be completely eliminated. Even though this result was disappointing, the test was considered a success in that it demonstrated the efficacy of the treatability tool itself. This tool offers a unique and valuable method for conducting in situ bioremediation treatability tests.

\section{Chico Municipal Airport, California}

A huff and puff treatability test of the in situ microbial filter concept was conducted at a site at the Chico Municipal Airport in California where there is a plume composed only of TCE. During the first few days of the test, the in situ microbial filter effectively bioremediated a $400 \mathrm{ppb}$ TCE stream to less than $10 \mathrm{ppb}$.

\section{Large-Scale Bioreactor Facility}

An Environmental Microbial Biotechnology Facility has been constructed at LLNL to grow the required biomass for field applications of the in situ microbial filter. This pilot-scale facility features a $1.5-\mathrm{kL}$ bioreactor as well as a suite of smaller bioreactors. This unique DOE facility has many potential uses and will facilitate collaboration with visiting researchers from other organizations.

\section{BENEFITS}

Groundwater contaminated with volatile organic compounds, such as TCE, is costly and time consuming to remediate using pump-and treat technology. In situ bioremediation of TCE-contaminated groundwater is seen as an attractive alternative to pump-and-treat, though it has not yet proven commercially successful. The most common approach for in situ bioremediation has been to inject nutrients to stimulate indigenous contaminant-degrading organisms. This approach has not proven to be reliable due to biofouling, inhibition of the biodegradation reaction, and a difficulty in bringing the stimulated population and contaminants into contact.

The in situ microbial filter approach provides a means to destroy contaminant plumes, without introducing the problems associated with nutrient injection, such as biofouling. Both source treatment as well as plume interception are possible using the in situ microbial filter technique. 
One of the greatest benefits of this project is the treatability tool that was recently developed to test the in situ microbial filter concept at the Wilson Corners Site. This tool will be of great utility in conducting in situ bioremediation treatability studies, including those bioremediation approaches involving stimulation of indigenous microorganisms.

\section{COLLABORATION/TECHNOLOGY TRANSFER}

Previous work has been conducted in collaboration with NASA.

The present huff-and-puff study is being performed with Brown and Caldwell.

For further information, please contact:

\section{Richard Knapp}

Principal Investigator

Lawrence Livermore National Laboratory

7000 East Avenue

P.O. Box $808 \mathrm{~L}-1$

Livermore, CA 94550

(510) 423-3328

\section{Jesse Yow}

Technical Program Manager

Lawrence Livermore National Laboratory

7000 East Avenue

P.O. Box $808 \mathrm{~L}-1$

Livermore, CA 94550

(510) 422-3521

\section{Rashalee Levine}

Program Manager

U.S. Department of Energy

Cloverleaf Building

19901 Germantown Road

Germantown, MD 20874-1290

(301) 903-7920
TTP Number: SF201101

\section{BIBLIOGRAPHY OF KEY PUBLICATIONS}

Duba, A.G., W.B. Durham, R.B. Knapp, and A.M. Wijesinghe, "A Two-Dimensional Physical Model of Coupled Processes in Bioremediation," EOS, 72: 127-128, 1991.

Hanna, M.L., D.R. Shonnard, and R.T. Taylor, "Measurements of Methylosinus Trichosporium OB3b Attachment to Sand With the Use of Disposable Mini-Column," Abstracts General Meeting American Society of Microbiologists, 248:417, 1993.

Jackson, K.J., M.L. Hanna, and R.T. Taylor, "Chemical Evolution of the Inorganic Components of the Aqueous Phase During Growth of a TCEDegrading Microbe," Geological Society of America Abstracts in Progress, 25:A436, 1993.

Knapp, R.B., D.J. Bishop, A.G. Duba, W.B. Durham, M.L. Hanna, K.J. Jackson, J.P. Knezovich, D.R. Shonnard, R.T. Taylor, and A.M. Wijesinghe, "Design of a Two-Dimensional Physical Model for In Situ Microbial Filters," EOS, 72: 127, 1991.

Shah, N.N., M.L. Hanna, J.K. Veir, and R.T. Taylor, "Characterization of Poly--Hydroxybutyrate Production by Batch Cultures of Methylosinus Trichosporium OB3b," Abstracts General Meeting American Society of Microbiologists, 249, 1994.

Shah, N.N., M.L. Hanna, K.J. Jackson, and R.T. Taylor, "Batch Cultivation of Methylosinus Trichosporium OB3b: IV. Production of Hydrogen-Driven Soluble or Particulate Methane Monooxygenase Activity," Biotechnology and Bioengineering, 1994, (in press.)

Shah, N.N., M.L. Hanna, and R.T. Taylor, "HighDensity Bioreactor Cultivation of Methylosinus Trichosporium OB3b With Hydrogen-Driven Methane Monooxygenase Activity," Abstracts General Meeting American Society of Microbiologists, 248:352, 1993. 
Shonnard, D.R., R.T. Taylor, M.L. Hanna, C.O. Boro, and A.G. Duba, "Injection-Attachment of Methylosinus Trichosporium OB3b in a Two-Dimensional Miniature Sand-Filled Aquifer-Simulator," Water Resources Research, 30:25-35, 1993.

Shonnard, D.R., R.T. Taylor, A.F.B. Thompson, and R.B. Knapp, "Hydrodynamic Effects on Microcapillary Motility and Chemotaxis Assays of Methylosinus Trichosporium OB3b," Applied and Environmental Microbiology 58:2737-2743, 1992.

Shonnard, D.R., R.B. Knapp, and R.T. Taylor, "Parameters Affecting the Motility of Methylosinus Trichosporium OB3b in Aqueous Suspensions," Abstracts General Meeting American Society of Microbiologist, 246:246, 1991.

Taylor, R.T., A.G. Duba, W.B. Durham, M.L. Hanna, K.J. Jackson, M.C. Jovanovich, R.B. Knapp, J.P. Knezovich, N.N. Shah, D.R. Shonnard, and A.M. Wijesinghe, "In Situ Bioremediation of Trichloroethylene Contaminated Water by a Resting-Cell Methanotrophic Microbial Filter," $H y$ drology Science Journal, 38:323-342, 1993.

Thompson, A.F.B., R.B. Knapp, M.L. Hanna, and R.T. Taylor, "Simulation of TCE Migration and Microbial Decay in a Porous Medium Under Conditions of Finite Degradation Capacity," Advances in Water Resources, 1993.
Taylor, R.T., A.G. Duba, W.B. Durham, M.L. Hanna, K.J. Jackson, M.C. Jovanovich, R.B. Knapp, J.P. Knezovich, N.N. Shah, D.R. Shonnard, and A.M. Wijesinghe, Simulated In Situ Methanotrophic Filter for Trichloroethylene Bioremediation, UCRL-JC-1 12040, Lawrence Livermore National Laboratory, Livermore, California, 1992.

Thompson, A.F.B., R.B. Knapp, M.L. Hanna, and R.T. Taylor, Simulation of TCE Migration and Microbial Decay in a Porous Medium Under Conditions of Finite Degradation Capacity, UCRL-JC112853, Lawrence Livermore National Laboratory, Livermore, California, 1993.

Wijesinghe, A.M., R.B. Knapp, R.T. Taylor, and M.L. Hanna, Preliminary Feasibility and Cost Analysis of the In-Situ Microbial Filter Concept, UCRL-ID111021 , Lawrence Livermore National Laboratory, Livermore, California, 1992. 


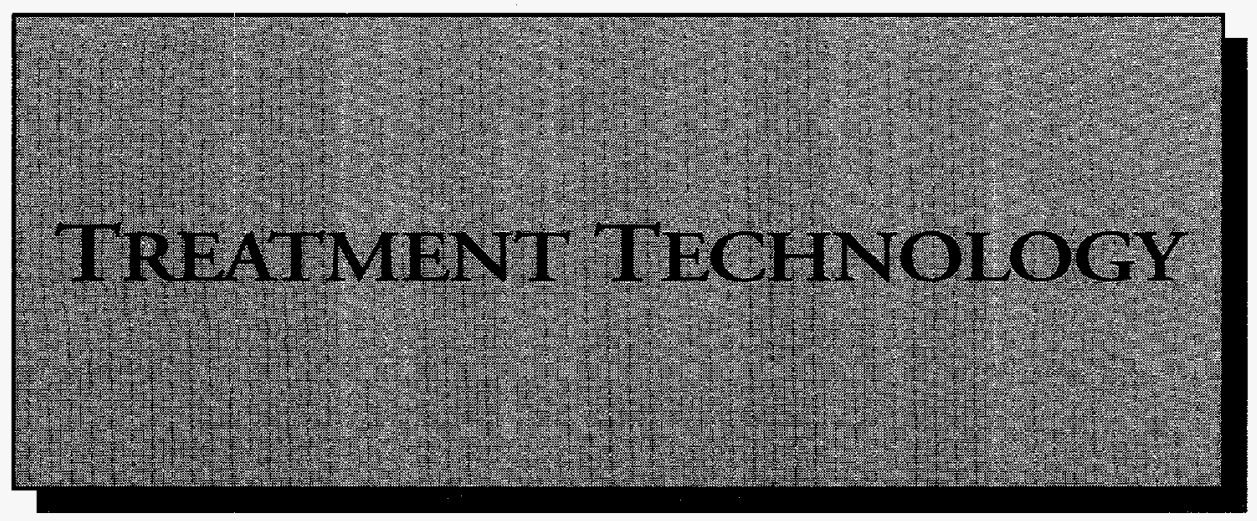


122 


\section{TASK DESCRIPTION}

The objective of this technology is to demonstrate the Thermal Enhanced Vapor Extraction System (TEVES). TEVES combines two soil heating methods, resistive and dielectric, with a vacuum vapor extraction system. The added heat will increase the mass removal rate of the soil contamination.

TEVES utilizes three rows of electrodes placed through an organic waste disposal cell in a tri-plate array configuration to a depth of 25 feet. See Figure 3.1. The center row electrodes are connected as the excitor (energy input) source. The two exterior rows are the ground/guard electrodes to contain the input energy to the treatment zone. Surface hardware connecting the electrodes are then installed. Two dual-purpose vacuum vapor extraction wells/electrodes are installed as part of the excitor array. A vacuum blower and an off-gas treatment system remove the heated soil contaminants.

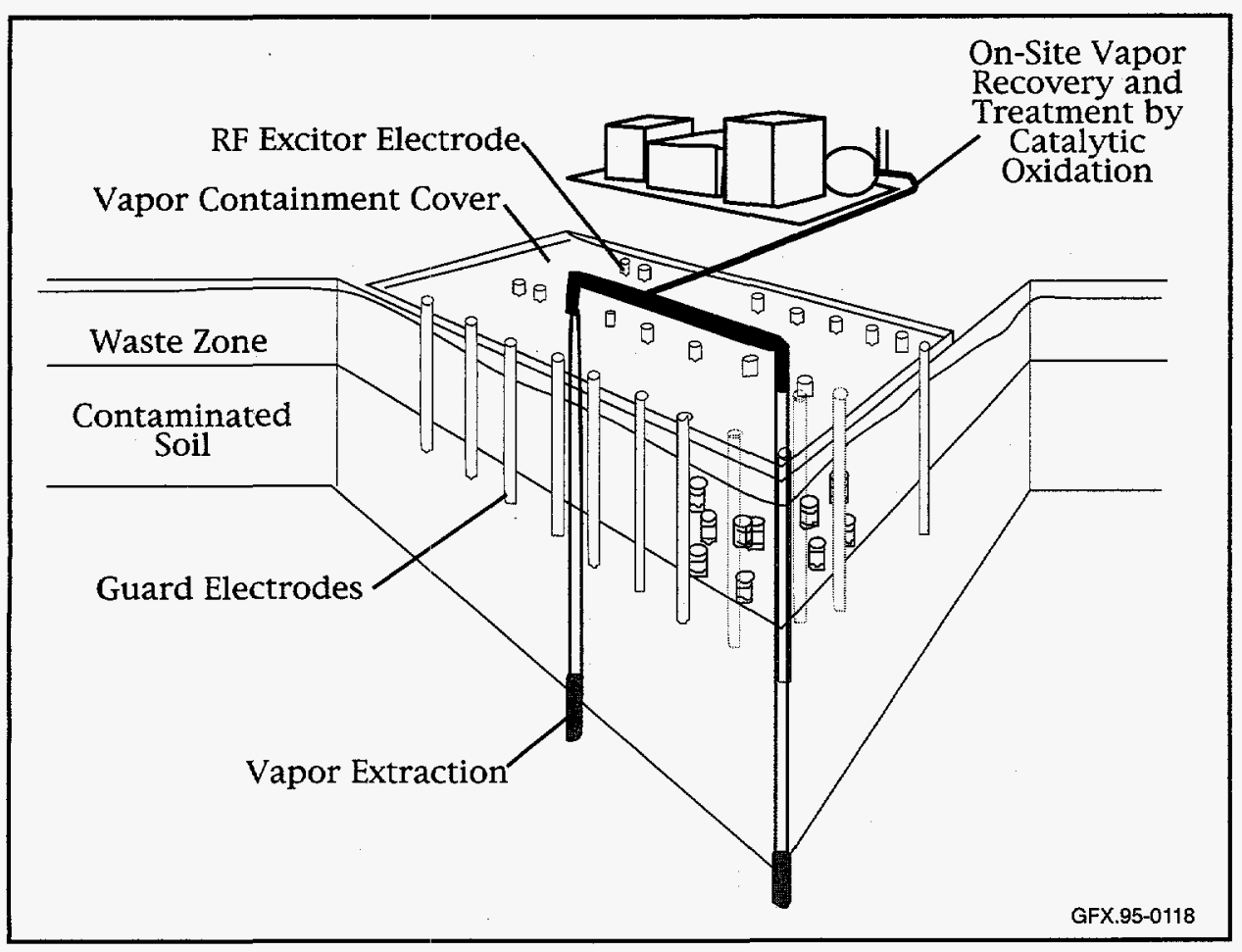

Figure 3.1. Thermal Enhanced Vapor Extraction System.
Resistive heating technology transmits powerline frequency $(60 \mathrm{~Hz})$ through the soil via the conductive path of the residual soil water. This soil heating technology vaporizes the added water into steam, which is another mechanism for enhancing contaminant removal. When the temperature nears $100^{\circ} \mathrm{C}$, the resistive heating energy input becomes restricted due to the increased soil resistance. At this point, it is not effective to continue with the resistive heating mode. Switching to the radio frequency heating is appropriate.

Radio frequency (RF) heating uses high-energy radiowaves $(2-20 \mathrm{Mhz})$ to heat the soil by dielectric heating. The RF energy is transmitted through the soils without using residual soil water as the conductive path. Energy deposition is a function of the frequency applied and the dielectric features of the soil medium. Frequency selection is based on tradeoffs of wave penetration depth and the dielectric constant of the soil profile. Lower frequencies penetrate further. By adjusting the transmitter frequency to match the impedance of the soil, soil heating can continue up to $250^{\circ} \mathrm{C}$ or greater.

\section{TECHNOLOGY NEEDS}

Landfill disposal pits, for disposing a spectrum of organic chemicals, are difficult to remediate by vacuum vapor extraction technology due to low mass removal rates. Innovative technologies that increase the mass removal rates of in situ 
extraction technologies are needed to reduce the cost of in situ remediation of difficult, high-boiling organic waste mixtures.

The field demonstration of TEVES will evaluate, for the first time, the sequential application of resistive heating followed by dielectric heating. Researchers will need to find equipment and materials in field applications that suit both heating technologies. Secondly, the treatment zone contains buried objects such as metal or glass that will have an effect on the resistive and dielectric heating. The results of a magnetic survey will be analyzed to estimate the mass and location of buried metal objects. Subsurface temperature measurements will determine the effect of buried objects on nonuniform soil heating.

\section{ACCOMPLISHMENTS}

- Completed site characterization to collect soil contaminant information for engineering design efforts.

- Began engineering design efforts with a laboratory column treatability study of actual soil removed during site characterization. This effort concluded that a treatment design temperature of $200^{\circ} \mathrm{C}$ is needed. Air permeability tests were performed and identified a highly permeable soil that was beneficial to the subsurface containment of vapor and steam expansion caused by soil heating. Subsurface containment modeling showed that only a moderate soil vacuum was necessary to contain the thermodynamic gas expansion.

- Completed soil heating (electrical and RF) and subsurface instrumentation design reports which supported the submittal of a RCRA RD\&D permit application to the New Mexico Environment Department.

- Installed all electrical service needs and the electrodes were emplaced in the ground.

- Completed final field construction of the RF shield and installation of the catalytic oxidation system as well as other instrumentation/data systems.
- The field demonstration began in November 1994 and is scheduled for completion in March 1995. The 60 hertz heating showed a significant increase in the mass removal of high boiling organics including a significant volume of oil. Post-demonstration closure activities will include a partial dig-back into the treatment zone to assess the effectiveness of contaminant removal from waste in buried containers.

\section{BENEFITS}

This technology can remove relatively low volatility soil contamination without excavation, retrieval, and ex-situ treatment. Electrical heating can be used to heat soil and remove contaminants hundreds of feet underground. In the process, soils are not changed, leaving future options still available. Based on laboratory tests, soil cleanup of $99+\%$ is possible depending on the contaminants involved.

\section{COLLABORATION/TECHNOLOGY}

\section{TRANSFER}

This project involves collaboration with the Illinois Institute of Technology Research Institute, Science \& Engineering Associates, and Groundwater Technology, Inc.

For further information, please contact:

James Phelan

Principal Investigator

Sandia National Laboratories

P.O. Box 5800

Albuquerque, NM 87185-5800

(505) $845-9882$

\section{George Allen}

Technical Program Manager

Sandia National Laboratories

P.O. Box 5800

Albuquerque, NM 87185-5800

(505) 845-7015 


\section{Skip Chamberlain}

Program Manager

U.S. Department of Energy

Cloverleaf Building

19901 Germantown Road

Germantown, MD 20874-1290

(301) 903-7248

TTP Number: AL221121

\section{BIBLIOGRAPHY OF KEY PUBLICATIONS}

Phelan, J.M., C.P. Arditor, W. Booher, "Thermal Enhanced Vapor Extraction System - Cooperative ER/OTD Technology Development, Spectrum '92," International Topical Meeting, Nuclear and Hazardous Waste Management, Boise ID, August 23-27, 1992.

Phelan, J.M., Thermal Enhanced Vapor Extraction System: Technology Demonstration to Clean-up Contaminated Soils, New Mexico Conference on the Environment, Albuquerque, NM, September 13$15,1992$.

Phelan, J.M., Thermal Enhanced Vapor Extraction System for VOCs in Soil, Fourth Annual Symposium on Emerging Technologies for Hazardous Waste Management, American Chemical Society, Atlanta, GA, September 21-23, 1992.
Dev, H., J. Bridges, G. Sretsy, J. Enk, N. Mshaiel, and M. Love, Radio Frequency Enhanced Decontamination of Soils Contaminated with Halogenated Hydrocarbons, Risk Reduction Engineering Laboratory, Office of Research and Development, U.S. EPA, Cincinnati, OH, EPA/600/2-89/008, February 1989.

Dev, H., G. Sretsy, J.E. Bridges, and D. Downey. "Field Test of the Radio Frequency In Situ Soil Decontamination Process," Superfund '88: Proceeding of the 9 th National Conference, HMCRI, November 1988.

Snow, R., and T. Bajzek, Thermal Enhanced Vapor Extraction System - Phase III Design Report, Illinois Institute of Technology Research Institute, Chicago, IL, March 17, 1993.

Phelan, J.M., and S.W. Webb, "Thermal Enhanced Vapor Extraction Systems-Design, Application, Performance Prediction, Including Contaminant Behavior," Proceedings of the 33rd Hanford Symposium on Health and the Environment on In Situ Remediation: Scientific Basis for Current and Future Technologies, Pasco, Washington, Nov. 7-11, 1994. 


\section{TASK DESCRIPTION}

This task is conducted as a joint effort under sponsorship of the DOE and the American Petroleum Institute (API). In situ remediation technologies will be tested and evaluated for source control and mass removal of DNAPL compounds in low permeability media (LPM). See Figure 3.2. This task is focused on chlorinated solvents (e.g., trichloroethylene and perchloroethylene) in the vadose and saturated zones of low permeability, massive deposits, and stratified deposits with inter-bedded clay lenses. The task includes technology evaluation, screening analyses, and field-scale testing at clean and contaminated sites in the United States and Canada.

The initial phase of the task includes preparation of a series of focus papers by a consortium of experts to

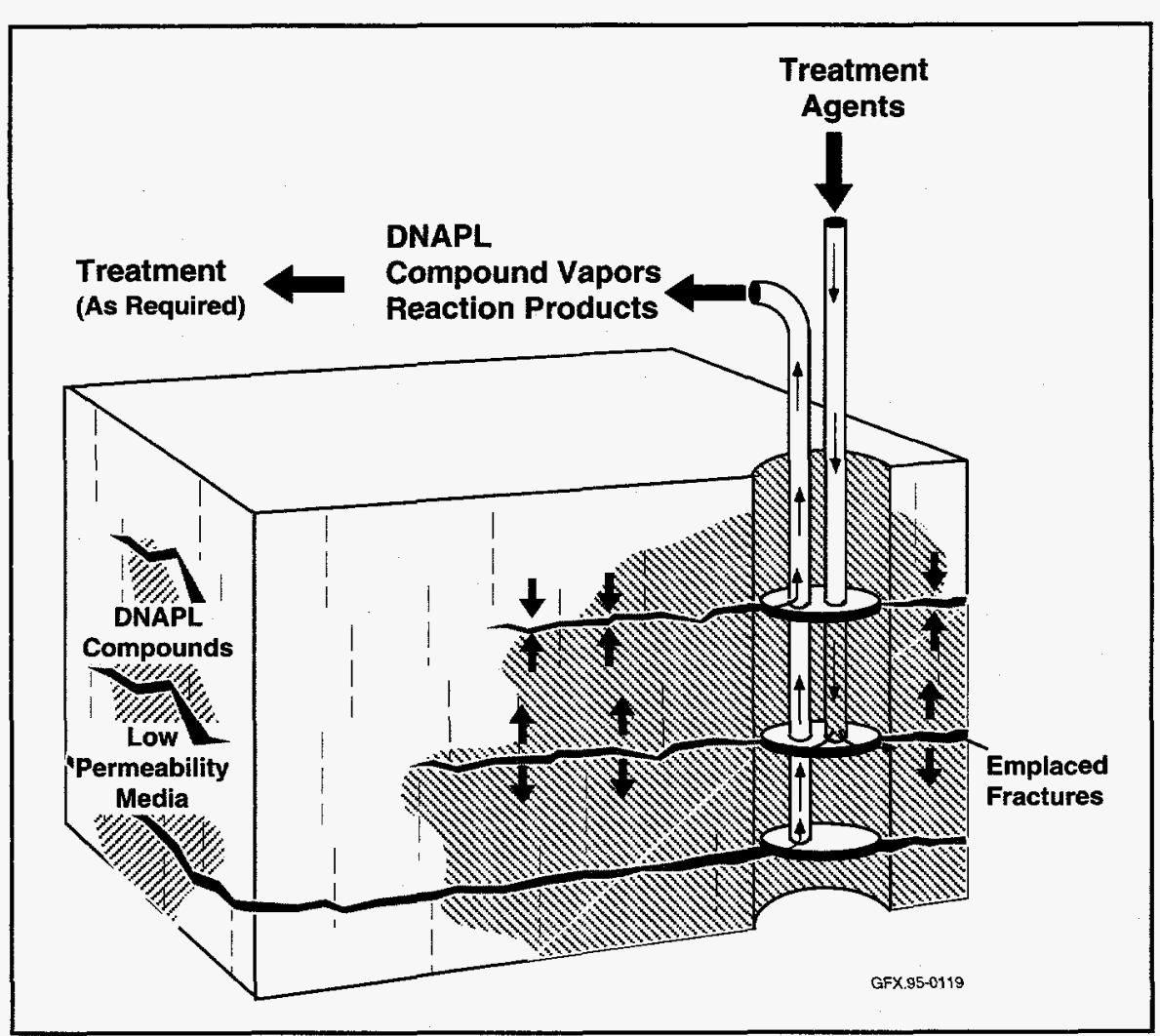

Figure 3.2. Source Control and Mass Removal of Dense Non-Aqueous Phase Liquid Compounds in Low Permeability Media. document the state-of-the-art for a variety of emerging in situ remediation technologies for DNAPLs in LPM. The focus papers will cover transport/fate processes and in situ treatment technologies, including separation and transfer processes (e.g., vapor extraction and subsurface mobilization) and destruction processes (e.g., chemical and biological degradation). Thermal enhancement methods will also be assessed, including hot air, steam injection, electromagnetic heating, and resistance heating. Finally, enabling technologies such as hydraulic and pneumatic fracturing, and mixing will be studied.

The second phase of the task includes field-scale testing of promising technologies at clean- and controlled-release test sites near Sarnia, Ontario, and Cincinnati and Portsmouth, Ohio. Capabilities also exist to conduct large-scale laboratory experiments with packed lysimeters or field-collected cores. Eventually, field testing will be conducted at a long-term contaminated site such as the X-231A or X$701 \mathrm{~B}$ units at the DOE Portsmouth site. Throughout this task, activities will be directed to understanding the processes that influence DNAPL migration and treatment in low permeability media. The task will also assess the operation and performance of the remediation technologies developed and tested.

\section{TECHNOLOGY NEEDS}

DNAPLs such as trichloroethylene and perchloroethylene constitute a major environmental problem 
across the DOE complex and the industrialized world. In addition, low permeability soil and geologic media represent site conditions that are common and problematic for environmental restoration. DNAPL compounds can migrate in low permeability media by preferentially moving into and through naturally occurring fractures, where they partition between the gas, aqueous, and sorbed phases within the fracture and matrix system. They may also form isolated "blobs" and "ganglia", known as residuals, as well as connected DNAPL pools. In the vadose zone, DNAPL compounds can continually volatilize into the soil air or leach into percolating water. In the saturated zone, DNAPLs can slowly dissolve and contribute contaminants into flowing groundwater.

The development of in situ remediation technology has generally overlooked treatment of DNAPLs in low permeability media. Conventional soil vapor extraction or groundwater pump and treatment approaches have been used, but with limited success. Removing DNAPLs in this conventional manner is also lengthy and costly. Although these technologies provide control of gaseous and dissolved contamination, they have little effect in removing or controlling the mass of DNAPLs within the subsurface. In situ treatment technologies are needed that will remove the sources of DNAPL contamination rather than merely treat DNAPL compounds in soil or in groundwater at extremely low concentrations.

\section{ACCOMPLISHMENTS}

An MOU between the OTD and API was prepared to provide a framework for DOE and API to work together in a wide range of subject areas. This project was the first effort conducted under this MOU and it was merged with an existing effort by API that focused on remediating light non-aqueous phase liquids (LNAPLs) in low permeability media.

The LNAPL project was initiated in 1992 to investigate and study remediation of petroleum hydrocarbons, such as gasoline in fine-grained soils. Results from the LNAPL effort will be made available and used to address DNAPL questions whenever appli- cable. The LNAPL work produced a series of focus papers describing processes and technologies for LNAPLs. This work was followed by a controlled release of gasoline within a $100 \mathrm{~m}^{2}$ sheet-pile enclosed test cell near Sarnia, Canada. Transport and distribution of the gasoline were monitored. A series of soil vapor extraction tests were made during the summer of 1993. During the summer of 1994, the Sarnia field tests resumed to evaluate the effects of hydro-fracturing and dewatering to enhance mass removal.

The DNAPLs in LPM project was initiated in late summer 1993. Researchers prepared DNAPL focus papers on fate and transport, treatment technologies, and risk assessment were prepared. They will be published in early 1995. These papers were used in selecting technologies to be tested and for designing the pilot-scale clean site tests and the Sarnia tests.

Clean site tests were carried out during summer and fall 1994 to conduct side-by-side comparisons of enabling technologies, such as hydraulic and pneumatic fracturing, and multiple point injection for the dispersal of treatment reagents and nutrients for bioremediation. These tests were carried out at Portsmouth, Ohio, Aber Road near Cincinnati, Ohio, and Sarnia, Canada, just outside of the controlled release cell. At Aber Road, hydraulic fracturing is coupled with heated fluid injection and tested. Additional studies on contaminant mobility and mass reduction will be carried out during 1995. It is anticipated that a full scale field test will be initiated during late 1995 .

As currently planned, field-scale testing during 1994/ 95 will continue at the test sites in Sarnia, Canada, and near Cincinnati and Portsmouth, Ohio. This work will evaluate the effects on pneumatic and hydraulic control, heat and mass transfer, and fracturing methods coupled with hot air and steam injection. Intensive monitoring of subsurface properties before, during, and after pilot tests will be used, along with tracer experiments, to describe process operation and performance and to calibrate existing models. Laboratory tests will focus on describing the fracture/matrix system to help understand short and long-term process performance. 


\section{BENEFITS}

There are many implicit benefits to be gained from the interactions and results of this project. There will be exchanges of science and technology with the national labs, academia, and private industry. Advancements in in situ treatment of DNAPLs in LPM are almost certain, and these will be made through leveraging of resources from DOE EM-50 and EM- 40 as well as API. A series of review papers will be published, documenting the state-of-the-art and practice related to transport/fate, in situ treatment, and risk assessment. Development and demonstration of technically viable in situ remediation methods for DNAPL compounds in LPM will provide appropriate solutions to a challenging problem for which acceptable solutions are unavailable today.

\section{COLLABORATION/TECHNOLOGY TRANSFER}

This project initiated cooperation in the environmental restoration and waste management area with API, its members (250 corporations in the petroleum and allied industries), DOE, the national laboratories, and DOE sites. BP Research is currently managing the LNAPL project for API and is co-managing the joint DOE/API project with ORNL. The joint project currently includes participants from over six universities and six private industries. Linkages are already in place for testing technologies at DOE sites (e.g., Portsmouth), which will facilitate project co-funding as well as rapid transfer of promising results into full-scale implementation within DOE environmental restoration programs.

For further information, please contact:

Robert L. Siegrist
Principal Investigator
Oak Ridge National Laboratory
P.O. Box 2008
Oak Ridge, TN 37831
(615) 574-7286

Anthony Malinauskas

Technical Program Manager

Oak Ridge National Laboratory

P.O. Box 2008

Oak Ridge, TN 37831

(615) 576-1092

Jeffrey S. Walker

Program Manager

U.S. Department of Energy

Cloverleaf Building

19901 Germantown Road

Germantown, MD 20874-1290

(301) 903-7966

\section{BIBLIOGRAPHY OF KEY PUBLICATIONS}

TTP Number: OR131007

Davenport, D.T., D.J. Georgopoulos, R.L. Siegrist, M.I. Morris, and O.R. "West, Technology Demonstration, Assessment, and Application for a RCRA Closure: Observations and Lessons Learned in the Process," Proceedings of the Spectrum '94 Conference, Atlanta, GA, August 14-18, 1994.

Gates, D.D. and R.L. Siegrist, "In Situ Chemical Oxidation of Trichloroethylene Using Hydrogen Peroxide," ASCE Journal of Environmental Engineering, 1994, (In press).

Gierke, J.S., C. Wang, O.R. West, and R.L. Siegrist, "In Situ Mixed Region Vapor Stripping in Low Permeability Media: 3. Model Development and Applications to Field Results and Process Operation," Environmental Science and Technology, 1994, (In review).

Huling, S.G. and J.W. Weaver, Dense Nonaqueous Phase Liquids. Ground Water Issue Paper, EPA/540/ 4-91-002, 1991 Office of Research and Development, Washington, D.C. , 1991.

Hunt, J.R., N. Sitar, and K.S. Udell, "Non-aqueous Phase Liquid Transport and Cleanup: Part I. Analysis of Mechanisms, and Part II. Experimental Studies," Water Resources Research, 24(8):1247-1269, 1988. 
In Situ Remediation of DNAPL Compounds in Low Permeability Media: Transport/Fate, Treatment, and Risk Reduction, Joint project report containing 16 focus papers authored by national experts, U.S. Department of Energy, Office of Technology Development, In Situ Remediation Integrated Program, 1994, (In review).

Korte, N.E., R.L. Siegrist, and P.M. Kearl, "In Situ Treatment of Mixed Contaminants by Process Modules Coupled with Groundwater Recirculation Systems," Proceedings, IJ'EC Special Symposium, American Chemical Society, Atlanta, GA, September, 1994.

MacDonald, J. A. and M. Kavanaugh, "Restoring Contaminated Groundwater: An Achievable Goal?," Environmental Science and Technology, 28(8):362A368A, 1994.

Siegrist, R.L., M.I. Morris, O.R. West, D.D. Gates, D.A. Pickering, et al., "Full-scale Demonstration of Physicochemical Processes for In Situ Treatment of Contaminated Soil," Proceedings Waste Management '93, Tucson, Arizona, U.S. Department of Energy, March 1993.

Siegrist, R.L. and J.J. van Ee, Measuring and Interpreting VOCs in Soils: State of the Art and Research Needs, EPA/540/R-94/506, Office of Research and Development, Washington, D.C., 1994.

Siegrist, R.L., O.R. West, J.S. Gierke, M.I. Morris, D.A. Pickering, D.W. Greene, C.A. Muhr, and D.T. Davenport, "In Situ Mixed Region Vapor
Stripping in Low Permeability Media: 2. Full-scale Field Experiments," Environmental Science and Technology, 1994, (In review).

Siegrist, R. L., D. D. Gates, O. R. West, T. L. Donaldson, L. Liang, O. F. Webb, S. L. Corder, and K. S. Dickerson, In Situ Physical/Chemical Treatment Technologies for Remediation of Contaminated Sites: Applicability, Development Status, and Research Needs. U.S. Department of Energy, Office of Technology Development, In Situ Remediation Integrated Program, Oak Ridge National Laboratory, Oak Ridge, Tennessee, 1994.

Smith, L.A. and R.E. Hinchee, In Situ Thermal Technologies for Site Remediation, Lewis Publishers, Chelsea, MI, 1992.

U.S. EPA, Dense Nonaqueous Phase Liquids -- A workshop Summary, EPA/600/R-92/030, Office of Research and Development, Washington, D.C., 1992.

U.S. EPA, Hydraulic Fracturing Technology - Technology Evaluation Report, EPA/540/R-93/505, Office of Research and Development, Cincinnati, $\mathrm{OH}$, 1993.

West, O.R., R.L. Siegrist, J.S. Gierke, S.W. Schmunk, A.J. Lucero, and H.L. Jennings, "In Situ Mixed Region Vapor Stripping in Low Permeability Media: 1. Process Features and Laboratory Experiments," Environmental Science and Technology, 1994. 


\subsection{IN SITU TREATMENT OF MIXED CONTAMINANTS IN GROUNDWATER}

\section{TASK DESCRIPTION}

The overall goal of this task is to package one or more treatment process units for in situ remediation of VOCs and radionuclides in groundwater as modular components in vertical and/or horizontal recirculation wells. This effort will span three years. It will include technology screening, modeling, experimentation, and demonstration at a DOE site.

Task objectives include: (1) evaluation of horizontal wells for inducing groundwater recirculation, (2) development of below-ground treatment modules for simultaneous removal of VOCs and radionuclides, and (3) demonstration of a treatment module coupled with a recirculation system at a DOE field site with VOCs and radionuclides present in the groundwater.

Recirculation wells are emerging technologies for treating subsurface groundwater and soil air. These specially designed wells pump water or soil air through a screened interval and transfer it back into the aquifer through a separate interval. See Figure 3.3. Treatment occurs below ground within the well casing, thereby reducing expense due to utility, maintenance, and regulatory costs. In addition, recirculation provides better control of groundwater flow through hydrodynamically connected wells. At present, practitioners use only VOC stripping as a treatment strategy.

This task consists of five phases to be accomplished over a three-year period. Phase 1 activities included selection of site characteristics, target contaminants, and appropriate unit operations. Portsmouth, Paducah, Oak Ridge, and Hanford were considered as project sites.
Portsmouth was selected based on the site's interest in implementing the technology as part of ongoing Environmental Restoration activities. The target contaminants are TCE and Tc-99.

Phase 2 activities included the collection of hydrogeologic data, hydrogeologic modeling and bench- and pilot-scale experiments. The bench experiments consisted of two parts. Various configurations were evaluated for performing air stripping of TCE within the well and various materials were evaluated for sorbing the Tc-99. The pilot-scale tests consisted of the installation of horizontal porous filter pipe at a clean test site at Portsmouth. The porous filter pipe was used instead of conventional well screen and represents the first test of this material in this country. Pumping tests and tracer

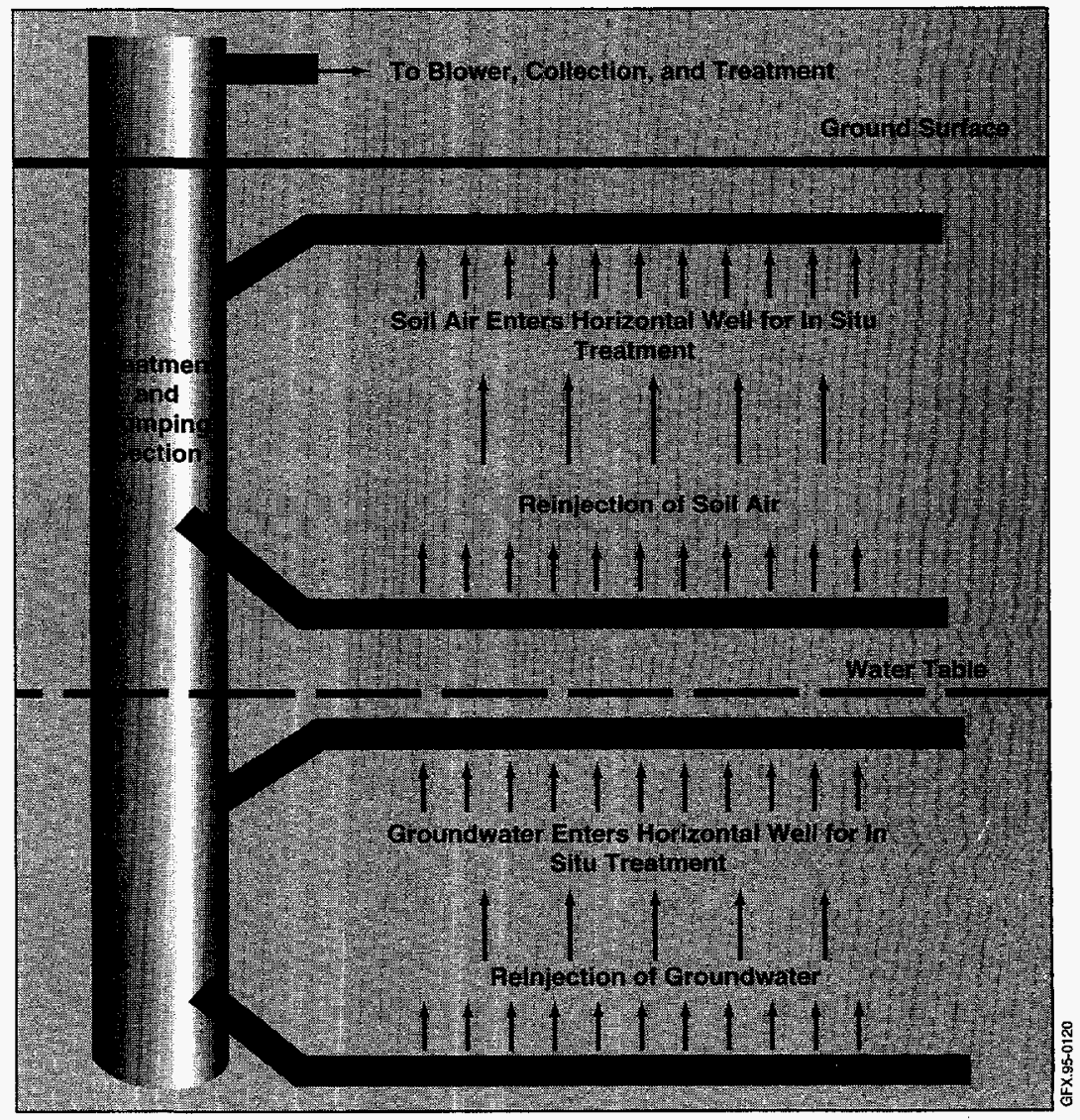

Figure 3.3. Recirculation Wells for Subsurface Groundwater and Soil Air Remediation. 
tests are also being performed as part of the pilot scale program.

The final integration of the treatment modules and the recirculation well system, including final scaleup occurs during Phase 3 . Initial testing of the wells and all ancillary equipment occurs during Phase 4 , while Phase 5 includes the field demonstration at a contaminated site and final reporting.

\section{TECHNOLOGY NEEDS}

Many DOE sites have groundwater contaminated with hazardous substances (e.g., VOCs) and radionuclides. Sites with mixed contaminants pose special treatment problems. For instance, treatment of VOC-contaminated groundwater above ground may be inefficient and costly, creating mixed or radioactive waste. Likewise, permits to reinject treated groundwater or to discharge treated water to surface waters may be difficult or impossible to obtain. Consequently, a method of treating mixed contaminants in situ would expedite treatment and be more cost effective.

\section{ACCOMPLISHMENTS}

Accomplishments on this project include the publication of a project description and a report that describes the technology screening effort that was used to select a treatment approach. These reports were used as a basis for selecting computer codes for modeling the expected benefit of the horizontal recirculation system. These reports were also used to develop the clean test site at Portsmouth for performance of the pilot test. This test area has been characterized and is suitable for a number of additional tests such as: evaluating contaminant recovery using horizontal recirculation, comparing recirculation efficiency of various fluids, and comparing groundwater tracers.

Once the clean test site was characterized, a pair of horizontal wells were installed. Instead of conventional well casing, porous, flexible, filter pipe was used. This is the first installation of such material in the United States. The porous filter pipe is made of high density polymer with essentially no microporosity. Thus, there is little potential for biofouling or for contaminant sorption. The flexible pipe installation was an ORNL-directed collaboration with FloTex and Schumacher, two German companies. German scientists assisted in the installation and also provided, at no cost to the project, laboratory tests that were used to select the appropriate filter material.

Based on the success of the installation at the clean test site, the X701B contaminated site has been selected for full-scale demonstration. This site has a well-characterized Tc-99 and TCE plume and provides an excellent location for the field program required in this project.

\section{BENEFITS}

Research of in situ treatment using groundwater recirculation was initiated by ORNL in fall 1991 with funding from the DOE International Technology Exchange Program (ITEP). As a result of this work, the environmental restoration potential of recirculation systems and their applicability to DOE Complex problems were determined. The work described herein will extend recirculation technology to many additional sites. Moreover, the development of coupled, in situ treatment modules for mixed contaminants will be applicable throughout the DOE Complex and industry as a whole. In addition, successful development of this technology will result in significant cost savings by decreasing treatment time, easing permitting, and decreasing utility costs.

Successful completion of this task will directly benefit the Portsmouth Gaseous Diffusion Plant, since it will provide an effective treatment of mixed contamination in the groundwater plume present under the X-701B site. This plume is over 0.5 mile long at the site boundary and contains high levels of TCE and TC-99. The work will benefit the Hanford site by providing alternate treatment modules that can remediate groundwater contaminated with carbon tetrachloride and other VOCs. 


\section{COLLABORATION/TECHNOLOGY}

\section{TRANSFER}

Previous work included collaboration with Virginia Technological University. Collaboration with other DOE facilities, both at the laboratory and field level, is expected to continue. For example, prior experience in horizontal well design at SRS will be considered. Research with vertical recirculation and in situ treatment of radionuclides is of interest at Hanford. Research on the ability of zero valence metals to dechlorinate TCE and sorb Tc-99 being conducted at Portsmouth, Paducah, and Oak Ridge is also being evaluated. Finally, the Portsmouth site is including this research as part of its RCRA compliance program. Interactions have already occurred with several of the environmental and construction subcontractors that are present on site. They are using the research results for preparation of compliance documents required by the regulatory community. The results of the research are also being published in open scientific literature and in various conference proceedings. A patent disclosure is also being filed on one aspect of the work.

\section{For further information, please contact:}

\section{Nic Korte}

Principal Investigator

Oak Ridge National Laboratory

P.O. Box 2008

Oak Ridge, TN 37831

(303) 248-6210

\section{Anthony Malinauskas}

Technical Program Manager

Oak Ridge National Laboratory

P.O. Box 2008

Oak Ridge, TN 37831

(615) 576-1092

Jeffrey $S$. Walker

Program Manager

U.S. Department of Energy

Cloverleaf Building

19901 Germantown Road

Germantown, MD 20874-1290

(301) 903-7966
TTP Number: OR141002

\section{BIBLIOGRAPHY OF KEY PUBLICATIONS}

Webb, O.F., R.L. Siegrist, M.R. Ally, W.E. Sanford, P.M. Kearl, and J.L., Zutman, "In Situ Treatment of VOC's by Recirculation Technologies," Proceedings of the 1994 Conference on Environmental Engineering, Boulder, Colorado, American Society of Civil Engineers, July 11-13, 1994, (in press).

Siegrist, R.L., O.F. Webb, M.R. Ally, W.E. Sanford, P.M. Kearl, and J.L. Zutman, In Situ Treatment of VOCs Recirculation Technologies, ORNL/TM12317, Oak Ridge National Laboratory, Oak Ridge, Tennessee, 1993.

Siegrist, R.L, P.M. Kearl, N.E. Korte and O.F. Webb, In Situ Treatment of Mixed Contaminants in Groundwater: Project Description, ORNL/FPO-94/ 53, Oak Ridge National Laboratory, Oak Ridge, Tennessee, 1994.

Ally, M., B. Bischoff, W. Bostick, J.M. StrongGunderson, In Situ Treatment of Mixed Contaminants in Groundwater: Review of Candidate Processes, ed. N.E. Korte, R.L. Siegrist, ORNL/TM-12772, Oak Ridge National Laboratory, Oak Ridge, Tennessee, 1994.

Korte, N.E., R.L. Siegrist, P.M. Kearl, In Situ Treatment of Mixed Contaminants by Process Modules Coupled with Groundwater Recirculation Systems, Presented to the American Chemical Society, Atlanta, Georgia, September 1994. 


\subsection{RESOURCE RECOVERY PROJECT}

\section{TASK DESCRIPTION}

The Resource Recovery Project (RRP) is evaluating, testing, and demonstrating pilot-scale technologies for reclamation of surface and groundwater from dilute heavy metal aqueous solutions. See Figure 3.4. The project emphasizes recovery of valuable mineral resources, including heavy and/or precious metals as well as industrial minerals. Economic analyses of each technology and the resources recovered will project resource recovery and/or remediation costs for DOE and industrial sites using similar technologies. The project is focused on resource conservation and end-use applications of the recovered resources by matching recovered products with resource consumers and minimizing non-useable by-products. Resource utilization addresses industrial, commercial, municipal/governmental, agricultural and recreational uses of water, metals, and other resources.

Cost/benefit analyses are an integral part of the project and include potential revenues from sales of water and mineral resources. The data obtained will demonstrate, at pilot-scale, which technologies are most effective at recovering commercially marketable products and remediating contaminated waters.

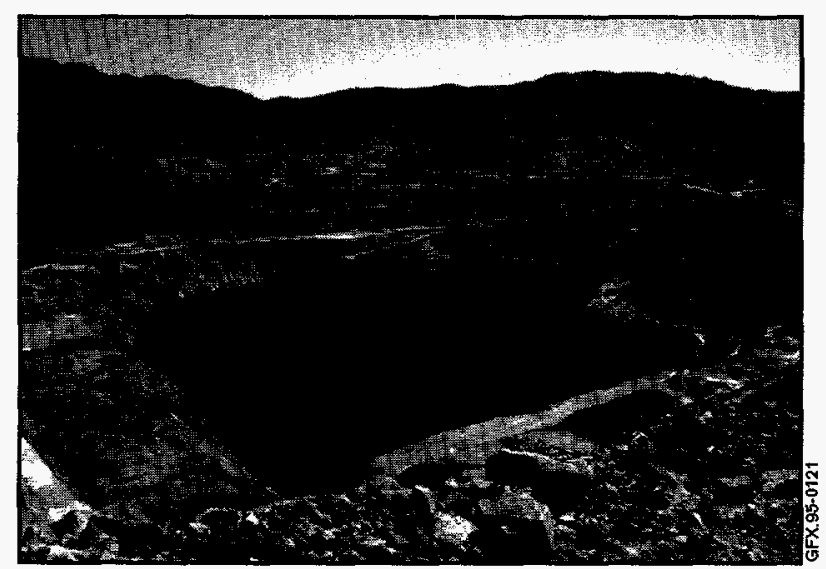

Figure 3.4. The Berkeley Pit Test Bed for the Resource Recovery Project.
Technologies already demonstrated or currently planned for demonstration under the RRP are discussed in the following paragraphs.

\section{TETRA Technologies, Inc., - High Density Solids} Process

Conventional heavy metals precipitation processes are complex and often require multiple steps and chemistries. Furthermore, the produced sludge is often $80-90$ percent water which must first be dewatered and then properly disposed of. Conventional dewatering processes only reduce water volume of the sludges by about 20 percent. TETRA Technologies' High Density Solids (HDS) process can simultaneously precipitate dissolved metals with differing solubilities at a single $\mathrm{pH}$ and in shorter cycle times. The process utilizes commercially available equipment. No special chemicals are needed. Much less water-bonding occurs with the HDS process, which greatly reduces the water volume of the sludge. In addition, the HDS sludge mass is a crystalline-like structure which allows conventional dewatering to reduce water content and achieve higher total solids. The process is further enhanced by a solids classification step to preferentially separate finer metal precipitate particles.

Vail Research and Technology Corporation and Pulsed Power Technologies, Inc. - Pulsed Electrical Discharges.

This technology is based on repetitive high energy electrical pulses from a charged capacitor bank discharged between two electrodes immersed in Berkeley Pit water to break down hazardous materials into their elemental components. An existing pulsed plasma discharge system will be used. The process of discharging high levels of electrical energy into Berkeley Pit water is expected to produce residual materials that will be marketable to copper and zinc smelters, recycling facilities, agricultural product manufacturers, and other industrial firms. A centrifuge will be used to perform a solid/liquid separation for product recovery. 
Electrochemical Design Associates - Rotating Cylinder Electrodes and Electrochemical Ion Exchange Modules.

Metals are electrically deposited directly from Berkeley Pit water in a series of stages with copper, zinc, and iron being primary targets for removal. Other trace metals will also be removed. Rotating cylinder electrode (RCE) cells at each stage will increase mass transfer rates during direct electro-deposition of metal powders. Final removal at each stage is accomplished with electrochemical ion exchange (EIX), which is a normal ion exchange except that the resin is incorporated in an electrode. Under a potential, the exchangeable heavy-metal solute is accelerated in its transport to the resin. EIX is used as an electrochemical polishing process after each RCE step for each metal removal stage. The current is periodically reversed to strip the resin.

\section{TECHNOLOGY NEEDS}

Heavy metal-contaminated water is a nation wide and global problem. Heavy metals pose a significant threat to both human health and safety as well as aquatic environments. Some metals are neurotoxicants such as lead, mercury, and cadmium, while others form potentially carcinogenic organometallics.

There are currently more than 300,000 abandoned hard rock mines identified in the United States that pose a threat to health and the environment due to acid mine drainage. Runoff containing acids, metal, and chemicals from abandoned mine sites has contaminated more than 12,000 miles of rivers and streams. More than 180,000 lakes and reservoirs in the United States are also contaminated.

Surface and groundwater contamination by heavy metals is a problem at numerous sites within the United States. Over seventy-five percent of all sites on the National Priorities List (Superfund) have surface or groundwater contamination. DOE has identified heavy-metal-contaminated ground and surface water at numerous facilities, while DoD has identified heavy-metal-contamination at over 900 Army installations, and contamination from heavy- metal-bearing waste water from 93 industrial-type DoD installations. Thus, it is necessary to develop technologies to recover heavy metals as useable products.

\section{ACCOMPLISHMENTS}

- Completed legal and regulatory issues report.

- Issued Berkeley Pit Water Quality characterization interim report.

- Established technology selection criteria and formed technology selection committee.

- Completed demonstrations of TETRA Technologies High Density Solids (HDS ${ }^{\mathrm{TM}}$ ) process. The process recovered copper, zinc, and gypsum for resale.

- Completed demonstration of metal precipitation through the application of pulsed electrical discharges proposed by Vail Research and Technology and Pulsed Power Technology. The final report is currently in preparation.

- Issued Request for Proposal for FY94 technology demonstrations. Based on solicitation, began selection of technologies and demonstrations.

- Initiated government, industry, and stakeholder partnerships for technology implementation.

- Completed modification of existing facility to house demonstrations.

- Completed Commercialization and Technology Transfer Business Plan.

\section{BENEFITS}

DOE has approximately 600 billion gallons of contaminated surface and groundwater that must be remediated. The data gathered during the demonstration and evaluation of these technologies will allow for timely and cost-effective selection of appropriate reclamation technologies at various sites throughout the DOE Complex. In addition, those technologies demonstrated through the RRP can be 
transferred to the mining industry, both home and abroad, where acid mine drainage is a multi-billion dollar problem as well as an environmental menace.

\section{COLLABORATION/TECHNOLOGY TRANSFER}

The RRP is an active national partnership with many public and private sector interests. Public sector participants include DOE, the state of Montana, EPA, Western Governors' Association, Montana Bureau of Mines and Geology, Colorado Center for Environmental Management, and the National Institutes of Water Resources. Private-sector participants include industrial mining and smelting companies, technology providers from overseas, Superfund responsible parties, environmental public interest groups, and other technology stakeholders.

The RRP prepared a Business Plan on specific technologies not yet commercialized. The plan is designed to assist and facilitate technical and business alliances among technology providers, remedial problem-holders, venture capitalists, and other financial institutions. These government/industry alliances and partnerships play a key role in the national effort to reclaim contaminated water and recover those same contaminants as marketable industrial/commercial resources.
For further information, please contact:

\section{Mike G. Lewis}

Project Manager

MSE, Inc.

P.O. Box 4078

Butte, MT 59702

(406) 494-7443

S. P. (John) Mathur

Program Manager

U.S. Department of Energy

Cloverleaf Building

19901 Germantown Road

Germantown, MD 20874-1290

(301) $903-7922$

TTP Number: PE021104

\section{BIBLIOGRAPHY OF KEY PUBLICATIONS}

Resource Recovery Project Preliminary Marketing Analysis for Potentially Recoverable Products, MSE Inc., Butte, MT, March 1994.

Resource Recovery Issues Identification and Analysis, MSE Inc., Butte, MT, March 1994.

Resource Recovery Project Berkeley Pit Water Characterization Interim Report, MSE, Inc., Butte, MT, April 1993.

Resource Recovery Project Technology Characterization Interim Report, MSE, Inc., Butte, MT, February 1993. 


\section{5

\section{TASK DESCRIPTION}

The objective of this restoration technology is to manipulate the naturally induced pressure gradients between the surface and subsurface to create a flow path of contaminant laden air from the subsurface air in the vadose zone to the surface. This is called Passive Soil Vapor Extraction (PSVE). PSVE is a subsurface technology that utilizes the difference in air pressure between the surface and subsurface. There are two different types of PSVE:

WELLHEAD PSVE If the two zones are connected by a well with a screened (open) interval above the water table, air flow results. Controls to enhance system operations include: (1) one way valves which allow air to escape from the well, but force fresh air to sweep through the soil and exit through the well, (2) monitors to determine the contaminant concentration in the escape air, and (3) a stripper or absorber to remove contaminants from the escaping air stream. Passive borehole remediation consists of installing granulated activated carbon (GAC) canisters or other non-powered treatment systems on open wellheads to capture the contaminants as they flow from boreholes.

\section{SURFACE PSVE If} there is no well present, air cycles in and out through the soil surface. Surface modification for enhanced flux is a method of changing or controlling the air entry. Examples would include pav- ing, tilling, plastic sheeting covers, aerodynamic barriers, and other surface effects. Combining these surface modifications with collection pipe networks can cause contaminated air to move laterally to a collection point to enable the contaminant to be stripped from the air, similar to the wellhead systems.

Since the driving force of this removal process (atmospheric pressure fluctuations) is provided naturally, the technology is inherently inexpensive. The key to this technology is to manipulate the natural force to remediate contaminated areas by using the knowledge of the pressure relations between the surface and subsurface at a given site. See Figure 3.5.

This information can be used to accurately install pathways, such as wells and pipe collection networks, to remove contaminants. The flow through these pathways can then be controlled by a solarpowered, microprocessor-operated valving system

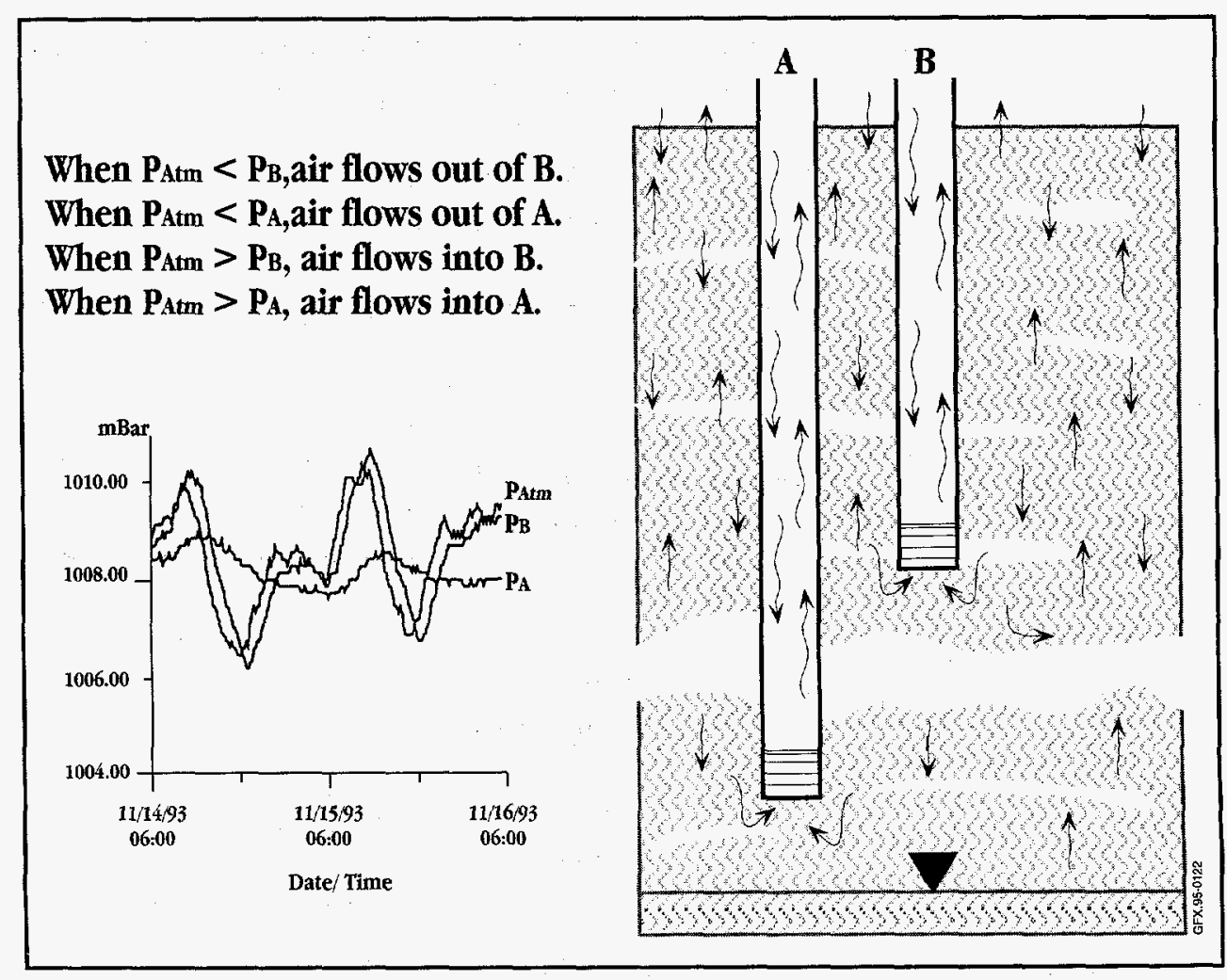

Figure 3.5. Barometric Pressure Fluctuations. 
or by wind or solar-powered pumping systems to optimize and economize the performance of the PSVE.

\section{TECHNOLOGY NEEDS}

One of the most significant problems affecting DOE sites is subsurface contamination by chlorinated solvents. These solvents tend to accumulate in the finer sediments of the unsaturated zone, where they serve as a continuing source of contamination to the water in the aquifers below. PSVE technology is applicable to the removal of residual volatile contaminants in the unsaturated zone, while inhibiting the downward migration of the contaminant.

When active soil vapor extraction, the baseline technology, removes contamination in the unsaturated zone, a residual remains that is resistant to the active extraction process. When the point where a residual remains is reached, the baseline technology becomes progressively less cost-effective due to the expense of running the active extraction equipment (i.e., vacuum motor-blowers) over a long period of time.

PSVE technology is a low-cost complement to active vapor extraction. Using passive soil vapor extraction, the residual contaminant can be removed effectively and efficiently by tailoring the removal process to the physical and chemical limitations affecting the situation.

\section{ACCOMPLISHMENTS}

- PSVE systems are currently being demonstrated at three separate DOE facilities representing different site conditions: Hanford, INEL, and the SRS.

- A 1993 PSVE Working Group was formed, consisting of experts from six DOE organizations, EPA, and private industry. The Working Group has combined its efforts to complete the technology development and move toward commercialization.

- The dynamics of the process are being studied to optimize removal rate, to minimize plume disper- sion, and to use the geology and geometry of each situation. Other related technology developments are plume control, off-gas treatment, and active extraction and bioremediation.

\section{BENEFITS}

Soil vapor flux enhancement by PSVE has the following benefits:

- It has been demonstrated to provide high performance in applications as a polishing tool after conventional active VOC extraction technologies have reached inefficiency and as a tool at the margins of subsurface plumes.

- It offers high cost savings in capital investment, maintenance, and cost of operations compared to the conventional active VOC extraction methods.

- It would work for any contaminant vapor in the vadose zone (above the water table).

\section{COLLABORATION/TECHNOLOGY TRANSFER}

The PSVE Working Group represents collaborations among Bechtel Corporation, EPA Region 10, INEL, LLNL, LANL, PNL, WSRC, and Science and Engineering Associates, Inc.

A CRADA has been established between WSRC and JND Sterling, Inc., to enhance the natural PSVE using a solar pumping system. Efforts are underway to develop a commercialization plan.

For further information, please contact:

Joe Shinn

PSVE Working Group

Lawrence Livermore National Laboratory

7000 East Avenue

P.O. Box $808, \mathrm{~L}-1$

Livermore, CA 94550

(510) 422-6806 


\section{Rashalee Levine}

Program Manager

U.S. Department of Energy

Cloverleaf Building

19901 Germantown Road

Germantown, MD 20874-1290

(301) $903-7920$
TTP Numbers: RL321105, SR141002,

AL141002, ID141001, SF241001

\section{BIBLIOGRAPHY OF KEY PUBLICATIONS}

Rohay, V., J. Rossabi, B. Looney, R. Cameron, and B. Peters, "Well Venting and Application of Passive Soil Vapor Extraction at Hanford and Savannah River," Proceedings of ER'93 Environmental Remediation Conference, Augusta, GA, Vol. 2, p.815818, 1993.

Rohay, V., Passive Vapor Extraction Feasibility Study, Technical Report WHC-SD-EN-TI-245, Westinghouse Hanford Company, Richland WA, 70pp., 1994. 


\subsection{IN SITU CORONA FOR IN SITU TREATMENT OF NON-VOLATILE ORGANIC CONTAMINANTS}

\section{TASK DESCRIPTION}

The objective of this project is to develop and demonstrate a new technology that uses electric fields to oxidize organic compounds in situ. This work is developing a practical technique for decomposing non-volatile and bound organic contaminants using gas-phase oxidants produced in situ. These gas-phase oxidants are created by electrical corona on soil particles by high voltage alternating current $(A C)$ delivered through an array of electrodes installed in the soil. The expected result is clean soil, obtained without resorting to excavation, high temperatures, or injected chemicals. Corona soil treatment is expected to treat difficult refractory compounds, such as PCBs, and may be very effective in low permeability soils. See Figure 3.6.

FY94 efforts focused on treating PCBs in soil. Byproduct formation and overall feasibility, followup testing to refine predictions regarding scale-up, and development of initial equipment specifications for large-scale testing were accomplished. Further work will evaluate the ability to remediate a high priority contaminant/soil matrix, most prob- ably PCBs in a low-permeability soil. Parallel efforts will continue toward selecting a site for field testing.

\section{TECHNOLOGY NEEDS}

The three-year project consists of research and development over a three-year period to sufficiently understand the physics and chemistry of in situ corona in terms of its potential for field applications. This project will give baseline laboratory data on treatment efficiency, reaction byproducts, energy requirements, and site applicability.

\section{ACCOMPLISHMENTS}

Based on the results of tests performed to date, it appears that in situ corona is feasible on a benchscale and is capable of removing a non-volatile contaminant such as naphthalene to below regulatory limits. The technology also appears to be fairly robust in that $99 \%$ of methylene-blue dyed sand was completely blanched to a snow-white appearance-even outside the electrode area-in another bench-scale experiment. This same methylene-blue sand was heated for 150 hours at various temperatures, including $100^{\circ} \mathrm{C}$, with very little change in color. This further suggests destruction by corona rather than by heating. Exposure of naphthalene and benzene to a simulated corona sheath in a high energy corona reactor demonstrated their rapid destruction and the simultaneous formation of carbon dioxide, with an on-line Fourier transform infrared gas analyzer.

Figure 3.6. Two Potential Mechanisms for Corona Destruction. 


\section{BENEFITS}

Based on electric field measurement tests, equations were developed to estimate voltage and power requirements associated with treating large volumes of soil. To treat a cylindrical soil volume $10-\mathrm{m}$ wide by $10-\mathrm{m}$ deep would require a power system rated at 1.2 MW and $5 \mathrm{kV}$. Calculations, based on present data, predict that soil could be treated with in situ corona at the relatively low overall cost of $\$ 100$ $\$ 120 / \mathrm{yd}^{3}$. Ex-situ treatment has been estimated to cost $\$ 200-\$ 1000 / \mathrm{yd}^{3}$.

\section{COLLABORATION/TECHNOLOGY TRANSFER}

Potential sites for DT\&E of this technology include the ORNL, Kansas City Plant, and the Twin City Ammunition Plant (non-government). Collaboration has been initiated with these sites. DoD sites are also being sought through a program led by Rice University.

For further information, please contact:

\section{Ronald Moss}

Principal Investigator

Pacific Northwest Laboratory

P.O. Box 999

Richland, WA 99352

(509) $376-4658$

\section{Steven Slate}

Technical Program Manager

Pacific Northwest Laboratory

P.O. Box 999

Richland, WA 99352

(509) 375-3903
Jeffrey S. Walker

Program Manager

U.S. Department of Energy

Cloverleaf Building

19901 Germantown Road

Germantown, MD 20874-1290

(301) 903-7966

\section{BIBLIOGRAPHY OF KEY PUBLICATIONS}

Caley, S.M., Bench-Scale Tests Using In Situ Corona for In Situ Treatment of Nonvolatile Organic Contaminants Test Plan, Pacific Northwest Laboratory, Richland, Washington, 1993.

Heath, W.O., S.M. Caley, L.M. Peurrung, B.D. Lerner, and R.W. Moss, In Situ Corona Project: Summary of Technical Progress in FY 1993, Pacific Northwest Laboratory, Richland, Washington, 1993.

Moss, R.W., and W.O. Heath, Draft Preliminary Field Site Selection for the In Situ Corona Project, Pacific Northwest Laboratory, Richland, Washington, 1993.

Heath, W.O., S.M. Caley, L.M. Peurrung, B.D. Lerner, and R.W. Moss, "Feasibility of In Situ Electrical Corona for Soil Detoxification," Proceedings of 33rd Hanford Symposium on Health and the Environment on In Situ Remediation: Scientific Basis for Current and Future Technologies, Pasco, Washington Nov. 7-11, 1994. 


\subsection{NAPL-CONTAMINATED SOIL/GROUNDWATER REMEDIATION USING FOAMS}

\section{TASK DESCRIPTION}

The innovative technology proposed for this project involves the use of foams to release and mobilize NAPL contaminants in the subsurface, coupled with in situ or ex situ bioremediation. This concept was originated by the Gas Research Institute (GRI). The foam can be produced in situ or above ground and injected into the contaminated zone. Injection/production wells (vertical, horizontal, or Bladen-lysimeters) can assist in delivering, transporting, and monitoring the foams through the subsurface. See Figure 3.7. The Bladenlysimeters are able to monitor and treat the contaminants simultaneously. They are relatively inexpensive.

The delivery of the foam, its sweep front, the foam stability, its efficacy to release NAPLs in the subsurface, and the resultant biodegradability of the foam/ NAPL mixture can be aided through the proper selection of foaming agents, nutrients, and gas/oil core aphrons. The foam should transport the contaminants upward in the groundwater, thus reducing the potential for driving the contamination to previously uncontaminated areas.

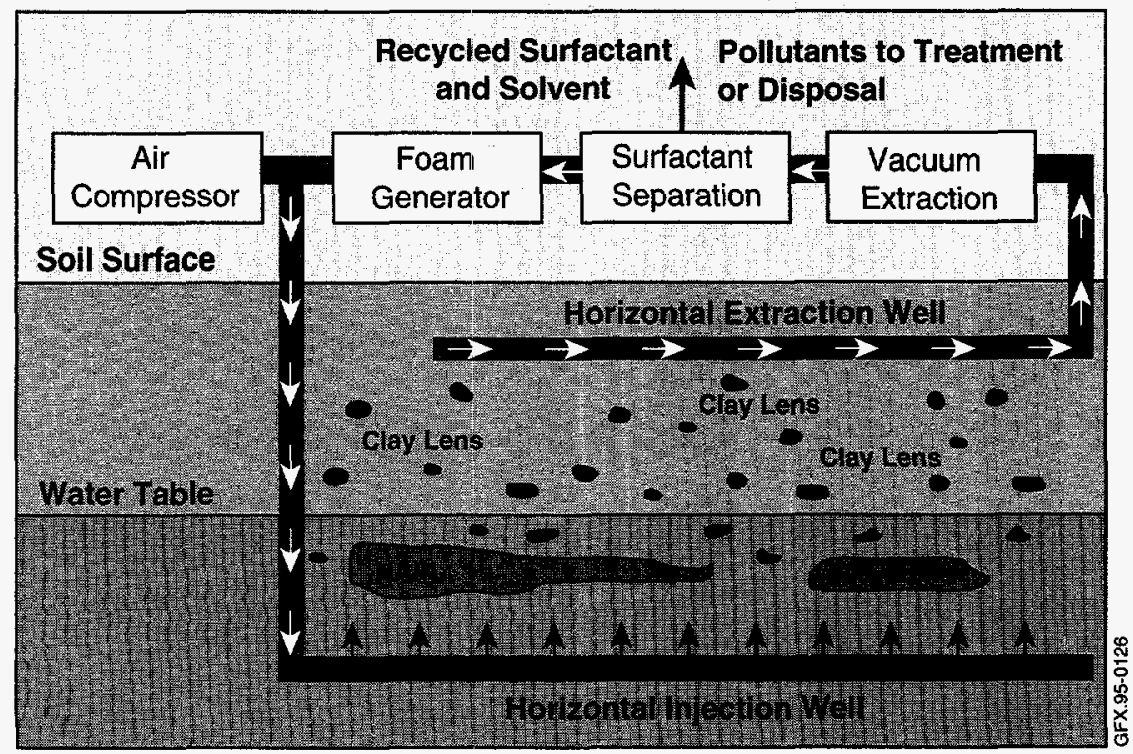

Figure 3.7. Injection/Production Wells Assist in the Delivery, Transport, and Monitoring of Foams Through the Subsurface.
This technique can also be coupled with bioremediation to increase remediation efficiency. It is anticipated that this technology can be supplied to the saturated and vadose zones for remediation of soils contaminated with chlorinated organics such as TCE or polyaromatichydrocarbons (PAHs) such as chrysene, benz(a)anthracene, anthracene, fluoranthene, or phenanthrene.

The technology can tailor the foam system to aerobic or anaerobic subsurface environments, depending on the selection of the carrier gas. This allows adequate biodegradation for the particular contaminant of concern in the foam-pollutant system. For example, TCE can be biodegraded aerobically, whereas PCE and $\mathrm{CCl}_{4}$ may need to be degraded anaerobically, because their aerobic methanotrophic degradation may not be feasible.

This project was initiated in FY94. At the end of the first year of this project, the proof-of-concept experiments will be near completion. Foams would be designed to effectively remove pollutants from soil matrices. The ability to couple bioremediation to foam treatments will also be demonstrated. In addition, initial data on foam deliverability will be obtained in laboratory systems and compared to model results. During the first year, data that help define suitable foam characteristics, effectiveness of pollutant removal, and effectiveness of bioremediation or other physical/chemical approaches will assist in estimating this technology potential relevant to surfactant flooding or other techniques. During the second and third years, the focus will be to optimize and develop suitable delivery/control systems. Modifications of methods and models currently used by the oil industry will be evaluated in large laboratory or small-field experi- 
ments to test components of the system. At the end of the third year, a full-scale demonstration will be designed.

\section{TECHNOLOGY NEEDS}

The bioavailability of surface-associated contaminants is a major concern in the remediation of soil and groundwater systems. The failure of many pump-andtreat processes is, in part, thought to be due to: (1) the slow release of contaminants, (2) a result of desorption limited release of sorbed material, or (3) because of the limited mobility of pooled and NAPL s held by capillary pressures.

Foam is a dispersant of gas bubbles separated by a thin liquid film containing surfactants. While successfully applied commercially to oil recovery, foams have not yet been applied to in situ remediation problems. Foams are currently used by the oil industry to improve crude oil recovery, resulting in $20 \%$ to $50 \%$ higher recoveries of oil for some applications.

In recent years, there has been considerable work in previously unrelated areas which has the potential to develop a new remediation technology with great flexibility and specificity. These areas include the development of designer foams, the development of physical/ chemical methods for removing pollutants from soils, and the development of presumably low cost in situ bioremediation methods.

\section{ACCOMPLISHMENTS}

Several experimental systems have helped answer key technical issues of foam remediation. Soil column experiments investigated factors affecting foam flow, foam pressure, and NAPL extraction efficiencies. Foam flow visualization and NAPL removal mechanisms were conducted with a constructed flat plate visualization cell. Preliminary investigations using Magnetic Resonance Imaging (MRI) to non-intrusively visualize NAPLs in 3-dimensions were conducted. These results were promising and suggested important insights into foam flow.

A general engineering foam flow model was developed to describe foam flow in porous media. To comple- ment this modeling effort, nuclear MRI will be used. The MRI technique can visualize NAPL ganglia in the soil matrix and can quantify NAPL removal mechanisms such as mobilization, emulsification, redeposition, coalescence, and migration through the porous media. Critical questions to be answered by the use of MRI are: (1) how much NAPL is displaced, (2) how much NAPL remains, and (3) what is the in situ configuration of the remaining NAPL portions (i.e., pools or ganglia) after the passage of foam in the soil. These questions need to be systematically addressed for various soil textures such as contaminated clays.

The foam computer program is based on convection/ dispersions species conservation equations. Foam rheological constitutive laws were written and validated against experimental data. The model uses the modified Darcy's laws for the gas/liquid foam. The purpose of the model is to provide sufficient understanding of foam flows and in situ foam-NAPL interactions so that realistic projections for field-scale remediation can be made.

The parallel-plate apparatus required to conduct the foam delivery and foam mobilization of DNAPLs in the subsurface was fabricated. Initial work was conducted on the foam flow in porous media and its effect on DNAPL mobilization. A Hewlett Packard gas chromatograph system (HP 5890 Series II), equipped with electron capture and flame ionization detectors, was procured to assist in the analyses of the chlorinated organics and other surrogate contaminants used in the studies.

\section{BENEFITS}

This new foam technology combines many of the technology needs previously described and has several potential advantages over existing technologies (e.g. surfactant flooding), including the following:

- Since the applied surfactant dosage in the foam is below the critical micelle concentration, no significant inhibition of the biodegradation is expected as compared with surfactant floods.

- The use of foams should enable the pollutants to be driven towards the surface, particularly when coupled with a vacuum extraction system to pull the 
foam/pollutant mixture upwards. As a consequence, the potential for transporting the contamination off-site is minimized.

- By performing the treatment in situ, pollutants cannot be moved from one place to another as compared with a pump-and-treat option.

- Because the foams are generated in situ, no volatile organic compound emissions are encountered.

- The technology allows aerobic or anaerobic environments to be established in the subsurface.

- Additionally, the foams can carry nutrients and microorganisms to enhance biodegradation of the mobilized pollutant.

\section{COLLABORATION/TECHNOLOGY TRANSFER}

The scope of work for the CRADA is being pursued with GRI and will also involve the Institute of Gas Technology and the Illinois Institute of Technology. The team is discussing the technology with other companies and plans a workshop with a variety of industry, government, and academic experts to identify major issues.

\section{For further information, please contact:}

\section{Robert Peters}

Principal Investigator

Argonne National Laboratory

Idaho Site

P.O. Box 2528

Idaho Falls, ID 60439

(708) 252-7773

\section{James Helt}

Technical Program Manager

Argonne National Laboratory

Idaho Site

P.O. Box 2528

Idaho Falls, ID 60439

(708) 252-7335
Jeffrey $S$. Walker

Program Manager

U.S. Department of Energy

Cloverleaf Building

19901 Germantown Road

Germantown, MD 20874-1290

(301) 903-7966

TTP Number: $\mathrm{CH} 241003$

\section{BIBLIOGRAPHY OF KEY PUBLICATIONS}

Peters, R.W., M.V.Enzien, J.X. Bouillard, J.R. Frank, V.J. Srivastava, J. Kilbane, and T. Hayes, "Non-aqueous Phase Liquids Contaminated Soil/Groundwater Remediation Using Foams," Proceedings of the 33rd Hanford Symposium on Health and the Environment on In Situ Remediation: Scientific Basis for Current and Future Technologies, Pasco, WA, November 7-11, 1994.

Enzien, M.V., D.L. Michelsen, K.C. Wang, A.F. Carney, R.W. Peters, J.X. Bouillard, and J.R. Frank, Foam Pressurel Flow Relationships Through Different Soil Types Using Ionic and Non-ionic Surfactants, Paper to be presented at the 7 th International Symposium on Gas, Oil, and Environmental Biotechnology, Colorado Springs, CO, December 12-14, 1994.

Enzien, M.V., D.L.Michelsen, R.W.Peters, J.X. Bouillard, J.R. Frank, T. Hayes, and V. Srivastava, Extraction and Mobilization of NAPLs for Enhanced In Situ Bioremediation Using Colloidal Gas- and Oil Core Aphrons, Paper to be presented at the Third International Symposium on InSitu and On-Site Bioreclamation, San Diego, CA, April 24-27, 1995.

Bouillard, J.X., M.V. Enzien, R.W. Peters, J.R. Frank, R.W. Botto, G. Cody, T. Hayes, and V. Srivastava, "Hydrodynamics of Foam Flows in Conjunction with In Situ Bioremediation of DNAPL Contaminared Subsurface," Proceedings of the Third International Symposium on In-Situ and On-Site Bioreclamation, San Diego, CA, April 24-27, 1995.

Longe, T.A., J.X. BouWard, and D.L. Michelsen, "Use of Micro-bubbleDispersion for Soil Scouring," Proceedings of the Third International Symposium on In Situ and On-Site Bioreclamation, San Diego, CA, April 24-27, 1995. 


\section{TASK DESCRIPTION}

The objective of this project is to demonstrate an inwell ultrasonic remediation process for treating chlorinated organics-contaminated groundwater at selected DOE/DoD sites. This process utilizes ultrasonics/acoustics down-hole in a well. The well installation for the system is shown schematically in Figure 3.8 .

Treatment is accomplished by circulating groundwater through the ultrasonic reactor in the well and reinjecting the treated water into the unsaturated zone, rather than transporting the treated water to the ground surface. The treated water, partially or completely free of contaminant concentrations, infiltrates back to the water table. This process is continued until contaminant concentrations in the

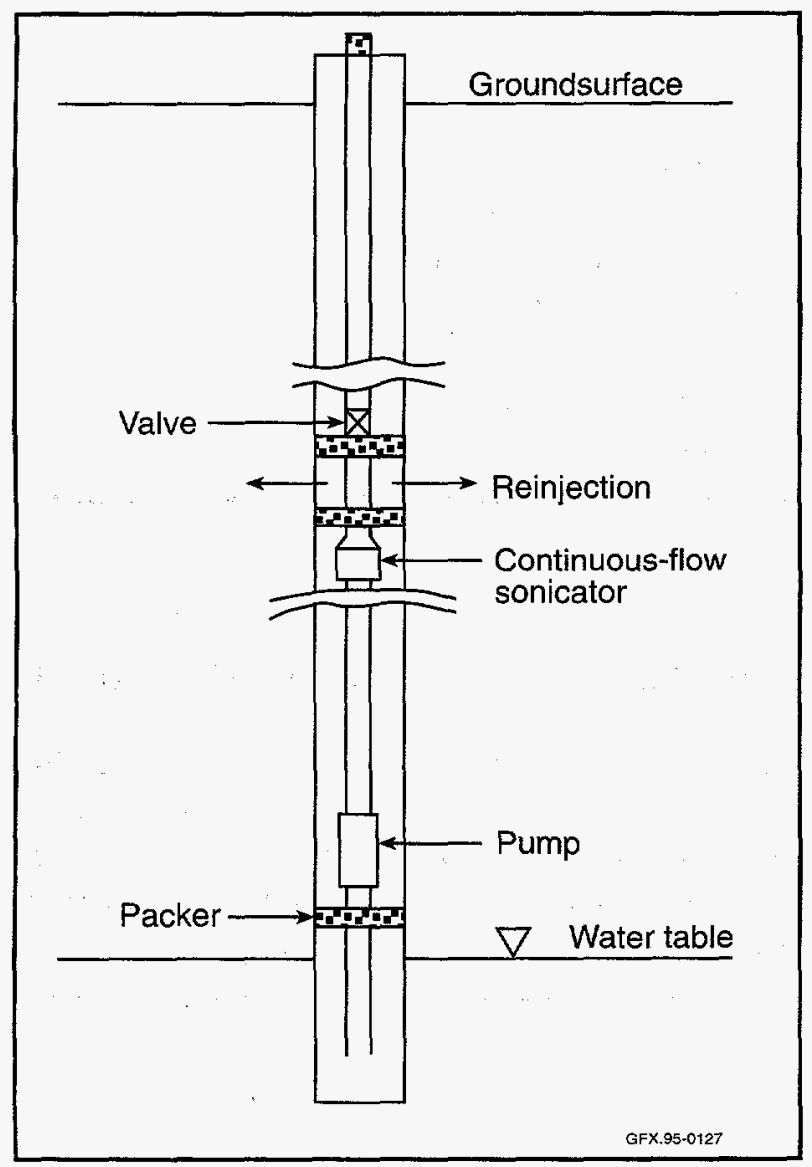

Figure 3.8. Schematic Diagram of a Sonication Well. ground are sufficiently reduced. Addition of oxidants/catalysts into the process may enhance the process efficiency and may reduce the required sonication period.

The demonstration will primarily show the effectiveness and efficiency of the process to remove toxic organic compounds, such as carbon tetrachloride and trichloroethylene, from the groundwater on a continuous basis. Phase I tasks will demonstrate the technical viability and will complete design/fabrication of a laboratory- and pilot-scale sonication reactor using improved process concepts to achieve the desired process efficiency. Upon successful development of the sonication reactor, major activities for the Phase II of this task include a field demonstration, identification, and quantification of any potential intermediate products. Completing systems engineering and economic analysis of the process are also included.

\section{TECHNOLOGY NEEDS}

Groundwater contamination by organic contaminants such as solvents and fuels is a serious concern at many DOE sites. Conventional pump-and-treat methods are expensive and may require further treatment/disposal of the removed contaminants. The in-well sonication process removes and decomposes toxic organic compounds from the aquifer without pumping the water to the surface, eliminating above-ground transportation and processing of hazardous chemicals and materials. The process converts the organic contaminants into nonhazardous and/or less hazardous products in the subsurface, thus, reducing potential secondary pollution as well as environmental and regulatory concerns.

\section{ACCOMPLISHMENTS}

In Phase I, researchers completed laboratory feasibility studies and the design of a pilot-scale sonica- 
tion reactor. The technical viability of the process was completed using carbon tetrachloride and trichloroethylene as the target contaminants. Experimental results showed that trichloroethylene concentrations (both in double distilled water and in simulated groundwater) were significantly reduced during sonication. Experimental results also showed that TCE destruction was significantly enhanced by the addition of Fenton's reagent. Preliminary economic analyses indicate a treatment cost of 50-80 cents/ 1000 gallons of water treated.

Negotiation with manufacturers for fabrication of this newly designed sonication reactor is being pursued. A DoD-contaminated site (Carswell Air Force Base) was selected for testing the ex-situ process to identify and quantify any potential intermediate products generated during the ultrasonic degradation.

\section{BENEFITS}

The in-well sonication process can continuously remove volatile and semi-volatile organic compounds from groundwater without bringing the water to the surface for treatment. It eliminates above-ground transportation, processing of hazardous chemicals, and treatment/disposal of hazardous materials. This process requires few unit operations and can be combined with other processes such as in-well vapor stripping. In-well sonication does not require that the contaminants be transferred from the aqueous phase onto a solid sorbent (e.g., GA) prior to treatment and disposal of the contaminants-laden solid sorbent. Since the process is not a thermal process and the processing will be performed in situ, environmental and regulatory concerns would be minimized.

\section{COLLABORATION/TECHNOLOGY TRANSFER}

Current investigation of this technology is being conducted by ANL in collaboration with Ogden and Company. Discussions with several private companies are underway. Potential commercial partners include S\&K Products International, Inc,, Lewis Corporation, Medsonic, Inc., Geraghty \& Miller, Inc., Ionization Research Company, and others. Negotiations are being pursued with other industrial companies interested in this technology.

\section{For further information, please contact:}

\section{Robert W. Peters}

Principal Investigator

Argonne National Laboratory

Idaho Site

P.O. Box 2528

Idaho Falls, ID 60439

(807) 252-7773

\section{James Helt}

Technical Program Manager

Argonne National Laboratory

Idaho Site

P.O. Box 2528

Idaho Falls, ID 60439

(708) 252-7335

\section{Rashalee Levine}

Program Manager

U.S. Department of Energy

Cloverleaf Building

19901 Germantown Road

Germantown, MD 20874-1290

(301) $903-7920$
TTP Number: CH241006

\section{BIBLIOGRAPHY OF KEY PUBLICATIONS}

Wu, J. and R.W. Peters, "Use of Ultrasonics for Degradation of Chlorinated Hydrocarbons in Aqueous Solution," Proceedings of the Air \& Waste Management Association Conference on Environmental Hot Topics, Chicago, Illinois, January 26-27, 1995. 


\section{TASK DESCRIPTION}

The goal of this task is to determine the conditions under which chemical oxidation can be effectively used as an in situ treatment process for soils contaminated with a variety of hydrocarbons and/or metals. The initial phase of this work includes batch and continuous laboratory-scale experiments on artificially contaminated clean soil. At successful completion of this phase, laboratory studies with contaminated soil will be conducted and a field demonstration of in situ chemical oxidation will be developed.

In the initial laboratory studies, hydrogen peroxide $\left(\mathrm{H}_{2} \mathrm{O}_{2}\right)$ and potassium permanganate $\left(\mathrm{KMnO}_{4}\right)$ will be evaluated as potential oxidants for in situ application. Low strength oxidant solutions (less than $10 \% \mathrm{H}_{2} \mathrm{O}_{2}$ and less than $6 \% \mathrm{KMnO}_{4}$ by weight) will be prepared and added to soil slurries contaminated with either diesel fuel or a mixture of TCE, PCE, and trichloroethane (TCA). The effect of the following parameters on treatment efficiency will be investigated: oxidant concentration, reaction time, oxidant dosing, and surfactant addition. The chemical composition of the post-treatment soils will be evaluated to determine what, if any, daughter products are formed as a result of the in situ chemical oxidation of the target contaminants.

Large-scale laboratory experiments using contaminated soil cores will be completed under the optimum conditions determined in the batch studies. These studies will be conducted using an apparatus that more closely replicates field conditions to investigate the effects of geohydrology, mass transfer limitation, and process scale-up. See Figure 3.9. During this phase of the study, techniques to deliver chemical oxidants in situ will also be evaluated.

Bench-scale experiments were conducted during FY94 with clean soil. Laboratory studies with contaminated soil will commence in early FY95. Efforts will also be initiated to locate a site suitable for the field-scale application of this technology. Depend- ing on site characteristics and selected oxidant delivery methods, a field demonstration of this technology may occur as early as mid-FY95.

\section{TECHNOLOGY NEEDS}

Soil and sediment contamination has been identified and documented throughout the DOE Complex. Mixtures of chlorinated hydrocarbons and metals were reported as the primary contaminants at $16 \mathrm{DOE}$ sites and at $9 \mathrm{DOE}$ facilities according to a survey from the Subsurface Science Program (DOE 1992). At the facilities, the most commonly reported chlorinated hydrocarbons (occurring at $50 \%$ or more of the facilities) were TCE, TCA, and PCE, with concentrations in the range of 0.2 to $12,000,000 \mu / \mathrm{kg}$. These chlorinated hydrocarbons are all known or suspected carcinogens which, when

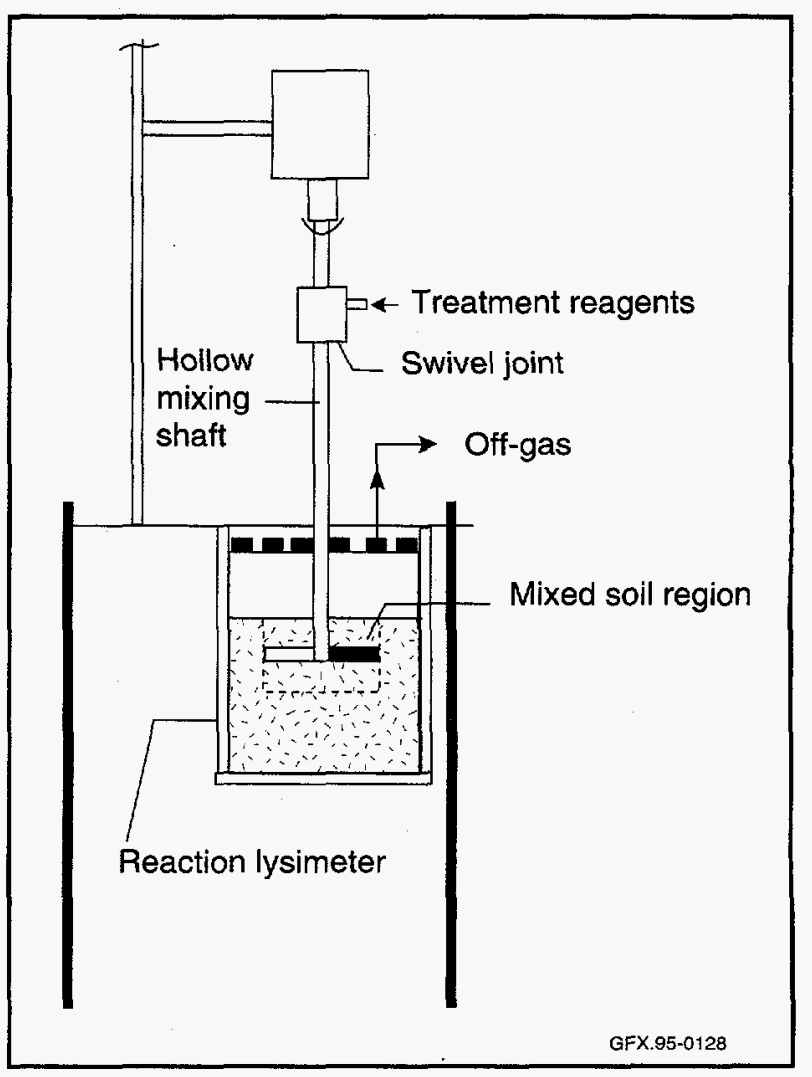

Figure 3.9. In situ Chemical Oxidation Process. 
in aqueous solutions, have shown to be amenable to oxidative processes that produce innocuous end products.

\section{ACCOMPLISHMENTS}

This current project was newly funded in FY94. A project team was assembled and a series of preliminary screening experiments were completed. The screening experiments were made using methods from previous chemical oxidation investigations at ORNL. In the current work, soil slurries contaminated with $250 \mathrm{mg}$ TCE$/ \mathrm{kg}$ soil were treated with 3.6 or $7.3 \mathrm{wt} \% \mathrm{H}_{2} \mathrm{O}_{2}$ solutions. TCE destruction rates of 74 and $97 \%$ were achieved, respectively. TCE destruction rates of greater than $98 \%$ were achieved when similarly contaminated soil slurries were treated with $1.5,3.0$, and $6.0 \mathrm{wt} \% \mathrm{KMnO}_{4}$ solutions.

A fractional factorial design with the Taguchi method was prepared for the laboratory studies. The equipment needed for the batch experiments was established. Clean soil from at least three DOE sites, ranging from sandy to high clay content soil, will be used in the experiments.

\section{BENEFITS}

In situ chemical oxidation may represent an option for rapid and cost-effective treatment of contaminated soils and sediments. In situ chemical oxidation offers several advantages over other in situ or ex-situ remediation technologies. In addition to the benefits associated with most in situ treatment processes (less worker exposure to hazardous compounds, reduced cost, and applicability to inaccessible sites), in situ chemical oxidation uses inexpensive, readily available reagents, is easily controlled, and is applicable to a wide variety of contaminants. In situ chemical oxidation may also enhance in situ biological processes.

Because in situ chemical oxidation using low strength hydrogen peroxide solutions has been previously approved and demonstrated at field scale with no adverse effects, it is expected that in situ chemical oxidation will be acceptable to regulators. With this technology, organic compounds are oxidized with low-strength chemical oxidants, resulting in the formation of simple inorganic compounds when complete oxidation is achieved. Previous experiments at ORNL indicated that complete oxidation of TCE occured when in situ chemical oxidation with $\mathrm{H}_{2} \mathrm{O}_{2}$ was employed.

\section{COLLABORATION/TECHNOLOGY TRANSFER}

Research in support of this activity is conducted at the University of Tennessee, Knoxville (UTK). Researchers at UTK will evaluate the effect of in situ chemical oxidation on metal mobility in soil. This work is a continuation of previous studies conducted in support of the Portsmouth X231-B demonstration. Several DOE sites have been identified that would be suitable for a field demonstration.

For further information, please contact:

\section{Dianne Gates}

Principal Investigator

Martin Marietta Energy System

P.O. Box 2008

Oak Ridge, TN 37831

(615) 576-0427

\section{Anthony Malinauskas}

Technical Program Manager

Oak Ridge National Laboratory

P.O. Box 2008

Oak Ridge, TN 37831

(615) 576-1092

\section{Jeffrey $S$. Walker}

Program Manager

U.S. Department of Energy

Cloverleaf Building

19901 Germantown Road

Germantown, MD 20874-1290

(301) 903-7966 
TTP Number : OR141001

\section{BIBLIOGRAPHY OF KEY PUBLICATIONS}

Siegrist, R.L., O.R. West, and D.D, Gates, Mixed Region Vapor Stripping and Oxidation Processes for NAPLs in Low Permeability Media, Special report by the American Petroleum Institute, Washington, D.C., 1994, (in press).

Gates, D.D., and R.L. Siegrist, Laboratory Evaluation of Chemical Oxidation Using Hydrogen Peroxide, ORNL/TM-12259, Report from The X-231B Project for In Situ Treatment of Physicochemical Processes Coupled with Soil Mixing, Oak Ridge National Laboratory, Oak Ridge, Tennessee, 1993.

Gates, D.D., R.L. Siegrist, and S.R. Cline, Laboratory Evaluation of the In Situ Chemical Oxidation of Volatile and Semi-Volatile Organic Compounds $U_{s-}$ ing Hydrogen Peroxide and Potassium Permanganate, Oak Ridge National Laboratory, Oak Ridge, Tennessee, 1994. 


\section{TASK DESCRIPTION}

The primary objective of this project is to conduct treatability studies on contaminated soils from $D O E$ sites to:

- determine the decontamination efficiencies of various processes on heavy-metal-contaminated soils from DOE sites;

- provide sufficient data concerning physical and chemical characteristics of the contaminated soils from the various participating DOE sites to permit optimization of treatment processes for specific soil. These data include soil particle size distribution, and physical and chemical characteristics; and

- minimize uncertainties in performance efficiency and cost as related to decontamination of soils.

The Heavy Metals-Contaminated Soil Project identified seven off-the-shelf technologies with the potential to accomplish its goals. Treatability-studies were conducted by the University of Nevada at Reno (UNR) for the following technologies:

- Air-Sparged Hydrocyclone

- Campbell Centrifugal Jig

- Centrifugal Gravity Concentrator

- Tall Column Flotation

- Automated Mechanical Flotation (Denver Unit)

- High Gradient Magnetic Separation System

- Sepor System

This project was a cooperative effort among the federal government, private industry and academia. The goal of the testing was to concentrate $80 \%$ of the contaminants in $20 \%$ of the original soil volume. Most of the seven technologies evaluated within the Heavy Metals Contaminated Soil Project for potential application to problems at DOE sites are routinely used by the mining industry. These technologies are discussed in greater detail in the following paragraphs.

\section{The Air-Sparged Hydrocyclone}

The Air-Sparged Hydrocyclone (ASH) flotation is a new particle separation technology that has been under development at the University of Utah and Advanced Processing Technologies, Inc. This technology combines froth flotation principles with the flow characteristics of a hydrocyclone, such that the ASH system can perform flotation separations in less than a second. This feature provides the ASH with a high processing capacity, 100-600 times greater than the capacity of conventional flotation or columns.

The ASH consists of two concentric right-vertical tubes, a conventional cyclone header at the top, and a froth pedestal at the bottom. See Figure 3.10a.

The inner tube has a porous wall (plastic, ceramic, or stainless steel) through which air is injected. The outer non-porous tube simply serves as an air jacket to provide for even distribution of air through the porous inner tube. The slurry is fed tangentially through the conventional cyclone header to develop a swirl flow of a certain thickness in the radial direction (called the swirl layer thickness) adjacent to the porous wall, leaving an empty air core centered on the axis of the ASH.

This swirl flow shears the injected air to produce a high concentration of small bubbles. Hydrophobic particles in the slurry collide with these bubbles. After attachment, their tangential velocity and centrifugal momentum decrease. The particles are transported radially into a froth phase that forms at the surface of the air core on the cyclone axis. The froth phase is stabilized and constrained by a froth pedestal at the underflow and thus moves toward the vortex finder of the cyclone header. It is discharged as an underflow product through the annual opening between the inner porous wall and the froth pedestal. 


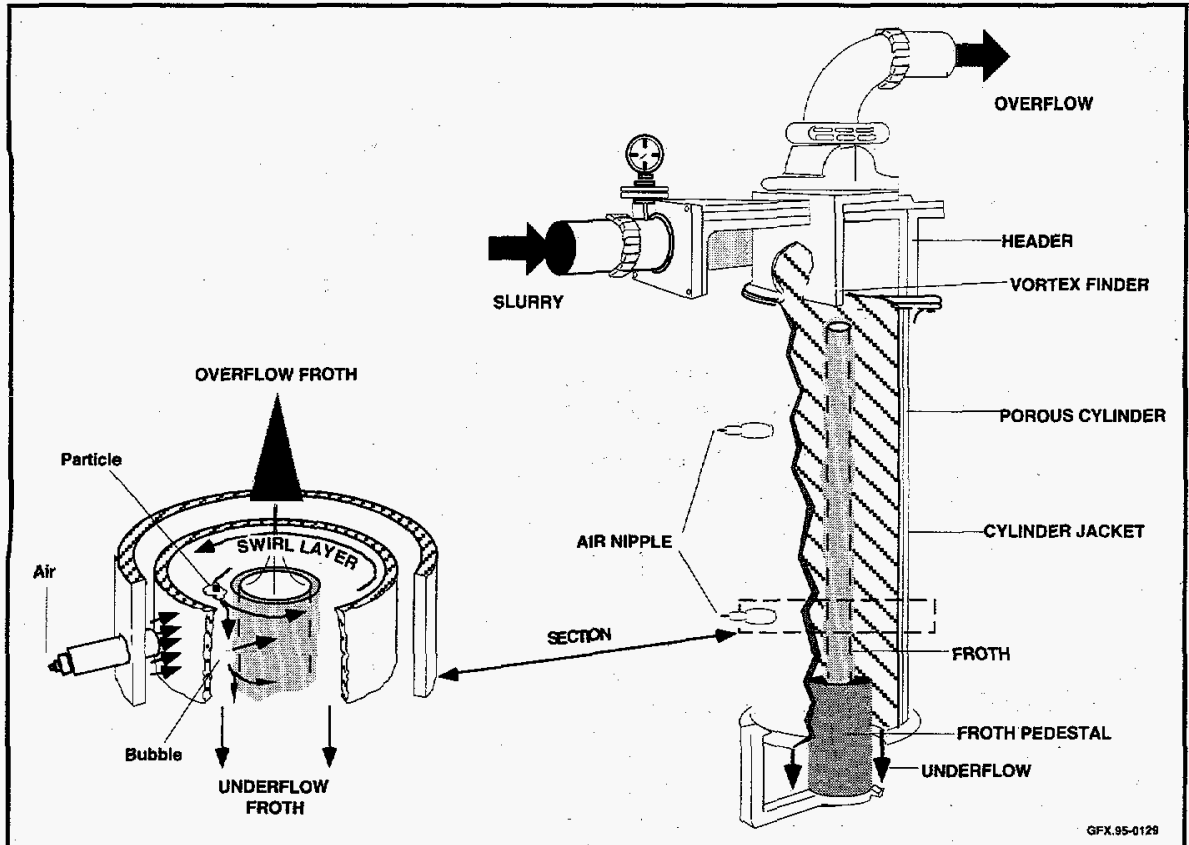

Figure 3.10a. Air-Sparged Hydrocyclone.

\section{The Campbell Centrifugal Jig}

The Campbell Centrifugal Jig (CCJ) is a patented new technology developed by TransMar, Inc., of Spokane, Washington, to separate fine, heavy mineral particles from gangue material (i.e., waste). The $\mathrm{CCJ}$ is a combination of two widely used methods of dense particle separation -- jigging and centrifuging. The CCJ combines continuous flow and pulsating bed of the standard mineral jib with the high

" $\mathrm{g}$ " forces of the centrifuge. Figure $3.10 \mathrm{~b}$ shows major elements and flow patterns in the CCJ.

The slurry enters the $\mathrm{CCJ}$ through the hollow shaft and is thrown radially outward by the vanes on the diffusser plate, impacting on the batter plate, which distributes the slurry over the rotating screen. Pulse

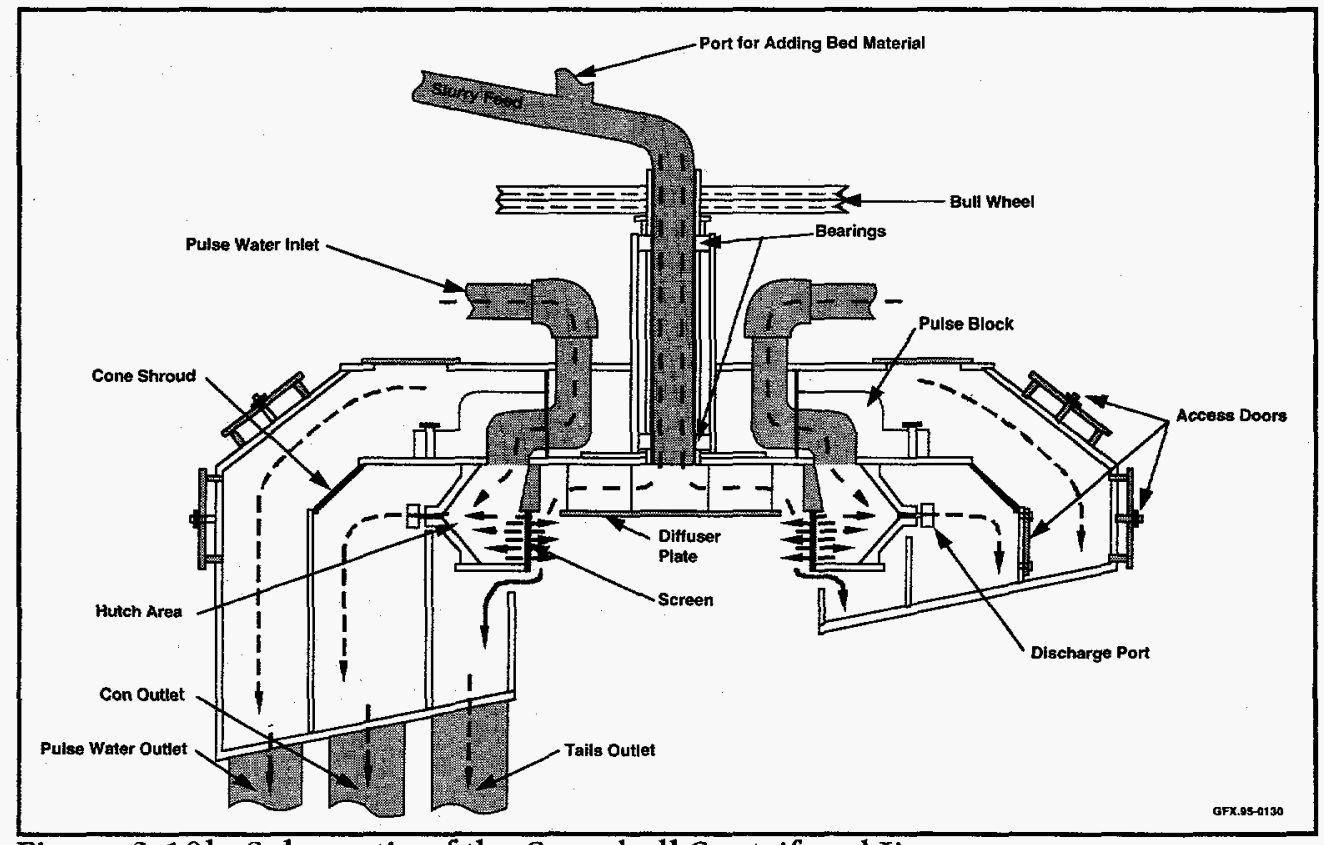

Figure 3.10b. Schematic of the Campbell Centrifugal Jig.

blocks rotate with the hutch and screen. Each time they align with one of the inlet ports, the pulse blocks provide a high pressure intensity water pulse to the outside of the screen, keeping the material fluidized. Heavy particles migrate through the bed and screen and enter the hutch to be recovered through the discharge ports as concentrate. Lighter particles are flushed downward across the jig bed and become tailings.

The Heavy Metal Contaminated Soil Project Phase 1 testing indicated that the CCJ can reliably remove from 70 to 90 percent of the heavy metal surrogate from gangue material. In addition, it can reduce the contaminated volume by factors from close to 100 to over 600 in a single pass through the system. Standard gravity separation uses several jigs in a series. It was also demonstrated that the CCJ can successfully operate on very small quantities of feed 


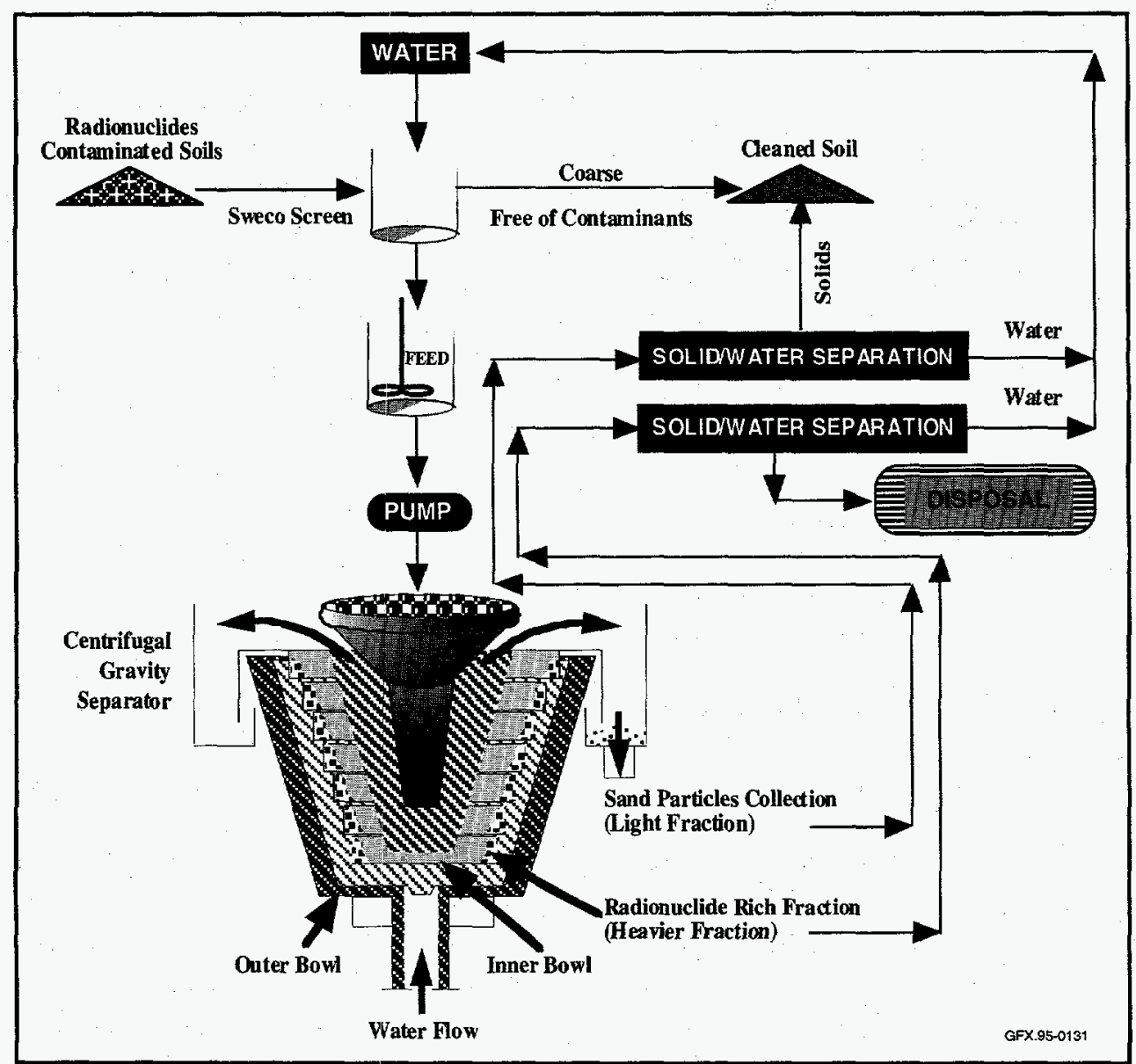

Figure 3.10c. Centrifugal Gravity Separation.

(1,500 to 2,000 pounds) and for short durations (30 minutes or less).

\section{Centrifugal Gravity Concentrator}

The Centrifugal Gravity Concentrator utilizes the principle of hindered settling combined with centrifugal action. See Figure 3.10c. This principle is possible with a water-jacketed perforated cone fed through a hollow-shaft hydraulic device.

The UNR unit is a centrifugal bowl concentrator with a water jacket around the bowl, essentially a modified centrifuge. Feed slurry enters the rotating ribbed bowl where heavier particles are trapped between the ribs. Compaction of the material between the ribs is prevented by injecting water through holes in the bowl. The water fluidizes the bed and allows heavier particles to continuously displace lighter particles. The water addition is the key to the performance of the Centrifugal Gravity Concentra- tor. The degree of fluidization controls the effectiveness of separation.

The Centrifugal Gravity Concentrator used in these experiments is a 3-inch stainless steel lab model. A motorized force of $60 \mathrm{~g}$ is exerted on the medium. The concentrator handles coarse or fine feed at $25 \%$ solids. The model's dimensions are 24 inches in length, 16 inches in width, and 20 inches in height.

\section{Tall Column Flotation}

The effectiveness of mechanical flotation devices decreases in ultra-fine particle size largely because of the large bubble size (as large as $1 \mathrm{~mm}$ ) and turbulent conditions present in the cell. The column flotation technology has been very popular and effective recently in the flotation of ultra-fine particles. Considering the fact that a large fraction of radionuclides is present in the $-\mathbf{3 8}$ micron size soil and its concentration is in parts per billion ( $\mathrm{ppb}$ ) range, it is conceivable that a combination of conditions such a fine bubble size (30-60 microns), quiescent conditions, and froth drainage mechanism prevalent in the column will result in selective separation of discrete ultra-fine radionuclides from contaminated soil.

The column flotation is a tall device, having at least a length-to-diameter ratio of 10:1. See Figure 3.10d. The reagentized slurry is fed at the upper portion of the column and travels downward. The hydrophobic particles attach to the rising stream of fine bubbles generated at the bottom of the column. The swarm of air bubble-laden particles are further 


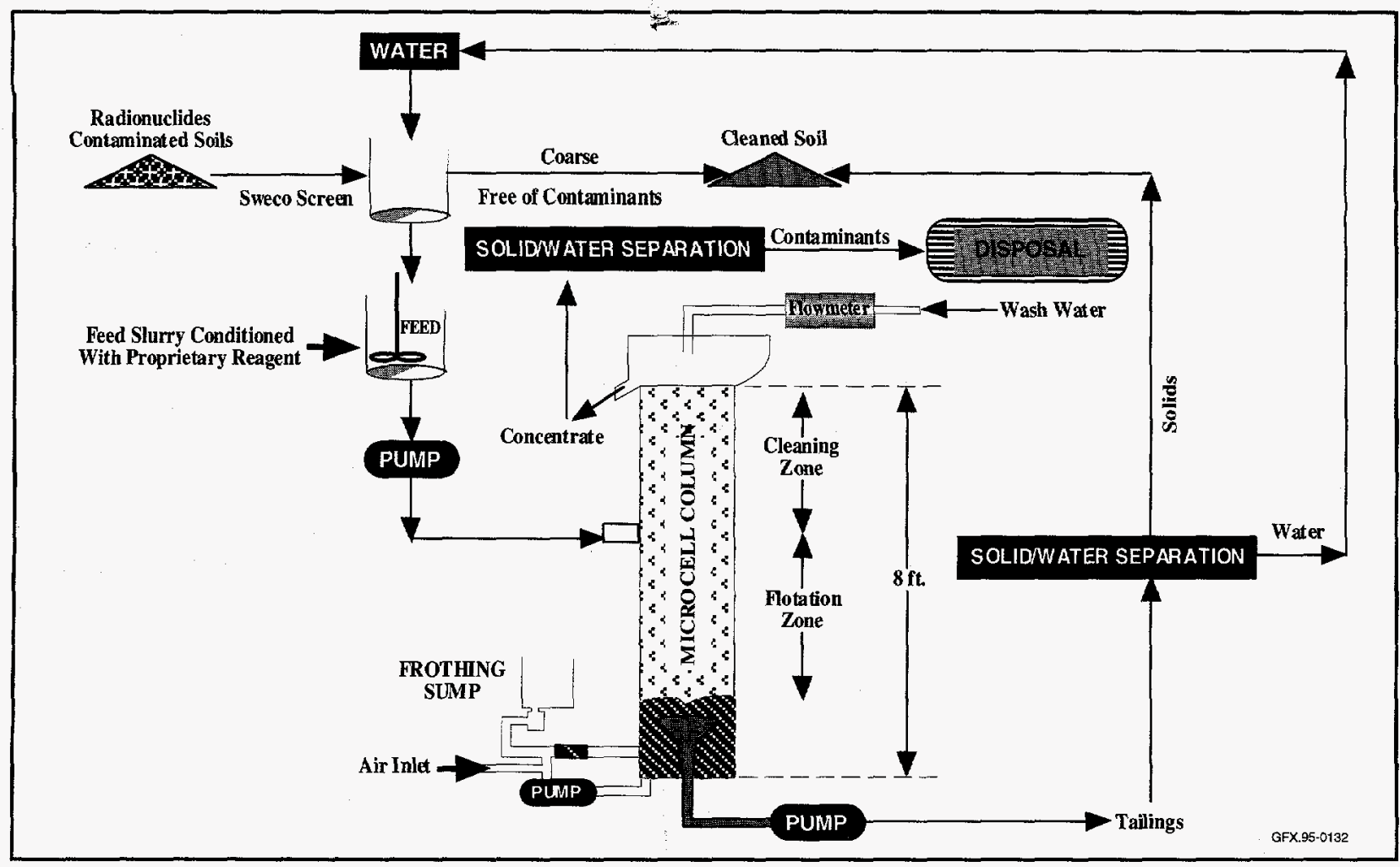

Figure 3.10d. Column Flotation.

washed at the top of the column to minimize the entrainment of unwanted material (in this case, clean soil). The radionuclide- enriched soil fraction overflows at the top of the column and hydrophilic clean soil unattached to bubbles is collected at the bottom.

The UNR column is made of plexiglass in four sections, measuring 2 inches in diameter and 10 feet tall. An external bubble generator system is attached to it at the bottom, which consists of an in-line mixer and a variable speed centrifugal pump. The level control system consists of overflow tubing, a sand-gate valve, and two flow meters (one for wash water and the other for air addition). The automatic level control system is made up of a pressure transducer, controller, and tailings discharge pump.

\section{Automated Mechanical Flotation (Denver Unit)}

Flotation is a physico-chemical process in which one mineral constituent can selectively be separated from another on the basis of surface properties. This is achieved by adding controlled additions of chemical reagents at a predetermined $\mathrm{pH}$, thereby selectively altering the surface characteristics of radionuclide enriched particulates. This treatment renders soil particles contaminated with radionuclides as hydrophobic (water repellent). Phase separation is then followed by passing air through reagentized slurry. Air bubbles selectively attach to radionuclide-enriched soil particles and are levitated to the surface in the form of froth. The separation of soil particles contaminated with radionuclides thus renders the remaining soil clean.

The Automated Mechanical Cell (see Figure 3.10e), developed by UNR, is a modification of the Denver D-12 laboratory machine that incorporates a 120 volt $A C$ adjustable automated froth removal system and a controller to maintain constant pulp-froth interface. The modification to the Denver unit is in the mounting of the main shaft. The unit has been outfitted with a 90-degree pivoting elbow with a keyed shaft allowing height adjustment and rotation of the unit into operating position. The unit has an adjustable speed motor with a two-blade froth removing paddle. Critical operational adjustments are made by 1) moving the motor housing laterally on the shaft to regulate clearance in the paddle-dam relationship without the need for any 


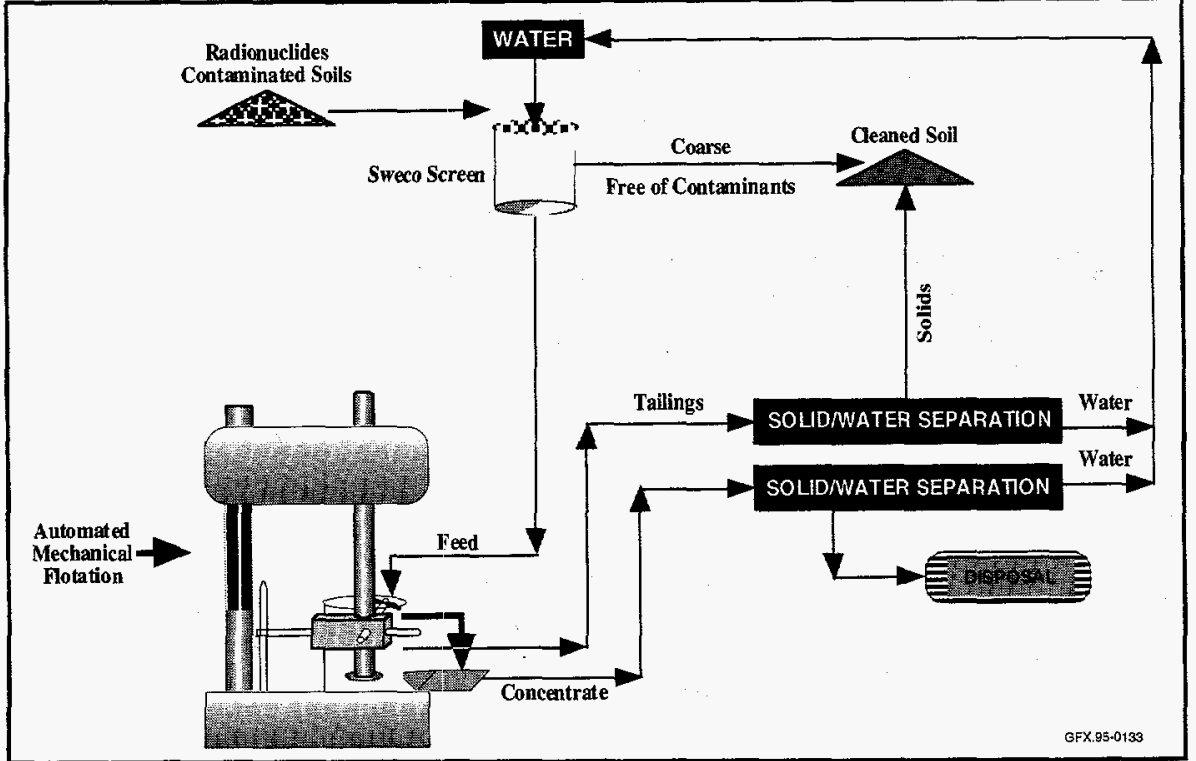

Figure 3.10e. Automated Mechanical Flow.

locking mechanism, and 2) moving the vertical collar pivot up or down to set the paddle depth into the froth. The froth collection system consists of a tapered bottom and inclined trough to collect heavy radionuclides. The pulp-froth interface level control is achieved by sensing the vertical position of a float in a sight glass by a proximity switch. The switch is connected to solenoid valves and flow regulators.

\section{High Gradient Magnetic Separation}

Los Alamos National Laboratory, in conjunction with its industrial partner Lockheed Environmental Systems and Technology Co., is exploring a promising new technique that could be used to remove radioactive contaminants from soils. The technique, high-gradient magnetic separation (HGMS), takes advantage of the fact that all actinide compounds are slightly magnetic. Much of the contaminated soil contains plutonium and uranium oxide particles. These slightly magnetic particles are attracted by very strong magnetic fields and thus can be separated from the mostly non-magnetic soil. The availability of reliable superconducting magnets, which create very strong magnetic fields, makes HGMS an attractive method for extracting actinide contaminants. Preliminary experiments with magnetic surrogates and modeling of the process have yielded encouraging results. Contaminated soil samples from DOE sites are now being tested, and the partners are working to develop the process for fullscale site remediation.

To begin the HGMS process, a slurry is made by mixing contaminated soil with water. This slurry then flows through a chamber filled with a matrix that can be magnetized, such as steel wool. See Figure 3.10f. A superconducting magnet surrounding the chamber produces a magnetic field strong enough to cause the magnetic particles, including the actinides, to adhere to the matrix. After the batch of slurry has passed through the chamber, the magnetic field is removed and water flows through the matrix to flush out the radioactive particles. The residue is then concen-

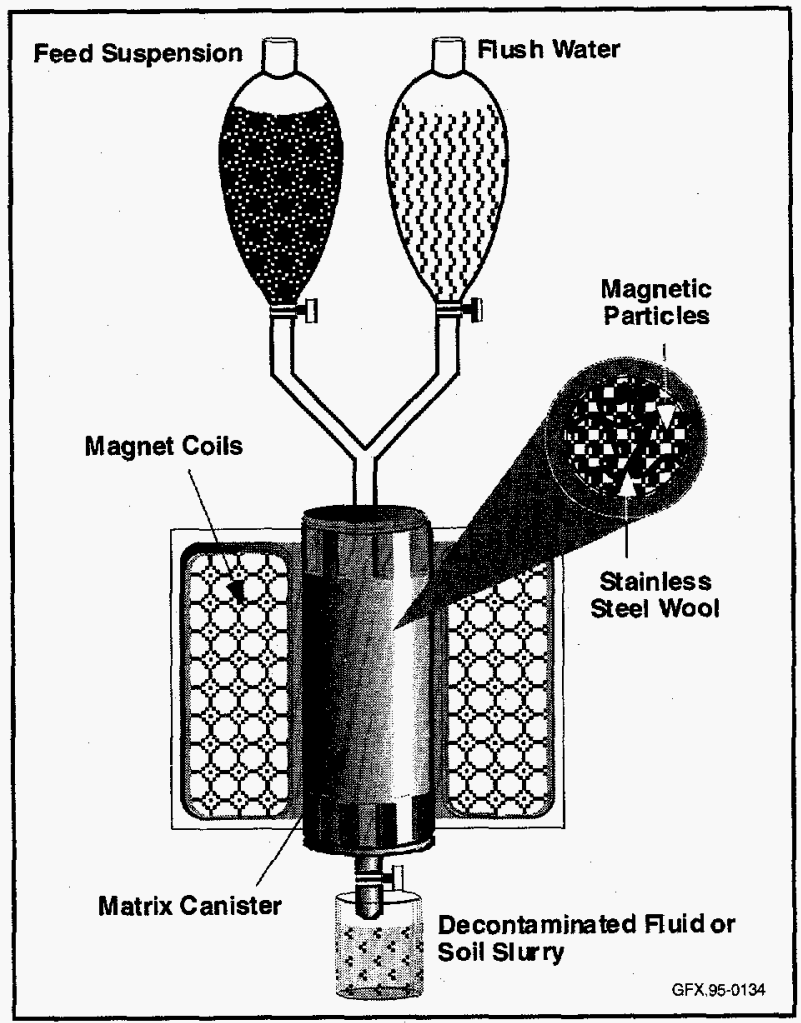

Figure 3.10f. High Gradient Magnetic Separation. 
trated and packaged for proper storage or disposal, the waste and matrix are recycled, and the soil from the slurry is returned to the environment, if it is sufficiently decontaminated.

\section{The Sepor System}

The U.S. Naval Academy (USNA) Sepor system is a commercially available, bench-scale air separation technology evaluated by the USNA to remove heavy metals from soils. The system produces two effluent streams, one containing predominately smaller sized particles, referred to as the fine discharge and the other containing predominately larger particles, referred to as the coarse discharge. It is the goal of the evaluation to concentrate most of the heavy metal in one of the effluent streams, so as to reduce the volume of contaminated soil requiring site removal.

The USNA Sepor system uses a centrifugal force effect to achieve separation. A schematic of this system is shown in Figure $3.10 \mathrm{~g}$. The contaminated soil is fed into this system through a feed pipe, whereupon it falls into a separating chamber. Separation is achieved through action of a centrifugal fan, which aerodynamically imparts a greater redial velocity to the larger size particles. The soil particles, which on average are larger than the heavy metal particles, move more

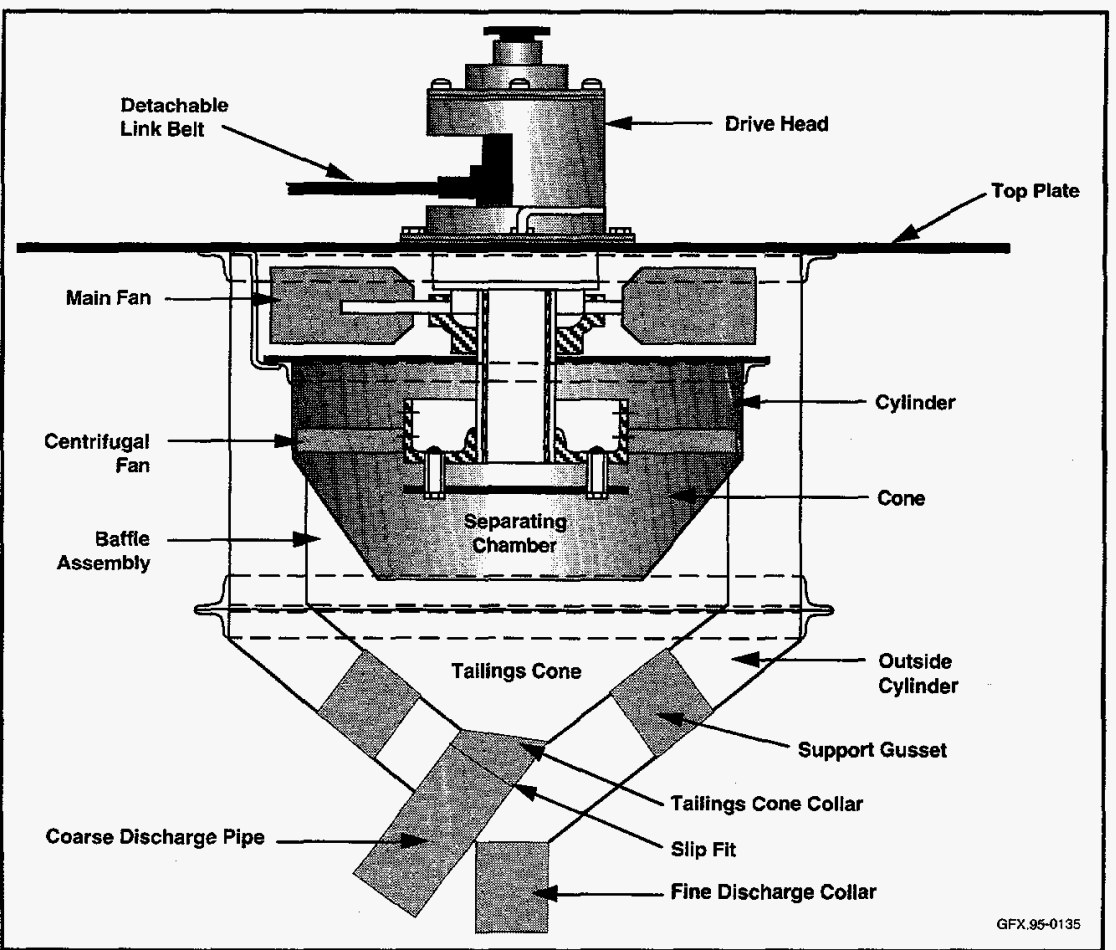

Figure $3.10 \mathrm{~g}$. SEPOR System. rapidly to the separating chamber wall, where they then drop down and are collected as they exhaust through the discharge pipe. The smaller particles are carried upward by the air, which is being circulated through the chamber by the main fan. Some of the smaller particles reenter the separating chamber through baffles, which are located near the bottom of the separating chamber. Eventually most of the smaller sized particles drop through the fine discharge pipe.

The USNA Sepor system is a bench-scale system with an 18 " diameter. The system has a soil feed capacity of $800 \mathrm{lbs} / \mathrm{hr}$. The feed rate of soil into the Sepor is controlled by a volumetric screw-type feeder, and can be varied through a wide range.

Sieving of the effluent is being investigated to improve the concentrating effect of the process. Airborne particulate emission is also being studied through the use of a real-time airborne particulate monitor. System design modifications are being implemented in order to minimize the release of airborne particles during testing as well as minimize soil hangup inside the Sepor.

\section{TECHNOLOGY NEEDS}

The cost of disposing large volumes of contaminated soil in Land Disposal Facilities (LDFs) is high. At the NTS, the current disposal fee for bulk wastes is $\$ 10$ per cubic foot, excluding excavation, handling, and transportation expenses. Therefore, the minimum cost for disposing of plutoniumcontaminated NTS soil could be on the order of $\$ 200$ million. Conventional technologies often produce waste volumes several times larger than in-place contaminated volumes. Without new technologies, projected costs could increase ten-fold. New cost-effective technologies are needed for heavymetal contaminated soils that address soil and vegetation removal, volume reduction, and waste disposal. 


\section{ACCOMPLISHMENTS}

- Modified an existing laboratory at UNR capable of handling radionuclides contaminated soils from DOE sites at Fernald, LANL, INEL, Hanford and Mound.

- Enlisted the EPA in Montgomery, Alabama, to analyze soil samples. These analyses were used in determining the efficiency of the technologies tested.

- Completed testing the technologies with plutonium and uranium. The results exceeded the requirement of $80 \%$ reduction, in many cases. Final test results are in preparation and will be issued during the second quarter of FY95.

\section{BENEFITS}

DOE estimates that it has over 200 million $\mathrm{yd}^{3}$ of contaminated soil that will need remediation. The current baseline technology for this remediation is containerization and disposal at an approved LDF. The current estimated cost, including disposal, excavation and transportation to a LDF is approximately $\$ 450 / \mathrm{yd}^{3}$. By reducing the volume of soil to be disposed of by $80 \%$, a significant dollar savings can be realized.

\section{COLLABORATION/TECHNOLOGY TRANSFER}

This project was executed for DOE by UNR through a subcontract from MSE, Inc., of Butte, Montana. MSE procured a Campbell Centrifugal Jig from Trans Mar, Inc., of Spokane, Washington, and an Air-Sparged Hydrocyclone from Advanced Processing Technologies, Inc., of Salt Lake City, Utah, for testing at the UNR facility. The United States Naval Academy (USNA) in Annapolis, Maryland, supplied the project with an air-classification unit obtained from SEPOR. The High Gradient Magnetic Separation technology was tested and evaluated by personnel from LANL. The remaining three technologies tested were available at UNR, where they were tested.
The data gathered from this project will be supplied to all participating DOE sites as well as any other site that might be interested in this type of treatment. The information will also be transferred to EM-40 for their evaluation and potential incorporation into their restoration activities. All test results will be made available to the public, the UNR library system, and anyone involved in the restoration of contaminated sites.

For further information, please contact:

Mike G. Lewis

Principle Investigator

MSE, Inc.

P.O. Box 4078

Butte, MT 59702

(406) 494-7443

\section{Manoranjan Misra}

Professor of Chemical and Metallurgical Engineering

University of Nevada at Reno/MS: 170

Mackay School of Mines

Reno, NV 89557-0136

(702) 784-4307

S. P. (John) Mathur

Program Manager

U.S. Department of Energy

Cloverleaf Building

19901 Germantown Road

Germantown, MD 20874-1290

(301) $903-7922$

TTP Number: PE031001

\section{BIBLIOGRAPHY OF KEY PUBLICATIONS}

Final reports of each individual technology are being prepared and will be available during the second quarter of FY95. 


\subsection{1

\section{TASK DESCRIPTION}

Researchers are developing an in situ, permeable subsurface treatment barrier to immobilize or destroy target contaminants. The treatment barrier is a zone of favorable redox potential created by adding chemical and/or microbiological reducing agents. The goal is to design a barrier emplacement method to effectively transform dissolved metals and radionuclides to less soluble forms and to promote the destruction of organics, especially chlorinated hydrocarbons.

A series of experiments is being performed to test different reagents or microbial nutrients for their efficiency in manipulating the redox conditions of an unconfined aquifer. Bench-scale testing is being used to determine the nature of the reactions that occur and the efficiency with which they are induced by the reagent or nutrient. Based on the bench-scale information, field experiments will be designed to test the feasibility of in situ redox manipulation. The initial field experiment will involve reduction through introduction of a chemical reagent.

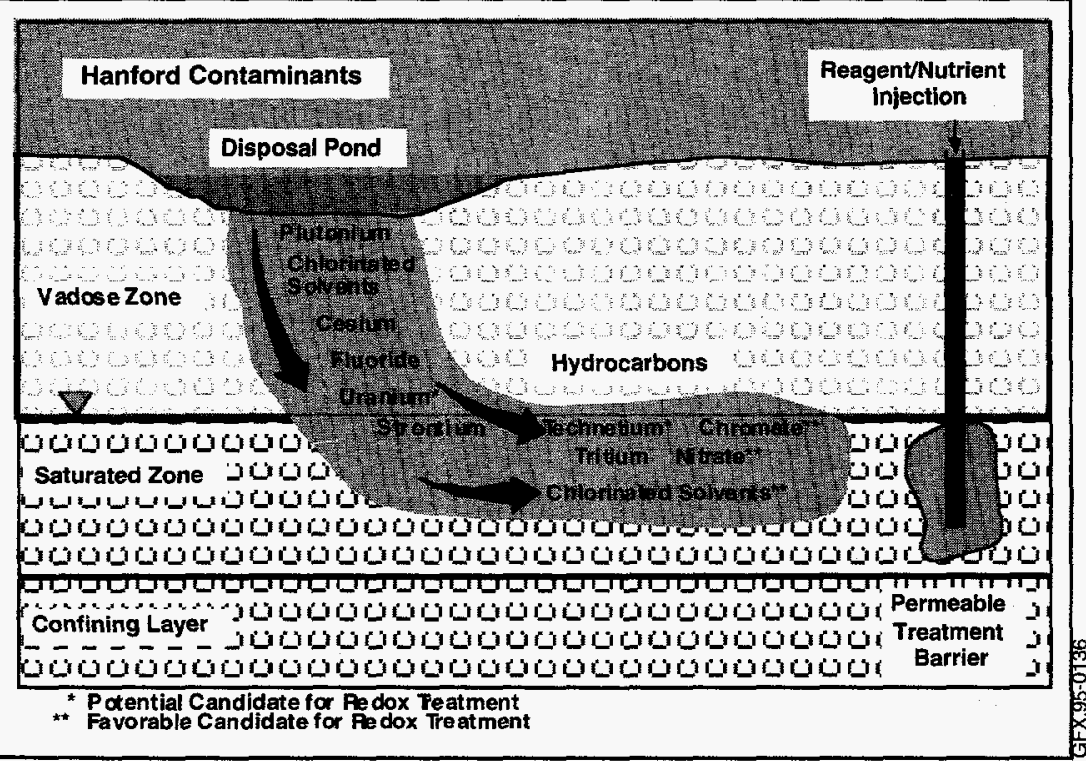

Figure 3.11. Permeable Treatment Barrier Concept.
The field test involves a forced gradient, single-well reactive tracer. The reagent is injected into the aquifer, creating a 60 - to $100-\mathrm{ft}$ diameter zone, and allowed to react for 5 to 30 days. Then water containing the reaction byproducts and any remaining reagent is pumped back out. In this manner, a permeable treatment barrier will be formed to stop any contaminant plumes. See Figure 3.11.

A key issue is the scale-up of redox manipulation from the carefully controlled conditions of the benchscale tests to the less certain conditions found in the field. The design methodology developed in this project includes tools to systematically analyze reagent and site chemistry in the context of field-scale transport. The analysis tools and framework being developed will be applicable to designing and evaluating other in situ chemical treatment technologies.

\section{TECHNOLOGY NEEDS}

An unconfined aquifer is usually an oxidizing environment. Therefore, contaminants mobile in the unconfined aquifer should be in the oxidized state. If the redox potential of the aquifer can be reduced, then a variety of metal contaminants could be immobilized. Chromate could be immobilized by reduction to highly insoluble chromium hydroxide or iron chromium hydroxide solid solution. This case is particularly favorable, because chromium is not easily reoxidized under ambient environmental conditions. In addition, uranium and technetium could be reduced to less soluble forms. Nitrate could be degraded. Laboratory studies have also shown that carbon tetrachloride and other chlorinated solvents can be degraded by microbes if the redox potential is 
reduced to the point where nitrate or iron acts as an electron acceptor in place of oxygen.

\section{ACCOMPLISHMENTS}

The fundamental research for this technology was completed under the Subsurface Science Program, Office of Health and Environmental Research.

\section{Microbiological Reduction}

Iron-reducing bacteria have been cultured under a variety of dissolved oxygen conditions in batch and continuous cultures. Cells cultured under low dissolved oxygen (less than $1 \mathrm{Mgml}^{-1}$ ) enzymatically reduced iron, uranium, and cobalt-EDTA in anaerobic assays. Cells cultured with higher dissolved oxygen (4-9 $\mathrm{Mgml}^{-1}$ ) did not exhibit metal reductase activity.

Next, the iron-reducing bacteria were tested for their potential to remediate subsurface environments contaminated with carbon tetrachloride and chromium. Cells of the environmental bacterium strain $\mathrm{BrY}$ were added to sealed, anoxic flasks containing Hanford groundwater, porous subsurface materials, and either carbon tetrachloride or oxidized chromium, $\mathrm{Cr}(\mathrm{VI})$. With lactate or hydrogen as the electron donor, $\mathrm{BrY}$ was able to dechlorinate carbon tetrachloride. Under the same conditions, it also reduced toxic soluble $\mathrm{Cr}(\mathrm{VI})$ to insoluble, less toxic $\mathrm{Cr}$ (III). Dechlorination proceeded through an indirect mechanism involving $\mathrm{Fe}$ (III) that was reduced and made chemically reactive by $\mathrm{BrY}$. However, $\mathrm{Cr}(\mathrm{VI})$ was reduced by direct enzymatic activity in the presence or absence of $\mathrm{Fe}$ (III)-bearing porous media.

\section{Chemical Reduction}

Sodium dithionite was found to reduce structural ferric iron in clays in Hanford soils. Laboratory experiments indicate that the half-life of the dithionite ion will be approximately two or three days under ambient conditions in the Hanford confined aquifer. This half-life should allow enough time for reduction of solids in the aquifer, while ensuring that dithionite does not remain as a contaminant in the groundwater for extended periods.
A series of batch experiments were conducted under controlled atmospheric conditions to determine factors affecting the aqueous stability of dithionite and its efficacy as a reductant of structural iron in clay-sized layer silicate minerals and in a sediment from the Hanford formation. These experiments showed that stability was enhanced in solutions buffered by $\mathrm{CaCO}_{3}$ near $\mathrm{pH} 8$ and with higher concentrations of dithionite.

To determine the longevity of the reduced structural iron after dithionite treatment, a flow-through column experiment using the Hanford formation sediment was conducted. The task involved reacting the reduced sediment with a fresh stream of oxygenated simulated Hanford groundwater. Changes in the $\mathrm{pH}$ and oxygen content of the effluent stream showed that a subsurface barrier created in this manner could maintain a reducing environment for approximately 45 pore volumes before being reoxidized by the groundwater.

\section{Site Selection and Characterization}

A test site at the Hanford $100 \mathrm{D}$ Area has been selected. Initial site characterization activities using existing monitoring wells have been initiated. A draft test plan has been submitted to DOE, EPA, and the State of Washington Department of Ecology.

Information from controlled laboratory and field characterization studies is being incorporated into numerical models of the field site. These analytical tools support the design of the field experiment by systematically integrating bench-scale results and site characterization data for the assessment of fieldscale performance. Operational specifications determined through the design analysis will include well placement, reagent concentration, injection and withdrawal rates, and durations of various phases of the experiment (injection, reaction, and withdrawal).

Laboratory bench-scale testing of the concept was completed in FY94. Additional testing to refine the process is planned in FY95. Field testing will be initiated in FY95. 


\section{BENEFITS}

There are numerous benefits from pursuing the destruction of chlorinated organics and the immobilization of heavy metals and radionuclides in situ. Up-front capital costs are lower with in situ redox control. The redox process can treat a variety of metals, radionuclides, and chlorinated organic solvents. This innovative technology allows placement of the treatment barrier where the contamination is located, rather than removing contaminated water to the surface for treatment. This process also avoids further disposal costs, since metals and radionuclides are immobilized in place. Since there would be no pumping during treatment, there would be no problems associated with withdrawing clean water adjacent to portions of the contaminated aquifer.

\section{COLLABORATION/TECHNOLOGY TRANSFER}

A potential site for demonstration, testing, and evaluation of this technology is the $100 \mathrm{H}$ Area at Hanford. Collaboration has been initiated with the site. The In Situ Redox Manipulation Project is also collaborating with WDC to test sonic drilling techniques at the field test site and with Schlumberger Inc. to test the applicability of geophysical techniques to characterize in situ remediation sites.

\section{For further information, please contact:}

\section{Jonathan Fruchter}

Principal Investigator

Pacific Northwest Laboratory

P.O. Box 999

Richland, WA 99352

(509) 376-3937

\section{Steven Slate}

Technical Program Manager

Pacific Northwest Laboratory

P.O. Box 999

Richland, WA 99352

(509) 375-3903
Jeffrey S. Walker

Program Manager

U.S. Department of Energy

Cloverleaf Building

19901 Germantown Road

Germantown, MD 20874-1290

(301) 903-7966

\section{BIBLIOGRAPHY OF KEY PUBLICATIONS}

Amonette, J.E., J.C. Templeton, R.A. Speed, and J.P. Zipperer, "Chemistry of Dithionite Ion in Aqueous Suspensions of Clay Minerals," Agronomy Abstracts, 1992:365.

Fruchter, J.S. 1993, "In Situ Redox Manipulation, Enhancement of Contaminant Destruction and Immobilization," Proceedings of the Technical Information Exchange Meeting on Waste Retrieval, Treatment and Processing, U.S. Department of Energy, Office of Environmental Management, Technology Development Program. March 15-17, 1993, Houston, Texas.

Gorby, Y.A., D.W. Kennedy, and J.E. Amonette, "Reduction of Structural Iron in Layered Silicates by Dissimilatory Fe(III)-Reducing Bacteria," Proceedings of the American Society of Microbiology, 1994, (in press).

Gorby, Y.A., D.J. Workman, D.W. Kennedy, and A.E. Plymale, "Transformation of Carbon Tetrachloride by an Iron-Reducing Bacterium in the Presence of Solid Phase Iron," Proceedings of the American Society of Microbiology, 1994, (in press).

Templeton, J.C., and J.E. Amonette, The Stability of Sodium Dithionite in Homogeneous and Heterogeneous Systems, $47 \mathrm{th}$ Northwest Regional Meeting of the American Chemical Society Program and Abstracts 1992:76.

Williams, M.D., S.B. Yabusaki, and C.R. Cole, "In Situ Redox Manipulation Field Experiment: Design Analysis," Proceedings of the 33rd Hanford Symposium on Health and the Environment, Pasco, Washington, November 7-11, 1994. 
Yabusaki, S.B., and C.R. Cole, Investigation of Tracer Behavior in Heterogeneous Porous Media, AGU 1993 Spring Meeting, Baltimore, Maryland, May 17-21, 1993.

Fruchter, J.S., F.A. Spane, J.K. Fredrickson, C.R. Cole, J.E. Amonette, J.C. Templeton, T.O. Stevens, D.J. Holford, L.E. Eary, B.N. Bjornstad, G.D. Black, J.M. Zachara, and V.R. Vermeul, Manipulation of Natural Subsurface Processes: Field Research and Validation, Final Report, Subsurface Science Program, Office of Health and Environmental Research, U.S. Department of Energy, Washington, D. C., 1994.

Fruchter, J.S., S.B. Yabusaki, M.D. Williams, and C.R. Cole, Draft Test Plan for the In Situ Redox Manipulation Field Experiment, 100D Area. U. S. Department of Energy, EM541, Washington, D.C., 1993. 


\section{TASK DESCRIPTION}

The objective of this task is to develop an electronbeam generated plasma process for efficient, versatile, on-site treatment of gaseous toxic and hazardous compounds (particularly carbon tetrachloride) with minimum creation of undesirable byproducts and additional treatment. A field unit is presently being upgraded to increase capacity and efficiency after a successful test at the Hanford site.

The Tunable Hybrid Plasma (THP) process injects a moderate-energy electron beam $(100-300 \mathrm{keV})$ into atmospheric air containing the organic contaminants. See Figure 3.12. The electrons and free radicals plasma generated from the electron beam interact with the organics in the atmospheric air. The organics are destroyed or oxidized to non-toxic chemicals. In cases where carbon tetrachloride is the main contaminant, dissociative attachment initiates the breakup of the carbon tetrachloride into non-toxic compounds. The electron beam ionizes the air stream. This ionization allows AC or DC electric fields to further increase the electron and gas temperatures to optimize the treatment processes.
This task is investigating the potential of the THP process to remove carbon tetrachloride and similar toxic gaseous compounds from waste gas streams containing dilute concentrations of toxic gases. The system includes the E-beam reactor, scrubber, and a control system to fully automate its operation and be cost competitive with other means for carrying out the same function. The electron-beam window tests carried out to date indicated that titanium could withstand the acid attack due to reaction products.

The products of the reaction for carbon tetrachloride destruction are passed through a conventional scrubber. All of these gaseous products-chlorine, hydrochloric acid, and carbon dioxide-dissolve in aqueous solutions or can be passed through the scrubber and released into the atmosphere. The scrubber can contain an aqueous solution with or without a caustic substance such as sodium hydroxide. The caustic solution is preferred since it produces sodium chloride and carbon dioxide gas, which can be easily disposed of.

\section{TECHNOLOGY NEEDS}

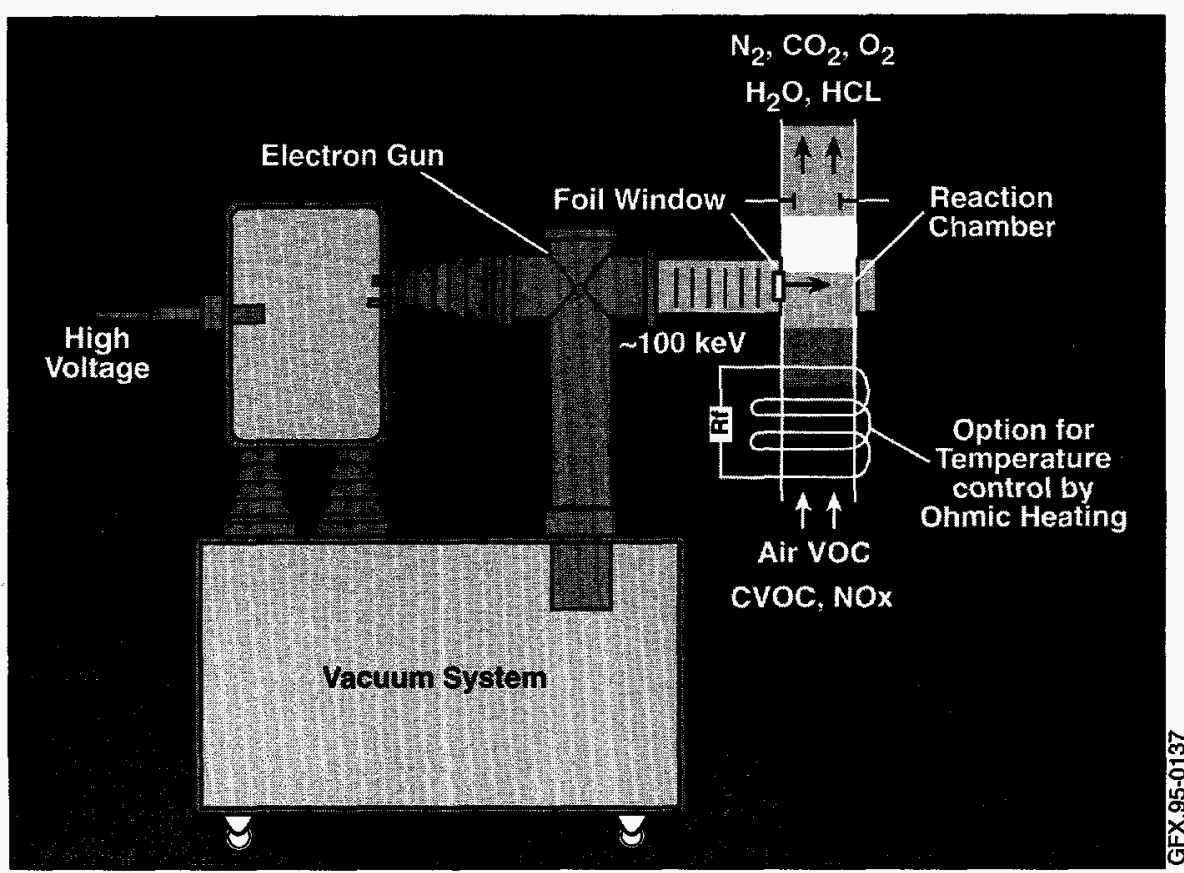

Soil vapor extraction is the baseline technology for remediating vadose zone soils. The baseline treatment technology for the extracted gas is granulated activated charcoal adsorption with off-site regeneration and ultimate disposal. Efficient and versatile on-site treatment such as the THP technology is an important alternative that should be developed.

\section{ACCOMPLISHMENTS}

- Initial studies resulted in removal of carbon tetrachloride below detection

Figure 3.12. Tunable Hybrid Plasma. 
limit in lab experiments. The THP technology decomposed carbon tetrachloride into harmless carbon dioxide and chlorine-salt.

- The output air stream frorn the THP reactor was fully characterized. The carbon balance resulted in carbon monoxide and carbon dioxide. The chlorine balance resulted in carbon tetrachloride going to chlorine and hydrochloric acid.

- A standard molecular sieve dryer using zeolite was used to selectively dry the waste air stream, while passing the toxic vapors. In addition, a commercial scrubber converted the acid gas byproducts to nonhazardous brine solutions.

- A successful field test was completed at the Hanford site which resulted in $\mathrm{CCl}_{4}$ destruction from 150$300 \mathrm{ppm}$ to less than $0.1 \mathrm{ppm}$. The $\mathrm{NaCl}$ and $\mathrm{CO}_{2}$ byproducts were safe to the environment.

\section{BENEFITS}

The advantages of this technology include:

- on-site treatment of toxic substances in gas streams with high destruction and removal efficiency;

- capability of eliminating contaminants from high volume waste gas streams with end products of small volumes of solid precipitates and toxic gases;

- relatively low cost;

- minimum pre- and post-treatment requirements;

- ability to treat gases frona solid waste treatment systems resulting in non-toxic emissions and small volumes of solid non-toxic residues; and

- versatile operation for processing a wide range of substances and concentrations.

Laboratory tests have demonstrated that all the products of the E-beam dissociation of carbon tetrachloride can be dissolved in an aqueous solution. This solution preferably contains a base such as sodium hydroxide $(\mathrm{NaOH})$ or sodium superoxide $\left(\mathrm{Na}_{2} \mathrm{O}_{2}\right)$, which combines with the dissolved hydrochloric acid and chlorine to form the sodium chloride (salt). The remaining byproduct, carbon dioxide, is released to the atmo- sphere. The salt is a non-hazardous waste, which can be disposed of in landfills if reduced to a solid. Brine solutions may be amenable to reuse.

\section{COLLABORATION/TECHNOLOGY TRANSFER}

Current investigation of this technology is being conducted by PNL, in coordination with MIT. The THP project has gained the interest of three Boston firms engaged in waste remediation. Additionally, preliminary discussions are underway with a licensee for commercialization of the process. The prospective licensee may participate in the demonstration.

For further information, please contact:

\author{
Daniel R. Cohn \\ Plasma Fusion Center \\ Massachusetts Institute of Technology \\ 167 Albany Street \\ Cambridge, MA 02139 \\ (617) 253-5524
}

Steven Slate

Technical Program Manager

Pacific Northwest Laboratory

P.O. Box 999

Richland, WA 99352

(509) 375-3903

\section{Rashalee Levine \\ Program Manager \\ U.S. Department of Energy \\ Cloverleaf Building \\ 19901 Germantown Road}

Germantown, MD 20874-1290

(301) $903-7920$

TTP Number: RL343501

BIBLIOGRAPHY OF KEY PUBLICATIONS

None at this time. 


\subsection{IN SITU CHEMICAL TREATMENT \\ FOR REMEDIATION OF SOILS \\ AND GROUNDWATER}

\section{TASK DESCRIPTION}

Conventional approaches to environmental remediation have relied primarily on physical isolation or removal technologies, including groundwater pumping. In most instances, the pump and treat approach has not succeeded in restoring contaminated aquifers to regulatory standards. This may be due to desorption of contaminant constituents from the soil particles in aquifers and to channeling effects associated with variations in hydraulic conductivity. Introduction of chemical treatment agents into contaminated aquifers should strongly bind the residual contaminants to aquifer sediments, and via diffusion, also treat regions of the aquifer that are by-passed during active pumping of groundwater. This approach should be especially effective for metals and radionuclides, whose solubilities or sorption characteristics are strongly dependent on con-

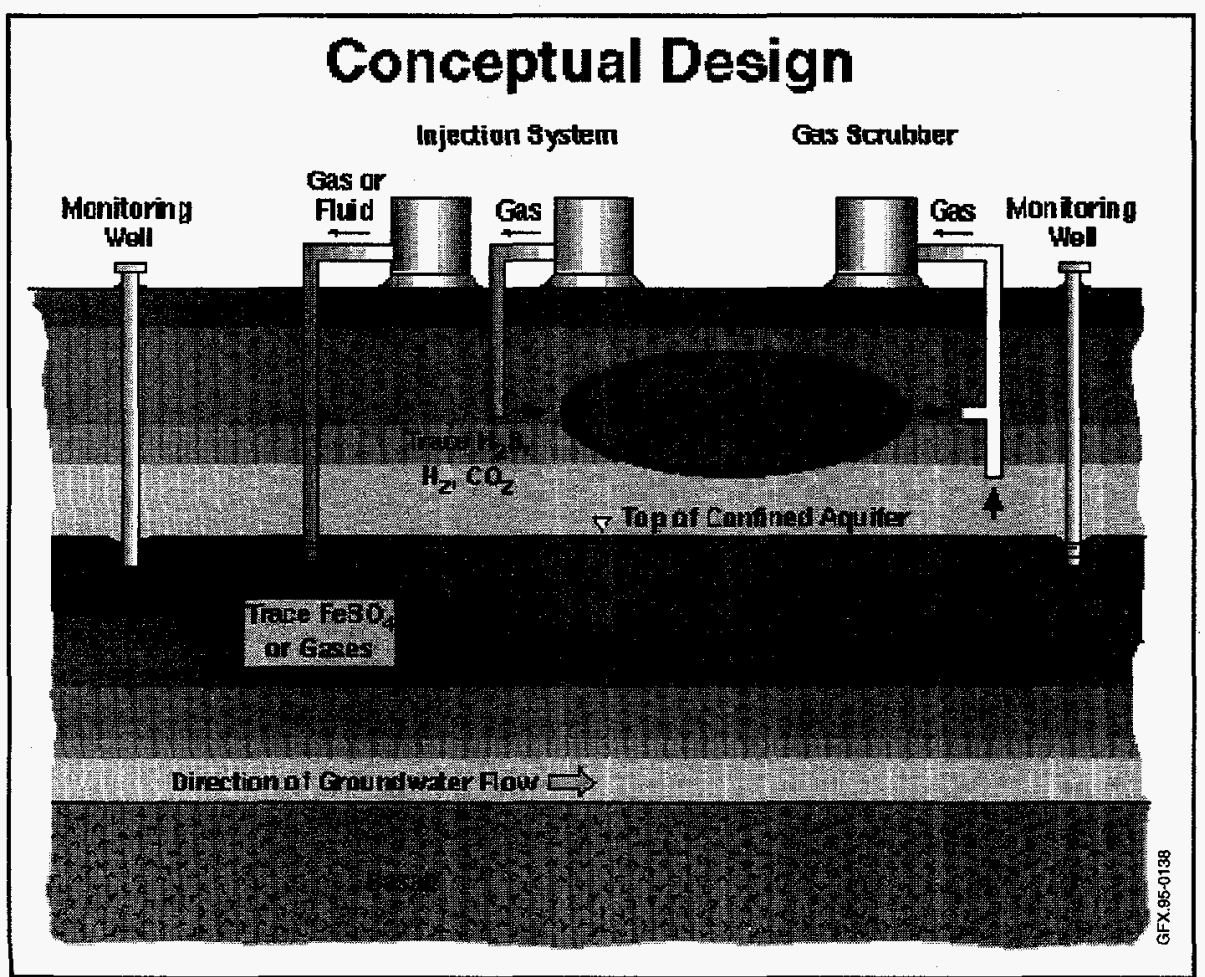

Figure 3.13. In Situ Chemical Treatment Conceptual Design. centrations of associated ligands or the redox and $\mathrm{pH}$ characteristics of the environment.

This project is testing the feasibility of treating unsaturated soils by injection of reactive gases. Dilute mixtures of hydrogen sulfide in air or nitrogen can treat soils contaminated with heavy metals and radionuclides such as chromate, uranium, lead, mercury, or cadmium. Clean soils from several DOE sites were used in this testing phase to verify that the approach is applicable to a variety of soil types, and to evaluate the impact of gas concentrations and residence time on performance. See Figure 3.13 .

Following the clean soil testing, actual contaminated soil from DOE sites will be tested to optimize treatment procedures, estimate treatment costs, and develop approaches for ensuring the control of the reactive gases and homogeneous treatment of large masses of contaminated geomedia. Finally, a field demonstration will be conducted at the $\mathrm{Cr}$ (VI) MWL at SNL.

\section{TECHNOLOGY NEEDS}

Although chemical principles are well established, insufficient data is available to assess the potential of the in situ chemical treatment approach. In particular, the interaction of potential treatment agents with soils or groundwater has not been sufficiently evaluated. Initial proof-ofconcept experiments have been conducted to better 
establish the approach. This testing, directed towards the treatment of solutions containing hexavalent chromium and soil spiked with hexavalent chromium, indicated that significant immobilization is possible. Researchers are conducting tests to quantify the amount and concentrations of treatment agents needed and to evaluate the potential for treating and immobilizing a variety of metals and radionuclides. Testing will be conducted with actual contaminated soils and groundwater from $\mathrm{DOE}$ facilities to fully establish the validity of the technology.

\section{ACCOMPLISHMENTS}

Bench-scale tests with soil artificially contaminated with hexavalent chromium, uranium, and nitrate were completed in FY93. These results indicated that greater than 90 percent of the chromate added to soils was immobilized following chemical treatment. Immobilization of approximately 50 percent of the uranium was observed, while nitrate was generally non-reactive. Gas mixtures containing as little as $100 \mathrm{ppm}$ hydrogen sulfide in nitrogen were demonstrated to be effective for use in treatment. These tests included three different soil types, suggesting that soil composition was not a limiting factor.

Bench-scale gas treatment and leaching studies continued in FY94 with contaminated soils from DOE work sites. Pilot-scale tests and system design activities commenced in FY94.

\section{BENEFITS}

In situ immobilization of contaminants avoids the costs and risks to public health and worker safety associated with excavation, surface treatment, tran'sportation, and disposal.

An advantage of gaseous reagents such as $\mathrm{H}_{2} \mathrm{~S}$ is the higher permeability of soils to gases than to liquid reagents. Gaseous reagents will invade smaller soil pores to react with soil contaminants, thereby improving treatment effectiveness.

\section{COLLABORATION/TECHNOLOGY} TRANSFER

Other potential sites for DT\&E of this technology include Hanford, Fernald, and Oak Ridge. Soils from the 100-D Area of the Hanford Site, a calcium chromate disposal site at SNL, and uranium contaminated sites at Fernald have been used in testing activities.

Hexavalent chromium contamination of soil is a widespread problem at private industry sites. As the reduction/immobilization process is refined, a private industry partner will be sought to enhance technology transfer.

\section{For further information, please contact:}

Edward C. Thornton

Principal Investigator

Westinghouse Hanford Company

P.O. Box 1970

Richland, WA 99352

(509) 376-6107

\section{James Berger}

Technical Program Manager

Westinghouse Hanford Company

P.O. Box 1970

Richland, WA 99352

(509) 376-9942

\section{Jeffrey S. Walker}

Program Manager

U.S. Department of Energy

Cloverleaf Building

19901 Germantown Road

Germantown, MD 20874-1290

(301) 903-7966 
TTP Number: RL431001

\section{BIBLIOGRAPHY OF KEY PUBLICATIONS}

Thornton, E.C., and R.L. Jackson, "Laboratory and Field Evaluation of the Gas Treatment Approach for In Situ Remediation of Chromate-Contaminated Soils," Proceedings of the 33rd Hanford Symposium on Health and the Environment, Pasco, Washington, November 7-11, 1994. (in press).

Thornton, E.C., Selection of a Field Demonstration Site for In Situ Chemical Treatment of Soil Testing Activities, WHC-SD-EN-ES-042, Westinghouse Hanford Company, Richland, Washington, 1994.

Thornton, E.C., and M.A. Baechler, Gas Treatment of Chromate-Contaminated Soils from a ChromateContaminated Waste Site, Draft Report, Westinghouse Hanford Company, Richland, Washington, 1994.
Thornton, E.C., M.A. Baechler, M.A. Beck, and J.E. Amonette, Laboratory Evaluation of the Hydrogen Sulfide Gas Treatment Approach for Remediation of Chromate, Uranium (VI), and Nitrate-Contaminated Soils, Draft Report, Westinghouse Hanford Company, Richland, Washington, 1993.

Thornton, E.C., C.H. Delegard, M.A. Baechler, and M.A. Beck, Gas Treatment and Column Leach Testing of Chromate, Uranium (VI), and NitrateContaminated Soil, Test Plan, WHC-SD-EN-TP019, Westinghouse Hanford Company, Richland, Washington, 1993.

Thornton, E.C., R.D. Miller, and S.P. Reidel, Technology Transition to Demonstration Plan -In Situ Remediation of Soil by the Gas Treatment Approach, Draft Report, Westinghouse Hanford Company, Richland, Washington. 


\subsection{MODELING STRATEGIES AND LABORATORY EXPERIMENTS FOR ENHANCING IN SITU BIOREMEDIATION}

\section{TASK DESCRIPTION}

The focus of the research is to improve the ability to predict in situ mixing and co-metabolic transformation of halogenated aliphatic compounds. The primary objective is to recommend effective designs of chemical delivery, mixing schemes, and strategies for improving in situ bioremediation. See Figure 3.14. In FY94, this nants. It also requires the proper methods for introducing chemicals into the soil and controlling the chemical concentrations. Other in situ remediation methods, such as in situ chemical treatment, redox manipulation, or sparging, also require a thorough understanding of dilution and mixing processes.

Laboratory studies and model simulations are needed

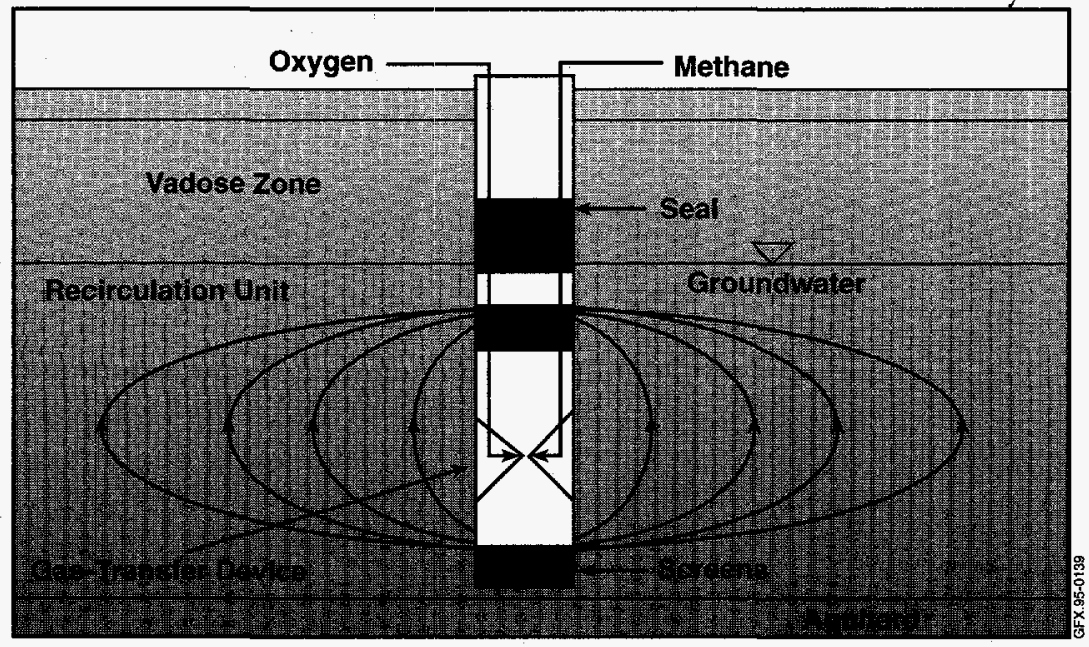

Figure 3. 14. Mathematical Models to Enhance In Situ Bioremediation.

to evaluate the potential for in situ bioremediation and to develop bioremediation systems. Mathematical modeling can be helpful in understanding the complex interaction of factors affecting in situ mixing in order to optimize bioremediation and other in situ remediation methods. Modeling is also useful for the design of effective delivery systems.

\section{ACCOMPLISHMENTS}

project was combined with OTD's bioremediation activities at Hanford. A recirculation unit is being designed for the delivery and mixing of chemicals at Hanford. Experiments will be conducted to evaluate schemes for the complete degradation of carbon tetrachloride. The in situ anaerobic transformation of carbon tetrachloride may leave some chloroform as a transformation product. This study will evaluate the ability of indigenous microorganisms from the Hanford subsurface to aerobically co-metabolically degrade chloroform. If successful, an aerobic process may be used as a final polishing step for remediation at the site.

\section{TECHNOLOGY NEEDS}

Effective microbial systems for degrading chloroform are needed at the Hanford Site as well as at other facilities. Efficient biodegradation requires the proper mixture of microorganisms, nutrients, and contamiquantify the rate of dilution describe the mechanisms which control mixing in the subsurface. Research is continuing by evaluating how geologic heterogeneity affects rates of dilution.

- Developed a boundary-element model to determine the flow around a recirculation unit. The model is now extended to account for heterogeneity in hydraulic conductivity and to improve its utility.

- Developed an aerobic co-metabolic transformation model for evaluating different kinetic models. Simulations of field experiments conducted at the Moffett Naval Air Station indicated that a model, which includes deactivation of the microbial population carrying out the co-metabolic transformation, yields results consistent with the observations.

- Developed a numerical model for the hydrodynamics of air sparging by approximating the air/water interface. A methodology was applied in two steps: 
1) locating the interface and 2) determining the pressure distribution and rates of flow.

- Fabricated a recirculating bioreactor to study the co-metabolic biodegradation of chloroform. The bioreactor will be packed with core material from the Hanford test site. Indigenous microorganisms will be stimulated by feeding a co-metabolic substrate. Operation under aerobic and anaerobic conditions will help evaluate the environment under which complete degradation to non-toxic end products can be achieved.

- Developing a soil microcosm method to rapidly screen for co-metabolic degradation of chloroform by Hanford subsurface organisms grown on different growth substrates. Studies will include the use of carbon-14 radiolabeled chloroform to determine whether complete degradation to carbon dioxide is achieved.

\section{BENEFITS}

This project will develop and apply mathematical models of subsurface flow, transport, and fate of halogenated aliphatic compounds to improve our understanding of processes associated with in situ bioremediation.

\section{COLLABORATION/TECHNOLOGY TRANSFER}

The technology is applicable to the VOC-contaminated sites at Hanford. This project involves a collaboration between EPA and DOE. Work is being carried out at Stanford University and at Oregon State University.

\section{For further information, please contact:}

\section{Peter Kitanidis}

Principal Investigator

Stanford University

Department of Civil Engineering

Stanford, CA

(415) 723-8321

\author{
Lewis Semprini \\ Principal Investigator \\ Oregon State University \\ Department of Civil Engineering \\ Apperson Hall 202 \\ Corrallis, OR 97331 \\ (503) $737-6895$
}

\author{
Rashalee Levine \\ Program Manager \\ U.S. Department of Energy \\ Cloverleaf Building \\ 19901 Germantown Road \\ Germantown, MD 20874-1290 \\ (301) 903-7920
}

TTP Number: HQ031006

\section{BIBLIOGRAPHY OF KEY PUBLICATIONS}

Kitanidis, P.K., "The Concept of the Dilution Index," Water Resources Research, 30(7), pp. 2011-2026, 1994.

Thierrin, J., and P.K. Kitanidis, "Solute Dilution at the Borden and Cape Cod Groundwater Tracer Tests," Water Resources Research, 30(11), pp. 2883-2890, 1994.

Kapoor, V., and P.K. Kitanidis, "Kinetics of Dilution and Concentration Fluctuations in Heterogeneous Porous Media," Transport in Porous Media, 1994.

MacDonald, T.R., and P.K. Kitanidis, "The Effects of Biofouling on In-Situ Bioremediation of TCE by Phenol Utilizers," Proceedings of the 1995 Conference on Bioremediation, San Diego, CA, April 1995.

DeMenibus, M.A., Mixing Strategies for In-Situ Bioremediation, Engineer Degree Thesis, Stanford University, Civil Engineering, 1994.

Semprini, L., G.D. Hopkins and P.L. McCarty, "A Field and Modeling Study of In Situ Transformation of Trichlorethylene by Methane Utilizers and Phenol Utilizers," Bioremediation of Chlorinated and PAH Compounds, ed. R.E. Hinchee, A. Leeson, L. Semprini, and S.K. Ong, pp. 248-254, Lewis Publishers, Boca Raton, Florida, 1994. 


\subsection{BIOPROCESSING TECHNOLOGIES FOR URANIUM-CONTAMINATED SOILS}

\section{TASK DESCRIPTION}

This task evaluates the use of naturally occurring bacteria and fungi to catalyze the extraction of uranium from soils and hence clean up uraniumcontaminated soils. These biotechnological methods are similar in many respects to those already used by the commercial scale heap and in situ leach processes for uranium and copper extractions. The source of soil for these studies is the Fernald site.

The bacterial species under study, Thiobacillus ferrooxidans, solubilizes uranium indirectly by a chain of oxidation steps. Under acidic conditions created by the microorganism itself, $T$. ferrooxidans oxidizes iron which in turn causes uranium to be oxidized. This form of uranium is soluble at low $\mathrm{pH}$ and can be removed. The ability of $T$. ferrooxidans to acidify its environment may be enhanced by addition of acid. In the experimental system in this project, the low $\mathrm{pH}$ is achieved and maintained through titration of the soil with sulfuric acid.

The fungi under study, $P$. simplicissimum and $A$. niger, produce compounds which solubilize uranium under slightly acidic to neutral soil conditions. The fungi are non-pathogenic and are capable of utilizing low value carbon sources. The solubilizing compounds found in digested culture broth produced by the fungi are thought to be small organic acids. To study their uranium solubilizing ability, the fungi are grown batchwise in a nutrient broth. After filtering the digested broth to remove the fungi, the broth is mixed with uranium-contaminated soil, left for approximately 24 hours, and then filtered. Up to $90 \%$ of the uranium can be removed from soil by this method. One advantage of this process is that the $\mathrm{pH}$ of the soil during extraction is in the 4-7 range which minimizes damage to the soil. The texture of the treated soil is very similar to that of the untreated soil.

Work completed in FY94 indicated that fungal mediated solubilization of uranium was preferred over the bacterial process due to the quality of the treated soil and the elimination of the post-treatment neutralization required for the bacterial process. The identity of the solubilization compounds produced by the fungi will be determined during FY95. Identification of these compounds will enable optimization of the fermentation and soil contacting processes.

\section{TECHNOLOGY NEEDS}

The uranium content of some contaminated soils at Fernald is very low compared to uranium contents of ores used for yellowcake production. This situation has created a need for evaluation of new technological possibilities for the treatment of large volumes of contaminated soils containing low or trace concentrations of uranium. These new methods must be environmentally acceptable, cost efficient and applicable to a wide range of situations. One possibility is the biotechnological approach.

\section{ACCOMPLISHMENTS}

- Evaluation of $T$. ferrooxidans for extraction of uranium from Fernald soil indicated that more than $90 \%$ of the uranium could be extracted. However, the relative contribution of the bacteria to the extraction process in this soil was uncertain.

Results indicated that bacteria may be effective in improving uranium extraction in soils with a high percentage of tetravalent uranium or low iron content.

Evaluation of $P$. simplicissimum and $A$. niger for extraction of uranium from Fernald soil has begun. Preliminary results are encouraging. Up to $90 \%$ of the uranium was extracted from the soil at $\mathrm{pH} 3.8$ 7.0. The extraction was not $\mathrm{pH}$ dependent and titration of the soil was not required. Maintaining a higher $\mathrm{pH}$ in this soil was expected to significantly 
improve the quality of the leached soil, because the high $\mathrm{pH}$ allows the uranium to be removed while preserving the texture of the soil. Extraction was accomplished by direct contact of the fungi with the soil and by application of digested broth from the fungi to the soil. No significant differences in the extraction were seen between the two approaches nor between the two fungi. Researchers are pursuing extraction by application of digested broth, because it simplifies the separation processes and reduces the nutrient loading applied to the soil.

\section{BENEFITS}

This technology preserves the texture and quality of the soil better than traditional chemical processing. The process is effective at removing uranium from soil. It performs the extraction at near normal $\mathrm{pH}$ for the soil, which reduces the damage to soil structure and chemistry. Maintaining the soil at near normal $\mathrm{pH}$ also reduces the amount of post-treatment neutralization required compared to other inorganic chemical treatments.

\section{COLLABORATION/TECHNOLOGY TRANSFER}

This technology has a high potential for future CRADA development with the mining and metals industry. This technology will have wide application to the environmental remediation activities for the DOE/DoD complex.

\section{For further information, please contact:}

\author{
G. Matthern \\ Principal Investigator \\ Lockheed/INEL \\ P.O. Box 1625 \\ Idaho Falls, ID 83415 \\ (208) 526-8747
}

\section{McClure}

Technical Program Manager

Idaho National Engineering Laboratory

P.O. Box 1625

Idaho Falls, ID 83415

(208) 526-1170

\section{Michael Malone}

Program Manager

U. S. Department of Energy

Cloverleaf Building

19901 Germantown Road

Germantown, MD 20874-1290

(301) $903-7996$

TTP Number: ID121103

\section{BIBLIOGRAPHY OF KEY PUBLICATIONS}

Delwiche, M.E., J.E. Wey, A.E. Torma, G.E. Matthern, D.T. Maiers, R. G. Reddy, and J.C. Cunnane, "Bioremediation of Uranium-Contaminated Soils," Technology and Programs for Radioactive Waste Management and Environmental Restoration, pp. 2039-2097, Laser Options, Inc., Tucson, AZ, 1994.

Bender, J., S. Rodriguez-Eaton, U.M. Ekanemesang, and P. Phillips, "Characterization of Metal-binding Bioflocculants Produced by the Cyanobacterial Component of Mixed Microbial Materials," Applied and Environmental Microbiology, 60(7): 23112315, 1994.

Sheppard, J.C., M.J. Campbell, T. Cheng and J.A. Kittrick, "Retention of Radionuclides by Mobile Humic Compounds and Soil Particles," Environmental Science and Technology, 14(11): 1349-1353, 1980. 


\subsection{DEMONSTRATION OF CO-METABOLIC TECHNIQUES}

\section{TASK DESCRIPTION}

This project demonstrated the effectiveness of biodegradation for the destruction of chlorinated solvents in groundwater and leachates. The field site for this demonstration was a groundwater seep discharging in the vicinity of the K1070-C/D Classified Burial Ground at the Oak Ridge K-25 Site. The feed stream leachate contained TCE, other chlorinated organics, and non-chlorinated organics at sub-ppm levels.

Bioreactor technology was employed for this demonstration. Two different microbial populations were tested. In both bioreactors, microorganisms were grown to form biofilms over the surfaces within the packed-bed. Contaminated water applied to the top of the packed bed trickled down over the packing surfaces, and was exposed to the microorganisms which then degraded the contaminants.

The microorganisms in the bioreactors degraded the chlorinated solvents cometabolically, i.e., using the same enzyme systems as those used to metabolize preferred, natural carbon/ energy sources. Because the chlorinated solvents themselves provided very little energy and could not themselves induce biodegradation, the natural carbon sources had to be added to the vapor phase. Thus, in one bioreactor, methanotrophic (methane-consuming) microorganisms were provided with methane and oxygen. In the second bioreactor, pseudomonas microorganisms were provided with aromatics such as toluene.

The technology was demonstrated using a pilot-scale bioreactor system loaned to ORNL by the Air Force Civil Engineering Support Agency, Tyndall Air Force Base. See Figure 3.16. Steam stripping was used in con- junction with the bioreactors to remove the VOCs from the water and to prevent exposure of the aerobic bioreactor environment to iron which would cause serious scale deposition. The VOCs removed in the steam stripper were treated in the bioreactors.

\section{TECHNOLOGY NEEDS}

The DOE has various sites with groundwater and leachates contaminated with volatile organic compounds. Methods are needed to destroy these chlorinated solvents more economically and efficiently.

\section{ACCOMPLISHMENTS}

The methanotrophic system was operated briefly several times. Destruction of chlorinated solvents was demonstrated, as evidenced by loss of target

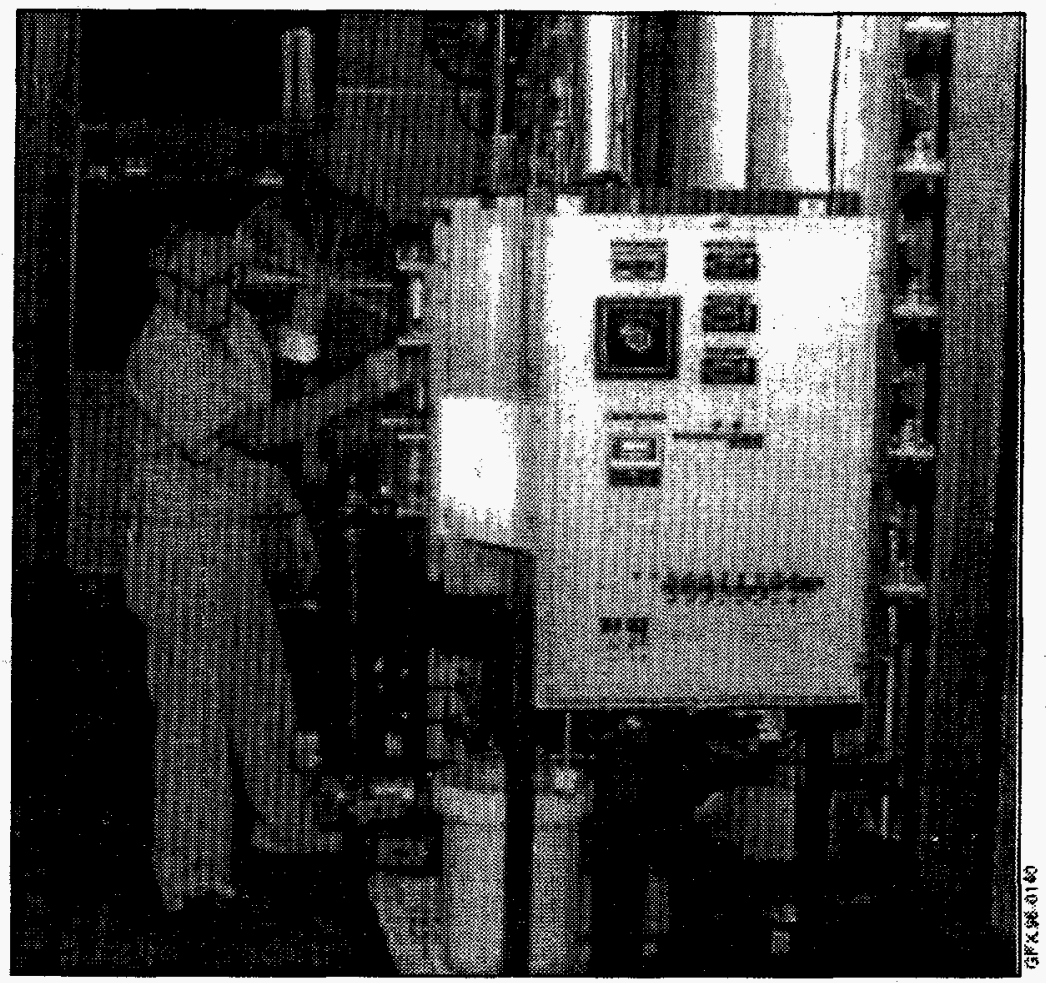

Figure 3.16. A Pilot-Scale Bioreactor System. 
compounds and generation of comparable quantities of chloride ion.

Tests were conducted jointly by Envirogen and ORNL staff using the bench-scale pseudomonas system over a period of several months. At higher concentrations, the leachate appeared to be somewhat inhibitory to the microbial culture. Some evidence was obtained for degradation of TCE. Further work is needed to determine a suitable operating mode for this reactor system with this feed stream.

Experimental tests at the K-25 Site in Oak Ridge were completed. The equipment is being removed from the site. Comprehensive data analysis and preparation of the final project report are underway. A report will be available as part of the final technical report.

\section{BENEFITS}

Co-metabolic biotreatment technologies such as these offer the possibility for destruction of VOCs in groundwater and leachates. Bioremediation allows for the complete degradation of these contaminants to less harmful by-products: water, carbon dioxide, and chloride.

The bioreactor technologies demonstrated in this project are primarily applicable to pump-and-treat or for situations where leachates are available aboveground. In situ variations and related technologies are also being developed and tested by other investigators at DOE and elsewhere.

\section{COLLABORATION/TECHNOLOGY}

\section{TRANSFER}

Tests of the pseudomonas system with a bench-scale bioreactor were carried out by Envirogen, Inc., under the auspices of a CRADA with ORNL. The project has benefitted from substantive collaborations with the Air Force and Envirogen, both of whom are potential users of this technology. In a separate but complementary program, ORNL has collaborated with the University of Tennessee to develop a multi-stage bioreactor system for cometabolic degradation of chlorinated solvents by methanotrophs.

\section{For further information, please contact:}

\section{Terrence Donaldson}

Principal Investigator

Oak Ridge National Laboratory

P.O. Box 2008

Oak Ridge, TN 37831

(615) 576-4853

\section{Anthony Malinauskas}

Technical Program Manager

Oak Ridge National Laboratory

P.O. Box 2008

Oak Ridge, TN 37831

(615) 576-1092

\section{Rashalee Levine \\ Program Manager \\ U.S. Department of Energy \\ Cloverleaf Building \\ 19901 Germantown Road \\ Germantown, MD 20874-1290 \\ (301) 903-7920}

TTP Number: OR101108

\section{BIBLIOGRAPHY OF KEY PUBLICATIONS}

Donaldson, T.L. et al., "Co-metabolic Biotreatment of TCE-Contaminated Groundwater: Laboratory and Bench-Scale Development Studies," Proceedings of Waste Management '92, vol. I, pp. 633-637, 1992.

Eng, W., A.V. Palumbo, S. Srirahan, and G.W. Strandberg, "Methanol Suppression of Trichloroethylene Degradation by Methylosinus Trichosporium," Applied Biochemistry and Biotechnology, 28/29:887-899, 1991.

Palumbo, A.V. et al., "A Co-metabolic Approach to Groundwater Remediation," Proceedings of Environmental Remediation '91, pp. 95100, 1991. 
Palumbo, A.V., W. Eng., P.A. Boerman, G.W. Strandberg, T.L. Donaldson, and S.E. Herbes, "Effects of Diverse Organic Contaminants on Trichloroethylene Degradation by Methanotrophic Bacteria and Methane Utilizing Consortia," Proceedings of the In Situ and On-site Bioreclamation Symposium, Butterworth-Heinemann, pp. 77-91, 1991.

Donaldson, T.L., A.J. Lucero, H.L. Jennings, and S.E. Herbes, Pilot-Scale Field Tests for the Methanotrophic Technology: Co-metabolic Bioreactor Demonstration a the Oak Ridge K-25 Site, ORNL/ TM 12235, Martin Marietta Energy Systems, Inc., Oak Ridge National Laboratory, Oak Ridge, Tennessee, 1992.

Donaldson, T.L. et al., Bench-Scale Process Development Studies for the Methanotrophic Technology: Cometabolic Bioreactor Demonstration at the Oak Ridge K-25 Site, ORNL/TM-12024, Martin Marietta Energy Systems, Inc., Oak Ridge National Laboratory, Oak Ridge, Tennessee, 1994, (in press).
Eng, W., and A.V. Palumbo, "Methanol Suppression of Trichloroethylene Degradation by Methylosinus Trichosporium and Mixed Cultures," Proceedings of the 12th Symposium on Biotechnology for Fuels and Chemicals, Gatlinburg, Tennessee, 1990.

Palumbo, A.V., G.W. Strandberg, and W. Eng., "Biodegradation Kinetics of Mixed Chlorinated Ethenes by Methylosinus Trichosporium," Proceedings of the Annual Meeting of the American Society for Microbiology, Anaheim, California, 1990.

Palumbo, A.V., E. Eng., P.A. Boerman, G.W. Strandberg, T.L. Donaldson, and S.E. Herbes, "The Effects of Diverse Organic Contaminants on Trichloroethylene Degradation by Methanotrophic Bacteria and Methane Utilizing Consortia," Proceedings of the First International Symposium for In Situ and On-Site Bioreclamation, San Diego, California, 1991. 


\subsection{BIOREMEDIATION OF PCB CONTAMINATION}

\section{TASK DESCRIPTION}

This project is focused on developing and demonstrating a bioremediation technology for polychlorinated biphenyl (PCB) contaminated soils and sludges. Bench-scale experimental studies are underway to identify favorable conditions for anaerobic dechlorination of PCBs. See Figure 3.17.

Microbial inocula have been provided by the General Electric Company (GE), the industrial partner of a DOE CRADA. The microbial cultures from GE were obtained in the form of PCB-contaminated sediments from the Hudson River in New York State. GE staff have shown that these sediments are capable of biodegradation of PCBs.

Project staff at ORNL are inoculating PCB-contaminated soils with these sediments to develop and test conditions to stimulate degradation of the PCBs in the soils. The goal is to achieve a sufficient amount of anaerobic dechlorination to enhance the subsequent susceptibility of the contaminants to complete mineralization under aerobic conditions.
Work during FY94 focused on validating and refining conditions to promote dechlorination at acceptable rates. The phenomenon appears to depend on nutrient conditions; however, the details of the biochemistry are not yet known. In FY95, studies using mixed waste containing PCBs and radionuclides are planned. Based on the costs and comparisons of this technology to others, a decision will be made as to whether a field experiment should be performed.

\section{TECHNOLOGY NEEDS}

DOE has significant quantities of PCB-contaminated soils in storage at several locations, notably at Oak Ridge. These soils have been excavated from spill sites and also contain radionuclides, hence, they are considered as mixed wastes. Bioremediation offers a potentially simple low-tech means to destroy the PCBs at relatively ambient conditions. Bioremediation of mixed waste provides a simple and clean way to separate the organic component from the radioactive waste.

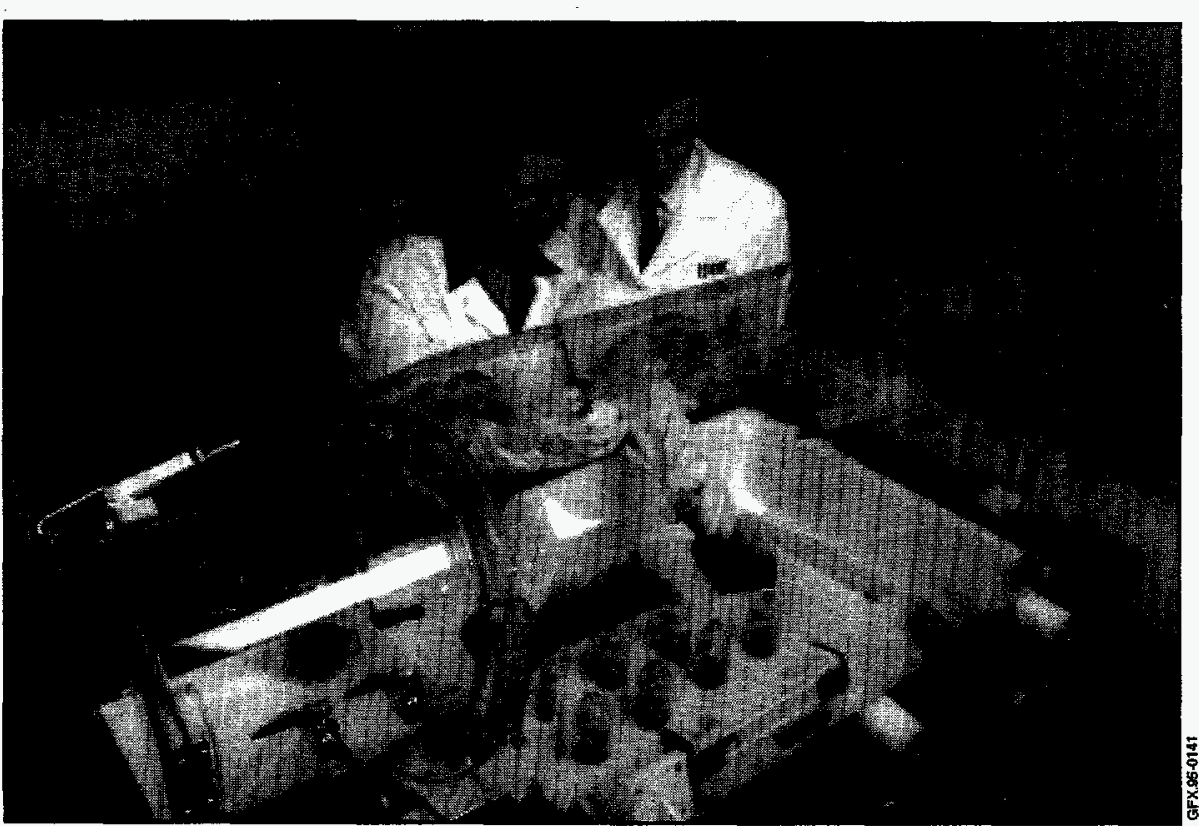

Figure 3.17. Laboratory Experiments at Oak Ridge to Identify Favorable Conditions for Anaerobic Dechlorination of PCBs.

\section{ACCOMPLISHMENTS}

Work to date demonstrated that the sediments from the Hudson River could inoculate soil slurry bioreactors. Tests with various nutrient amendments and inducement with certain PCB congeners led to the selection of specific conditions that favor anaerobic dechlorination of the meta position on the biphenyl rings. Removal of chlorines from the meta position could increase the susceptibility of the rings to oxidation. Further tests are underway to 
validate and refine the conditions to promote meta dechlorination.

\section{BENEFITS}

Bioremediation of PCBs is an inexpensive and more environmentally appealing alternative to incineration.

\section{COLLABORATION/TECHNOLOGY TRANSFER}

The project is being carried out under the auspices of a CRADA with GE. ORNL is benefiting from GE's field expertise and from its knowledge of $P C B$ degradation in sediments. Microbial inocula for the ORNL experiments, which originated from Hudson River sediments, is being provided by GE. In turn, GE is benefiting from the ORNL work by extending its knowledge-base beyond PCB degradation in sediments to PCB degradation in soils, a significantly different matrix at the physicochemical and biological levels. Results from studies at ORNL and GE have been presented widely at technical symposia and DOE meetings.

For further information, please contact:

\section{Thomas Klasson}

Principal Investigator

Oak Ridge National Laboratory

P.O. Box 2008

Oak Ridge, TN 37831

(615) 574-6813

\section{Anthony Malinauskas}

Technical Program Manager

Oak Ridge National Laboratory

P.O. Box 2008

Oak Ridge, TN 37831

(615) 576-1092
Jeffrey S. Walker

Program Manager

U.S. Department of Energy

Cloverleaf Building

19901 Germantown Road

Germantown, MD 20874-1290

(301) 903-7966

TTP Number: OR121110

\section{BIBLIOGRAPHY OF KEY PUBLICATIONS}

Donaldson, T.L, PCB-Eating Microbes, Oak Ridge National Laboratory Review. 21(4):44-45., 1988.

Donaldson, T.L., and D.A. Abramowicz, "Bioremediation of PCB-Contaminated Soils," Proceedings of the U.S. DOE Information Exchange Meeting on Waste Treatment, Retrieval, and Processing, pp. 121-124, Houston, TX, March 15-17, 1993.

Hill, D.L., T.J. Phelps, D.C. White, A.V. Palumbo, T.L. Donaldson, and G.W. Strandberg, "Bioremediation of Polychlorinated Biphenyls: Degradation Capabilities in Field Lysimeters," Applied Biochemistry and Biotechnology, 20/21:233-243, 1989.

Klasson, K.T., and B.S. Evans, "PCB Dechlorination in Anaerobic Soil Slurry Reactors," Proceedings of the 6th Annual International Symposium on Gas, Oil, and Environmental Biotechnology, Institute of Gas Technology, Chicago, Illinois, 1993.

Donaldson, T.L. et al., Bioremediation of PCBContaminated Soil at the Y-12 Plant, ORNL/TM10750, Martin Marietta Energy Systems, Inc., Oak Ridge National Laboratory, Oak Ridge, Tennessee, 1988.

Klasson, K.T., M.E. Reeves, B.S. Evans, and T.L. Donaldson, "Biological Dechlorination of PCBs Using Hudson River Sediments as Inoculum," Proceedings of the Ache Summer National Meeting, Minneapolis, Minnesota, 1992.

Phelps, T.J. et al., "Bioremediation of Polychlorinated Biphenyls: Degradation Capabilities in Field Lysimeters," Proceedings of the 10th Symposium on 
Biotechnology for Fuels and Chemicals, Gatlinburg, Tennessee, 1988.

Reeves, M.E., T.L. Donaldson, and C.C. Chang, "Anaerobic Dechlorination of Chlorinated Biphenyls by Mixed Bacterial Cultures from PCB-Contaminated Sediments," Proceedings of the 12th Symposium on Biotechnology for Fuels and Chemicals, Gatlinburg, Tennessee, 1990.

Reeves, M.E., "Anaerobic Dechlorination of PCBs in Soils and Sawdust," Proceedings of the ASM Conference on Anaerobic Dehalogenation and its Environmental Implications, Athens, Georgia, 1992.
Reeves, M.E., T.L. Donaldson, and C.C. Chang., "Anaerobic Dechlorination of Chlorinated Biphenyls by Mixed Bacterial Cultures from PCB-Contaminated Sediments," Proceedings of the Ache Summer National Meeting, San Diego, California, 1990.

Reeves, M.E., and T.L. Donaldson, "Bacterial Dechlorination of Chlorinated Biphenyls by Mixed Bacterial Cultures from PCB-Contaminated Sediments," Proceedings of the In Situ and On Site Bioreclamation International Symposium, San Diego, California, 1991. 


\section{TASK DESCRIPTION}

The goal of this task is to develop a biosorbent technology that can selectively remove uranium or other designated metals present at low concentrations in surface or groundwater. This work will lead to a demonstration of biosorption for remediation of uranium-contaminated groundwater and surface water.

The proposed process utilizes biosorbents (sorptive biomass, or biological material) immobilized in permeable beads that are in turn contained within flow-through bioreactor systems. See Figure 3.18. Systems will be operated in a continuous or semicontinuous on-site mode as a pump-and-treat method. The system will achieve waste fixation and volume reduction. Uranium concentrations will be reduced from $\mathrm{ppm}$ to $\mathrm{ppb}$ levels.

The major focus for FY94 included (1) completing bench-scale optimization tests, (2) comparing the immobilized biosorbent to other commercially available biological and nonbiological sorbents, (3) pre- paring a technology development progress report to include a cost and market analysis, (4) initiating pilot-scale tests, and (5) designing a site-specific process for use at the Ronneberg mining site in eastern Germany.

\section{TECHNOLOGY NEEDS}

Technologies are needed to treat wastewater contaminated with low concentrations of uranium. Large volumes of this wastewater exists within the DOE complex. Current technologies for uranium removal include precipitation with alkali, adsorption onto activated carbon or other inorganic resins, reverse osmosis, and extraction with tributyl phosphate or other materials. These technologies may generate unacceptable secondary wastes, e.g., large quantities of sludge and/or mixed waste. None of these technologies is suitable for treatment of dilute waste streams. Additionally, processes based on these technologies are expensive.

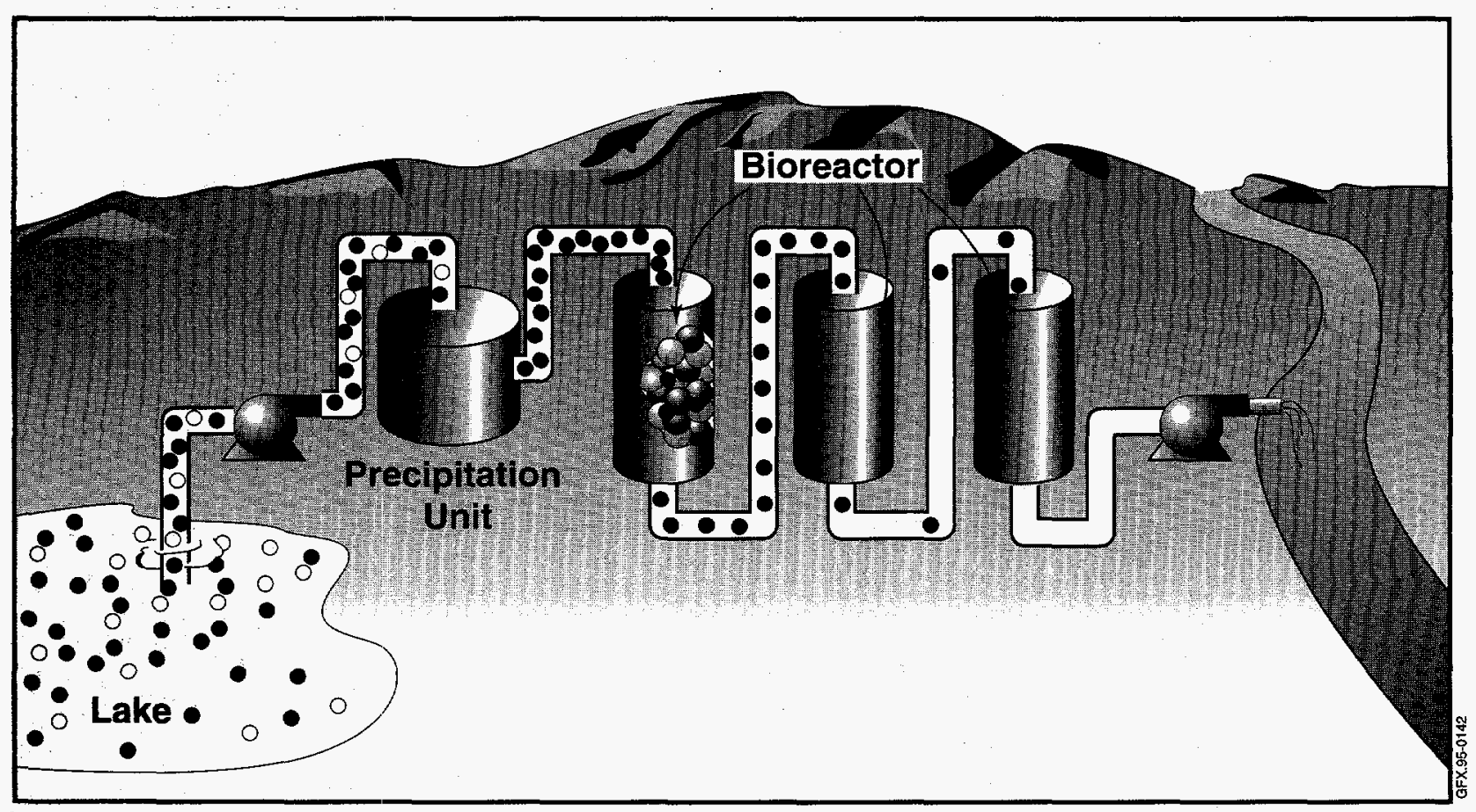

Figure 3.18. Biosorption for Treatment of Uranium-Contaminated Surface Water. 


\section{ACCOMPLISHMENTS}

Various strains of bacteria, yeast, fungi, and algae were screened for their ability to extract uranium from contaminated water containing low concentrations of this heavy metal. Certain species of Pseudomonas were identified as the optimal biological material for the removal of uranium from acidic water. Pseudomonas aeruginosa, the lead candidate, was shown to bind over 30 percent of its dry weight as uranium. Methods to improve binding characteristics, e.g., by pretreatment with polar organic solvents, were developed. Bound hexavalent uranium is converted by living cells to insoluble tetravalent uranium, which precipitates intracellularly. Uranium binding and removal by killed biomass were also demonstrated. Certain cellular components were shown to bind uranium in cell-free systems.

In previous work, Pseudomonas aeruginosa, immobilized within a matrix of calcium alginate, reduced uranium levels in simulated wastewater from 10 $\mathrm{ppm}$ to $6.8 \mathrm{ppb}$. Over 350 column volumes were successfully treated before breakthrough occurred. Bound uranium was quantitatively removed from the column by treatment with five column volumes of $0.15 \mathrm{M}$ nitric acid.

In more recent work, improved stable immobilization matrices were developed. Tests of $P$. aeruginosa, immobilized within polyacrylamide, were carried out using an actual domestic wastewater. The test biosorbent was shown to be superior to several commercial non-biological sorbents, including chelating resins, weak cation-exchange resins, and activated carbon. Preliminary tests indicated that the enhanced specificity of the biosorbent for uranium allowed it to be competitive with strongly acidic cation-exchange resins for treatment of multicomponent solutions.

A new, less-costly polyurethane-based immobilization matrix was developed and is now being tested. Column tests with $P$. aeruginosa immobilized in polyurethane gel beads were conducted. The uranium biosorption capacity of the beads in column operation was $29.1 \mathrm{mg}$ uranium/g beads. Compared with the capacity of raw biomass (approxi- mately $100 \mathrm{mg}$ uranium/g biomass), no significant loss of uranium binding activity was noted in the biosorbent immobilized in the polyurethane gel beads, which indicated that the immobilization process does not deactivate or interfere with uranium binding.

\section{BENEFITS}

Removal of uranium using biological material offers a highly specific, inexpensive method to remediate water contaminated with low levels of this radionuclide.

\section{COLLABORATION/TECHNOLOGY}

\section{TRANSFER}

This technology development work is being carried out in cooperation with an industrial partner, Ogden Environmental and Energy Services, Inc. (a U.S. based company), via a CRADA with DOE. The technology will be demonstrated by Ogden at Ronneberg, a German uranium mine site with a large surface impoundment, an underground mine subject to groundwater encroachment, and various small drainage streams. There have been no previous efforts at site remediation. The targeted waste site was identified by Ogden in cooperation with DFA, (formerly Wismut), the German enterprise that is responsible for activities analogous to those covered by UMTRA.

The technology will also be applicable to remediating sites in the U.S. where uranium contamination is a problem. The investigators are in the process of establishing a U.S. field demonstration site.

Technology development is being carried out in the United States in collaboration with a researcher at Florida International University. This technology will be evaluated in tandem with biosorption under development at the U.S. Geological Survey, Los Alamos National Laboratory in the United States, University of Birmingham in the United Kingdom, and McGill University in Canada. 
For further information, please contact:

\section{Brendlyn Faison}

Principal Investigator

Oak Ridge National Laboratory

P.O. Box 2008

Oak Ridge, TN 37831

(615) 576-0484

\section{Anthony Malinauskas}

Technical Program Manager

Oak Ridge National Laboratory

P.O. Box 2008

Oak Ridge, TN 37831

(615) 576-1092

\section{Jeffrey $S$. Walker}

Program Manager

U.S. Department of Energy

Cloverleaf Building

19901 Germantown Road

Germantown, MD 20874-1290

(301) $903-7966$

\section{BIBLIOGRAPHY OF KEY PUBLICATIONS}

None at this time. 


\subsection{ADSORPTION/DESORPTION RELATIVE TO APPLYING BIOREMEDIATION TO ORGANICS}

\section{TASK DESCRIPTION}

The purpose of this investigation is to develop and demonstrate technologies which will accelerate rates of in situ biological remediation of soil containing sorbed contaminants. See Figure 3.19. This work involves two related approaches for increasing contaminant biodegradation: (1) the use of adhesion-deficient bacteria to degrade sorbed volatile organics, primarily TCE and mixtures with TCE, and (2) the use of surfactants to desorb contaminants. Both of the approaches to enhance biodegradation are being tested in two phases. The first phase involves laboratory proofof-principle technology development. The second phase involves field demonstration at a DOE site.

The first approach, being conducted under a subcontract to Envirogen, involves the development and demonstration of naturally-occurring adhesiondeficient microorganisms for degrading TCE. Because these bacteria do not stick to surfaces, they can move to sources of contamination, degrading groundwater contaminants as they migrate. In addition, the bacteria can also degrade contaminants sorbed to aquifer solids. Treatment with these bacteria should significantly

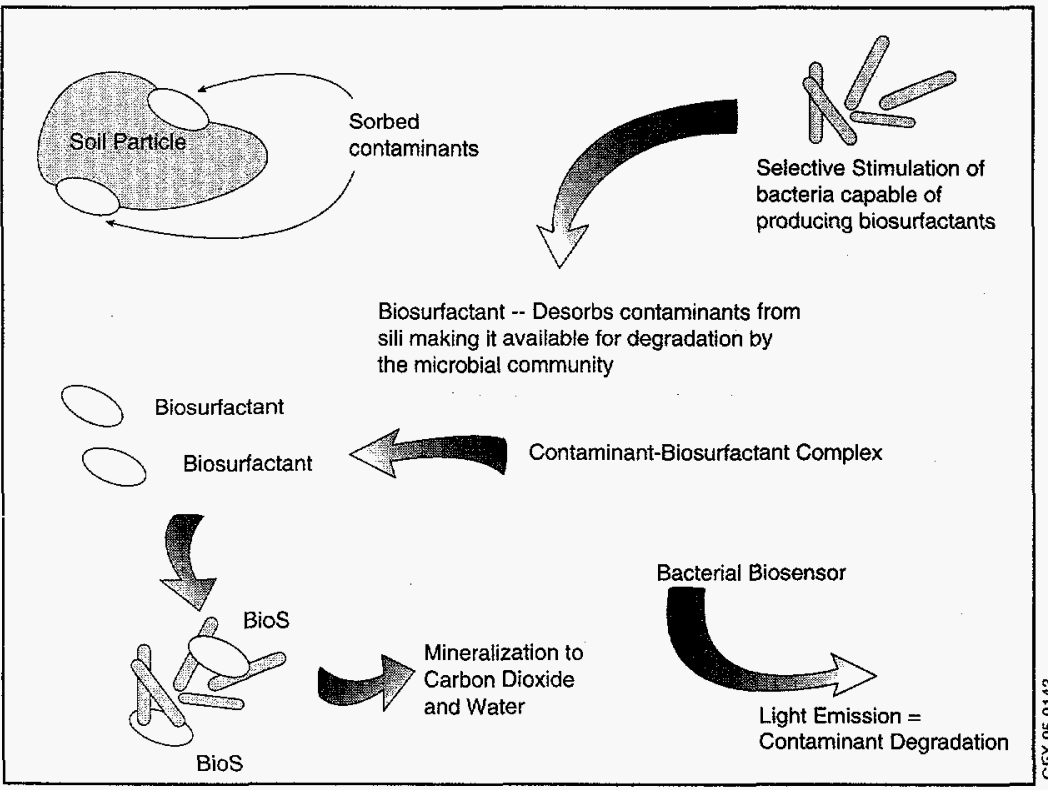

Figure 3.19. Biosurfactants and Bacterial Sensors. decrease a time-release source of contaminants, while cleaning up the groundwater.

The second approach, being conducted by researchers at ORNL, involves the use of surfactants and biosurfactants to cause solubilization of contaminants, making them available to bacterial degradation. Methods are being developed to stimulate biosurfactant production in situ. For example, the use of oleophilic fertilizers is expected to shift the community structure to one of biosurfactant producers, thereby increasing the rates of contaminant desorption and subsequent biodegradation. To monitor biodegradation, bacterial biosensors are being used. These biosensors directly report/measure the physiological activity of the contaminant-degrading microorganisms and the changes that occur in contaminant bioavailability when biosurfactants, surfactants, and other compounds are added.

The technology will be implemented in the field as follows. A simple nutrient solution will feed the adhesion-deficient bacteria at the subsurface before injection. An operating system consisting of storage tanks, pumps, and the associated instrumentation will be used to add the bacteria, surfactants, biosurfactants, or compounds that promote biosurfactant production. Application of the system will require multiple delivery wells, including horizontal wells.

\section{TECHNOLOGY NEEDS}

In situ technologies are needed to treat sorbed organic contaminants. Results from this study have the potential to greatly increase the efficiency of in situ bioremediation at a hazardous site through the selective stimulation of indigenous microorganisms, by the introduc- 
tion of highly-active mobile bacteria, and by desorption of contaminants.

\section{ACCOMPLISHMENTS}

Work was performed on applying genetically engineered biosensor microorganisms to detect changes in biodegradation of contaminants in response to biosurfactants, surfactants, and other degradation enhancers. One biosensor that was developed produced visible light in the presence of toluene. The light was detected and measured using sensitive photomultiplier equipment, allowing quantification of the toluene.

Numerous strains of biosurfactant producing bacteria were isolated and characterized. Biosurfactant production was evaluated under various growth conditions.

Methods were developed to select adhesion-deficient variants of TCE-degrading microorganisms. Kinetics studies were performed on these variants to determine which has the best TCE degradation characteristics (i.e., in terms of speed of degradation, range of TCE concentration that is treatable, and longevity of TCE degradative activity).

\section{BENEFITS}

Sorbed contaminants can extend treatment times for remediation activities that utilize pump-and-treat approaches. This project offers an in situ remediation alternative that is less expensive and more cost-effective than the pump-and-treat method. Although developed for TCE degradation, aspects of this project are applicable to bioremediation of other types of contaminants.

Moreover, the successful completion of this project will result in an environmentally safe process that mineralizes contaminants (in this case, TCE) in the subsurface where they are contained, thereby eliminating the risk of exposure to cleanup personnel and others through air contamination or transfer of contaminated adsorbents to a landfill. Because neither contaminated water nor sludge will be pumped above ground, there is no risk of reduced air quality because of volatile vaporization. Furthermore, none of the materials required for operation are expected to deteriorate the equipment as compared to the catalytic oxidation process.

This technology should result in cleanup of small source areas in less than one year, resulting in significant cost savings in operational, maintenance, and monitoring costs associated with a contamination plume.

\section{COLLABORATION/TECHNOLOGY TRANSFER}

The laboratory work on the TCE degrading/adhesiondeficient organisms is being performed by the industrial collaborator, Envirogen. Several candidate sites, including DOE-Kansas City, are being evaluated for the potential application of this technology. Aquifer material from these sites will be used in the laboratory studies for examination of bacterial mobility in the subsurface. These materials will be used for examination of degradation of sorbed TCE.

Envirogen's participation and the participation of the site in field phase will facilitate technology transfer as well as future CRADAs. Technology transfer is anticipated to occur in less than 12 months. This project is ideally suited to technology transfer because it represents a joint effort of a national laboratory with an industrial partner. Bacteria that produce natural biosurfactants are potentially patentable and, if particular biosurfactants are found that are useful in bioremediation efforts, the bacteria or the biosurfactants could be licensed to industry and/or produced for use at DOE sites.

\section{For further information, please contact:}

\author{
Anthony Palumbo \\ Principal Investigator \\ Oak Ridge National Laboratory \\ P.O. Box 2008 \\ Oak Ridge, TN 37831 \\ (615) 576-8002
}




\section{Janet Strong-Gunderson}

Principal Investigator

Oak Ridge National Laboratory

P.O. Box 2008

Oak Ridge, TN 37831

(615) 576-0179

\section{Anthony Malinauskas}

Technical Program Manager

Oak Ridge National Laboratory

P.O. Box 2008

Oak Ridge, TN 37831

(615) 576-1092

\section{Jeffrey $S$. Walker}

Program Manager

U.S. Department of Energy

Cloverleaf Building

19901 Germantown Road

Germantown, MD 20874-1290

(301) 903-7966

\section{TTP Number: OR141003}

\section{BIBLIOGRAPHY OF KEY PUBLICATIONS}

Strong-Gunderson, J.M., B. Applegate, G.S. Sayler, and A.V. Palumbo, "Biosurfactants and Increased Bioavailability of Sorbed Organic Contaminants: Measurements Using a Biosensor," Proceedings of the Sixth International Institute of Gas Technology Symposium on Gas, Oil, and Environmental Biotechnology, 1994, (in press).

Strong-Gunderson, J.M., and A.V. Palumbo, "Adsorption and Desorption of Contaminants Relative to Bioremediation," Proceedings of the Technical Information Exchange Meeting with Industry on Environmental Restoration Needs in the Northwest United States, Outreach to Industry: Partnerships for the Future. Seattle, Washington, January 1994. 


\section{TASK DESCRIPTION}

The project goal is to demonstrate the feasibility of using plants to remediate soils, sediments, and surface waters contaminated by heavy metals and radionuclides. See Figure 3.20. This technology, known as phytoremediation, is especially suited to areas of land or water where low concentration of contaminants are widespread.

The system was tested initially using plant material grown in heavy metal contaminated soils at the Silver Bow Creek Superfund site near Butte, Montana and in acidic mine water near the Berkeley Pit. Other plant biomass specimens derived from contaminated DOE facilities or from other sites will also be subjected to testing and evaluation in the initial feasibility study.

An extensive literature search is underway to identify plant species that are hyper-accumulators of contaminants of concern to DOE. A test program to verify the contaminant uptake capacity of selected species and potential for in situ bioremediation is being implemented sequentially from hydroponic tests to pot studies with contaminated soil and, eventually, field demonstrations. The Fernald Incinerator Area has been identified as a potential site for the first field demonstration.

Extending the capabilities to remediation of contaminated water using aquatic plants is a goal of the project. The Berkeley Pit in Butte contains about 20 billion

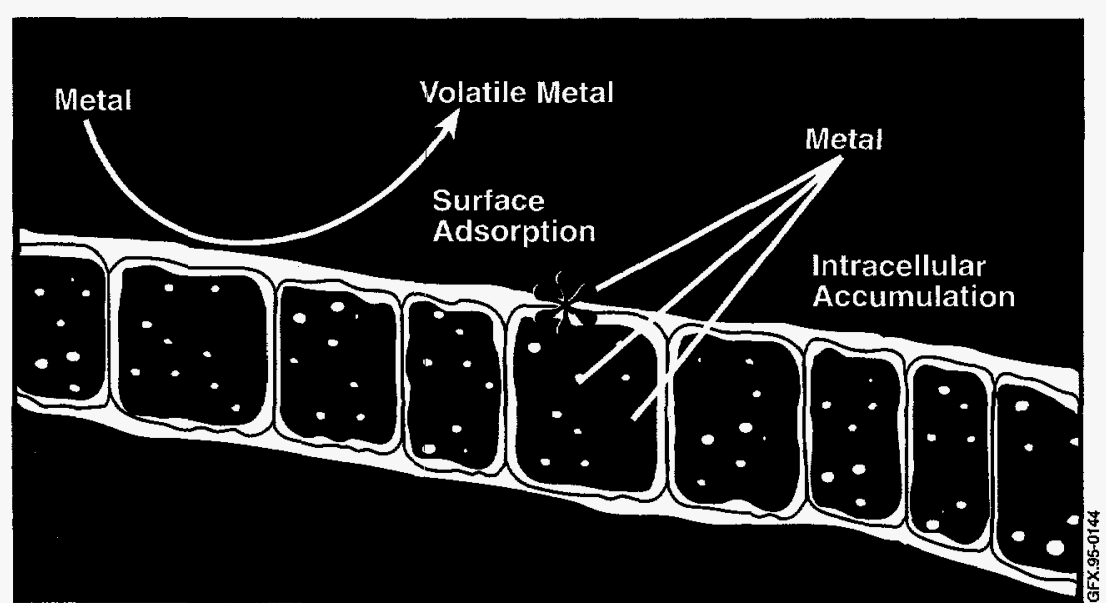

Figure 3.20. Removal of Metals Using Algae. gallons of acidic water contaminated with heavy metals such as copper and zinc. Additionally, a number of DOE sites have surface and groundwater that could be pumped to the surface for treatment with both heavy metal and radionuclide contamination. A wide range of aquatic plants will be considered for treatment of contaminated water, including submerged rooted aquatic plants, floating aquatic plants, and microalgae.

\section{TECHNOLOGY NEEDS}

Widespread heavy metal contamination exists in soils and groundwater across the DOE complex. A large amount of this contamination is of low concentration. For such low levels of contamination in a relatively large quantity of soil and water, removal and storage or remote treatment (such as incineration for soil) is extremely expensive. Phytoremediation technology could be less expensive than soil removal and treatment given the areal extent and topography of the sites under consideration, the problems associated with process-generated fugitive dust emissions, and the investment of energy and money in the soil-moving or waterpumping and treatment processes. Moreover, in situ technology may receive regulatory acceptance more easily than ex-situ treatments.

\section{ACCOMPLISHMENTS}

Feasibility of the approach was initially evaluated by: (1) obtaining biomass samples from plants growing on contaminated soils and water to determine the accumulation of heavy metals/ radionuclides, and 2) subjecting the biomass to the Ukrainian Fractionation Separation Technology (FST) to evaluate the effectiveness of this fractionation technology in concentrating and separating heavy metals from the 
bulk biomass to allow easy disposal of contaminants.

For these tests, alfalfa was harvested from areas of heavy metal soil contamination. Rubber rabbit brush and pine needles were harvested from uranium waste rock dumps. Soil samples were also collected and analyzed to evaluate plant efficiency for metal uptake. During the summer and fall of 1993 , biomass was collected from 32 locations for analysis and processing, including algae from acidic mine water near the Berkeley Pit in Butte, Montana. Laboratory analyses and data compilation and computations were completed. Initial tests of the Ukrainian FST indicated that more effective separation and/or biomass concentration technologies will be needed.

A current project at the Fernald site involves the development of field protocols for the use of native, crop, and weedy plant species to remediate uranium-contaminated soil. Several field trials were completed during FY94 and have served as a tool to evaluate preliminary candidate species, to provide accurate estimates of the rate of phytoremediation at the site, and to validate field and laboratory test protocols.

\section{BENEFITS}

The natural ability of plants to take up metals is an inexpensive and publicly appealing method by which to remediate low-level, widespread heavy-metal/ radionuclide contamination. The vast extent of land and water contaminated with heavy metals and radionuclides warrants use of such an economical technology.

\section{COLLABORATION/TECHNOLOGY TRANSFER}

MT International of the United States established a joint venture agreement--American-Ukraine Biotech IV (AUB)--with the Central Scientific Research Laboratory of Comprehensive Processing of Plant Raw Materials of the Ukrainian Academy of Agrarian Sciences. The Ukrainian Academy of Agrarian Sciences and Berevetnik Scientific Research Institute have conducted large scale soil remediation, implementing a biomass processing system near the radioactive Chernobyl site. AUB provided the laboratory-scale FST system design and personnel necessary for operation. MSE, Inc. established a contract with MT International to provide access to the Ukrainian technology.

A contract was established with Harbor Branch Oceanographic Institution, Inc. and Microbial Products, Inc. to assist in screening algae species for phytoremediation potential. MSE, Inc. will coordinate activities to perform field demonstrations at Fernald, Ohio.

\section{For further information, please contact:}

\section{Gordon Huddleston}

Principal Investigator

MSE, Inc.

P.O. Box 4078

Butte, MT 59702

(406) 723-8213

\section{Neal Egan}

Technical Program Manager

MSE, Inc.

P.O. Box 4078

Butte, MT 59702

(406) 494-7367

\section{Rashalee Levine}

Program Manager

U.S. Department of Energy

Cloverleaf Building

19901 Germantown Road

Germantown, MD 20874-1290

(301) 903-7920

TTP Number: PE031002

\section{BIBLIOGRAPHY OF KEY PUBLICATIONS}

None at this time. 


\section{TASK DESCRIPTION}

This program addresses key technical issues associated with designing, implementing, controlling, and measuring the performance of in situ bioremediation. The specific bioremediation process used in this field test stimulates indigenous aquifer microorganisms to degrade nitrates, carbon tetrachloride, and chloroform in sediments and groundwater. The program is implementing an integrated effort of laboratory-, bench-, and field scale testing to develop this in situ technology. Laboratory studies on carbon tetrachloride and chloroform degradation kinetics have been and are currently being performed in conjunction with soil column studies to provide reaction and biofilm process information. The results of this and site characterization efforts are being incorporated into a design tool/process simulator that is used for field design and process control. Field activities for the demonstration began in February 1995. See Figure 3.21.

Native microorganisms can be stimulated with acetate to consume and degrade carbon tetrachloride and nitrates in soils and groundwater. In laboratory-, bench-, and pilot-scale tests, it has been demonstrated that greater than $99 \%$ of nitrate carbon tetrachloride contamination in groundwater can be degraded.

The in situ bioremediation process involves a delivery of acetate and nitrate through a series of injection and extraction wells. These nutrients are mixed with the groundwater to maximize contaminant degradation and minimize excessive microbial growth around the well. The injected nutrients produce an active bioremediation zone consisting of organisms that will degrade contaminants within the aquifier. Contaminants in the sediment and groundwater within the active zone, as

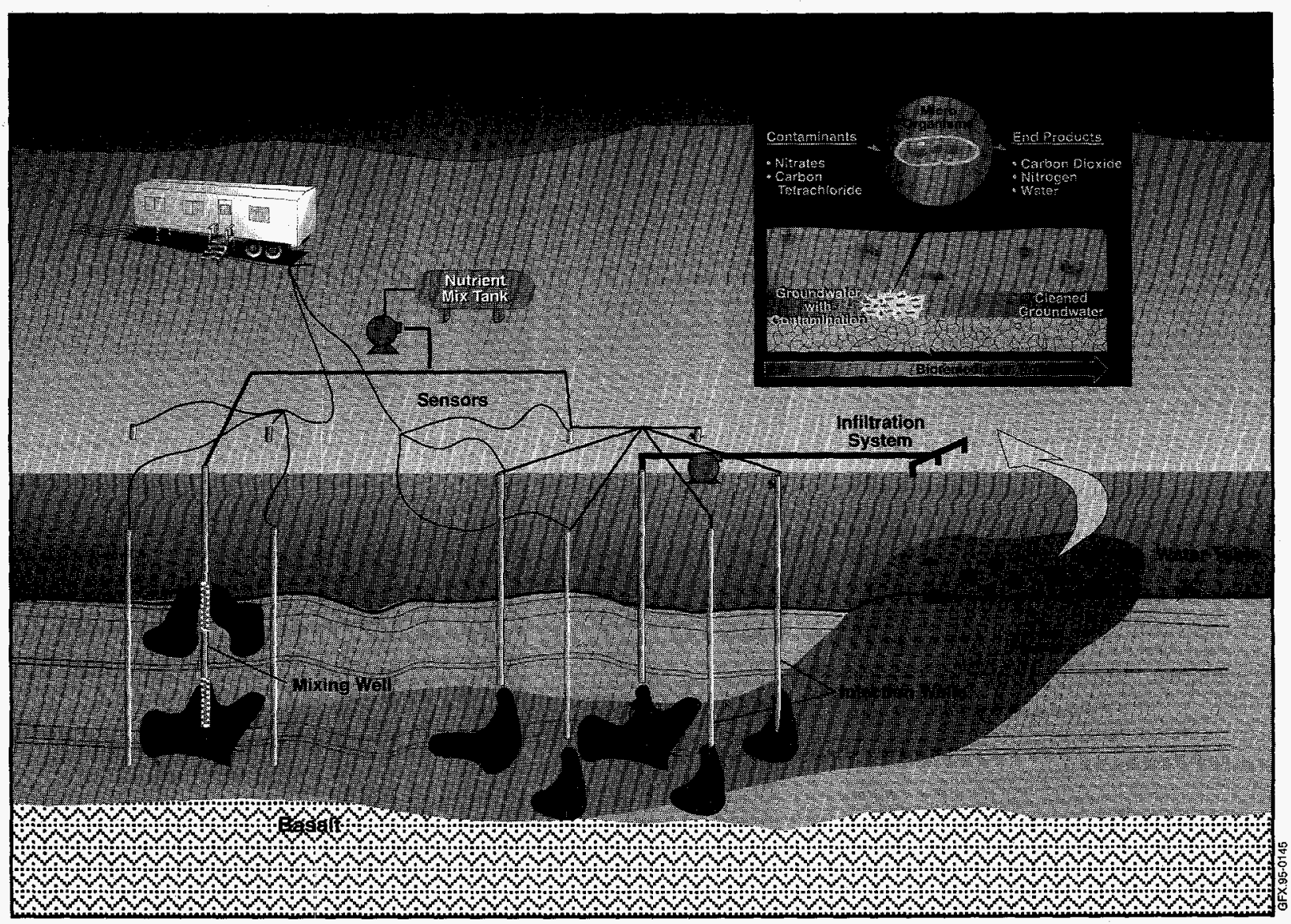

Figure 3.21. In Situ Bioremediation. 
well as contaminants in groundwater pumped through the zone, are degraded to innocuous byproducts.

\section{TECHNOLOGY NEEDS}

Pump-and-treat is the current technique to remediate contaminated groundwater. This process is difficult and expensive; therefore, more cost-effective and efficient methods, particularly in situ methods, must be developed. In situ bioremediation is being developed to stimulate the growth of naturally occurring organisms that can degrade and detoxify chemical contamination in place in soils and groundwater.

Although bioremediation is broadly applicable and versatile, it is also a site specific technology. Therefore, treatability studies and site-specific testing are needed to implement the technology. Several key technical issues have prevented widespread use of bioremediation for organic and inorganic subsurface contaminants. These issues include: (1) adequate nutrient delivery systems, (2) effective mixing technologies for contacting microorganisms, nutrients, and contaminants, (3) control of biofouling or excessive microbial growth, and (4) adequate tools for designing, predicting, and monitoring the performance of in situ technologies in heterogeneous subsurface environments.

\section{ACCOMPLISHMENTS}

Through FY94 and early FY95, there were a number of significant accomplishments in the development and demonstration of in situ bioremediation of carbon tetrachloride. The test site at Hanford was characterized during completion of six wells. Additional characterization information is being collected from groundwater recirculation to refine the operating strategy for active bioremediation.

The biological degradation of carbon tetrachloride was demonstrated in the laboratory soil column. The reaction kinetics for these processes were determined for inclusion into a modeling design tool.

A simulation design tool was developed specifically for this in situ bioremediation process. A number of simulations were conducted to help identify critical field operation parameters related to bioremediation and nutrient injection. The modeling design tool was demonstrated for 2-D, 3-D and multiphase in situ bioremediation simulations. The same design tool is being further developed as a generic product for in situ bioremediation design.

Field test equipment was installed at the site. It is being used as part of the final characterization tests. This equipment includes a process trailer containing the nutrient injection system, process control computer, down-well equipment for groundwater recirculation, and sampling equipment.

The test plan was completed and site operating procedures were written for use during field operations. The first phase, an abiotic control phase of operation, was started February 1, 1995.

\section{BENEFITS}

Present estimates indicate that this technology should remediate the Hanford test site in half the time required by conventional pump-and-treat methods. These estimates, based on permeable soils and groundwater with VOC contaminants only, indicate that this technology will be faster and safer than the baseline methods, while costing about the same as pump-andtreat per volume of soil remediated. The increase in safety results, because no contaminated media needs to be brought to the surface. It is expected that if the cost/ benefit analysis included the baseline cost of treating nitrates in addition to VOCs, bioremediation costs would still be significantly lower than the baseline.

In situ bioremediation provides a potentially significant benefit for VOCs and other contaminants that are trapped in adsorptive soils or less permeable silts, sediments, and clays. Bioremediation can destroy the VOCs in place and reduce the mass transport limitations associated with VOC adsorption/desorption to sediments, and dissolution into the groundwater that limits pump-and-treat technologies.

The time and cost of cleanup could be substantially reduced if bioremediation could be effectively employed alone or in conjunction with other bulk-contaminant removal technologies. The technology provides ultimate on-site destruction of the contami- 
nant, converting the hazarclous compounds to nonhazardous products. In addition, this treatment method has the potential of reducing further spread of contamination. The increased numbers of microorganisms will reduce the soil permeability and, therefore, reduce the rate of migration of VOCs out of and into the contaminated zone. Other advantages include:

- worker exposure to chernical contaminants is decreased;

- the movement of radionuclides in the groundwater may be slowed; and

- bioremediation is a natural process with high likelihood for acceptance.

\section{COLLABORATION/T'ECHNOLOGY}

\section{TRANSFER}

In order to ensure successful transfer of the technology to industry and commercial environmental consulting firms, industrial partnerships are being pursued with industrial companies desiring the technology for their own cleanup actions and with consulting or service companies who want to provide services to other clients for site cleanup. Negotiations with several companies are underway.

In the case of this particular technology, there is not one specific design, apparatus, or prescribed mixture of microbes and nutrients that can be transferred for general use. This technology and its applications will be site and contaminant specific. Therefore, the product from this project with the most commercial value is an integrated design tool for in situ bioremediation. This integrated design tool can be transferred for use across the DOE complex, DoD installations, and to industrial sites throughout the world.

For further information, please contact:

\author{
Daniel Anderson \\ Principal Investigator \\ Pacific Northwest Laboratory \\ P.O. Box 999 \\ Richland, WA 99352 \\ (509) 376-9428
}

\author{
Steven Slate \\ Technical Program Manager \\ Pacific Northwest Laboratory \\ P.O. Box 999 \\ Richland, WA 99352 \\ (509) 376-3903
}
Rashalee Levine
Program Manager
U.S. Department of Energy
Cloverleaf Building
19901 Germantown Road
Germantown, MD 20874-1290
(301) 903-7920

\section{TTP Number: RL311104}

\section{BIBLIOGRAPHY OF KEY PUBLICATIONS}

Brouns, T.M., S.S. Koegler, and J.K. Fredrickson, "Biological Treatment of Hanford Groundwater: Pilot-Scale Process Development," Proceedings of the International Topical Meeting on Nuclear and Hazardous Waste Management, Spectrum '90, September 30-October 4, 1990, Knoxville, Tennessee. American Nuclear Society, La Grange Park, Illinois.

Brouns, T.M., S.S. Koegler, W.O. Heath, J.K. Fredrickson, H.D. Stensel, D.L. Johnstone, and T.L. Donaldson, Development of a Biological Treatment System for Hanford Groundwater Remediation: FY 1989 Status Report, PNL-7290, Pacific Northwest Laboratory, Richland, Washington, 1990.

Brouns, T.M., S.S. Koegler, and W.O. Heath, U1/ U2 Crib Groundwater Biological Treatment Demonstration Project: FY 1989 Annual Report, PNL-SA17588, Pacific Northwest Laboratory, Richland, Washington, 1989.

Chiang, C.Y., C.N. Dawson, and M.F. Wheeler, Modeling of In Situ Biorestoration of Organic Compounds in Groundwater, Rice University Technical Report, TR90-31, 1990.

Hooker, B.S., R.S. Skeen and J.N. Petersen, "Biological Destruction of $\mathrm{CCl}_{4}$, Part II: Kinetic Modelling," Biotechnology and Bioengineering, 1994. 
Hooker, B.S., R.S. Skeen, S.M. Cote, M.J. Truex, and J.N. Petersen, "Application of a Structured Kinetic Model to In Situ Bioremediation of Hanford Groundwater," Bioremediation of Chlorinated and Polycyclic Aromatic Hydrocarbon Compounds, R.E. Hinchee, L. Semprini, and S. K. Ong (eds.), Lewis Publishers, Ann Arbor, MI, 387-91, 1994.

Hansen, E.J., Transformation of Tetrachloromethane Under Denitrifying Conditions by a Subsurface Bacterial Consortium and Its Isolates, MS thesis, Washington State University, Pullman, Washington, 1990.

Koegler, S.S., T.M. Brouns, W.O. Heath, and R.J. Hicks, Biodenitrification of Hanford Groundwater and Process Effluents: FY 1988 Status Report. PNL6917, Pacific Northwest Laboratory, Richland, Washington, 1989.

Madsen, E.L., "Determining In Situ Biodegradation," Environmental Science and Technology, 25:1663-1673, 1991.

Petersen, J.N., R.S. Skeen, K.M. Amos, and B.S. Hooker, "Biological Destruction of $\mathrm{CCl}_{4}$ Part I: Experimental Design and Data," Biotechnology and Bioengineering, 43, 521-8, 1994.

Peyton, B.M., R.S. Skeen, B.S. Hooker, R.W. Lundman, and A.B. Cunningham, "Evaluation of Bacterial Detachment Rates In Porous Media," Applied Biochemistry and Biotechnology, 1994.

Shouche, M.J., J.N. Petersen, and R.S. Skeen, "Use of a Mathematical Model for Prediction of Optimum Feeding Strategies for In situ Bioremediation," Applied Biochemistry and Biotechnology, 39, 763-79, 1993.

Skeen, R.S., S.P. Luttrell, B.S. Hooker, and J.N. Petersen, "In Situ Bioremediation of Hanford Groundwater," Remediation, 3, 353-67, 1993.

Skeen, R.S., K.M. Amos, M. Shouche, and J.N. Petersen, "Kinetics of the Degradation of Carbon Tetrachloride by a Denitrifying Microbial Consortium," Accepted for publication in Water Research.

Thomsen, J.K., T. Geest, and R.P., Cox, "Mass Spectrometric Studies of the Effect of $\mathrm{pH}$ on Accumulation of Intermediates in Denitrification by
Paracoccus Denitrificans," Applied Environmental Micrabiology, 60, 563-541, 1994.

Truex, M.J., R.S. Skeen, S.M. Caley, and D.J. Workman, "Comparative Efficiency of Microbial Systems for Destroying Carbon Tetrachloride Contamination in Hanford Ground Water," Bioremediation of Chlorinated and Polycyclic Aromatic Hydrocarbon Compounds, R. E. Hinchee, L. Semprini, and S. K. Ong (eds.), Lewis Publishers, Boca Raton, Florida, pp. 80-85, 1994.

Truex, M.J., D.R. Brown, and D.B. Elliott, Cost/ Benefit Analysis Comparing Ex Situ Treatment Technologies for Removing Carbon Tetrachloride from Hanford Ground Water, PNL 8334, Pacific Northwest Laboratory, Richland, Washington, 1992.

Clement, T. P., B. S. Hooker, and R. S. Skeen, "Modeling Biologically Reactive Transport in Porous Media," Proceedings of the International Conference on Mathematics and Computations, Reactor Physics, and Environmental Analyses, Portland, Oregon, 1995 (in press).

Newcomer, D.R., L.A. Doremus, S.H. Hall, M.J. Truex, V.R. Vermeul, and R.E. Engelman, Geology, Hydrology, Chemistry, and Microbiology of the In Situ Bioremediation Demonstration Site, PNL-10422, Pacific Northwest Laboratory, Richland, Washington, 1995.

Truex, M.J., C.D. Johnson, D.R. Newcomer, L.A. Doremus, B.S. Hooker, B.M. Peyton, R.S. Skeen, and A. Chilakapati, "Deploying In Situ Bioremediation at the Hanford Site," In-Situ Remediation: Scientific Basis for Current and Future Technologies, Part 1, G.W. Gee and N.R. Wing (eds.), Battelle Press, Richland, WA, pp. 209-231, 1994.

Hooker, B.S., R.S. Skeen, M.J. Truex, and B.M. Peyton, "A Demonstration of In Situ Bioremediation of CCl4 at the Hanford Site." In-Situ Remediation: Scientific Basis for Current and Future Technologies, Part 1, G.W. Gee and N.R. Wing (eds.), Battelle Press, Richland, WA, pp. 281-292, 1994.

Skeen, R.S., M.J. Truex, J.N. Petersen, and J.S. Hill, "A Novel Reactor for Monitoring Biodegradation," Environmental Progress, 13:174-177, 1994. 


\section{TASK DESCRIPTION}

The objective of this project is to demonstrate the In-Well Vapor Stripping system for extracting VOCs from groundwater at Edwards AFB. The demonstration will primarily show the effectiveness and efficiency of the method to remove TCE from the groundwater on a continuous basis. A combined soil vapor extraction and groundwater remediation system will also be demonstrated. The combined system can be used to remove VOCs contained in both the soil vadose zone and the aquifer zone.

The In-Well Vapor Stripping system is a remediation technology designed to preferentially extract VOCs dissolved in groundwater by converting them to a vapor phase and treating the vapor. The system involves the combination of air-lift pumping and aeration within the borehole to strip volatiles from the groundwater. The water inside the wellbore is aerated by injecting air at the base of the wellbore creating a turbulent frothing action. The rising air bubbles strip the dissolved contaminants from the water and carry them to the surface in a vapor stream where they are treated. The aeration process also acts as a groundwater pump, lifting aerated water inside the wellbore to an upper well screen interval where the cleansed water is diverted back into the sediments and allowed to return to the water table. This simultaneous extraction of groundwater from the lower screen and re-introduction of water above the water table creates a circulation cell in the aquifer. This circulation sequentially removes the volatile organics from the groundwater.

\section{TECHNOLOGY NEEDS}

Many DOE sites have aquifers where groundwater is contaminated with VOCs. Carbon tetrachloride, chloroform, and TCE are found at many DOE sites. It is expensive to pump the water to the surface for treatment. Furthermore, if the water contains tritium, as at many sites, surface storage and disposal of the tritiated water is a major problem. Using In-
Well Vapor Stripping, the VOCs are removed from the aquifer without removing the contaminated water. The system converts a groundwater contamination problem into a vapor stream, which can be easily treated at the surface.

The in-well vapor stripping method, as currently envisioned, will not remove non-volatile compounds from the groundwater. If wells are not properly located, it is possible to spread the partially remediated (lower concentration) plume by recirculating partially treated water beyond the radius of influence of the well. Discharges to the vadose zone may also mobilize pockets of contaminant in the vadose zone, adding to the total mass of contaminants in the aquifer, but these can be captured by the in-situ VOC removal well. Current efforts to improve this system are focused on resolution of these issues.

\section{ACCOMPLISHMENTS}

- Prepared the In-Well Vapor Stripping System Project Management Plan for the Edwards AFB demonstration has been prepared. The Edwards AFB installation is the first planned demonstration of In-Well Vapor Stripping in the United States.

- Installed three wells and characterized the site for chemical and physical parameters.

- Performed a series of full-scale laboratory tests at the Hanford site to verify the concept and design of the prototype system. The tests were used to refine operating parameters, design specifications, and air stripping efficiency.

\section{BENEFITS}

The In-Well Vapor Stripping system can continuously remove VOCs from groundwater without pumping the water to the surface or removing the water from the ground. It has the advantage of being an in situ method, See Figure 3.23. It avoids the 
need for handling contaminated water above the ground surface and for disposing or storing partially treated water.

There is no need for an above-ground air-stripping tower or storage tanks to contain the tritiated water that is free of VOCs. Compared to the baseline pump-and-treat method, where reinjection of tritiated water was permitted, the in-well VOC removal system would not require the expense of drilling injection wells. The method has the further advantage of enabling recirculation of chemical aids to groundwater remediations, such as surfactants and catalysts. Finally, it also has the advantage that a single well can be used for extraction of soil vapors and for groundwater remediation. The baseline technology would require separate pump-and-treat wells and soil vapor extraction wells. The in-well VOC removal system is more economical and more efficient than pump-and-treat and soil vapor extraction.

\section{COLLABORATION/TECHNOLOGY TRANSFER}

In-Well Vapor Stripping is currently being developed in cooperation with NoVOCs, Inc. In September 1994, EG\&G Environmental, Inc. purchased NoVOCS, Inc. and initiated an aggressive program for commercialization. EG\&G Environmental is installing the technology directly as well as licensing other contractors to install systems. Stanford University owns the patent for this technology.

\section{For further information, please contact:}

\section{Gaynor Dawson}

President

EG\&G Environmental, Inc.

\section{Route 1}

Box 5038 Groverlane

Richland, WA 99352

(509) 967-2347

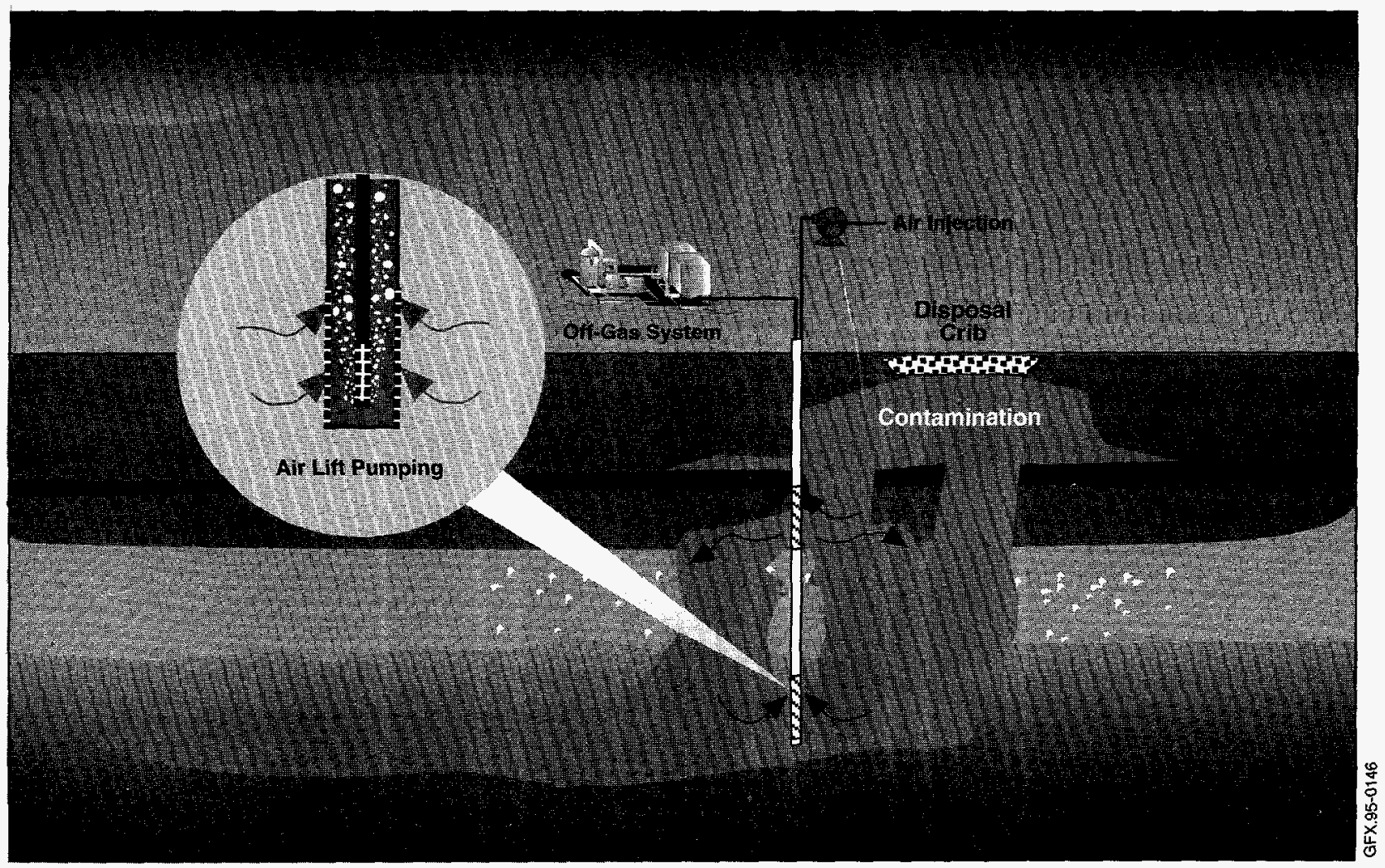

Figure 3.22. In-Well Vapor Stripping. 


\section{Steve Gorelick}

Principal Investigator

Stanford University

Department of Geological \& Environmental Sciences

(415) $725-2950$

\section{Tyler Gilmore}

Principal Investigator

Pacific Northwest Laboratory

P.O. Box 999

Richland, WA 99352

(509) 372-6063

\section{Rashalee Levine}

Program Manager

U.S. Department of Energy

Cloverleaf Building

19901 Germantown Road

Germantown, MD 20874-1290

(301) $903-7920$
TTP Number: HQ031003, RL 311101

\section{BIBLIOGRAPHY OF KEY PUBLICATIONS}

Gvirtzman H. and S.M. Gorelick, "The Concept of In-Situ Vapor Stripping for Removing VOCs from Groundwater," Transport in Porous Media, 8:7192, 1992.

Dawson, G.W., In-Well Treatment of Remediation of VOCs in Ground Water, Presented at the Defense Waste Cleanup Conference, Washington DC, October 4, 1994. 


\section{TASK DESCRIPTION}

This project will develop and evaluate viable concepts for in situ bioremediation of mixtures of chlorinated solvents in groundwater. This objective will be achieved by developing methods to control multiple microbial populations.

TCE and PCE will be used as model solvents in this work because these compounds are common contaminants at government and industrial sites. In addition, these materials represent the two most common groups of co-metabolically degradable chlorinated solvents: those that degrade aerobically and anaerobically (TCE) and those that degrade strictly anaerobically (PCE). The technologies developed in this work are envisioned to involve volumetric treatment of in situ contamination by continuously cycling the subsurface through aerobic and anaerobic conditions.

This work is focused on one main task: Mixed Solvent Remediation Process Development. Research will be conducted to understand the effects of adding nutrients such as oxygen on the growth of combined populations of aerobic and anaerobic microorganisms and their ability to destroy chlorinated solvents. The information will help determine nutrient cycling and other processing methods to destroy contaminant mixtures in groundwater. Saturated media will be used in these tests because they minimize the complexity of the experiments and allow for comparison with previous work. These efforts will culminate in developing a remediation strategy for a field site. See Figure 3.23.

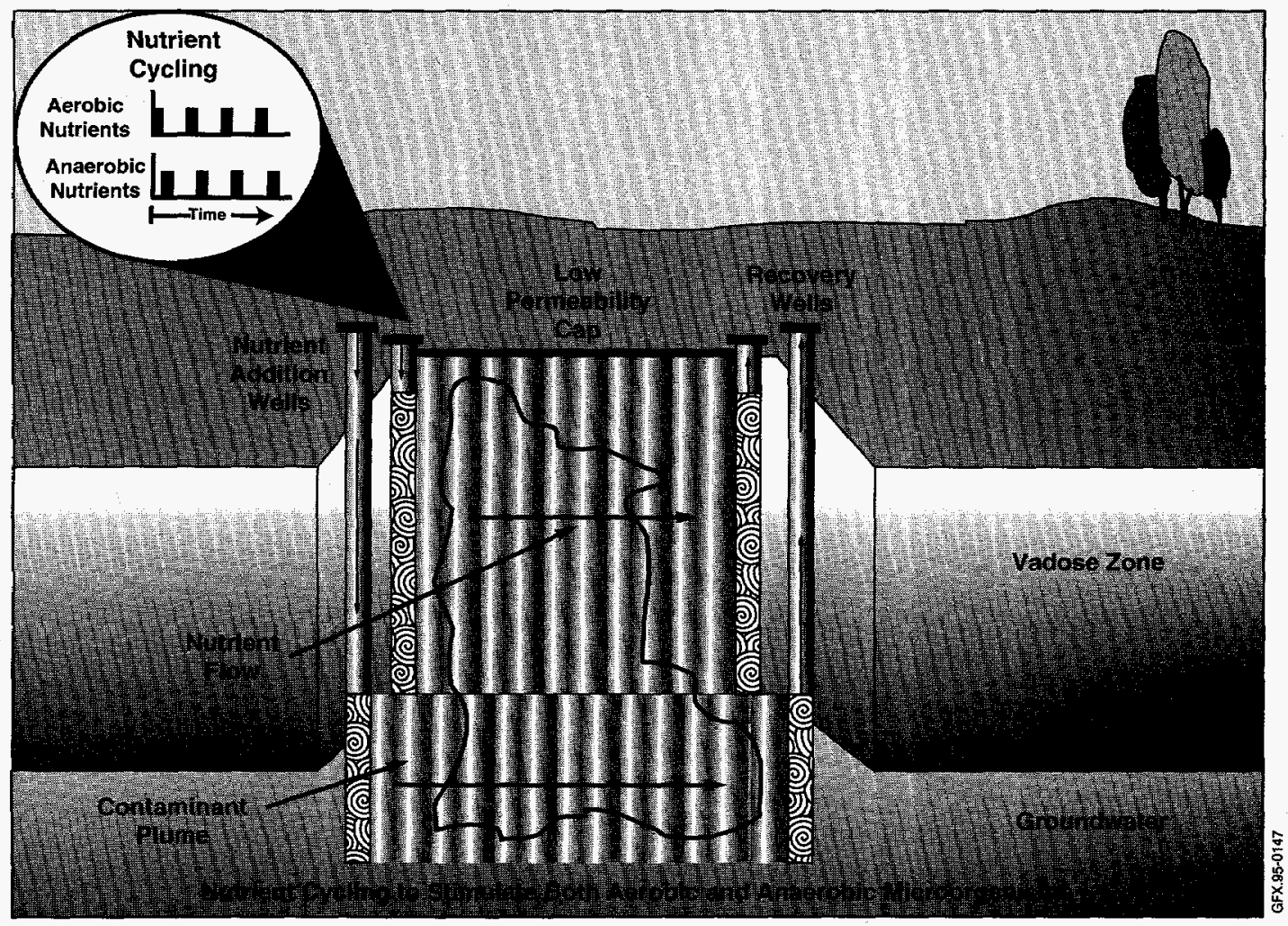

Figure 3.23. Treatment Strategy for In Situ Anaerobic and Aerobic Bioremediation of Mixed Chlorinated Solvents. 
To facilitate field application of the results from this research, an in situ treatability protocol is being developed in FY95. This test will use computational tools to analyze field tracer data and nutrient injection data to evaluate the potential for anaerobic and/or aerobic bioremediation at a given waste site. In addition, the test will provide the microbial characterization information that is needed for remediation system design. Currently, the cost of developing this information is extremely high since a combination of both laboratory and field analysis is required. It is anticipated that using a single in situ test will greatly reduce these costs. The usefulness of the in situ treatability test will be demonstrated at several field sites in FY96.

\section{TECHNOLOGY NEEDS}

Chlorinated solvent contamination in soils and groundwater is a wide-spread problem at government and industrial sites. There is no field-ready in situ treatment technology for this problem. Pumpand-treat is the primary remediation technology for groundwater; however, a major disadvantage of this approach is the inability to extract all the contaminants because the materials can adsorb to the soil or be retained in soil pores. In addition, pump-andtreat increases risk of exposing workers to the hazardous material. It is expensive due to the large volumes of contaminated media that must be handled above-ground.

In situ bioremediation can circumvent these problems because contaminants are not extracted. However, implementing in situ bioremediation to treat the DOE's chlorinated solvent contamination requires developing techniques to remediate single contaminants and mixtures of contaminants in saturated and unsaturated soils. This situation is complicated, because many of the different classes of microorganisms required for degradation need different chemical conditions for active metabolism. The conditions which support activity by one class of organisms may inhibit another class. The goal of this task is to develop processes to treat contaminant mixtures by applying basic engineering principles to process design and evaluation.

\section{ACCOMPLISHMENTS}

A test plan for FY94 experiments was completed. This document contains a detailed description of all the tests that will be conducted along with the associated analytical and microbial procedures.

An extensive review of methanogenic kinetics literature was conducted, focusing on anaerobic degradation of chlorinated solvents and the growth and respiration of methanogenic microorganisms. This information was used to devise balanced growth and respiration reaction equations. In addition, rate expressions for these reactions were hypothesized.

Experiments were conducted on the kinetics of growth, methane production, and PCE dechlorination by an anaerobic microbial consortium isolated from contaminant-free river sediment samples. The purpose of these experiments was to provide a conservative representation of dechlorination by examining anaerobic PCE degradation by an environmental isolate that had no prior exposure to chlorinated solvents. This work is being contrasted to published studies where organisms have had long durations (typically years) to adapt to the presence of the contaminant. Soil column reactors were designed to test candidate substrates and measure the effects of soil water potential and $\mathrm{pH}$ buffering on the growth of bacteria in unsaturated soils.

Microcosms have been established using aquifer materials from several private, DOE, and DoD waste sites that have PCE contamination. This material is being used to evaluate natural methods to increase the efficiency of anaerobic dehalogenation activity. Biologically reactive flow-and-transport computational tools have been developed to simulate both aerobic and anaerobic microbial activity in the saturated subsurface. These computer tools are being used to rapidly evaluate the effectiveness of potential bioremediation system designs and nutrient feeding strategies for aquifer restoration. 


\section{BENEFITS}

This work will lead to the development of a fieldready method to bioremediate mixtures of chlorinated solvents in situ.

\section{COLLABORATION/TECHNOLOGY}

\section{TRANSFER}

This project is a collaboration between PNL, Washington State University, and Montana State University. Demonstration at a DOE site will help facilitate technology transfer.

For further information, please contact:

\section{Rodney Skeen}

Principal Investigator

Pacific Northwest Laboratory

P.O. Box 999

Richland, WA 99352

(509) 376-6371

\section{Steven Slate}

Technical Program Manager

Pacific Northwest Laboratory

P.O. Box 999

Richland, WA 99352

(509) 375-3903

Rashalee Levine

Program Manager

U.S. Department of Energy

Cloverleaf Building

19901 Germantown Road

Germantown, MD 20874-1290

(301) 903-7920
TTP Number: RL341002

\section{BIBLIOGRAPHY OF KEY PUBLICATIONS}

None at this time. 


\section{TASK DESCRIPTION}

The objective of this task is to develop a mathematical model to determine the optimum operating conditions for electrokinetic decontamination of specific waste sites. See Figure 3.24. Under study are process responses to a number of changes that can occur during remediation, including changes in $\mathrm{pH}$, together with the effects of various naturally occurring matter and co-disposed wastes. All of these can affect the speciation and solubility of the heavy metals and, hence, their mobility. Variations in soil permeability and water content will also be investigated. Tests will be conducted in a three-

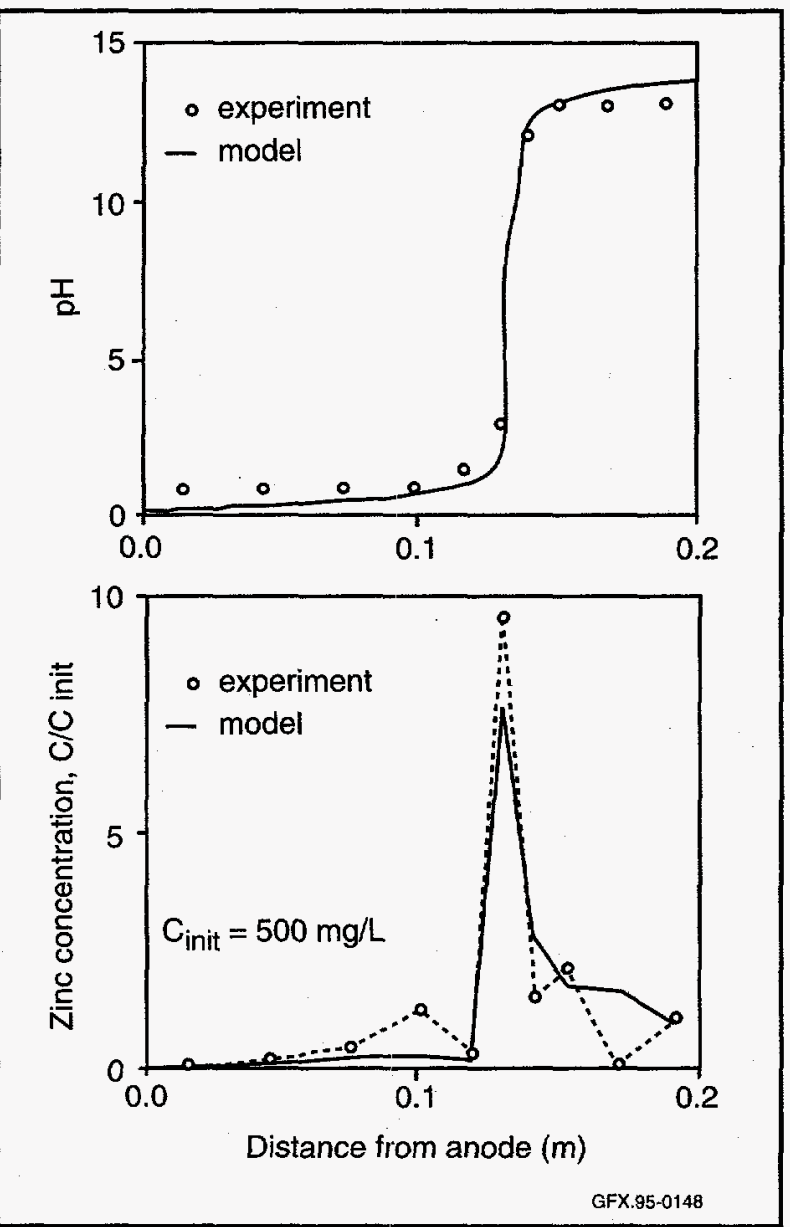

Figure 3.24. Comparison of Experiment and Model Results for Zinc Distribution ( $t=9$ days $)$. dimensional apparatus to verify the model with respect to its applicability to soils contaminated with a mix of metals and/or organic wastes.

\section{TECHNOLOGY NEEDS}

Electrokinetic remediation is not fully understood because of the many parameters that affect the process and because of the complex interactions that occur when a direct current is applied between buried electrodes in complex waste-geochemical mixtures. Laboratory experiments have demonstrated that certain pollutants dissolved in an aqueous phase can be removed from contaminated soils by electro-osmosis and electromigration. However, the reproduction of site conditions in the laboratory has proven difficult and can account for anomalous results in the field.

Several field trials and detailed laboratory investigations have revealed factors that can reduce the effectiveness of the electrokinetic remediation process including: (1) the presence of buried metallic conductors in the soil; (2) immobilization of metal ions by undesirable chemical reactions with naturally occurring and co-disposed chemicals; and (3) $\mathrm{pH}$ and reduction-oxidation changes induced by the process electrode reactions. The physical site characteristics, including permeability and degree of water saturation, can also alter the process effectiveness. A mathematical model of all these effects operating simultaneously is necessary because the effects of parameters measured in isolation will not be the same as the effects of the parameters occurring simultaneously.

\section{ACCOMPLISHMENTS}

Experiments in one-dimensional cells have demonstrated that electromigration is the principal removal mechanism for ionic metal wastes and that electro-osmosis may make a negligible contribu- 
tion. Moreover, in the removal process, metals may accumulate in a narrow band in the soil, where there is a jump in the $\mathrm{pH}$, instead of being purged--a phenomenon akin to isoelectric focusing. A model that accounted for transport and chemical reactions, including ionic complex formation, adsorption, and precipitation, gave results that agreed with experimental results for the removal of zinc from soils containing excess sodium ions. The model showed that the electric field was very large at the location of the $\mathrm{pH}$ jump and very small elsewhere. It also showed that rinsing the cathode to wash away sodium ions and the hydroxyl ions generated by electrolysis will prevent a high $\mathrm{pH}$ front from entering the soil and will result in successful metal removal. This behavior was confirmed experimentally.

It was found that equilibrium models could be used to determine the metal speciation in complex geochemical mixtures and, if presented as Pourbaix diagrams, are particularly useful for rapidly identifying conditions that might enhance mobility. It was concluded that the excellent removal efficiencies that have been obtained in the laboratory could be achieved in the field, if mobilization problems were adequately addressed. In this respect, it is expected that the model developed will provide an important guide to laboratory and pilot-scale treatability studies.

\section{BENEFITS}

In situ application of low-power direct current to contaminated soils may help to remove radioactive and heavy metals as well as water-soluble organics. For soils of low permeability (clays and silts), this may be the only practical in situ method for removing these contaminants. Cost estimates for cleanup are highly dependent on the types and concentrations of contaminants and the extent of remediation desired. However, this method will be economically attractive for sites that are responsive to electrokinetic treatment.

\section{COLLABORATION/TECHNOLOGY TRANSFER}

Close cooperation among these researchers and others at DOE sites who are attempting practical application of electrokinetic remediation is being maintained. General understanding of process fundamentals will be the key to applying the technology in an efficient and cost-effective manner.

For more information, please contact:

Ronald F. Probstein

Principal Investigator

Massachusetts Institute of Technology

777 Massachusetts, Room 3-246

Cambridge, MA 02139

(617) 253-2240

Jeffrey S. Walker

Program Manager

U.S. Department of Energy

Cloverleaf Building

19901 Germantown Road

Germantown, MD 20874-1290

(301) 903-7966

TTP Number: HQ031004

BIBLIOGRAPHY OF KEY PUBLICATIONS

Probstein, R.F., P.C. Renaud, and A.P. Shapiro, "Electroosmosis Techniques for Removing Materials from Soil," U. S. Patent 5,074,986, Dec. 24, 1991.

Probstein, R.F., and R.E. Hicks, "Removal of Contaminants from Soils by Electric Fields," Science (260): 498-503., 1993.

Shapiro, A.P., and R.F. Probstein, "Removal of Contaminants from Saturated Clay by Electroosmosis," Environmental Science and Technology (27, No. 2): 283-291, 1993. 
Jacobs, R.A., M.Z. Sengun, R.E. Hicks, R.F. Probstein, "Model and Experiments on Soil Remediation by Electric Fields," Journal of Environmental Science and Health, A29(9), 1933-1955, 1994.

Hicks, R.E., and S. Tondorf, "Electrorestoration of Metal-Contaminated Soils," Environmental Science and Technology, (28, No. 12): 2203-2210, 1994. 


\subsection{ELECTROKINETIC REMEDIATION OF HEAVY-METAL-CONTAMINATED UNSATURATED SOIL}

\section{TASK DESCRIPTION}

The goal of this project is to develop an in situ electrokinetic process for removing chromate contamination from unsaturated soil. See Figure 3.25. After the technology was developed and tested at the bench- and pilot-scale in FY93, a field test in clean soil was initiated in FY94 to characterize the process and to demonstrate in situ water control in unsaturated soil. Demonstration of the process in chromate-contaminated soil is scheduled for FY95.

\section{TECHNOLOGY NEEDS}

A large portion of DOE's contaminated soil is unsaturated, containing small amounts of water. This is typical of the western states. In regions where contaminated saturated soils are more common, there also exists a zone of contaminated unsaturated soil (the vadose zone) lying above the saturated zone. There currently are no viable in situ methods for remediating heavy metal contamination from these unsaturated soils. Excavation and processing, or disposal at a licensed landfill will not always be feasible and will always be expensive.

This research is immediately directed at remediating chromate $\left(\mathrm{CrO}_{4}^{2-}\right)$ contamination in unsaturated soil in Sandia's CWL, where chromium contamination has been detected to a depth of 75 feet. Other DOE sites contaminated with mobile negatively charged compounds (anions) (e.g., $\left.\mathrm{MoO}_{4}^{2-}, \mathrm{SeO}_{4}^{2}, \mathrm{HAsO}_{4}^{2-}, \mathrm{UO}_{2}\left(\mathrm{CO}_{3}\right)_{3}^{4-}\right)$ should be treatable with this technology. These anions are highly mobile in soil because they typically do not adsorb strongly on the soil surface.

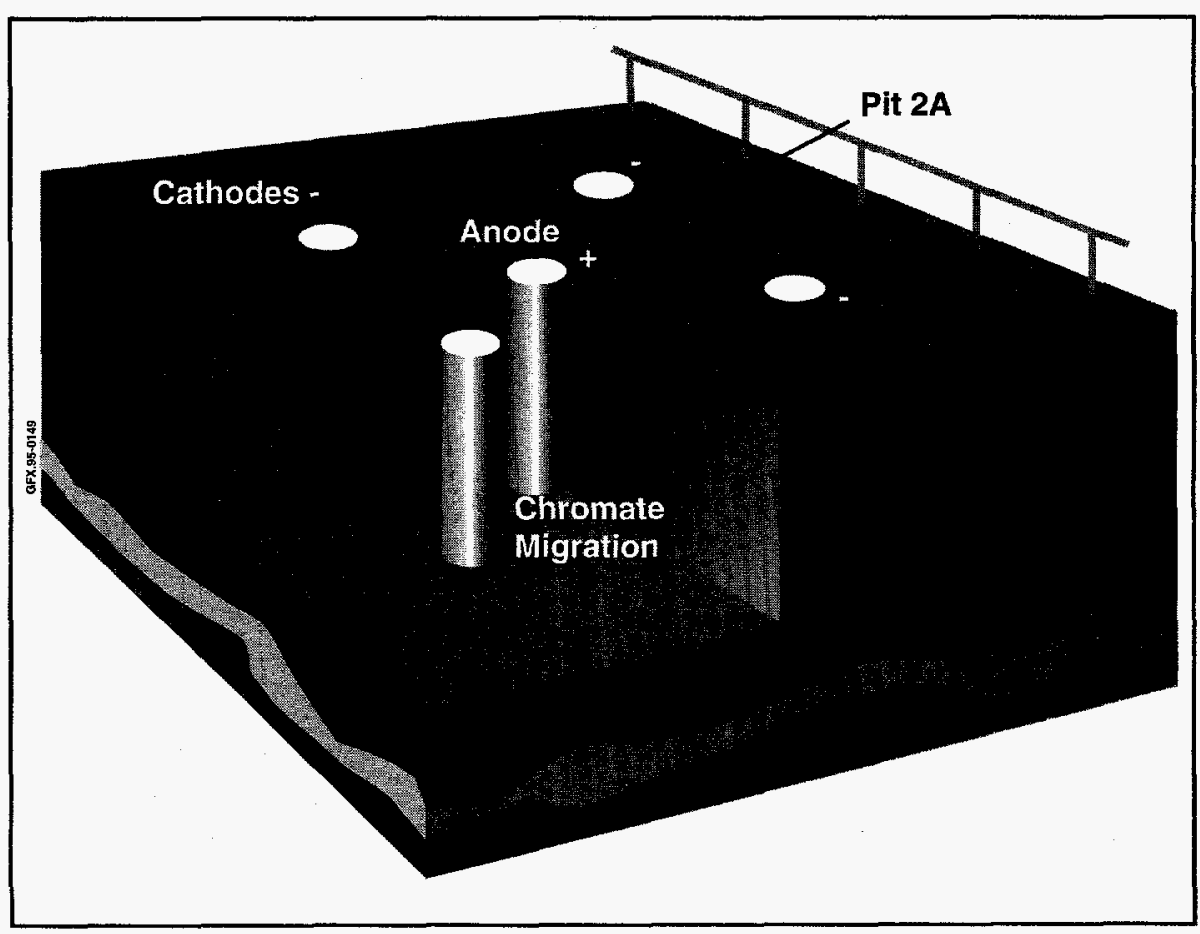

Figure 3.25. Proposed Electrode Array for Electrokinetic Remediation of the Sandia Unlined Chromic Acid Pit.

\section{ACCOMPLISHMENTS}

Preliminary experiments at SNL demonstrated that electrokinetic processes can move large organic dye anions, as well as chromate anions, through unsaturated sands with moisture contents typical of subsurface soils found in arid regions. The minimum moisture content for observable migration to occur in the soils tested was $3.5 \mathrm{wt} \%$. An electrode system was developed for extracting anionic contaminants from unsaturated soil without significantly changing the moisture content of the soil. Control of water 
introduction and removal of $95 \%$ of the chromate contamination were demonstrated in bench-scale testing. This electrode system is presently under review by the Sandia patent office.

A prototype electrode system was fabricated and tested for use in the FY94 clean soil field test. The test plans were prepared, reviewed, and approved, and the field test was initiated in FY94. Results should be available in early 1995 .

A preliminary test plan and application for a RCRA Research Development and Demonstration (RD\&D) permit have been prepared for the FY95 chromate removal demonstration.

A CRADA with United Technologies Corporation was signed.

\section{BENEFITS}

There are no viable in situ methods for removing heavy metal contamination from unsaturated soils. Current baseline technology involves excavating the soil and subsequent processing by soil washing or disposal at a licensed landfill. Because excavation may not be technically, economically, or politically acceptable, development of a cost-effective in-situ technology for removing contaminants is highly desirable. This is particularly true for the chromium contamination at the Sandia CWL, where contamination has been detected at depths as great as 75 feet. Excavation to such depths is not economically feasible.

Estimates for electrokinetic remediation range from $\$ 50$ to $\$ 150$ per ton. Processes involving excavation of soil cost $\$ 200$ to $\$ 500$ per ton.

\section{COLLABORATION/TECHNOLOGY TRANSFER}

Sandia soils were characterized for fundamental electrokinetic properties at the University of Washington. All additions to the subsurface will be identified and discussed with the New Mexico Environmental Department to ensure compliance with all applicable regulations. An industrial partner with prior field experience in electro-kinetics, ElectroPetroleum, Inc., will assist with design review, installation, and operation of the field demonstration at Sandia. United Technologies Corporation is interested in further developing the technology to better suit their needs, test the technology at their site, and, if successful, develop the technology commercially.

For further information, please contact:

Eric R. Lindgren

Principal Investigator

Sandia National Laboratories

P.O. Box 5800

Albuquerque, NM 87185-5800

(505) $844-3820$

George Allen

Technical Program Manager

Sandia National Laboratories

P.O. Box 5800

Albuquerque, NM 87185-5800

(505) 844-9769

Jeffrey S. Walker

Program Manager

U.S. Department of Energy

Cloverleaf Building

19901 Germantown Road

Germantown, MD 20874-1290

(301) $903-7966$

TTP Number: AL231009

BIBLIOGRAPHY OF KEY PUBLICATIONS

Lindgren, E.R., E.D. Mattson, and M.W. Kozak, "Electrokinetic Remediation of Anionic Contaminants from Unsaturated Soils," Proceedings of the International Symposium on Environmental Contamination in Central and Eastern Europe, Budapest '92, pp. 614-616. Budapest, Hungary, 1992. 
Lindgren, E.R., R.R. Rao, and B.A. Finlayson, "Numerical Simulation of Kinetic Phenomena," Proceedings of the Industrial and Engineering Chemistry Special Symposium, American Chemical Society, Atlanta, GA, September 27-29,1993.

Mattson, E.D., and E.R. Lindgren, "Electrokinetic Extraction of Chromate from Unsaturated Soils," Emerging Technologies in Hazardous Waste Management $V, A C S$ Symposium Series, Washington, D.C., 1993.

Lindgren, E.R., and E.D. Mattson, Final Electrokinetic Test Plan for Clean Unsaturated Soil, Test Plan, Sandia National Laboratories, Albuquerque, New Mexico, 1994. 


\section{TASK DESCRIPTION}

Pilot-scale electrokinetic removal of uranium from contaminated soil will be demonstrated in this project. See Figure 3.26. Site selection and treatability studies will precede the pilot test. A full-scale field test at a site to be determined is envisioned following evaluation of the pilot scale results. Removal efficiency, control of added fluids, contaminant recovery and disposal, power consumption, mass balance, and control of soil $\mathrm{pH}$ must all be evaluated to assure that this process is viable. Technology advances made by Russian scientists in this area of environmental remediation will be used as much as possible. The selected site should allow easy permitting for testing, be representative of the uranium problems throughout DOE, and be accessible to industry, regulatory agencies, and academia.

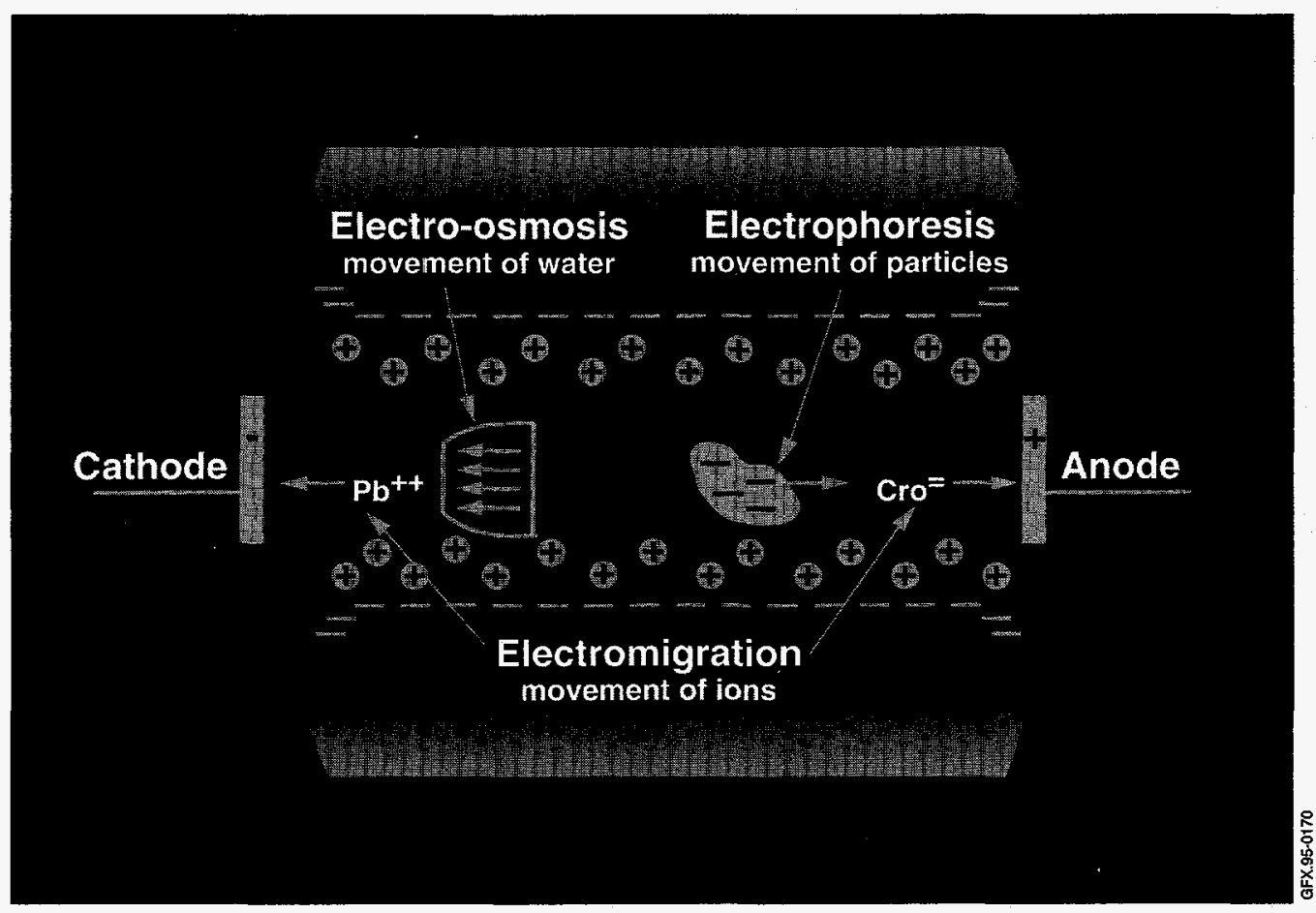

Figure 3.26. Contaminant Transport Processes Induced by Applying Direct Current Between Buried Electrodes.

\section{TECHNOLOGY NEEDS}

Remediation of uranium-contaminated soil is one of the major cleanup tasks facing DOE. In situ methods are needed that can remove enough uranium to reduce contaminant concentrations to acceptable levels and will allow the soil to return to productive use. Electrokinetic methods are being evaluated for this purpose, and their applicability to uranium removal from saturated and partially saturated soils needs to be documented.

\section{ACCOMPLISHMENTS}

A contract was placed with a U.S. firm to perform treatability studies. An interim report on treatability of K-25 soils from Oak Ridge was issued in draft form in July, 1994. Russian scientists contributed to the studies by evaluating and recommending c a n d id a t e leachants for uranium.

A primary site (K-311-1 Diffusion Cascade Purge Vent) and an alternative site (K-1300 Toll Enrichment Exhaust Stack) were selected. Soil sampling for treatability tests and a subsequent pilot-scale demonstration is in progress. 
A final treatability test report and a site characterization report are undergoing review and should be issued by January 1995 .

\section{BENEFITS}

Radionuclide contamination in excess of established limits is known to be present at 59 waste sites at 14 DOE facilities. Potentially contaminated soils surrounding these sites extend for hundreds of square miles, making dig-and-treat technologies impracti$\mathrm{cal}$ and exceedingly costly. In situ treatment that is cost effective and removes the contaminants without adversely affecting the physical/chemical or agronomic characteristics of the soil is a high priority technology need for DOE. Electrokinetic remediation is a strong candidate technology meeting that need. This project combines the use of selective extractants to remove the uranium with electrokinetics to transport the contaminants to ion exchange media. The media surrounding the electrodes capture and concentrate the uranium for later recovery or disposal.

\section{COLLABORATION/TECHNOLOGY TRANSFER}

HAZWRAP personnel have visited sites in Russia where electrokinetics has been used to remediate uranium contamination from soil. This information will be helpful in developing the technical specifications for a demonstration at a DOE site. The Russian scientists provide technical expertise for the test design and choice of leaching agents. Isotron Corporation has been placed under contract to perform treatability studies and the pilot-scale demonstration of electrokinetic remediation.
For more information, please contact:

\author{
Rick Swatzell \\ Principal Investigator \\ HAZWRAP \\ P.O. Box 2003 \\ Oak Ridge, TN 37831-7606 \\ (615) 435-3126
}

Randy L. Snipes

HAZWRAP Technology Manager

Martin Marietta Energy Systems

P.O. Box 2003

Oak Ridge, TN 37831-7606

(615) 435-3128

Jeffrey S. Walker

Program Manager

U.S. Department of Energy

Cloverleaf Building

19901 Germantown Road

Germantown, MD 20874-1290

(301) 903-7966

TTP Number: OR221102

\section{BIBLIOGRAPHY OF KEY PUBLICATIONS}

Trombly, Jeanne, "Electrochemical Remediation Takes to the Field," Environmental Science and Technology, (28, No. 6), 289A-291A, 1994.

Turney, W.R., et al., Heap Leach Studies on the Removal of Uranium from Soil, Los Alamos National Laboratory Report LA-UR-94-1361, 1994. 


\subsection{7 \\ FIELD DEMONSTRATION OF \\ ELECTROKINETIC MIGRATION TECHNOLOGY \\ AT OLD TNX BASIN}

\section{TASK DESCRIPTION}

The primary goal of this project is to demonstrate the ability of Isotron Corporation's proprietary ELECTROSORB $^{\mathrm{TM}}$ electrokinetic migration technology to remove mercury contamination from an unsaturated soil in the Old TNX Seepage Basin at the SRS. The ELECTROSORB ${ }^{\mathrm{TM}}$ technology uses cylindrical electrode assemblies where the electrode is coated with Isotron's ISOLOCK ${ }^{\mathrm{TM}}$ polymer material. The polymer is impregnated with $\mathrm{pH}$-regulating chemicals to prevent fluctuations in $\mathrm{pH}$ during the demonstration. The electrodes are placed in boreholes in the soil and a direct current is applied. See Figure 3.27. Under the influence of the current, ions migrate through the pore water to an electrode, where they are trapped in the polymer matrix. If desired, the polymer can also contain ion exchange resins or other sorbants that can trap and hold ions before they reach the electrode.

When electric current is applied to the system at the Old TNX Seepage Basin, electrodes are monitored and periodically replaced with fresh electrode as-

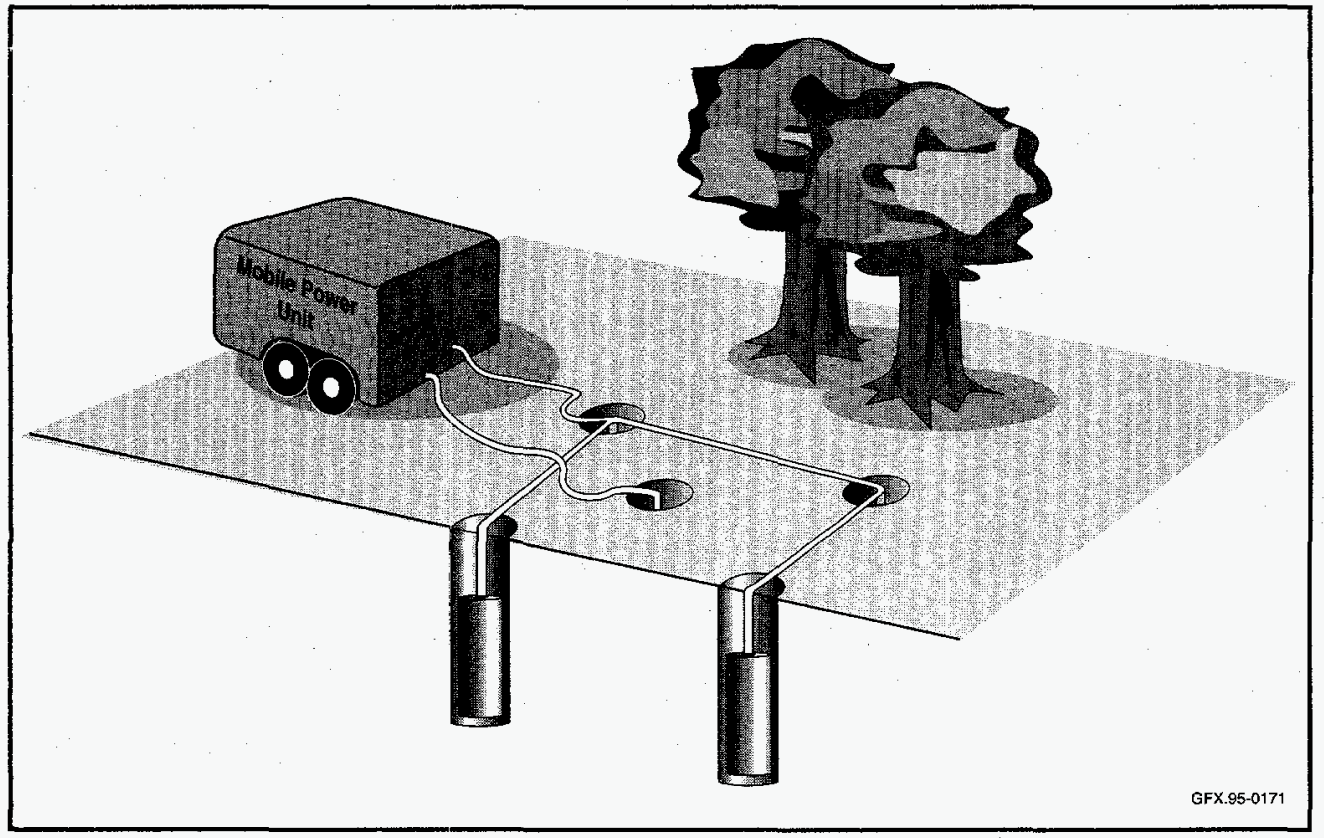

Figure 3.27. Isotron Electrode Array at Old TNX Basin. semblies. This allows the used assemblies to be chemically treated and analyzed for the presence of mercury and other metals in the polymers and on the electrodes. Soil samples before, during, and after the demonstration will be taken at selected sites to follow the concentration of mercury in the soil.

\section{TECHNOLOGY NEEDS}

The electrode assemblies and equipment needed for operation are all commercially available. Special features of this technology are the polymer matrices that serve as ion traps. These matrices also serve as sources of chemicals that can regulate $\mathrm{pH}$ or that will enhance the efficiency of the process.

An important issue that had to be addressed was the need for a reliable procedure to analyze the soil for mercury and other ions. The Analytical Development Section at Savannah River Technology Center (SRTC) has developed two methods for soil analysis and has purchased analytical instruments to quantify total mercury in the soil and electrode components. Although it is known that the mercury was introduced into the soil as the mercuric ion, the effects of time, chemistry, and the electric field on mercury speciation in the soil may be very hard to determine. 


\section{ACCOMPLISHMENTS}

Laboratory studies were conducted using soil from the Old TNX Seepage Basin in one-dimensional cells designed to produce data that will move the technology to the field. Operating parameters, such as current density, time, $\mathrm{pH}$ regulators, polymer construction, and electrode construction, were determined and have been translated into the electrode array design and operating plans for the demonstration. The effectiveness of complexing agents was also studied. These were introduced from the polymer at an electrode so that they could migrate through the soil and interact with the metal ions to mobilize and remove mercury.

The demonstration began at Old TNX Basin in July 1994 , and should conclude by January 1995 . The boreholes were drilled. The trailer containing the equipment for operating and monitoring the electrodes passed the required safety check. Electricity was supplied to the trailer and environmental permits were obtained.

Analytical procedures were developed for mercury analysis. New analytical instrumentation was available for total mercury and mercury speciation analyses. Initial results indicated that during the first months of power application, mercury was moved into the test region from outside the treated area, but mercury was not trapped by any of the electrodes. Other ions, notably lead and chromate, were trapped in the anode polymer. Some lead was also observed at the cathode.

\section{BENEFITS}

Field demonstration of this technology will determine its ability to decontaminate mercury as well as provide information on scale-up of the 1-dimensional cell data to the field. If the demonstration is successful, this technology may be considered for decontamination efforts elsewhere in the DOE complex.

\section{COLLABORATION/TECHNOLOGY TRANSFER}

Isotron Corporation has applied for patents on the design of the electrode assemblies and for several aspects related to the operation of the electrode array. Modeling of the ELECTROSORB process has been initiated by Dr. Ralph White of the University of South Carolina under a South Carolina University Research and Education Foundation contract, funded from Interim Waste Technology funds at SRTC.

For further information, please contact:

Jane Bibler

Principal Investigator

Westinghouse Savannah River Company

P.O. Box 616

Aiken, SC 29802

(803) $725-5276$

John Steele

Technical Program Manager

Westinghouse Savannah River Company

P.O. Box 616

Aiken, SC 29802

(803) $725-1830$

Jeffrey $S$. Walker

Program Manager

U.S. Department of Energy

Cloverleaf Building

19901 Germantown Road

Germantown, MD 20874-1290

(301) 903-7966

\section{BIBLIOGRAPHY OF KEY PUBLICATIONS}

Bibler, J.P., Work Plan for Drilling at Old TNX Basin, SRC-RP-93-1216, Rev. 1, Westinghouse Savannah River Company, Aiken, South Carolina, 1993. 
Bibler, J.P., and T.F. Meaker, Work Plan For Sampling and Operating Electrokinetic Migration Electrodes at Old TNX Basin, WSRC-RP-93-1455, Westinghouse Savannah River Company, Aiken, South Carolina, 1993.

Bibler, J.P., Interim Action Proposed Plan for the Electrokinetic Migration Technology Demonstration at Old TNX Seepage Basin, WSRC-RP-931180, Rev. 2, Westinghouse Savannah River Company, Aiken, South Carolina, 1993.

Bibler, J.P., Safety, Health and Emergency Response Plan, WSRC-RP-931216, Westinghouse Savannah River Company, Aiken, South Carolina, 1993.

Bibler, J.P., and T.F. Meaker, Sampling and Operating Procedures for Electrokinetic Migration Demonstration at Old TNX Basin Quality Assurance Plan, WSRC-RP-93-1457, Westinghouse Savannah River Company, Aiken, South Carolina, 1993.

Bibler, J.P., and T.F. Meaker, Safety, Health and Emergency Response Plan, WSRC-RP-93-1456, Westinghouse Savannah River Company, Aiken, South Carolina, 1993.

Bibler, J.P., Sampling and Analysis Plan for a Demonstration of Electrokinetic Migration Technology at the Old TNX Seepage Basin, WSRC-RP-93-1584, Westinghouse Savannah River Company, Aiken, South Carolina, 1993.
Isotron, Inc., Electrokinetlc Migration Technology for Mercury Decontamination of Old TNX Area, WSRC-RP-93-1486, Rev. 1. (Phase 1 Technical Report delivered to WSRC by Isotron Corp. for work done under Subcontract No. AA89030P.), 1993.

Polochko, M.A., and L.L. Tovo., Operating Procedure for Mercury Determination by Cold Vapor Atomic Absorption, Analytical Development Section Procedure 1505, Westinghouse Savannah River Company, Aiken, South Carolina, 1992.

Tovo, L.L., Analytical Study Plan for the Electrokinetic Migration Project, WSRC-RP-93-1559, Westinghouse Savannah River Company, Aiken, South Carolina, 1993.

Tovo, L.L., Operating Procedure for the Questron Mercury Analyzer, Analytical Development Section Procedure 1508, Westinghouse Savannah River Company, Aiken, South Carolina, 1993.

Whitaker, M.J., Dissolution of Radioactive and Nonradioactive Sludge, Soil, and Biological Materials for Elemental Analysis by Microwave Acid Digestion, Analytical Development Section Procedure 2251, Westinghouse Savannah River Company, Aiken, South Carolina, 1993. 


\subsection{OPTIMAL REMEDIATION DESIGN: \\ METHODOLOGY AND USER-FRIENDLY SOFTWARE FOR CONTAMINATED AQUIFERS}

\section{TASK DESCRIPTION}

This project focuses on developing a methodology and associated tools to manage and optimize groundwater contamination remediation. This methodology will result in a decision support tool for incorporating information on remedial requirements, optimal remedial design alternatives, and associated engineering costs. User friendly interfaces will also be developed to expand the range of potential users.

Optimization tools will be developed to apply nonconvex objective functions to problems using twoand three-dimensional simulators of groundwater systems. Optimization tools will extend MODFLOW, an existing three-dimensional groundwater flow and transport code for saturated groundwater systems, to employ graphically-oriented hydrological and numerical data manipulations. Unsaturated flow and transport conditions will then be incorporated.

\section{TECHNOLOGY NEEDS}

Groundwater remediation is an expensive undertaking that may exist for decades. The critical question within the DOE complex is how to manage and optimize the long-term groundwater remediation process. Both containment and decontamination strategies must be applied to the subsurface remediation process. The locations and rates of pumping for each groundwater remediation well, which may change with time, must be selected carefully. The locations and sampling intervals of monitoring wells must be maintained. Operation and maintenance costs associated with these decisions can be enormous when projected over realistic remediation periods, typically 30 to 100 years. Therefore, the benefits to DOE from remedial design optimization can be enormous.

\section{ACCOMPLISHMENTS}

During the past year, MODLP, a program for solving linear optimal hydraulic control of groundwater contamination based on MODFLOW simulation, was developed. It was delivered to investigators preparing the remedial design for the LLNL main site CERCLA cleanup. In addition, user document describing the general structure of the computer code, the types of constraints that may be imposed, detailed input instructions, interpretation of output, and the interaction with MODFLOW simulation kernel was delivered along with the computer code itself.

\section{BENEFITS}

MODLP is a computational tool that helps design capture zones for controlling the movement of contaminated water. It creates and solves linear optimization problems that contain constraints on hydraulic head or head differences in a groundwater system.

\section{COLLABORATION/TECHNOLOGY TRANSFER}

This work is performed in collaboration with the Research Center for Groundwater Remediation Design of the University of Vermont, and the University of Connecticut.

Any enhancement to optimization tools would have an immediate impact on LLNL's remediation implementation. This is the reason for the close coordination between LLNL and the University of Vermont. Because LLNL is acting as a client for the optimization tools being developed by this work, technical transfer is anticipated to be rapid and ongoing. 
For further information, please contact:

David Rice

Principal Investigator

Lawrence Livermore National Laboratory

7000 East Avenue

P.O. Box $808, \mathrm{~L}-1$

Livermore, CA 94550

(510) 423-5059

\section{Jesse Yow}

Technical Program Manager

Lawrence Livermore National Laboratory

7000 East Avenue

P.O. Box 808, L-1

Livermore, CA 94550

(510) 422-3521

\section{Jeffrey $S$. Walker}

Program Manager

U.S. Department of Energy

Cloverleaf Building

19901 Germantown Road

Germantown, MD 20874-1290

(301) 903-7966

\section{BIBLIOGRAPHY OF KEY PUBLICATIONS}

Dougherty, D.E., "Building Groundwater Optimizers That Respond to the Needs of Decision-Makers," Proceedings of the Annual Water Resources, Planning, and Management Conference, Denver, Colorado, American Society of Civil Engineers, May 1994 (In press.).

McGrath, W.A., and G.F. Pinder, "Delineating a Contaminant Plume Boundary," Proceedings of 10 th International Conference on Computational Methods in Water Resources, Heidelberg, Germany. Kluwer Academic Press, July 1994 (In press.).

Ahlfiekl, D.P., and D.E. Dougherty, MODLP Program Description: A Program for Solving Linear Optimal Hydraulic Control of Groundwater Contamination Based on MODFLOW Simulation, Research Center for Groundwater Remediation Design, University of Vermont, Burlington, Vermont, 1993.

Dougherty, D.E., "Finite Element Methods in Geoenvironmental Restoration," Proceedings of the VIII International Conference on Finite Elements in Fluids, University Polytecnica de Catalunya, Barcelona, Spain, 1993.

McGrath, W.A., and G.F. Pinder, "Locating Contaminant Plumes Under Uncertainty," Proceedings of the American Geophysical Union, Fall Meeting, San Francisco, California, 1993. 


\section{TASK DESCRIPTION}

Six Phase Soil Heating (SPSH) is being developed to quickly and inexpensively remove contaminants such as gasoline and solvents from soils that have been difficult or impossible to treat because of 1) their impermeability, 2) low contaminant volatility, or 3) high water content.

This technology uses low-frequency electricity delivered to six electrodes in a circular array to heat soils as an enhancement to soil vapor extraction (SVE), a proven in situ technology for removing volatile organic contaminants from permeable soils. With SVE, a vacuum created over an area of soil pulls contaminated vapor in the soil into a well, where the vapors are treated to remove the contaminants. However, conventional SVE will not work if the contaminants cannot easily be vaporized, or if the soil is too tight for air to pass through readily. With SPSH, the temperature of the soil and contaminant is increased, thereby increasing the contaminant's vapor pressure and its removal rate. For every 20 degrees centigrade increase in soil temperature, the vapor pressure of contaminants typically doubles.

SPSH also creates an in situ source of steam to strip contaminants from soils. The stream serves two important purposes. First, its physical action drives contaminants out of portions of the soil that tend to "lock in" the contaminants. This is a characteristic of impermeable soils like clays. Second, the steam acts as a carrier gas for the contaminants, enabling the contaminants to be swept out of the soil into a vacuum vent.

The energy required to accomplish treatment amounts to about $100 \mathrm{kWh}$ per cubic meter of soil, or less than $\$ 5$ per ton. Total costs for SPSH are estimated to be $\$ 40$ to $\$ 75$ per ton. By comparison, the cost to excavate soil, even for shallow depths under 30 feet, ranges from $\$ 10$ to $\$ 50$ per ton. And the exhumed soil must then be treated and disposed of at significantly more expense-as much as another $\$ 250$ to $\$ 1000$ per ton.

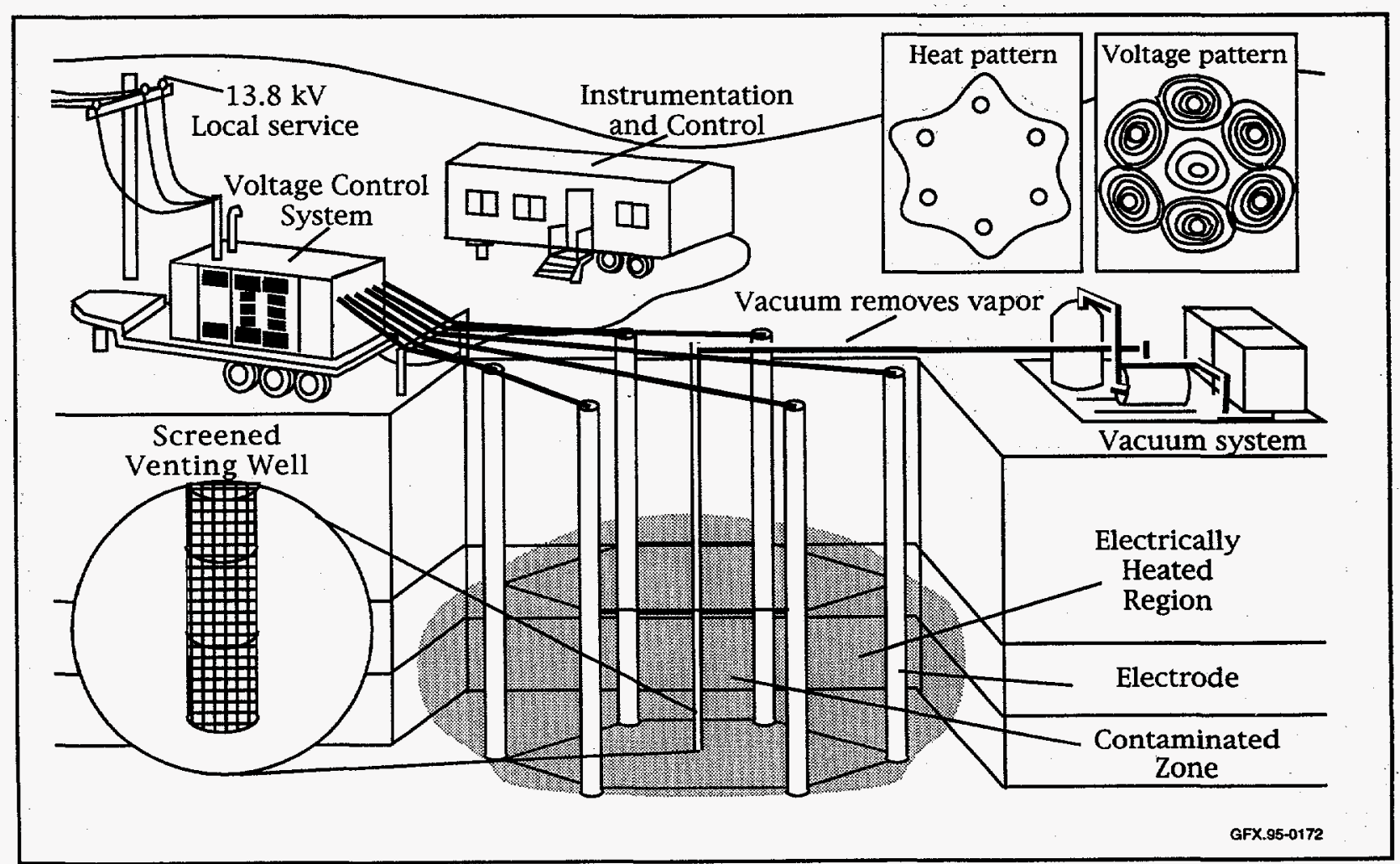

Figure 3.29. Six-Phase Soil Heating. 
What makes SPSH truly unique is the patented use of polyphase $\mathrm{AC}$ electricity to create a uniform heating pattern with minimal heating at the electrodes themselves. The technique works by dividing conventional three-phase electricity into six electrical phases. Each phase is delivered to one of six electrodes made of steel pipe that are installed in a circular pattern. See Figure 3.29. The electrode spacings and the connected electrical phases are both 60 degrees apart, resulting in a uniform ratio of voltage difference to physical distance between all electrodes in the array. This scheme enables uniform heating of equal soil volumes inside and outside of the electrode array at relatively low applied voltages (200 to 2000 volts). A seventh, electrically neutral pipe is installed in the center of the electrode array, and is connected to a vacuum system for continuously remove volatile contaminants and byproducts from the soil. These contaminant-laden off-gases are treated above the surface as they are removed from the soil.

\section{TECHNOLOGY NEEDS}

Most DOE sites have been contaminated with volatile organic compounds, including chlorinated solvents such as TCE and PCE; non-chlorinated solvents such as methyl ethyl ketone (MEK), benzene, and acetone; and fuels such as gasoline. Techniques for retrieving these VOCs from soils are being developed and demonstrated at various DOE demonstration sites. These techniques include in situ air sparging, dynamic stripping, radio frequency heating, electromagnetic heating, and six-phase soil heating to remove VOCs as vapors from contaminated soils. The baseline technologies, soil vapor extraction within the vadose zone and pump-and-treat for groundwater, are limited by the mobility of the contamination in the subsurface. Six-phase soil heating increases mobility and should result in faster and more complete removal of contamination from less permeable soils.

\section{ACCOMPLISHMENTS}

Field Demonstration. A field demonstration of six phase soil heating at a contaminated site was performed in November 1993 at DOE's SRS. The test site consisted of a $3 \mathrm{~m}$ thick clay layer, $10 \mathrm{~m}$ below the surface, contaminated with PCE and TCE. The goal of the demonstration was to determine the ability of SPSH to enhance the removal of volatile contaminants from low permeability clay soils. The soil electrodes were inserted to a total depth of $15 \mathrm{~m}$, set out in a $10 \mathrm{~m}$ diameter hexagonal array.

Power was applied to the soil for approximately 25 days, at an average level of $200 \mathrm{~kW}$. Over a period of approximately 7 days, soil temperatures uniformly increased to $100^{\circ} \mathrm{C}$ and remained there for approximately 18 days. During this time data was collected on moisture removal rates, soil temperatures, pressures within the soil, and off-gas contaminant concentrations. 70,000 liters of moisture were removed during venting from the soil pattern at a peak rate of approximately $2401 / \mathrm{hr}$. Pre- and post-test soil samples were taken at various locations within the soil to determine the overall increase in remediation efficiency. In the clay zone within the electrode array, which was heated to $100^{\circ} \mathrm{C}, 0.3 \%$ of the initial PCE contamination remained after heating. This corresponds to $99.7 \%$ removal of PCE. Seven percent of the initial PCE contamination remained in the clay zone outside of the electrode array, where the temperature rose to only $50^{\circ} \mathrm{C}$. This demonstrates that six-phase heating accelerated the removal of PCE from the clay.

Laboratory Tests. PNL has developed extensive laboratory capabilities for treatability testing of SPSH for almost any soil/contaminant combination. Laboratory capabilities include soil column, bench-scale, and pilotscale tests to evaluate (1) the uniformity of heating and drying, (2) the effectiveness of contaminant removal, and (3) the performance of engineering systems to control the process.

\section{BENEFITS}

SPSH technology is particularly well-suited for heating, and remediating very-low permeability soils contaminated with VOCs. In addition, the sixphase system delivers significantly more power to the bulk soil and less at the electrodes than other resistive heating techniques. This gives a more uniform heating and requires fewer electrodes to treat a volume of soil. The six-phase system also uses conventional utility power transformers at a low capital cost-as much as one-tenth the cost of radio frequency systems for the same power capability. 


\section{COLLABORATION/TECHNOLOGY}

\section{TRANSFER}

This technology was developed by PNL. Relationships are presently being developed with industrial firms that may culminate in licensing agreements with PNL for use of SPSH at a large number of their sites.

\section{For further information, please contact:}

\section{T. M. Bergsman}

Principal Investigator

Pacific Northwest Laboratory

(509) 376-3638

\section{P. A. Gauglitz}

Principal Investigator

Pacific Northwest Laboratory

P.O. Box 999

Richland, WA 99352

(509) 372-1210

\section{S. Kowall}

Principal Investigator

Pacific Northwest Laboratory

P.O. Box 999

Richland, WA 99352

(509) 376-4421

\section{Steven Slate}

Technical Program Manager

Pacific Northwest Laboratory

P.O. Box 999

Richland, WA 99352

(509) 375-3903

\section{Rashalee Levine}

Program Manager

U.S. Department of Energy

Cloverleaf Building

19901 Germantown Road

Germantown, MD 20874-1290

(301) 903-7920
TTP Number: RL331003, RL341011

\section{BIBLIOGRAPHY OF KEY PUBLICATIONS}

P.A. Gauglitz, J.S. Roberts, T. M. Bergsman, S.M. Caley, W.O. Heath, M.C. Miller, R.W. Moss, R. Schalla, M.H. Schlender, T.R. Jarosch, C.A. EddyDilek, and B.B. Looney, Six-Phase Soil Heating for Enhanced Removal of Contaminants: Volatile Organic Compounds in Non-Arid Soils Integrated Demonstration, Savannah River Site, PNL-10184, Pacific Northwest Laboratory, Richland, Washington, 1994.

P.A. Gauglitz, J.S. Roberts, T. M. Bergsman, S.M. Caley, W.O. Heath, M.C. Miller, R.W. Moss, R. Schalla, T.R. Jarosch, C.A. Eddy-Dilek, and B.B. Looney, "Six-Phase Soil Heating Accelerates VOC Extraction from Clay Soil," Proceedings of SPECTRUM '94: International Nuclear And Hazardous Waste Management, Atlanta, Georgia, August 14$18,1994$.

P.A. Gauglitz, J.S. Roberts, T. M. Bergsman, S.M. Caley, W.O. Hearh, M.C. Miller, R.W. Moss, R. Schalla, M.H. Schlender, T.R. Jarosch, C.A. EddyDilek, and B.B. Looney, "Field Test of Six-Phase Soil Heating at the Savannah River Site," Proceedings of the 33rd Hanford Symposium on Health and the Environment, In Situ Remediation: Scientific Basis for Current and Future Technologies, Pasco, Washington, November 7-11, 1994.

S.M. Caley, W.O. Heath, T. M. Bergsman, P.A. Gauglitz, G. Pillay, R.W. Moss, R.R. Shah, S.C. Goheen, D.M. Camaioni, "ERACE - An Integrated System for Treating Organic-Contaminated Sites," Proceedings of the 33rd Hanford Symposium on Health and the Environment, In Situ Remediation: Scientific Basis for Current and Future Technologies, Pasco, Washington, November 7-11, 1994. 


\section{$3.30 \quad$ SOIL BIOREACTOR STUDIES}

\section{TASK DESCRIPTION}

This task was performed at Savannah River to remediate VOCs in non-arid soils. It involves the development and testing of the Differential Soil Bioreactor, a new laboratory device for performing treatability studies for in situ bioremediation. See Figure 3.30. Demonstrations using samples of groundwater and sediments from the SRS have identified indigenous methanotrophic bacteria which can be grown by adding suitable nutrients to levels at which the biodegradation rate of trichloroethylene is significantly increased.

\section{TECHNOLOGY NEEDS}

In situ bioremediation, used for over twenty years to remediate petroleum hydrocarbon spills, is now being applied to other contaminants (chlorinated solvents, nitrates, etc.). It is the most economical and most benign method of removing contaminants that are widely dispersed in groundwater or the vadose zone. However, it is still considered an immature, experimental and uncertain technology by many regulatory bodies

due to the lack of established engineering design procedures that can predict how long it will take and what levels of remediation can be achieved. This procedure must include a mathematical model describing the hydrology, geochemistry, and microbiology, coupled with a set of experiments designed to provide the parameter values appropriate for the particular site. The Differential Soil Bioreactor is designed to measure the kinetics of growth, biodegradation and attachment/ detachment of indigenous microorganisms under conditions that simulate those in the actual aquifer.

\section{ACCOMPLISHMENTS}

- Three Differential Soil Bioreactors were designed and built to simulate conditions in groundwater at the SRS.

- Adsorption isotherms for TCE on Savannah River sediments were measured.

- Real-time (several-months long) experiments showed that addition of methane stimulates growth of methanotrophic bacteria in Savannah River sediments. Addition of nitrogen and phos-

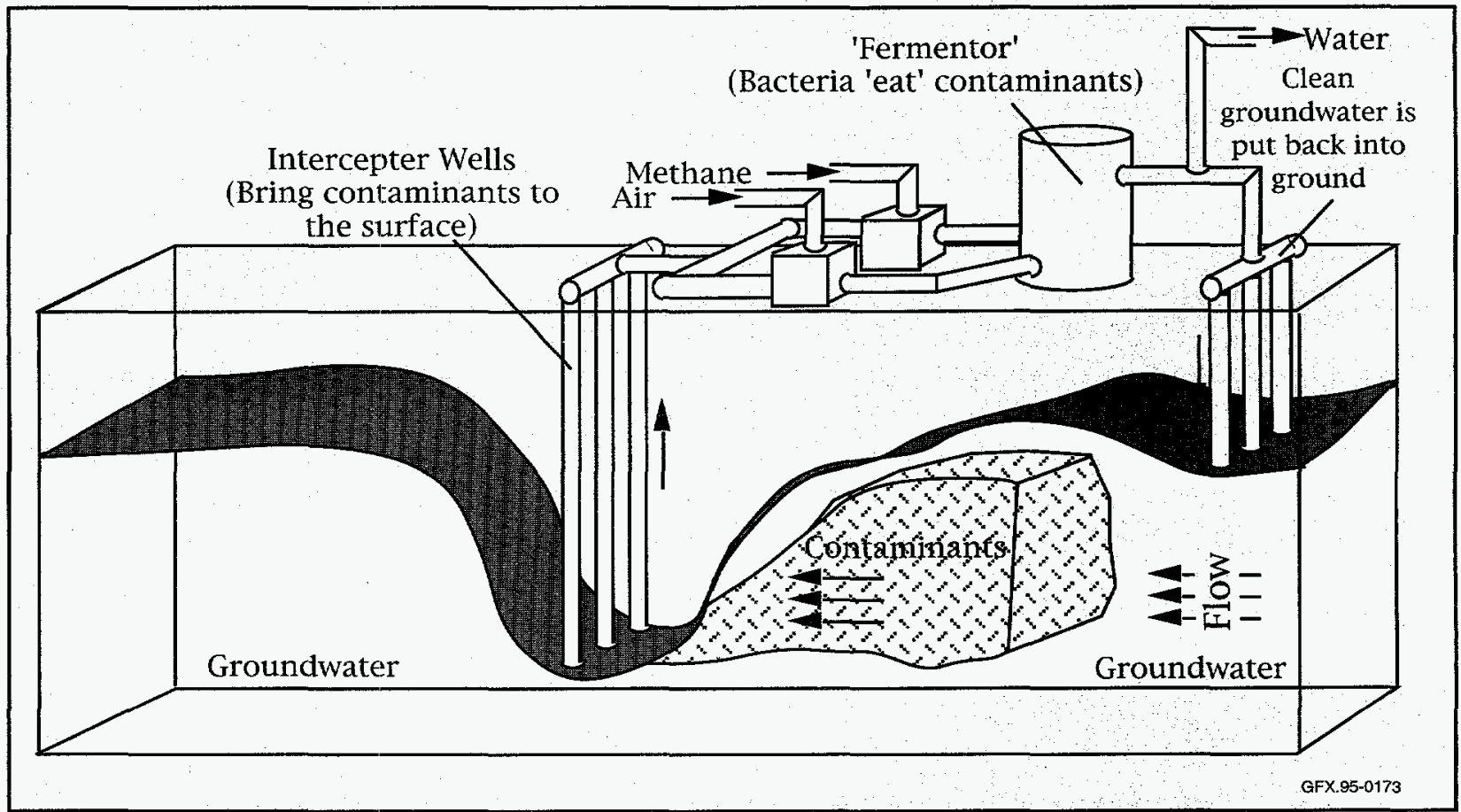

Figure 3.30. Conceptualized Full-Scale Bioreactor. 
phorus sources had no effect at concentrations tested.

- Maximum rate of TCE degradation measured as $8.5 \mathrm{mg} / \mathrm{m}^{3}$ day and was confirmed by measurements of chloride ions.

\section{BENEFITS}

The Differential Soil Bioreactor provides a real-time laboratory simulation of the growth of microorganisms and the biodegradation of contaminant in a finite element of subsurface material. The material is in the form of a disc, through which groundwater is recirculated at a velocity equal to that at the field site. Recirculation eliminates concentration gradients through the disc, so that all the microorganisms are exposed to the same physical and chemical environment, and thus have the same kinetics.

Most treatability studies for in situ bioremediation are done in batch microcosm or column studies. There is no flow in a batch study, so phenomena such as the distribution of microbes between the liquid and the soil and the interactions between contaminant adsorption and biodegradation may not be the same as in the field. Furthermore, although a microcosm can be "spiked" periodically with nutrients, it cannot simulate the slow, steady development of the desired microbial population in an aquifer when selected nutrients are injected continuously.

A column study is more realistic, but it is unclear how the results should be translated to predict bioremediation performance at field scale. The inherent kinetics of microbial growth, attachment/detachment, and biodegradation can not be obtained from the data due to the large concentration gradients through the column. The Differential Soil Bioreactor is a new type of treatability study that overcomes these problems.

\section{COLLABORATION/TECHNOLOGY TRANSFER}

None.
For further information, please contact:

\author{
Dr. Graham Andrews \\ Principal Investigator \\ Idaho National Engineering Laboratory \\ P.O. Box 1625 \\ Idaho Falls, ID 83415 \\ (208) 526-0174
}

\section{T. Williams}

Technical Program Officer

U.S. Department of Energy

Idaho Operations Office

850 Energy Drive

Idaho Falls, ID 83401

(208) $526-2460$

\section{Kurt Gerdes}

Program Manager

U.S. Department of Energy

Cloverleaf Building

19901 Germantown Road

Germantown, MD 20874-1290

(301) 903-7289

TTP Number: ID121102

\section{BIBLIOGRAPHY OF KEY PUBLICATIONS}

Andrews G.F., "Predicting Yields for Autotrophic and Co-Metabolic Processes," Applied Biochemistry and Biotechnology, 1994 (in press).

Hansen S., G.F. Andrews, "Site Specific Evaluation of Different In-Situ Bioremediation Strategies for a TCE-Contaminated Aquifer," Proceedings Air and Waste Management Association, 37th Annual Meeting, Cincinnati, $\mathrm{OH}, 1994$ (in press).

Andrews G.F., S. Hansen, F.S. Colwell, The Kinetics of TCE Degradation in a Soil Environment, Ache Annual Meeting, Los Angeles, CA, Nov. 1991. 


\subsection{COLD PLASMA DESTRUCTION \\ OF SAVANNAH RIVER SITE \\ OFF-GAS}

\section{TASK DESCRIPTION}

The Cold Plasma off-gas treatment system, or "silent discharge" plasma process was developed by LANL. This process is a member of the free radical oxidation technologies, all of which utilize some energy source to create reactive free radicals which act as oxidizing species or which can be easily oxidized or reformed to simpler products. Specifically, high voltage is employed to generate electric discharges by stripping electrons from neutral gas molecules to partially ionize the gas. The electrodes are covered by a dielectric to separate them from the gas phase. The dielectric acts as a capacitor, eliminating arcing and promoting the formation of numerous micro-discharges, while serving to protect the electrode surfaces from the reactive gases. The discharges generate non-thermal, non-equilibrium plasmas in which the stripped electrons are not in thermodynamic equilibrium with the gas molecules. The electrons discharged are highly reactive and catalyze the conversion of chlorinated VOCs.

In the Cold Plasma system, micro-discharges are generated with electrode geometries - parallel rectangular plates separated by a dielectric - that enhance electric fields and reduce the energy barrier necessary for electron discharge. This geometry generates a high density of micro-discharge events. The resulting extremely low discharge inductance allows for the use of higher frequency pulse power supplies, which in turn, produce higher densities of electrons (current) and radicals. The same technology is used in commercial ozone generators.

\section{TECHNOLOGY NEEDS}

Several different technologies were tested at the SRS to remove VOCs from the subsurface environment. These VOCs were the by-product of past chemical spills, including pipeline breakage and rupture, which allowed different chernicals to enter the sub- surface environment. These chemicals included PCE, TCE, and TCA. Some chemicals that were discharged at the SRS reacted with subsurface soils in situ to create additional VOCs.

The continuing VOCs problem led DOE to set up a series of integrated demonstration tests that used various off-gas cleanup technologies. SRS currently uses a thermal catalytic oxidation system. However, a vacuum extraction system (VES) coupled with activated carbon adsorption was demonstrated. The VES process is considered the industry standard. Because of concentrations of PCE and TCE, the activated carbon tanks must be changed frequently. Chemical oxidation systems were examined, including the Cold Plasma system, to reduce the loading on the activated carbon tanks. These systems were also tested for their ability to reduce toxicity and hazards associated with TCE and PCE.

\section{ACCOMPLISHMENTS}

A test of the Cold Plasma technology was completed during the last quarter of 1993. The field unit, consisting of two cell banks ( 20 cells per bank), was capable of handling flow rates up to approximately $3.3 \mathrm{scfm}$ with a power consumption of 15 to $17 \mathrm{~kW}$. A high frequency amplifier was used and operated at $1500 \mathrm{~Hz}$ delivering from 4 to $5 \mathrm{~J}$ per pulse. The unit was equipped with a caustic scrubber to neutralize acidic products.

Conversions greater than $99 \%$ were obtained for TCE over a broad range of energy densities (3.71 to $16.14 \mathrm{~J} / \mathrm{cm}^{3}$ ), concentrations, and flow rates. PCE conversions were also equal to or greater than $99 \%$ over the whole range of test parameters. Ease of treatment was established as TCE > PCE > TCA (from easiest to hardest). The mineralization of the VOCs was incomplete, as about 20 small incomplete decomposition products (e.g., PCE, TCA, TCE, carbon tetrachloride) were observed for most 
of the runs. In addition, considerable losses in the power supply and to dielectric losses in the Pyrex cell liners must be addressed prior to upgrading this technology into a commercially viable system.

\section{BENEFITS}

Cold Plasma technology allows the reactions to take place at ambient temperatures and pressures, with relatively low energy consumption. Additionally, advantages over the thermal destruction techniques are: (1) energy use that is proportional to the contaminant concentration, especially critical to remediation applications where concentrations vary significantly with time; and (2) greater conversion of chlorinated VOCs.

\section{COLLABORATION/TECHNOLOGY TRANSFER}

A CRADA with EPRI became effective in FY94. LANL and Southern Company are carrying out preliminary studies on treatment economics and choice of industrial demonstration site.

\section{For further information, please contact:}

\author{
Louis A. Rosocha \\ Principal Investigator \\ Los Alamos National Laboratory \\ P.O. Box 1663 \\ Los Alamos, NM 87545 \\ (505) $667-8493$

\section{Bruce Erdal} \\ Technical Program Manager \\ Los Alamos National Laboratory \\ P.O. Box 1663 \\ Los Alamos, NM 87545 \\ (505) 667-8914
}

\section{Kurt Gerdes}

Program Manager

U.S. Department of Energy

Cloverleaf Building

19901 Germantown Road

Germantown, MD 20874-1290

(301) $903-7289$

TTP Number: AL121109

\section{BIBLIOGRAPHY OF KEY PUBLICATIONS}

Rosocha, L.A., "Nonthermal Plasma Applications to Pollution Control and Environmental Remediation," First International Conference on Advanced Oxidation Technologies, London, Ontario, Canada, (Los Alamos National Laboratory Report LA-UR94-2115), June 25-30, 1994. 


\subsection{2 \\ INTEGRATED PULSED \\ ULTRAVIOLET IRRADIATION}

\section{TASK DESCRIPTION}

Argonne National Laboratory demonstrated and evaluated a pulsed ultraviolet-irradiation system developed by Purus, Inc. at the non-arid demonstration site at Savannah River. The Purus system consists of four reactor chambers, each containing a xenon flash lamp. During the two weeks of testing, samples were taken and analyzed from the inlet and outlet sides of the Purus system. The contaminants of concern on the inlet were PCE, TCE, and TCA. The contaminants of concern on the outlet were PCE, TCE, TCA, carbon tetrachloride, and chloroform.

\section{TECHNOLOGY NEEDS}

Several different technologies were tested at the SRS to remove VOCs from the subsurface environment. These VOCs were the by-product of past chemical spills, including pipeline breakage and rupture, which allowed different chemicals to enter the subsurface environment. Some chemicals that were discharged at the SRS reacted with subsurface soils in situ to create additional VOCs.

In addition to investigating the Cold Plasma system as a means of treating off-gas (described in section 3.31), the SRS also investigated the pulsed ultraviolet irradiation process. The pulsed ultraviolet irradiation process is a chemical oxidation process developed and manufactured by Purus, Inc., San Jose, California. This oxidation process uses pulsed UV irradiation as a means of destroying the influent VOCs, containing primarily TCE and PCE.

\section{ACCOMPLISHMENTS}

The Purus system was evaluated by examining the reduction of both TCE and PCE and searching for any change in the concentrations. Operating conditions included flow rates, ranging from 25 to 100 scfm; inlet concentration of PCE, ranging from 360 to $10,700 \mathrm{ppmv}$; and flash lamp rates, ranging from 1 to $30 \mathrm{~Hz}$.

The Purus system efficiently reduced the concentrations of both PCE and TCE. The potential byproducts, TCA, carbon tetrachloride, and chloroform showed no significant increases throughout the range of the various operating parameters. Overall, the Purus system appears to be a costefficient means of reducing the concentrations of PCE and TCE, while the removal of the initial photo-oxidation products and TCA is slower and needs further evaluation.

\section{BENEFITS}

The Purus UV-irradiation system, with its rapid chain reactions, seems to cost-effectively remove PCE and TCE from air streams generated from soil vapor extraction and other methods. However, this system provided only limited removal of by-product TCA under the conditions tested. Previous work (Blystone et al., 1991) showed that the major initial by-products of TCE and PCE photo-oxidation are the highly toxic compounds DCAC and TCAC. These compounds photoreact further to DCC and eventually to $\mathrm{HCl}, \mathrm{CO}_{2}$, and probably formyl chloride. Initial by-products (like TCA) require much longer exposures for complete conversions than do PCE and TCE.

Efficient chain reactions can occur only if the initial products can be economically removed. Because DCAC, DCC, and TCAC are reactive and hydrolyze easily to DCAA, $\mathrm{CO}_{2}$, and TCAA, respectively, a promising approach would involve some form of alkaline scrubbing to concentrate the product gases, followed by thermal or biological treatment of the haloacetic acids or salts produced. 


\section{COLLABORATION/TECHNOLOGY TRANSFER}

This technology was developed in cooperation with Purus, Inc. (San Jose, CA).

For further information, please contact:

Werner Haag

Purus, Inc.

2713 N. First Street

San Jose, CA 95134

(408) 955-1000

Michael L. Wilkey

Principal Investigator

Argonne National Laboratory

Idaho Site

P.O. Box 2528

Idaho Falls, ID 83403-2528

(708) 252-9240

James E. Helt

Technical Program Manager

Argonne National Laboratory

Idaho Site

P.O. Box 2528

Idaho Falls, ID 83403-2528

(708) 252-7335

\section{Kurt Gerdes}

Program Manager

U.S. Department of Energy

Cloverleaf Building

19901 Germantown Road

Germantown, MD 20874-1290

(301) 903-7289
TTP Number: CH221107

\section{BIBLIOGRAPHY OF KEY PUBLICATIONS}

Schneider, J., et al., Demonstration of the Pulsed Ultraviolet-Irradiation Gas-Treatment System, Savannah River Site, ANL/ESD/TM-73, 1994.

Blystone, P.G., et al., "Advanced Ultraviolet Flashlamps for the Destruction of Organic Contaminants in Air," Proceedings of the American Chemical Society Industrial and Engineering Chemistry Division Special Symposium, Atlanta, GA, Oct. 1-3, 1991.

Hazen, T.C., Test Plan for In-Situ Bioremediation Demonstration of the Savannab River Integrated Demonstration Project DOE/OTD TTP No.: SR 0566-01 $(U), 1991$, Westinghouse Savannah River Company, Aiken, SC, Sept. 18, 1991, Revision 3: Report WSRC-RD-91.23, April 23, 1992.

Marine, I.W., and H.W. Bledsoe, Supplemental Technical Data Summary: M-Area Groundwater Investigation, E.I. DuPont de Nemours and Company, Savannah River Laboratory, Aiken, SC, DPSTD-84-112, 1984. 


\section{TASK DESCRIPTION}

This technology involves the use of radio frequency (RF) energy to heat vadose zone sediments to enhance conventional vapor extraction remediation of chlorinated volatile organic contaminants (primarily PCE and TCE). The technique heats the sediments through a dielectric heating mechanism in which the application of an electromagnetic field physically distorts the molecular structure of the material. See Figure 3.33. The physical distortion is transferred into mechanical and then into thermal energy. The frequencies applicable for heating earthen materials and mineral formations lies between .01 and $60 \mathrm{MHz}$. The most commonly used frequencies, 6.78 and $13.56 \mathrm{MHz}$, are those set aside for use by industrial, scientific and medical equipment. Because of its ability to penetrate and couple with the soil, RF heating is faster than convective or conductive heating modes. Furthermore, the technology offers a means of heating sediments to temperatures well in excess of $100^{\circ} \mathrm{C}$, making the technique applicable for sediments contaminated with semi-volatile organics.

The RF heating project is centered around the use of a dipole applicator developed and patented by KAI Technologies, Inc. The single wand applicator, approximately 20 feet in length, is constructed of flexible copper coaxial cable to facilitate the use of a 4" diameter horizontal well drilled to dissect and traverse a shallow clay lens located from 35 to 40 feet below the ground surface. The chlorinated solvents are held up and concentrated in these lowpermeability clay zones and are leached out slowly, thereby acting as long-term sources for groundwater contamination.

Computer modeling was performed to determine the output impedance history and temperature contours. The modeling was based on laboratory measurements of representative soils and assumes a

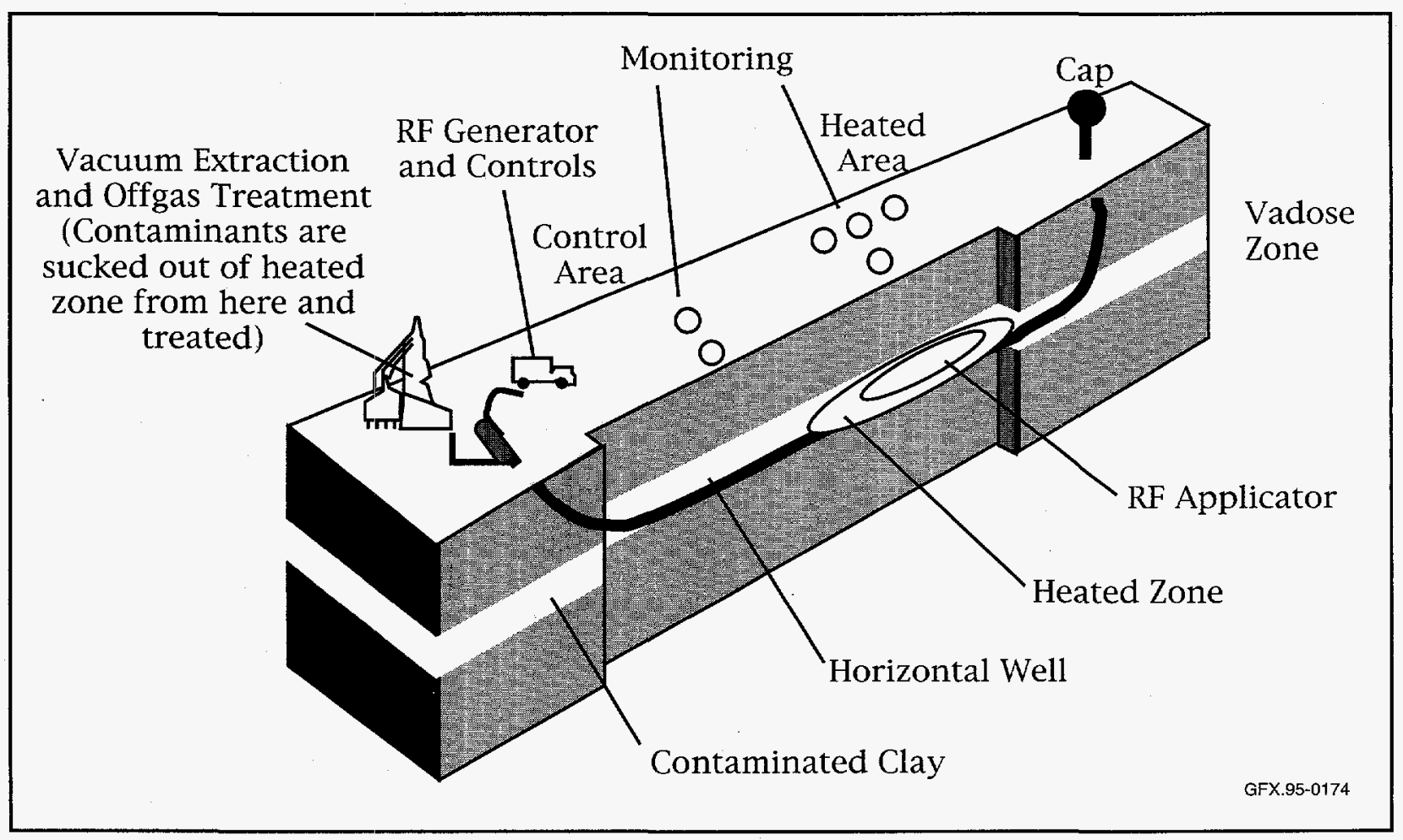

Figure 3.33. Radio Frequency Heating. 
homogeneous medium with no heat loss. The results predict that after 21 days a volume of approximately 1,000 cubic feet will be heated to a temperature in excess of $100^{\circ} \mathrm{C}$.

The field test includes three separate operations: 1) a "cold" pump test to establish a baseline performance for the vacuum extraction system without heating; the duration of this test is approximately one week; 2) a heating phase with the RF hardware operation for approximately 4 weeks; and 3) a cooldown phase to monitor changes in off gas venting as the subsurface temperature returns to ambient.

\section{TECHNOLOGY NEEDS}

Numerous sites across the country, both commercial and within the DOE complex, have significant levels of organic contaminants within the unsaturated soil zone. Chlorinated volatile organic solvents can be held within this zone, especially in clays and organic materials. These zones slowly release the solvents and provide a long term source for groundwater contamination. Despite the volatile nature of these contaminants, the clays severely limit the mass transfer rates of the material. With this mass transfer limitation the use of soil vacuum extraction requires a long period of operation and the placement of numerous wells. By selectively heating the soils, the release of the solvents from the soil can be significantly enhanced.

\section{ACCOMPLISHMENTS}

The RF heating demonstration integrated RF application and vacuum extraction from a single, horizontal well. The horizontal well was drilled through a contaminated clay layer located between the MAarea and an adjacent seepage basin at the SRS. Offgas drawn from the well was destroyed with a skid-mounted thermal-catalytic oxidation system.

During the 21 day demonstration period, approximately 11,000 Kilowatt-hours of RF energy were successfully coupled to the subsurface clay layer, and heated a sediment volume of approximately 60 cubic meters to greater than $60^{\circ} \mathrm{C}$. Wellhead con- centrations of VOCs increased during the heating phase, indicating an increase in liberation of VOCs from the soil; over $170 \mathrm{~kg}$ of VOCs were successfully extracted over the course of the demonstration. Two significant findings made during the test impeded the full assessment of the technology. First, a steam block formed downhole when temperature exceeded $100^{\circ} \mathrm{C}$. This vapor block limited the achievable vacuum and, therefore, reduced the extraction rates. Second, the choice of casing material, and in particular, the temperature limits of the fiberglass screen, reduced the applicator power output. To control downhole temperatures at acceptable levels, the duty cycle of the applicator was lowered by $20 \%$. In addition, liquid water infiltration into the well restricted the vapor flow from the well. This required modifications of the RF applicator control programming.

\section{BENEFITS}

There are two major benefits of this technology over conventional technologies. First, heating technologies in general offer a means of reducing remediation times. The increase in the vapor pressure of volatile contaminants from ambient temperature to $100^{\circ} \mathrm{C}$ suggests that remediation times can be reduced by a factor ranging from one half to one eighth. Furthermore, removal of residual pore water as steam during heating can increase the permeability of the sediments and can provide additional reduction in remediation times. Second, the RF technology in particular, offers a means of heating sediments in situ to temperatures in excess of $100^{\circ} \mathrm{C}$. Therefore, the technology can be used to remediate both shallow and deeper sediments contaminated with semi-volatile organic compounds (SVOCs). Presently, excavation combined with ex-situ desorption is the primary means for remediating shallow sediments contaminated with SVOCs. For deeper sediments, no current applicable baseline technology exists. In addition, the RF dipole technology can be used in conventional wells provided a compatible casing material is employed (e.g., nonconductive, high temperature plastic or composite material) that does not require injection of any substance. 


\section{COLLABORATION/TECHNOLOGY TRANSFER}

The RF dipole technology was developed and patented by KAI Technologies. As a result of the test at SRS, a second demonstration was planned and conducted at Kelly Air Force Base, San Antonio, Texas in collaboration with the EPA SITE Program and the Air Force Center for Environmental Excellence. This second demonstration benefited from the lessons learned at SRS incorporating vertical wells with a dual antenna arrangement and multiple independent extraction wells.

For further information, please contact:

Ray Kasevich

KAI Technologies, Inc.

170 West Road

Portsmouth, NH 03801

(617) 932-3328

Tim Jarosch

Principal Investigator

Westinghouse Savannah River Company

P.O. Box 616

Aiken, SC 29802

(803) $725-5189$

John Steele

Technical Program Manager

Westinghouse Savannah River Company

P.O. Box 616

Aiken, SC 29802

(803) $725-1830$

\section{Kurt Gerdes}

Program Manager

U.S. Department of Energy

Cloverleaf Building

19901 Germantown Road

Germantown, MD 20874-1290

(301) 903-7289
TTP Number: SR131001

\section{BIBLIOGRAPHY OF KEY PUBLICATIONS}

Harrold, R.T., T.S. Snyder, and R.S. Kasevich, In Situ Radio Frequency Soil Remediation Heating Demonstration: Final Report on Treatability Studies, Westinghouse Science and Technology Center, Document No. 93-9ID0-RFHET-R1, prepared for WSRC under contract No. AA80586W, 1993.

Savannah River In-Situ Radio frequency Heating Demonstration: Field Test Plan, Westinghouse Savannah River Co. Document No. WSRC-RP-921428 , prepared by the Westinghouse Science and Technology Center for WSRC under Contract No. AA80586W, 1993.

Eddy-Dilek, C.A., T.R. Jarosch, C.B. Fliermans, B.B. Looney, and W.H. Parker, Characterization of the Geology, Geochemistry, and Microbiology of the Radio Frequency Heating Demonstration Site at the SRS, Westinghouse Savannah River. Co., Document No. WSRC-TR-93-459, prepared for the DOE Office of Technology Development under Contract No. DE-AC09-89SR18035, 1994.

Jarosch, T.R., R.J. Beleski, and D. Faust, Final Report: In-Situ Radio Frequency Heating Demonstration, Westinghouse Savannah River Co., Document No. WSRC-TR-93-673, prepared for the DOE Office of Technology Development under Contract No. DE-AC09-89SR18035, 1994. 


\section{TASK DESCRIPTION}

Several technologies are emerging for treatment of offgas streams. These technologies can be divided into classes based on capture of contaminants, destruction of contaminants, and hybrid systems that combine capture and destruction. The most common capture system collects solvents onto granular activated carbon (GAC) filters that are subsequently treated at a hazardous waste facility. Classes of destructive techniques include catalytic, biologic, thermal, and free-radical destruction. The technologies chosen for demonstration at the SRS under this project represented many different classes of destructive and hybrid technologies.

Ozone-Enhanced Oxidation is a free radical destruction technology. Free radicals that can be easily oxidized to simpler products are created by interaction with activated ozone molecules. The ozone is produced with non-thermal plasma (electrical discharge) generators. With free radical oxidation of chlorinated volatile organic compounds (CVOCs) in a humid air stream, the hydroxyl and atomic oxygen radials, both strongly oxidizing agents, are formed. The free radicals then recombine to form hydrochloric acid $(\mathrm{HCl})$ and carbon dioxide $\left(\mathrm{CO}_{2}\right)$.

While in some respects considered a baseline technique, thermal catalytic oxidation (TCO) has only recently emerged as a reliable technology for CVOCs, and is subject to ongoing improvements in the catalysts. TCO uses a fixed or fluidized bed of noble metal and noble metal oxides supported on alumina catalysts at temperatures from 350 to $650^{\circ} \mathrm{C}$. Catalysts for CVOCs are manufactured by Johnson Matthey, Engelhard, and Allied Signal. Gas flow rates, determined by the amount of catalyst and the required residence time for destroying the CVOC, typically range from 5000 to 10,000 standard cubic feet per hour.

\section{TECHNOLOGY NEED}

Subsurface volatile organic hydrocarbon contamination exists at DOE sites in both the saturated and unsaturated zones. When the solvent is in the unsaturated zone, it can be directly removed through vacuum venting, provided it is sufficiently volatile. When a volatile solvent is in the saturated zone, it can be mobilized by pumping the contaminated water to the surface and air stripping or through in situ volatilization. All of these processes generate contaminated air streams that must be treated before atmospheric discharge.

During the course of the first in situ air stripping demonstration with horizontal wells at the SRS MArea, it became evident that technologies for controlling solvent emissions would be beneficial to protecting the environment. Additionally, because of the 1990 Clean Air Act Amendment (CAAA) and changes in requirements by the State of South Carolina Department of Health and Environmental Control, it will soon become necessary to control these emissions to meet regulatory requirements.

Current choices for abating CVOC emissions are limited to activated carbon adsorption and incineration. Activated carbon is a simple and efficient technology, but generates a secondary waste that requires treatment and is not effective for large flow rates or contaminant concentrations. Incineration is effective for high flow rates and concentrations, but has poor public acceptance and generates chlorinated products of incomplete combustion as well as $\mathrm{NO}_{\mathrm{x}}$. Thermal catalytic oxidation is emerging as a more robust, acceptable destruction technique, but still requires long-term performance testing.

\section{ACCOMPLISHMENTS}

\section{Ozone-Enhanced Oxidation}

Testing of the Ultrox D-TOX ${ }^{\mathrm{TM}}$ Pilot Plant took place in February and March 1993. This technology uses a 
proprietary catalyst for ozone activation and freeradical formation. PCE was the major contaminant consisting of over $90 \%$ of the total vapor influent, with the remainder being TCE and TCA. The ozone to CVOC ratio was be varied from $<1$ to 10 (weight). The test was run for two days.

The main byproduct, other than $\mathrm{HCl}$, was $\mathrm{CCl}_{4}$. When the ozone to VOC ratio was below 1:1, additional byproducts-chloroform, and penta- and hexachloroethane, were formed. An ozone excess was demonstrated to increase the system performance. Humidity played a minor role in forming the byproducts, and byproduct formation increased when the influent vapor was over-saturated with water. When CVOCs reacted with ozone in the catalyst bed, phosgene was formed.

\section{Thermal Catalytic Oxidation}

A test of a Johnson Matthey monolith catalyst was completed at the SRS in December 1992. In addition, commercial offgas treatment units employing the Allied Signal monolith catalyst were used successfully at SRS to control emissions during tests of in situ enhanced remediation technologies.

The Johnson Matthey catalyst effectively destroyed TCE and PCE at temperatures above $500^{\circ} \mathrm{C}$ at flow rates of 10,000 to 30,000 standard cubic feet per hour. A dramatic drop in the PCE destruction efficiency occurred at temperatures below $500^{\circ} \mathrm{C}$. the primary side products observed were 1,1-DCE, and trace (< 2ppmv) chloroform.

\section{BENEFITS}

- Free radical oxidation processes displayed better energy utilization in comparison to thermal techniques, However, the formation of chlorinated side products (e.g., phosgene) poses an obstacle to commercialization.

- Thermal catalytic processes destroyed $>99 \%$ of the off-gas CVOCs, with only slightly detectable products of incomplete conversion. These technologies tend, however, to become energy-intensive at CVOC concentrations below $100 \mathrm{ppmv}$.

\section{COLLABORATION/TECHNOLOGY TRANSFER}

In addition to the companies previously mentioned, partnerships were formed with a number of other companies including NuTech, Purus, Synthetica, and NUCON. The University of Wisconsin was also an active partner on the photocatalytic oxidation demonstration.

Potential sites where innovative off-gas treatment processes could be implemented include Hanford (200 Area Plumes and 200-ZP-1 sites), LANL (TA-54 site), and the Princeton Physics Plasma Laboratory. The most speculative issues regarding commercial application of these technologies involve capital costs and operating reliability. The former issue requires continued scale-up so that technical issues related to full-scale commercial operations can be resolved. The latter issue requires further demonstrations involving extended time-on-stream tests.

\section{For further information, please contact:}

\section{J. M. Haselow}

Principal Investigator

Westinghouse Savannah River Company

P.O. Box 616

Aiken, SC 29802

(803) 725-5219

\section{J. Steele}

Technical Program Manager

Westinghouse Savannah River Company

P.O. Box 616

Aiken, SC 29802

(803) $725-1830$

\section{Kurt Gerdes}

Program Manager

U.S. Department of Energy

Cloverleaf Building

19901 Germantown Road

Germantown, MD 20874-1290

(301) 903-7289 
TTP Number: SR121107

\section{BIBLIOGRAPHY OF KEY PUBLICATIONS}

Jarosch, T., Final Report of Offgas Treatment Technologies for Abatement of Atmospheric Emissions of Chlorinated Volatile Organic Compounds, draft report, WSRC-RP-94-927, Rev 0, November 1994 


\section{TASK DESCRIPTION}

This project is designed to demonstrate the efficiency of and to develop cost data for treating residual solvents removed from the subsurface with vacuum extraction. The solvents will be recovered with a commercially available regenerative adsorbent system (RAS) developed and patented by Purus, Inc., San Jose, California. The RAS uses an adsorption/desorption-condensation cycle to treat a stream from a vapor extraction well typical of those used in the remediation of the unsaturated zone at SRS which is contaminated with chlorinated volatile organics (CVOCs, in particular, PCE and TCE). See Figure 3.35. The system operates at a maximum flow rate of $150 \mathrm{scfm}$ and can treat a stream containing from 1000 to $3000 \mathrm{ppmv}$ of solvent vapors.

The goal of this project is to develop recovery technologies that offer an alternative to destruction techniques. Recovery and recycle provide an avenue for reducing requirements for production of virgin solvents and reduce current emissions of carbon dioxide and hydrochloric acid (the desired products of destruction techniques).

\section{TECHNOLOGY NEEDS}

There is an estimated 3 million pounds of residual chlorinated solvents in the sediments and groundwater in the A/M Area of SRS. These chlorinated solvents are some of the most prevalent contaminants found in the subsurface across the country, within both the DOE complex and industry. The Clean Air Act Amendments require that the best available technology be used for abatement of emissions from sources such as those generated in soil vapor extraction operations.

\section{ACCOMPLISHMENTS}

Preliminary testing of the Purus regenerative adsorption system began in early November 1994. A total of approximately 20 liters of solvent were collected over four operating cycle of 4.5 hours each with the blower operating at $50 \mathrm{scfm}$ and a total CVOC concentration ranging from 2000 to 2400 ppmv. Two four liter samples acceptance tested. Testing revealed the solvents to be unusually stable and to have very low water content. The solvents

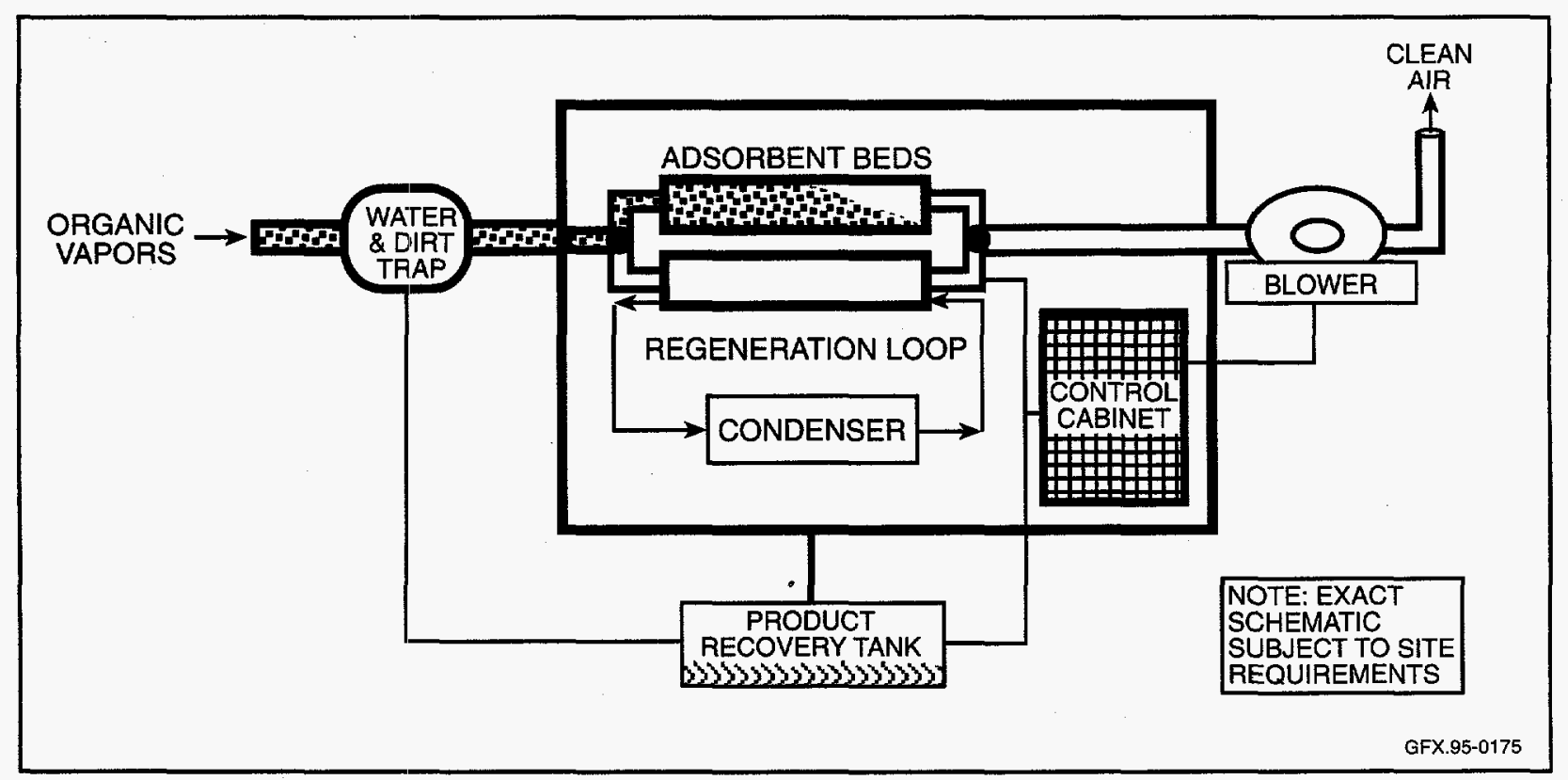

Figure 3.35. Off-Gas Treatment System. 
can be reused "as is" without blending with existing stockpiles. Operations were halted temporarily until this analysis was complete and due to the discovery of the ability of adsorption/recovery technologies to concentrate naturally occurring radon. The demonstration resumed operations in March 1995 with a modified health and safety plan and standard work practices which address the radon activity.

\section{BENEFITS}

The RAS uses a synthetic adsorbent (Ambersorb, a pyrolized styrene-divinylbenzene manufactured by Rohm \& Haas) which, although more expensive, offers many advantages over the more conventional GAC. These advantages include little or no effect of relative humidity on performance, lower water adsorption capacity, faster desorption kinetics and more complete regeneration, longer regeneration life time, and reduced chances for autocatalytic ignition. Central to the success of recovery, is the ability to recycle the solvent effectively. This includes designation of the solvent as a "product" (which permits handling it as a hazardous material versus a hazardous waste), obtaining a recycling vendor, and investigating the long-term market for the product. At present, the solvent can be considered a product if no reclamation is required and a vendor has been contracted to accept the solvent for recycle.

\section{COLLABORATION/TECHNOLOGY TRANSFER}

The field test is a collaborative effort between:

- Savannah River Technology Center, WSRC

- Tetra-Tech, Inc, Pasadena, CA

- Purus, Inc., San Jose, CA

- Associated Chemicals International, Inc., Severna Park, MD
Funding and additional support with regional economic diversification and technology transfer is being provided by:

- Pacific Northwest Laboratory, Richland, WA

- Westinghouse Hanford Company, Richland, WA

- RIMTech, Pasadena, CA

- Scientech, Inc., Idaho Falls, ID

For further information, please contact:

John L. Steele

Principal Investigator/Technical Program

Manager

Westinghouse Savannah River Company

P.O. Box 616

Aiken, SC 29802

(803) $725-1830$

Kurt Gerdes

Program Manager

U.S. Department of Energy

Cloverleaf Building

19901 Germantown Road

Germantown, MD 20874-1290

(301) 903-7289

TTP Number: SR141023

BIBLIOGRAPHY OF KEY PUBLICATIONS

None at this time. 


\subsection{6}

\section{BIOREMEDIATION \\ OF TOXIC METALS}

\section{TASK DESCRIPTION}

The objective of this project is to develop a superior process for removing, recovering, and disposing immutable toxic pollutants (metals and radionuclides) currently present in many waste sites and waste streams at SRS, other DOE facilities, and in industrial wastewaters worldwide. The process involves the use of a bioreactor containing algae embedded within a unique polymeric foam material configured for binding metals from wastewater on the embedded algae as the wastewater flows over the barrier. See Figure 3.36.

\section{TECHNOLOGY NEEDS}

The remediation of toxic metals in aqueous solutions has traditionally been carried out using chemical processes. This approach is costly, requires a well regulated chemical makeup in order to work properly, and often leaves significant levels of contaminant in the solution. Bioremediation techniques typically reveal less interference from commonly occurring ions and show promise of reduced cost.
The bioremediation process being developed by this project offers additional advantages for improved metal recovery and waste disposal options.

\section{ACCOMPLISHMENTS}

Assembled a multidisciplinary research team consisting of biologists, chemists, and engineers representing DOE labs, universities, and private industry.

Completed a report identifying and describing all heavy metal containing waste sites at SRS and prioritizing them in terms of their potential as demonstration sites for cleanup by the bioremediation process.

Designed a unique test assembly to evaluate the flow and metal binding capabilities of various materials including algae/foam complexes and ion exchange resins.

Grew large quantities of several strains of algae under a variety of culture conditions for future testing.

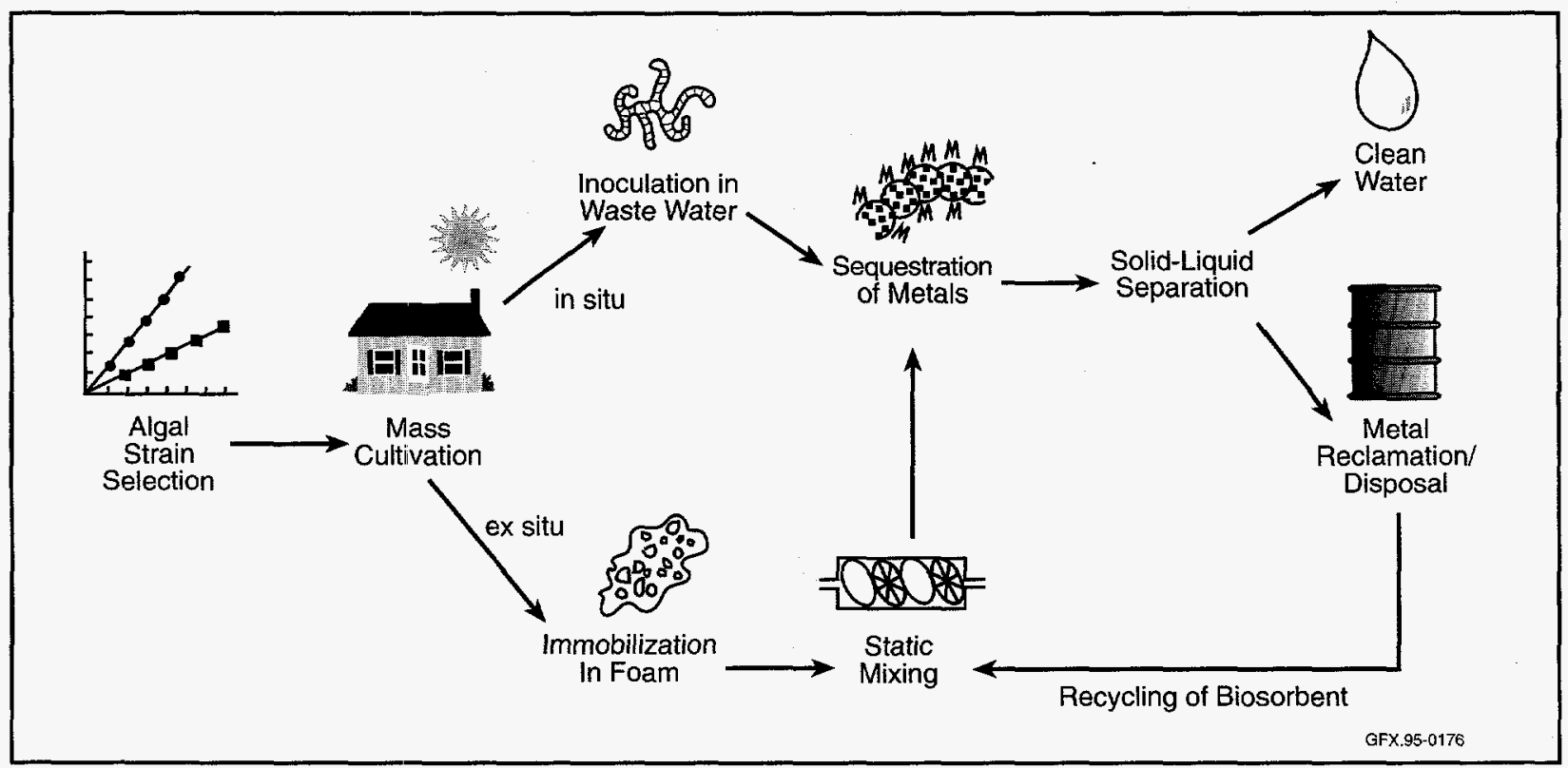

Figure 3.36. Bioremoval Using Algae. 
Evaluated the growth characteristics of several new algal strains being considered for testing in the bioremediation process.

Filed patent disclosures on unique strains of algae evaluated for metal binding and unique immobilization (polymer binding).

\section{BENEFITS}

Bioremediation processes based on living and or inert biomass have significant potential advantages in the treatment of heavy metal waste: (1) higher metal affinities; (2) specificities for particular metals; (3) less interference by other ions; (4) reduced sludge production: and (5) greater heavy metal concentration during elution. This process is expected to be more economical than conventional remedial processes.

\section{COLLABORATION/TECHNOLOGY TRANSFER}

Approximately $50 \%$ of the total funding of this project is being used to benefit the local economy.

- The industrial partner, Frisby Technologies Inc., collaborating with SRTC via a subcontract, has established a branch facility in Aiken, SC.

- Other local economic benefits are being obtained via a South Carolina University Research and Education Foundation (SCUREF) contract with University of South Carolina (Columbia, SC) for technical support, and through the purchase of supplies and equipment from local vendors.
For further information, please contact:

Edward W. Wilde

Principal Investigator

Westinghouse Savannah River Company

P.O. Box 616

Aiken, SC 29802

(803) 725-6049

\section{John L. Steele}

Technical Program Manager

Westinghouse Savannah River Company

P.O. Box 616

Aiken, SC 29802

(803) $725-1830$

Kurt Gerdes

Program Manager

U.S. Department of Energy

Cloverleaf Building

19901 Germantown Road

Germantown, MD 20874-1290

(301) 903-7289

TTP Number: SR141019

BIBLIOGRAPHY OF KEY PUBLICATIONS

None at this time. 


\section{VALIDATION AND PUBLICATION OF SAVANNAH RIVER BIOREMEDIATION FIELD EXPERIMENTS}

\section{TASK DESCRIPTION}

In FY93-94 a field experiment using bioremediation was conducted under the VOC Non-Arid Integrated Demonstration. This demonstration, which was carried out at SRS, involved the injection of gases into the subsurface via a horizontal well system. See Figure 3.37. Air and methane injection were used in order to stimulate the indigenous microbial community to degrade TCE/PCE contamination at this site.

Baseline groundwater data collected before initiation of the field demonstration provided information on pre-test microbial and chemical conditions at the site. This data showed that the subsurface microbial community was under nutrient stress, had the capability to degrade chlorinated solvents, and had low numbers of methanotrophs. The potential for stimulation of the microbial community was excellent.
The focus of the present project (validation and publication of the results) is to enhance the data analysis and interpretation of the results to enable the bioremediation technology to be evaluated for applicability at other DOE sites. Analysis of raw data, analytical methods, and mass balance experiments are being completed. A plan is being developed defining further needs to clean up SRS. The plan will evaluate the status of TCE/PCE in situ degradation, and will determine the follow up necessary for use of biomolecular probes and the potential use of tracers to better explain the results of data already collected. It will also include a strategy for improving the application of bioremediation technology for achieving successful remediation of a TCE/PCE contaminated site. A report will be prepared summarizing results of data on processes, analytical methods, and mass balance on in situ TCE/PCE degradation.

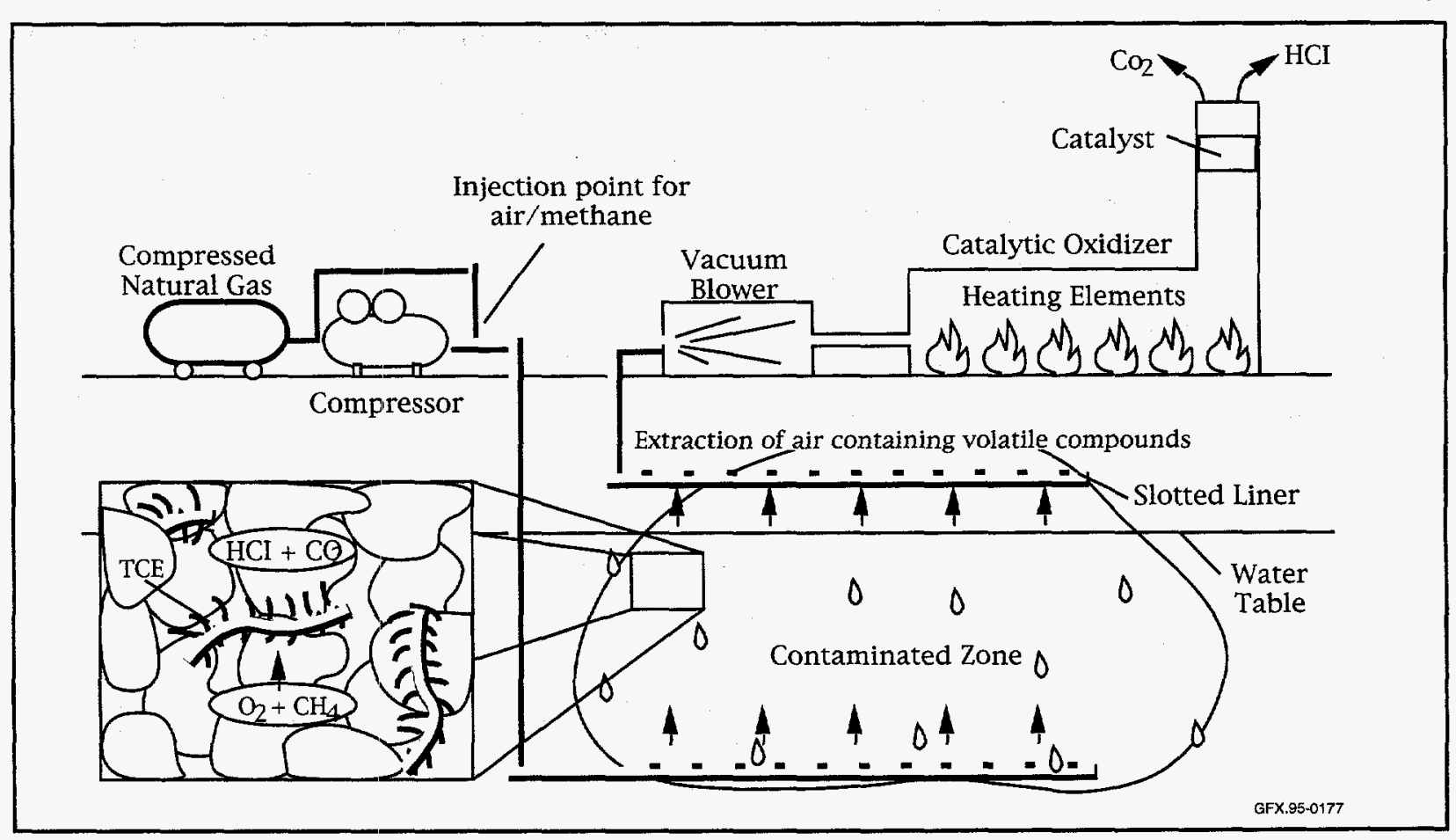

Figure 3.37 In Situ Bioremediation. 


\section{ACCOMPLISHMENTS}

Field operations were carried out over a period of 14 months in a phased pattern to provide optimal conditions for assessing the performance of the system. The first two stages consisted of air extraction alone from the vadose zone well, after which air injection was added via the horizontal well below the water table. Extracted air was treated using an electrically heated catalytic oxidation system. Stages 3 and 4 involved the addition of methane in air (at $1 \%$ then at $4 \%$, respectively) to stimulate methanotrophic microorganisms. Stage 5 involved the use of both short and long pulses of methane plus air in conjunction with air alone. The final stage involved the pulsing of methane using a short pulse interval (found to be optimal in Stage 5) in conjunction with continuous injection of organic phosphate (triethyl phosphate) and nitrous oxide in air. This represents the first time ever that carbon, nitrogen, and phosphorous nutrients were injected simultaneously as gases.

In all, more than $108,206,345$ scf of air and $1,392,774 \mathrm{scf}$ of methane were injected into the subsurface. The air injection-extraction system operated at $94.1 \%$ efficiency during the 384 operating days, and the off-gas treatment system destroyed more than 11,370 pounds of chlorinated solvents (more than 95\% of what was extracted). Results from the final stage indicated dramatic increases in TCE/PCE mineralization, apparently caused by reduction in nutrient stress due to injection of phosphorous and nitrogen compounds.

The Bioremediation Technical Support Group (BTSG) of the Integrated Demonstration for Cleanup of VOC in Groundwater and Soil at NonArid Sites met on October 27, 1993, in Atlanta, Georgia. This expert panel was given all of the data tables, statistical analyses, and figures from the 14-month methane stimulated in situ bioremediation demonstration. The data included all parameters from all sources of soil, gas, sediment, and groundwater analyses. At this meeting, the BTSG recommended production of seven reports: 1) Preliminary Technology Report, 2) Nucleic Acid Probe Report, 3) Biodegradation Analyses Report, 4) Modeling/Simulation Report, 5) Community Struc- ture Analyses Report, 6) Field Engineering/Site Preparation Report, and 7) Overall Technology Performance Report.

Biostimulation of indigenous microbial population was indicated by several factors:

- During the $1 \%$ (but not $4 \%$ ) methane injection period, most, if not all, of the methane was consumed by the TCE-degrading microflora.

- Carbon dioxide concentrations, indicative of increases in microbial respiration increased in both vadose zone piezometers and in the extraction well over time.

- Methane-oxidizing bacteria densities increased at the rate of an order-of-magnitude every two weeks during the first ten weeks of methane injection. Groundwater from wells showing the greatest decrease in TCE/PCE concentrations showed as much as a five-order-of-magnitude increase in methanotrophs.

- Biomass and enzyme activities increased in all wells known to be stimulated by the injection process.

The BTSG felt, under proof of bioremediation, that 1) decline in TCE and PCE in groundwater and soil gas, 2) decline in TCE and PCE in sediments, 3) decrease in TCE/PCE ratio in offgas, and 4) increasing chloride with decreasing TCE in water needed more analytical development and should not be stated emphatically at this time.

Bioremediation, the biological-assisted destruction of contaminants, was indicated from several sources of data:

- Decrease in TCE and PCE in groundwater at monitoring wells occurred during the demonstration. However, subsurface heterogeneities caused a non-uniform effect: the changes did not occur regularly over time or over the demonstration site. During the in situ air stripping demonstration, $40 \%$ of the monitoring wells had overall decreases in TCE and PCE concentrations in the water. During the in situ bioremediation demonstration, $60 \%$ of the same wells were showing significant decreases and fewer of the wells were 
showing any increases. All five vadose zone piezometers showed large decreases in TCE and PCE concentration over time, up until initiation of injection of $4 \%$ methane.

- Decline in TCE and PCE in sediments in interim core samples collected after the first three months of methane injection

- Increased mineralization, enzyme activity, and densities of methanotrophs correlated with decreases in chlorinated solvents, especially after multiple nutrient injection started

\section{BENEFITS}

This successful demonstration of the bioremediation of chlorinated solvents has wide-ranging benefits for the cleanup of these solvents across the DOE Complex as well as at many other sites worldwide. In addition, the techniques developed and demonstrated during this project will be applicable for the bioremediation of any organic contaminant. These techniques include horizontal well technology, nutrient injection strategies, and microbial monitoring techniques, such as biomolecular probe monitoring and phospholipid fatty acid analysis.

\section{COLLABORATION/TECHNOLOGY TRANSFER}

A licensing seminar for the in situ bioremediation technology using methane injection via horizontal wells was held in Augusta, Georgia. The technology was very well received by the commercial sector. More than 75 companies were represented and many expressed interest in using the technology based on the preliminary data. Fourteen companies have licensing agreements for the technologies, and at least two companies are using parts of the demonstrated technology in field remediation activities.

\section{For further information, please contact:}

\author{
Dr. Terry Hazen
}

Principal Investigator

Westinghouse Savannah River Company

P.O. Box 616

Aiken, SC 29802

(803) 725-6413

John L. Steele

Technical Program Manager

Westinghouse Savannah River Company

P.O. Box 616

Aiken, SC 29802

(803) $725-1830$

\section{Jeffrey S. Walker}

Program Manager

U.S. Department of Energy

Cloverleaf Building

19901 Germantown Road

Germantown, MD 20874-1290

(301) 903-7966

TTP Number: SR101101

\section{BIBLIOGRAPHY OF KEY PUBLICATIONS}

Lombard, K.H., J. Borthen, and T.C. Hazen, Design and Configuration Management of System Control Components for in situ Methanotrophic Bioremediation of Groundwater and Sediment Contaminated with Chlorinated Hydrocarbons, R. E. Hinchee (ed), p. 81-96. In Situ and On-Site Bioreclamation. The Second International Symposium, 1994.

Fliermans, C.B., J.M. Dougherty, M.M. Franck, P.C. McKinsey and T.C. Hazen, "Immunological Techniques as Tools to Characterize the Subsurface Microbial Community at a Trichloroethylene Contaminated Site," Applied Biotechnology for Site Remediation, eds. R.E. Hinchee, D.B. Anderson, F.B. 
Metting, and G.D. Sayles, Lewis Publishers, Ann Arbor, MI, p. 186-203, 1994.

Morrissey, C.M., S.E. Herbes, O.M. West, A.V. Palumbo, T.J. Phelps, and T.C. Hazen, "Use of Laboratory Soil Columns to Optimize in situ Biotransformation of Tetrachloroethylene," Applied Biotechnology for Site Remediation, eds. R.E. Hinchee, D.B. Anderson, F. B. Metting, and G.D. Sayles, Lewis Publishers, Ann Arbor, MI, p. 326-331, 1994.

Enzien, M.V., F. Picardal, T.C. Hazen, R.G. Arnold, and C.B. Fliermans, "Reductive Dechlorination of Trichloroethylene and Tetrachloroethylene Under Aerobic Conditions in a Sediment Column," $A p$ plied and Environmental Microbiology, 60:22002205, 1994.

Hazen, T.C., Preliminary Technology Report for In Situ Bioremediation Demonstration (Methane Biostimulation) of the Savannah River Site Integrated Demonstration Project, DOE/OTD, WSRC-TR-93670, Westinghouse Savannah River Company, Aiken, SC., 1994.

Lombard, K.H. and T.C. Hazen, Test Plan for the Soils Facility Demonstration- Petroleum Contaminated Soil Bioremediation Facility $(U)$, WSRC-TR94-0179, Westinghouse Savannah River Company, Aiken, SC., 1994.
Hazen, T.C., K.H. Lombard, B.B. Looney, M.V. Enzien, J.M. Dougherty, C.B. Fliermans, J. Wear, and C. A. Eddy-Dilek, "Preliminary Technology Report for In Situ Bioremediation Demonstration (Methane Biostimulation) of the Savannah River Site Integrated Demonstration Project." Proceedings American Nuclear Society Spectrum '94 Conference: 946-951,1994.

Lombard, K.H. and T.C. Hazen, "A Petroleum Contaminated Soil Bioremediation Facility," Proceedings American Nuclear Society Spectrum '94 Conference, 952-959, 1994.

Borthen, J., F. Meyer, K. Lombard, and T.C. Hazen, "Catalytic Oxidation of Trichloroethylene and Perchloroethylene Mixtures," Proceedings AIChE 1993 Summer National Meeting: Control and Measurement of VOC Emissions, 1994. 

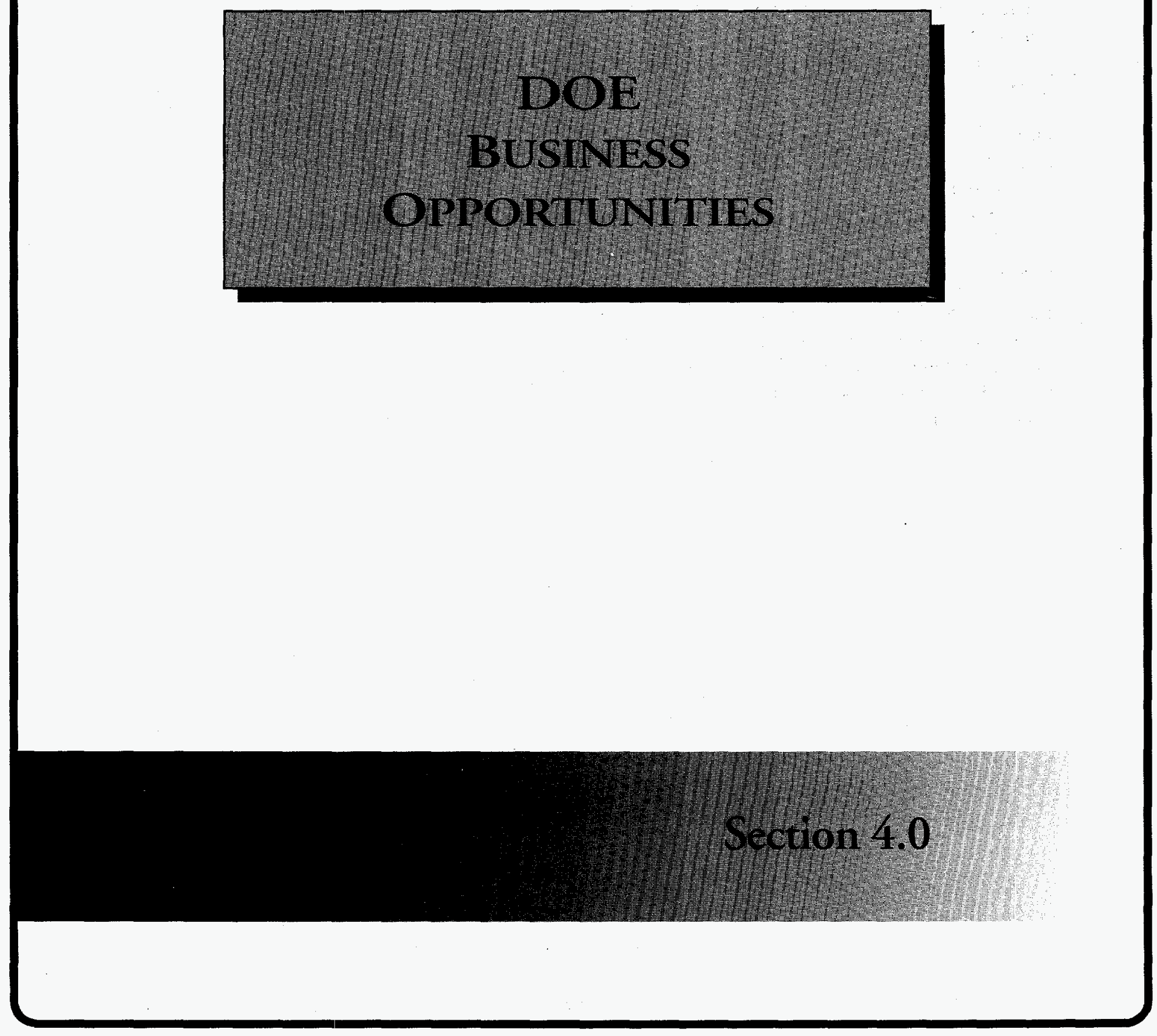
230 


\subsection{DOE BUSINESS OPPORTUNITIES}

\section{WORKING WITH THE DOE OFFICE OF ENVIRONMENTAL MANAGEMENT}

DOE provides a range of programs and services to assist universities, industry, and other private-sector organizations and individuals interested in developing or applying environmental technologies. Working with DOE Operations Offices, as well as management and operating contractors, EM employs a number of mechanisms to identify, integrate, develop, and adapt promising emerging technologies. These mechanisms include contracting and collaborative arrangements, procurement provisions, licensing of technologies, consulting arrangements, reimbursable work for industry, and special consideration for small business. EM facilitates the development of subcontracts, $R \& D$ contracts, and cooperative agreements to work collaboratively with the private sector.

\section{COOPERATIVE RESEARCH AND DEVELOPMENT AGREEMENTS (CRADAS)}

CRADAs are mechanisms for collaborative R\&D. They are agreements between a DOE R\&D laboratory and any non-federal source to conduct cooperative R\&D that is consistent with the laboratory's mission. The partner may provide funds, facilities, people, or other resources. DOE provides the CRADA partner with access to facilities and expertise; however, external participants receive no federal funds. Rights to inventions and other intellectual property are negotiated between the laboratory and the participant. Certain generated data may be protected for up to five years. Several companies may combine their resources to address a common technical problem. Funds can be leveraged to implement a consortium for overall program effectiveness.

\section{PROCUREMENT MECHANISMS}

DOE-EM procurement mechanisms are for technology development in the form of unsolicited proposals and formal solicitations, although the latter are preferable. The principal contractual mechanisms used by EM for industrial and academic response include Research Opportunity Announcements (ROAs) and Program R\&D Announcements (PRDAs).

EM utilizes the ROA to seek advanced research and technologies for a broad scope of cleanup needs. The ROA supports applied research ranging from concept feasibility to full-scale testing. In addition, the ROA is open continuously for a full year following the date of issue and includes a partial procurement set-aside for small businesses. Typically, ROAs are published annually in the Federal Register, announced in the Commerce Business Daily, and provide multiple awards.

PRDAs are program announcements which solicit a broad mix of advanced development and demonstration proposals. A PRDA requests proposals for a wide-range of technical solutions to specific EM problem areas. Multiple awards, which may have distinct approaches or concepts, are generally made. Numerous PRDAs may be issued each year.

EM awards grants and cooperative agreements if $51 \%$ or more of the overall value of the effort is related to a public interest goal. Such goals include possible non-DOE or other federal agency participation and advancement of present/future U.S. capabilities in domestic and international environmental cleanup markets. They may also include technology transfer, advancement of scientific knowledge, or education and training of individuals as well as business entities. 
For more information about PRDAs and ROAs, contact:

\author{
Tom Martin \\ U.S. Department of Energy \\ Morgantown Energy Technology Center \\ P.O. Box 880 , MS 107 \\ Morgantown, West Virginia 26507
}

(304) $285-4087$

\title{
LICENSING OF TECHNOLOGIES
}

DOE contractor-operated laboratories can license DOE/EM-developed technology and software. In situations where DOE retains the ownnership of a new technology, the Office of General Counsel will serve as the licensing agent. Licensing activities are conducted according to existing DOE intellectual property provisions.

\section{TECHNICAL PERSONNEL EXCHANGE ASSIGNMENTS}

Personnel exchanges provide opportunities for scientists from private industry and DOE laboratories to work together at various sites on environmental restoration and waste management problems. Private industry must contribute substantial cost-sharing for these personnel exchanges. To encourage such collaboration, the rights to any resulting patents go to the private sector company. These personnel exchanges, which can last from three to six months, result in the transfer of technical skills and knowledge.

\section{CONSULTING ARRANGEMENTS}

Laboratory scientists and engineers are available to consult in their areas of technical expertise. Most contractors which operate laboratories have consulting provisions. Laboratory employees who wish to consult can sign non-disclosure agreements, and are encouraged to do so.

\section{REIMBURSABLE WORK FOR INDUSTRY}

DOE laboratories are available to perform work for private industry and other federal agencies, as long as the work pertains to the mission of a respective laboratory and does not compete with the private sector. The special technical capabilities at DOE laboratories are incentives for the private sector to use DOE's facilities and contractor expertise. An advanced class patent waiver gives ownership of any inventions resulting from the research to the participating private sector company.

\section{INTERACTIONS WITH SMALL BUSINESSES}

EM seeks the participation of small businesses in its RDDT\&E programs (1) through collaborative efforts with the National Laboratories, or (2) directly via solicitations issued by the DOE Small Business Innovation Research (SBIR) Program Office and the Small Business Technology Transfer (T2) Pilot Program (STTR). EM also has established a partial procurement set-aside for small firms (500 employees or less) for applied research projects through its ROA. 
For further information about SBIR and STTR programs, please contact:

U.S. Department of Energy

Small Business Innovation Research Program Hotline

ER-16 GTM

Washington, D.C. 20585

(301) $903-5707$

\section{EM CENTER FOR ENVIRONMENTAL MANAGEMENT INFORMATION}

The EM Center for Environmental Management Information is designed to provide ready access to prospective research and business opportunities in waste management, environmental restoration, and decontamination and decommissioning activities. The Center can identify links between industry technologies and program needs. It connects potential partners to an extensive complex-wide network of DOE headquarters and operations office contacts.

To reach the EM Center for Environmental Management Information, call 1-800-736-3282.

\section{OFFICES OF RESEARCH AND TECHNOLOGY APPLICATIONS}

The Offices of Research and Technology Applications (ORTA) serve as technology transfer agents for the federal laboratories. They coordinate technology transfer activities among laboratories, industry, and universities. ORTA offices license patents and foster communication between researchers and technology customers.

\section{ORTA Contacts:}

Laboratory

Ames Laboratory

Argonne National Lab

Brookhaven National Lab

Fermilab

Idaho National Engineering Lab

Lawrence Berkeley Lab

Lawrence Livermore National Lab

Los Alamos National Lab

Morgantown Energy Technology Ctr

National Renewable Energy Lab

Oak Ridge Institute/Science \& Ed

Oak Ridge National Lab

Pacific Northwest Lab

Pittsburgh Energy Technology Center

Princeton Plasma Physics Lab

Sandia National Lab

Savannah River Technology Center

Stanford Linear Accelerator Center

Westinghouse Hanford Company
Contact

Todd Zdorkowski

Shari Zussman

Margaret Bogosian

John Vernard

Ann Rydalch

Cheryl Fragiadakis

Dave Conrad

Pete Lyons

Rodney Anderson

Dana Moran

Mary Loges

Bill Martin

Marv Clement

Kay Downey

Lew Meixler

Warren Siemens

Jack Corey

Jim Simpson

Dave Greenslade
Phone Number

(515) 294-5640

(708) 252-5361

(516) 282-7338

(708) 840-2529

(208) 526-1010

(510) 486-6467

(510) 422-7839

(505) 665-9090

(304) 285-4709

(303) 275-3015

(615) 576-3756

(615) 576-8368

(509) 375-2789

(412) 892-6029

(609) 243-3009

(505) 271-7813

(803) 725-1134

(415) 926-2213

(509) $376-5601$ 

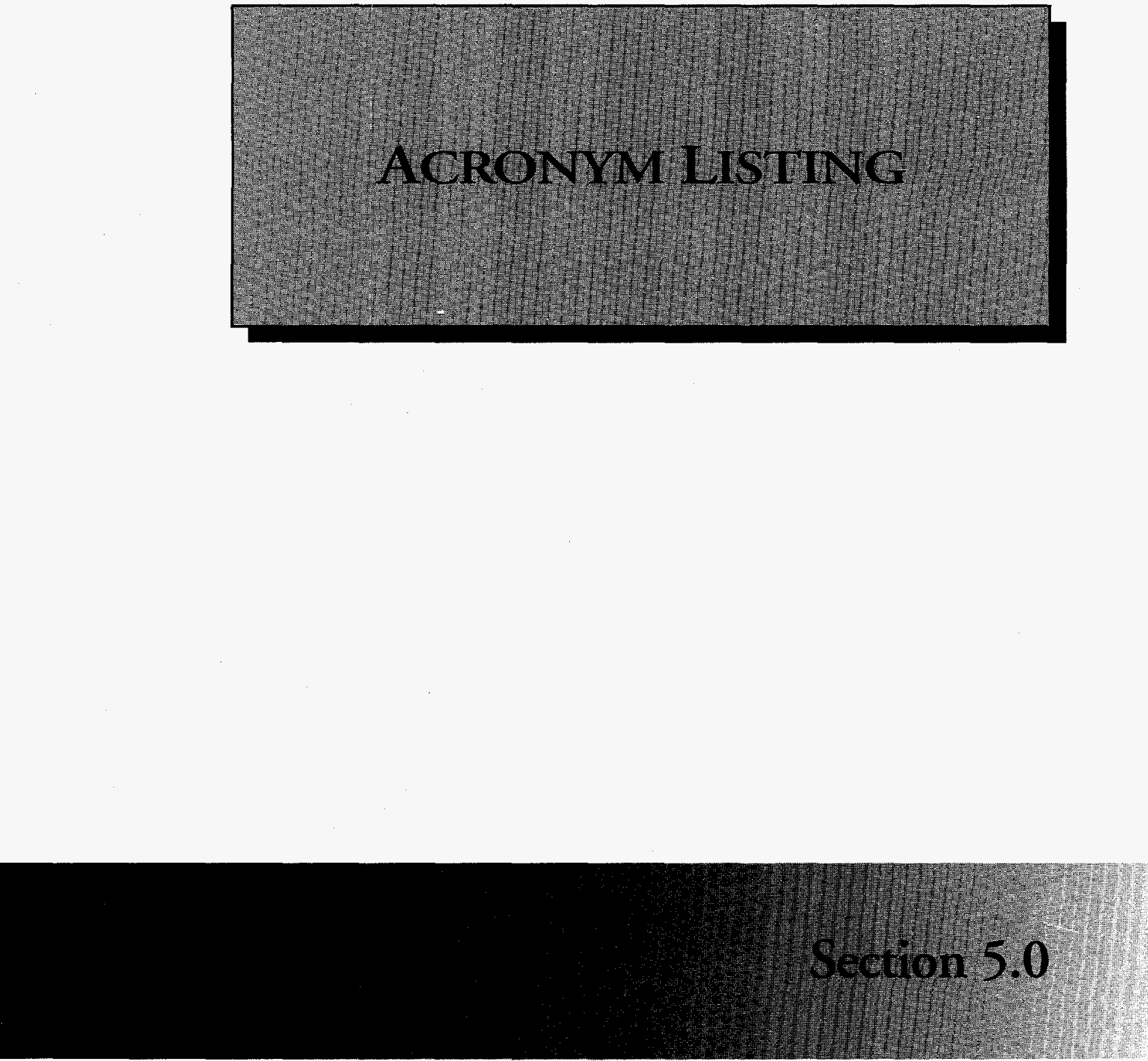


\begin{tabular}{|c|c|}
\hline $\mathrm{AC}$ & Alternating Current \\
\hline AEM & Acoustic Emission Monitoring \\
\hline ANL & Argonne National Laboratory \\
\hline API & American Petroleum Institute \\
\hline ASH & Air-Spared Hydrocyclone \\
\hline ATM & Air Turbine Motor \\
\hline AUB & American-Ukraine Biotech IV \\
\hline BWNT & Babcock and Wilcox Nuclear Technologies \\
\hline $\mathrm{CCJ}$ & Campbell Centrifugal Jig \\
\hline CERCLA & Comprehensive Environmental Response, Compensation, and Reliability Act \\
\hline $\mathrm{cm}$ & Centimeter \\
\hline $\mathrm{cm} / \mathrm{s}$ & Centimeter Per Second \\
\hline CRADA & Cooperative Research and Development Agreement \\
\hline $\mathrm{Cr}$ & Chromium \\
\hline CS & Colloidal Silica \\
\hline DoD & Department of Defense \\
\hline DOE & Department of Energy \\
\hline DNAPL & Dense Non-Aqueous Phase Liquids \\
\hline DSITMS & Direct Sampling Ion Trap Mass Spectrometer \\
\hline DT\&E & Demonstration, Testing, and Evaluation \\
\hline EDS & Energy Dispersive Spectroscopy \\
\hline EELS & Electron Energy Loss Spectroscopy \\
\hline EIX & Electrochemical Ion Exchange \\
\hline $\mathrm{EM}$ & Environmental Management \\
\hline EM-30 & Office of Waste Management \\
\hline EM-40 & Office of Environmental Restoration \\
\hline EM-50 & Office of Technology Development \\
\hline EM-52 & Office of Technology Transfer and Program Integration \\
\hline EM-53 & Office of Research and Development \\
\hline EM-54 & Office of Demonstration, Testing, and Evaluation \\
\hline EM-60 & Office of Facility Transition and Management \\
\hline EPA & Environmental Protection Agency \\
\hline EPRI & Electric Power Research Institute \\
\hline ER & Environmental Restoration \\
\hline FEMP & Fernald Environmental Management Project \\
\hline FY & Fiscal Year \\
\hline GAC & Granular Activated Carbon \\
\hline GE & General Electric \\
\hline GRI & Gas Research Institute \\
\hline HGMS & High-Gradient Magnetic Separation \\
\hline HOPS & Heuristic Optimized Processing System \\
\hline HLW & High-Level Waste \\
\hline $\mathrm{Hz}$ & Hertz \\
\hline ID & Integrated Demonstrations \\
\hline INEL & Idaho National Engineering Laboratory \\
\hline
\end{tabular}


IP

ICP-MS

ISR

ISSECS

KAFB

$\mathrm{Kg}$

$\mathrm{kV}$

LANL

LBL

LDF

LLNL

LNAPS

LPM

LRAD

$M \& O$

Mhz

$\mathrm{ml}$

MIT

$\mathrm{mm}$

MW

MOU

MRI

MWD

MWLID

MWL

MPN

MRI

ORISE

OGMS

ORNL

OTD

nm

PAH

PAWS

PB

PCB

PCE

PNL

ppB

ppm

ppmv

PSVE

PSX

RCE

RCRA

RD\&D

RDDT \&E

RF

RRP
Integrated Programs

Inductively Coupled Plasma Mass Spectroscopy

In Situ Remediation

Integrated Spectroscopic System for Environmental Contaminant Speciation

Kirtland Air Force Base

Kilogram

Kilovolt

Los Alamos National Laboratory

Lawrence Berkeley Laboratory

Land Disposal Facility

Lawrence Livermore National Laboratory

Light Non-Aqueous Phase Liquids

Low Permeability Media

Long-Range Alpha Detector

Management and Operations

Megahertz

Milliliter

Massachusetts Institute of Technology

Millimeter

Megaswatt

Memorandum of Understanding

Magnetic Resonance Imaging

Measurement-While-Drilling System

Mixed Waste Landfill Integrated Demonstration

Mixed Waste Landfill

Most Probable Number

Magnetic Resonance Imaging

Oak Ridge Institute for Science and Education

Open Gradient Magnetic Separator

Oak Ridge National Laboratory

Office of Technology Development

Nanometer

Polyaromatic Hydrocarbon

Portable Acoustic Wave Sensor

Polybutene

Polychlorinated Biphenyl

Perchloroethylene

Pacific Northwest Laboratory

Parts Per Billion

Parts Per Million

Parts Per Million Volts

Passive Soil Vapor Extraction

Polysiloxane

Rotating Cylinder Electrode

Resource Conservation and Recovery Act

Research, Development, and Demonstration

Research, Development, Demonstration, Testing, and Evaluation

Radio Frequency

Resource Recovery Project 
SCAPS

scf

SCUREF

SEA

SIMS

SNL

SPE

SRS

TC

TCE

TCP

TDR

TEVES

THP

TTP

XRF

UFA

UNR

USNA

UTK

UMTRA

VOC

WDC

WHC

WIPP

WSRC
Site Characterization and Analysis Penetrometer System

Standard Cubic Feet

South Carolina University Research and Education

Foundation

Science and Engineering Associates

Secondary Ion Mass Spectrometer

Sandia National Laboratories

Solid Phase Extraction

Savannah River Site

Technetium

Trichloroethylene

Thermocouple Psychrometers

Time Domain Reflectrometry

Thermal Enhanced Vapor Extraction System

Tunable Hybrid Plasma

Technical Task Plan

$\mathrm{X}$-ray Fluorescence

Unsaturated Flow Apparatus

University of Nevada - Reno

United States Naval Academy

University of Tennessee - Knoxville

Uranium Mill Tailings Remedial Action

Volatile Organic Compound

Water Development Corporation

Westinghouse Hanford Company

WIPP Waste Isolation Pilot Plant

Westinghouse Savannah River Company 

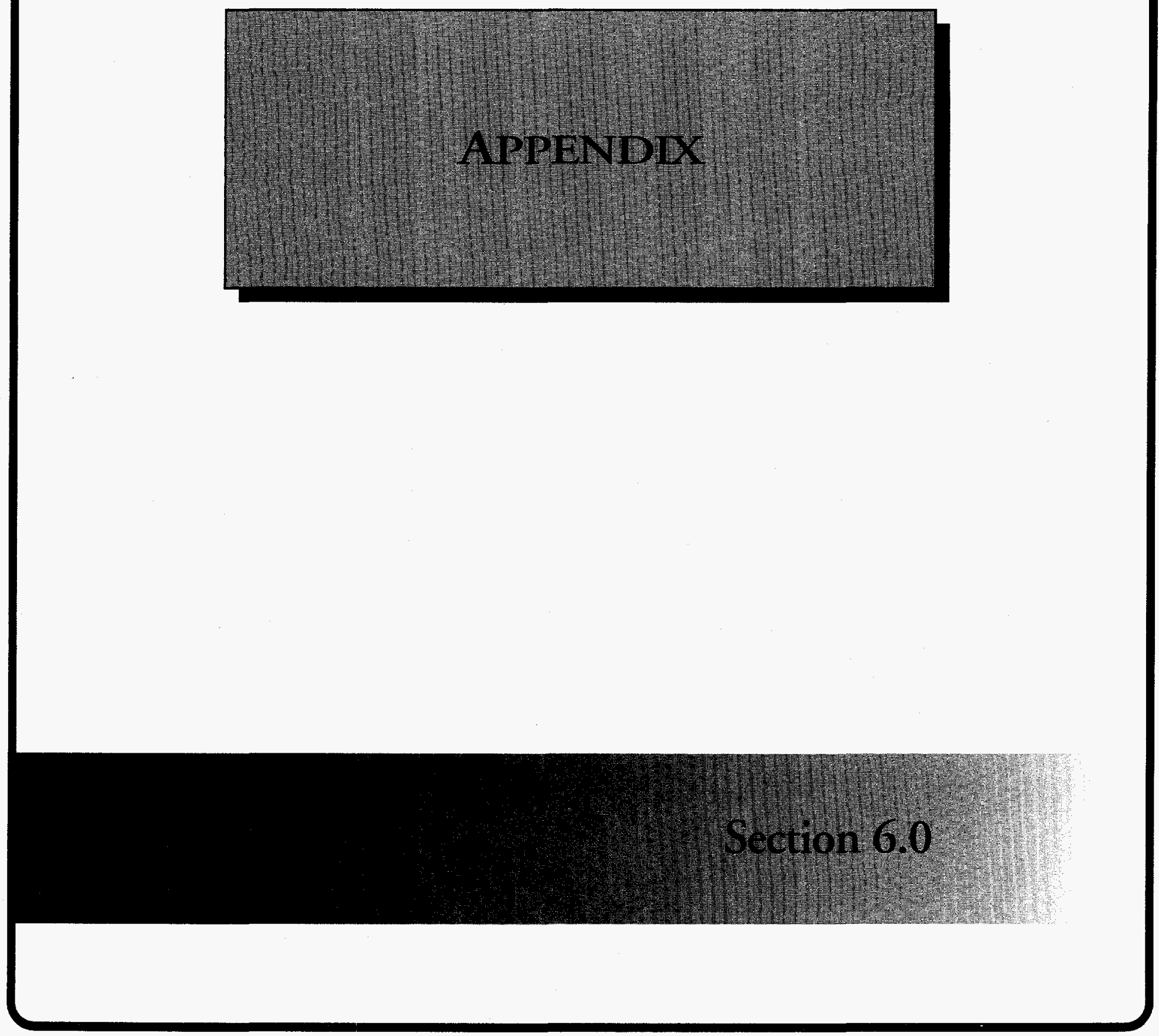


\section{TECHNICAL TASK PLANS}

Technical Task Plans (TTPs) identify and summarize funded work managed by OTD at headquarters, the field and the national laboratories. All tasks require a TTP number, which contains eight characters assigned by DOE Headquarters. The format consists of two alpha characters followed by six numerical characters. Characters 1 and 2 designate the DOE Operations Office/Funding Allotment Code. Character 3 denotes the laboratory/contractor/university designator. Character 4 denotes the fiscal year in which the task is first funded. The below characters reflect TTPs from FY94-95.

\section{Characters $1,2 \& 3$}

AL0 Albuquerque Operations Office

AL1 Los Alamos Nationall Laboratory (LANL)

AL2 Sandia National Laboratory, Albuquerque (SNLA)/Martin Marietta

AL3 Sandia National Laboratory, Livermore (SNLL)

AL4 Kansas City Plant (KCP)/Allied-Signal Aerospace

AL9 RUST GEOTECH

$\mathrm{CHO}$ Chicago Operations Office

$\mathrm{CH} 1$ Ames Laboratory

$\mathrm{CH} 2$ Argonne National Laboratory (ANL)/University of Chicago

CH3 Brookhaven National Laboratory (BNL)/Associated Universities, Inc.

$\mathrm{CH} 5$ National Renewable Evergy Laboratory

FNO Fernald Environmental Management Project (FEMP)

FN1 Fluor Daniel Environmental Restoration Management Company

HQ0 OTD Headquarters

ID0 Idaho Operations Office

ID1 Idaho National Engineering Laboratory (INEL)/EG\&G

ID4 Westinghouse Idaho Nuclear Company

ID6 Babcock \& Wilcox, Inc

ID7 Lockheed Idaho Technology Company

ME0 Morgantown Energy Technology Center (METC)

NV0 Nevada Operations Office

OH0 Ohio Operations Office

OH1 Fernald Environmental Management Project (FEMP)

$\mathrm{OH} 2$ EG\&G Mound Applied Technologies

OR0 Oak Ridge Operations Office

OR1 Martin Marietta Energy Systems (MMES)

OR3 Oak Ridge Institute for Science and Education

PE0 Pittsburgh Energy Technology Center

PE1 MSE, Inc.

RF0 Rocky Flats Environmental Technology Office

RF1 Rocky Flats Plant/EG\&G

RL0 Richland Operations Office

RL2 Kaiser Engineers Hanford Company (KEH)

RL3 Pacific Northwest Laboratory (PNL)/Battelle Memorial Institute

RL4 Westinghouse Hanford Company 
SF0 Oakland Operations Office

SF1 Lawrence Berkeley Laboratory (LBL)/University of California

SF2 Lawrence Livermore National Laboratory (LLNL)/University of California

SF3 Energy Technology Engineering Center (ETEC)

SR0 Savannah River Operations Office

SR1 Westinghouse Savannah River Company (WSRC)

\section{Character 4}

$1 \quad$ FY 1991

$2 \quad$ FY 1992

3 FY 1993

$4 \quad$ FY 1994

$5 \quad$ FY 1995

6 FY 1996

7 FY 1997

8 FY 1998

9 FY 1999

0 FY 2000 